The State of Biosafety and Biosecurity in South Africa 
(C) Academy of Science of South Africa

ISBN: 978-0-9870160-2-7

May 2015

Published by:

Academy of Science of South Africa (ASSAf)

PO Box 72135, Lynnwood Ridge, Pretoria, South Africa, 0040

Tel: +27123496600 • Fax: +27865769520

E-mail:admin@assaf.org.za

Reproduction is permitted, provided the source and publisher are appropriately acknowledged.

The Academy of Science of South Africa (ASSAf) was inaugurated in May 1996. It was formed in response to the need for an Academy of Science consonant with the dawn of democracy in South Africa: activist in its mission of using science and scholarship for the benefit of society, with a mandate encompassing all scholarly disciplines that use an open-minded and evidence-based approach to build knowledge. ASSAf thus adopted in its name the term 'science' in the singular as reflecting a common way of enquiring rather than an aggregation of different disciplines. Its Members are elected on the basis of a combination of two principal criteria, academic excellence and significant contributions to society.

The Parliament of South Africa passed the Academy of Science of South Africa Act (Act 67 of 2001), which came into force on 15 May 2002. This made ASSAf the only academy of science in South Africa officially recognised by government and representing the country in the international community of science academies and elsewhere. 


\section{The State of Biosafety and Biosecurity in South Africa}

May 2015

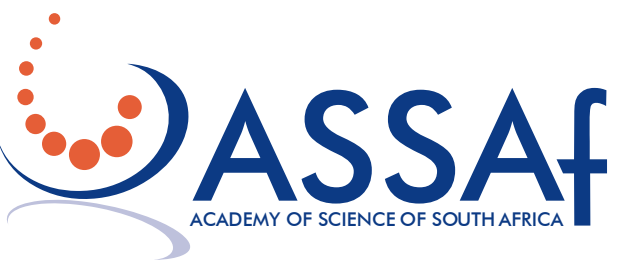




\section{TABLE OF CONTENTS}

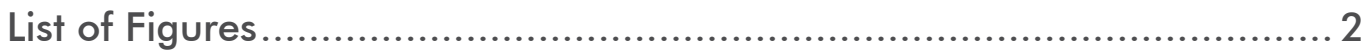

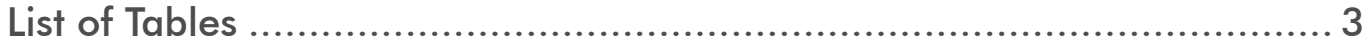

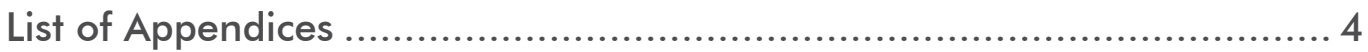

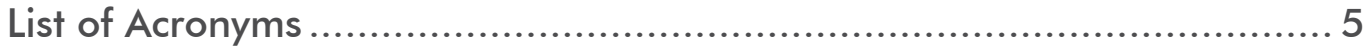

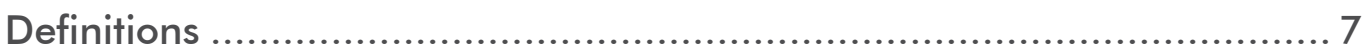

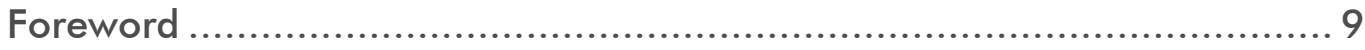

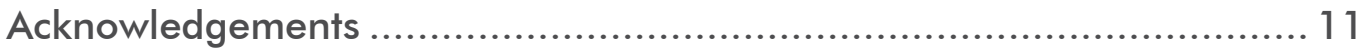

EXECUTIVE SUMMARY ....................................................... 13

1. BACKGROUND ......................................................... 17

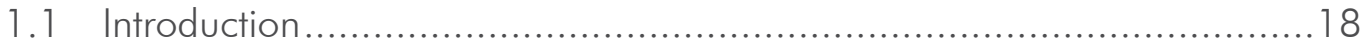

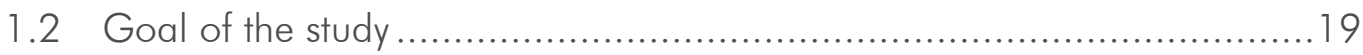

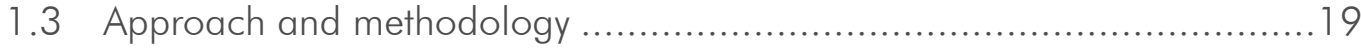

2. RESEARCH ETHICS - BIOSAFETY AND BIOSECURITY IN CONTEXT ............................................................... 1

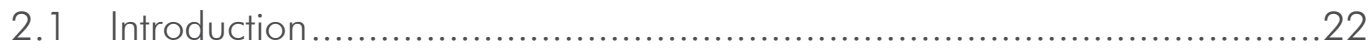

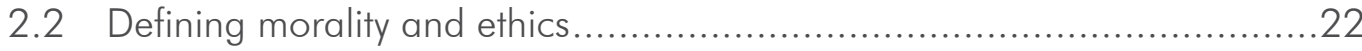

2.3 Dual-use research - the main moral dilemma related to biosafety

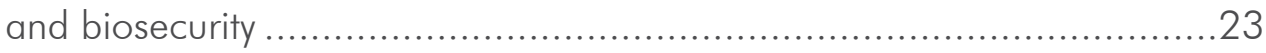

2.4 Ensuring ethical research and development......................................25

2.5 The institutionalisation and management of research ethics in

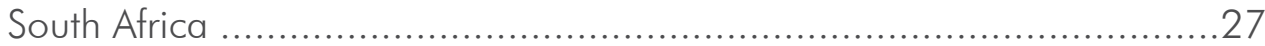

3. REGULATORY FRAMEWORK - SOUTH AFRICAN LEGISLATION RELATED TO BIOSAFETY AND BIOSECURITY .........................29

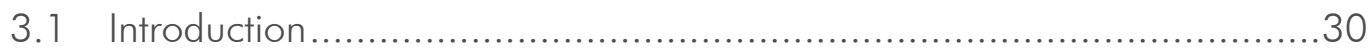

3.2 An assessment of existing legislation and regulations relevant to biosafety and biosecurity in South Africa

3.3 Review of infectious agents and related regulations 
4. IMPLEMENTATION - BIOSAFETY AND BIOSECURITY PRACTICE IN SOUTH AFRICAN LIFE SCIENCE FACILITIES

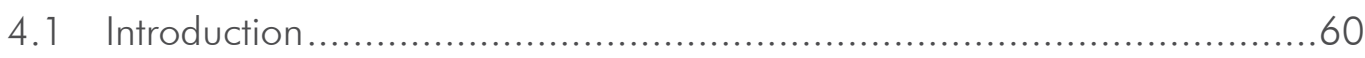

4.2 Mapping of the life sciences facilities in South Africa ..........................61

4.3 Assessment of measures to ensure ethical, biosafety and biosecurity practices in life science facilities in South Africa

5. RESPONSIVENESS - MANAGING INFECTIOUS DISEASE OUTBREAKS IN SOUTH AFRICA ........................................85

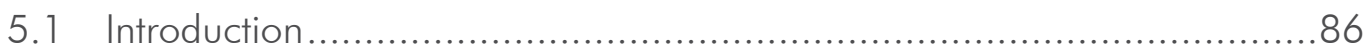

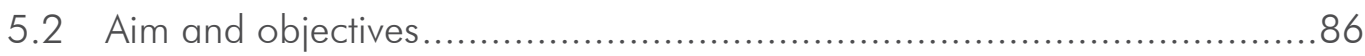

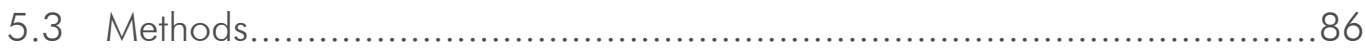

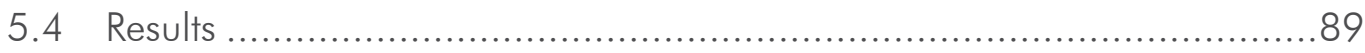

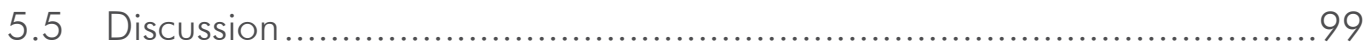

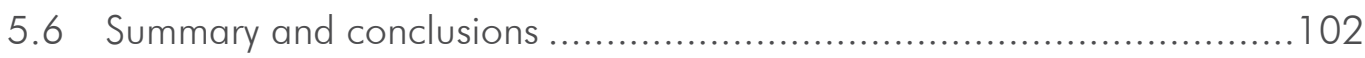

6. KEY FINDINGS AND RECOMMENDATIONS .........................103

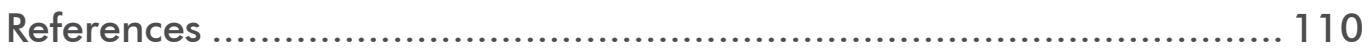

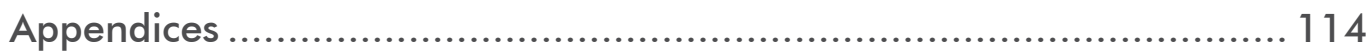




\section{List of Figures}

Figure 3.1: Hierarchical process to determine type and target of infectious agent

Figure 3.2: Flow diagram of the legislative process in South Africa .55

Figure 4.1: Map of life science facilities: number of laboratories by business sector, activity and province

Figure 4.2: Number of laboratories by sector 63

Figure 4.3: Map of life science facilities: number of laboratories by life science sector and province....

Figure 4.4: Funding sources of life sciences laboratories

Figure 4.5: Sample demographics according to recruitment source and sector.

Figure 4.6: Sample description according to province and recruitment source 


\section{List of Tables}

Table 3.1: Legislation listed according to the South African government's submission to the United Nations Security Council Resolution 1540 (UNSCR 1540) matrix.

Table 3.2: Legislation additional to that listed in UNSCR 1540 ..................38

Table 3.3: International and local lists used to develop a single, comprehensive list of South African relevant infectious agents......42

Table 3.4: Human health: current regulations, policy and guidelines by issuing department 46

Table 3.5: Animal health: current regulations, policy and guidelines by issuing department 48

Table 3.6: Plant health: current regulations, policy and guidelines by issuing department

Table 3.7: Additional regulations governing infectious agents..... .49

Table 4.1: Detail of survey sample and distribution 69

Table 5.1: Demographic and employment profile of participants .90 


\section{List of Appendices}

Appendix 1: Biographies of panel members......................................... 114

Appendix 2: Key biosafety and biosecurity legislation relating to agriculture and bio-diversity

Appendix 3: Human infectious agents and the regulations in which they are specifically named highlighted in colour

Appendix 4: Animal infectious agents and the regulations in which they are specifically named highlighted in colour...

Appendix 5: Human and animal infectious agents and the regulations in which they are specifically named highlighted in colour.....

Appendix 6: Plant infectious agents and the regulations in which they are specifically named highlighted in colour...

Appendix 7: Life sciences mapping information sheet

Appendix 8: Participation information sheet for qualitative interviews 150

Appendix 9: Question guide for semi-structured interviews regarding responsiveness to infectious disease outbreaks in South Africa

Appendix 10: Informed consent form for qualitative interviews.... 153

Appendix 11: Information sheet and questionnaire for mapping life science facilities

Appendix 12: Data tables of responses to survey questions 


\section{List of Acronyms}

\begin{tabular}{|l|l|}
\hline Abbreviation & Description \\
\hline ARC & Agricultural Research Council \\
\hline ASSAf & Academy of Science of South Africa \\
\hline BSL & Biological safety level \\
\hline CBEP & Cooperative Biological Engagement Programme \\
\hline CDC & US Centres for Disease Control and Prevention \\
\hline COC & Code of conduct \\
\hline DAFF & Department of Agriculture, Forestry and Fisheries \\
\hline DoH & Department of Health \\
\hline DST & Department of Science and Technology \\
\hline DTRA & United States' Defense Threat Reduction Agency \\
\hline DUR & Dual-use research \\
\hline FAO & Food and Agricultural Organisation of the United Nations \\
\hline GIS & Geographic information systems \\
\hline GMOs & Genetically modified organisms \\
\hline HIV & Human immunodeficiency virus \\
\hline HREC & Human Research Ethics Committee \\
\hline IATA & International Air Transport Association \\
\hline IHR & International Health Regulations \\
\hline IAP & Interacademy Partnership \\
\hline IP & Intellectual property \\
\hline LMOs & Living modified organisms \\
\hline MASSAf & Member of ASSAf \\
\hline MRC & Medical Research Council \\
\hline NHLS & National Health and Laboratory Services \\
\hline NHREC & National Health Research Ethics Council of South Africa \\
\hline NIAID & National Institute of Allergy and Infectious Diseases \\
\hline NICD & National Institute of Communicable Diseases \\
\hline & \\
\hline
\end{tabular}




\begin{tabular}{|l|l|}
\hline Abbreviation & Description \\
\hline NIH & National Institutes of Health \\
\hline NMMU & Nelson Mandela Metropolitan University \\
\hline NPW & Non-Proliferation of Weapons of Mass Destruction \\
\hline NRF & National Research Foundation \\
\hline NSABB & National Science Advisory Board for Biosecurity \\
\hline NSI & National Security Information \\
\hline OHSA & Occupational Health and Safety Act \\
\hline OIE & $\begin{array}{l}\text { Office International des Epizooties (International Office of } \\
\text { Epizootics) World Organisation for Animal Health }\end{array}$ \\
\hline R\&D & Research and development \\
\hline RHB & Regulations for Hazardous Biological Agents \\
\hline REC & Research ethics committee \\
\hline SABS & South African Bureau of Standards \\
\hline SACIDS & Southern Africa Centre for Infectious Diseases \\
\hline SADC & Southern African Development Community \\
\hline SAPS & South African Police Services \\
\hline SARS & Severe acute respiratory syndrome \\
\hline SOPs & Standard operating procedures \\
\hline the dti & Department of Trade and Industry \\
\hline TIA & Technology Innovation Agency \\
\hline TOR & Terms of reference \\
\hline TRC & Truth and Reconciliation Commission \\
\hline UCT & University of Cape Town \\
\hline UK & United Kingdom \\
\hline UN & United Nations Security Council Resolution 1540 \\
\hline UNSCR 1540 of America \\
\hline USA & Whoth Organisation \\
\hline WHO & WMDs destruction \\
\hline WM & Weations \\
\hline
\end{tabular}




\section{Definitions}

Bioethics - The study of the ethical and moral implications of biological discoveries, biomedical advances and their applications, as in the fields of genetic engineering and drug research (World Health Organisation [WHO], 2006). Bioethics within the life sciences is not limited to animal and clinical research ethics, but encompasses many interlinking areas of responsible conduct of research including research misconduct, obligations to society, responsibilities towards creation of beneficial research and avoidance of maleficence.

Biological laboratory - A facility within which biological agents, their components or their derivatives, and toxins are collected, handled and/or stored. Biological laboratories include clinical laboratories, diagnostic facilities, regional and national reference centres, public health laboratories, research centres (including academic, pharmaceutical, environmental) and production facilities (including the manufacturing of vaccines, pharmaceuticals, large-scale genetically modified organisms [GMOs]) for human, veterinary and agricultural purposes (WHO, 2006).

Biosafety, or more specifically laboratory biosafety - In the context of this document 'biosafety' refers to practices, procedures and proper use of equipment and facilities, in order to assure the safe handling, storage and disposal of (potentially) harmful biological material (including pathogens and their products) (adapted from WHO, 2006). This includes measures to prevent harm caused by inadvertent or accidental exposure to dangerous pathogens and toxins (WHO, 2004 and European Commission for Standardisation, 2008). It should be noted that the term biosafety can also be used to describe the efforts to assess, manage and communicate the potential risks resulting from biotechnology and its products and in particular GMOs, but this falls outside the scope of this document.

Biosecurity - refers to measures to protect against the inadvertent, inappropriate, intentional and malevolent use of (potentially) dangerous biological material (including pathogens and their products) or the malevolent use of biotechnology against humans, livestock or crops. This also includes the protection of valuable biological material (adapted from $\mathrm{WHO}, 2006$ ).

Biorisk - The risk (risk is a function of likelihood and consequences) of occurrence of a particular biological event (including naturally-occurring diseases, accidents, unexpected discovery, or deliberate misuse of biological agents and toxins) which may adversely affect the health of human populations (WHO, 2004 and 2007a). An assessment of these risks can be both quantitative and qualitative. 
Biorisk spectrum - A continuum of biorisks ranging from naturally-occurring diseases (chronic and infectious diseases) to accidents, to the deliberate misuse of biological agents and toxins with the intention to cause harm (WHO, 2007a).

Biorisk reduction - The reduction of the occurrence of risks associated with exposure to biological agents and toxins, whatever their origin or source, encompassing the full spectrum of biorisks (WHO, 2007a).

Laboratory biosafety - The containment principles, technologies and practices that are implemented to prevent unintentional exposure to biological agents and toxins, or their accidental release (WHO, 2004 and European Commission for Standardisation, 2008).

Laboratory biosecurity - The protection, control and accountability for valuable biological materials within laboratories, in order to prevent their unauthorised access, loss, theft, misuse, diversion or intentional release (WHO, 2006).

Dual-use life sciences research - Knowledge and technologies generated by legitimate life sciences research that may be appropriated for illegitimate intentions and applications (WHO, 2005 and 2007a).

Life sciences - All sciences that deal with organisms, including humans, animals and plants, and including but not limited to biology, bio-technology, genomics, proteomics, bioinformatics, pharmaceutical and biomedical research and techniques.

Global health security - The activities required, both proactive and reactive, to minimise vulnerability to acute public health events that endanger the collective health of populations living across geographical regions and international boundaries (WHO, 2007b).

Public health - The science and art of preventing disease, prolonging life, and promoting health through the organised efforts and informed choices of society, organisations, communities and individuals in both the public and private spheres (Winslow, 1920). Health is defined by the Constitution of the World Health Organisation as a state of complete physical, mental and social well-being and not merely the absence of disease or infirmity.

Research excellence - Research that is of high quality, ethical, rigorous, original and innovative. 


\section{Foreword}

The Academy of Science of South Africa (ASSAf) has a mandate to provide evidencebased scientific advice to South African policymakers and this consensus report is in fulfilment of this mandate.

This consensus study was initiated by the ASSAf Standing Committee on Biosafety and Biosecurity. The key objective was to undertake a consensus study in which the findings and recommendations will contribute to policy development/modification and to inform practice in relation to the improvement of biosafety and biosecurity in the country.

This consensus report provides a review of the state of the biosafety and biosecurity in South Africa. This review includes an overview of existing legislation, regulations and practices as they relate to biosafety and biosecurity; an evaluation of existing measures and capacity to detect, control and prevent the natural, accidental and spread of infectious agents; and a critical overview of current practice in relation to the implementation of biosafety and biosecurity measures and the application of ethics in South African laboratories.

Key findings from the study include the poor education and/or training on research ethics for life scientists, inadequate compliance with the statutory obligations to report Notifiable Medical Conditions, the lack of a database of both public and commercial laboratories in the country and a low level of awareness among life scientists about national and international conventions, laws and regulations related to their research.

Based on these findings, the report makes a number of recommendations which are under these four themes:

1. Improving the capacity to detect and respond to infectious disease outbreaks.

2. Education and awareness raising.

3. Ethics review.

4. Scientific openness and transparency.

The report provides guidance on how the relevant stakeholders can implement these recommendations in a manner that can improve the state of biosafety and biosecurity in South Africa. 
This report is the product of the work of a 10-member consensus study panel. The ASSAf Council would like to extend its appreciation to this panel for their expert contributions to the study and the development of this report.

The report was peer-reviewed by three experts: Prof Barry Schoub, former National Institute of Communicable Diseases (NICD) Executive Director and Emeritus Professor at the University of the Witwatersrand (South Africa); Prof Eucharia Kenya, Deputy Principal at Embu University College (Kenya); and Prof Malcolm Dando, Professor of International Security at the University of Bradford (United Kingdom). The ASSAf Council wishes to extend its gratitude to the reviewers for providing valuable inputs that have greatly improved the report.

The ASSAf Council trusts that the report's recommendations will be implemented in a manner that will improve the state of biosafety and biosecurity in South Africa.

The ASSAf Council wishes to express its appreciation to the United States' Defense Threat Reduction Agency's (DTRA) Cooperative Biological Engagement Programme (CBEP) for funding the study.

Professor Daya Reddy

President: Academy of Science of South Africa 


\section{Acknowledgements}

This consensus report is collaborative work of a 10-member study panel of experts that was appointed by the ASSAf Council. They were: Prof Jill Farrant (MASSAf), University of Cape Town, Panel Chairperson; Prof Daniel du Toit, Tshwane University of Technology; Dr Chandré Gould, Institute for Security Studies; Dr Petrus Jansen van Vuren, National Institute for Communicable Diseases; Dr Shadrack Moephuli, Agricultural Research Council; Dr Nhlanhla Msomi, Independent Consultant; Prof lqbal Parker (MASSAf), the International Centre for Genetic Engineering and Biotechnology; Dr James Southern, Independent Consultant; Prof Anton van Niekerk (MASSAf), Stellenbosch University and Ms Delille Wessels, Agricultural Research Council - Onderstepoort Veterinary Institute. These members generously donated their time for execution of this report and they are gratefully acknowledged.

Panel members were each allocated different sections within the scope of the brief and were assisted by contracted researchers appointed by ASSAf for this purpose. Data were collected, analysed and discussed electronically at six meetings held between November 2012 and June 2014. Issues raised by the findings were deliberated upon and this report reflects the findings, conclusions and recommendations of the panel.

The panel would like to acknowledge the following individuals for their different contributions to the study and the report: Dr Louise Bezuidenhout, Consultant; $\mathrm{Mr}$ Shaun Edge, Embassy of Japan; Ms Andrea Palk, Stellenbosch University; Dr Nandi Siegfried, Consultant; Ms Katya Mauff, University of Cape Town; Prof Janusz Paweska and Dr Jacqueline Weyer, NICD; Prof Zeblon Vilakazi, University of the Witwatersrand and Dr Rachel Chikwamba, Council for Scientific and Industrial Research.

The panel would also like to thank the following government department personnel for their inputs prior to the initiation of the study: Mr Ben Durham, Department of Science and Technology; Ms Wadzi Mandivenyi, Department of Environmental Affairs; Dr Frew Benson, Department of Health; Ms Nompumelelo Mkhonza, Dr Julian Jaftha and Dr Botlhe Modisane, Department of Agriculture, Forestry and Fisheries.

All personnel who participated in the information gathering process for the study are also acknowledged. Sincere appreciation also goes to the institutions and organisations that participated and contributed. The research ethics committees from the University of Cape Town, Nelson Mandela Metropolitan University and the National Health Laboratory Services are thanked for granting ethics approval. 
The three independent peer reviewers were: Prof Barry Schoub, former National Institute of Communicable Diseases (NICD) Executive Director and Emeritus Professor at the University of the Witwatersrand (South Africa); Prof Eucharia Kenya, Deputy Principal at Embu University College (Kenya); and Prof Malcolm Dando, Professor of International Security at the University of Bradford (United Kingdom). The panel wishes to express its gratitude for their inputs which have enriched the report.

Dr Hennie Groenewald's invaluable contributions in finalising the report are greatly acknowledged.

The support of Ms Phakamile Mngadi from the ASSAf secretariat throughout the execution of this study is greatly appreciated, as well as inputs from Professor Roseanne Diab and Ms Patricia Scholtz in the final stages of the study.

The publisher for the report was Kashan Advertising.

The United States' DTRA's CBEP provided financial support for the study.

Professor Jill Farrant

Panel Chairperson: The State of Biosafety and Biosecurity in South Africa 


\section{Executive Summary}

This consensus study report presents the findings of a systematic assessment of the state of biosafety and biosecurity in South Africa, including an evaluation of legislation, regulations and practices at both national and institutional levels. The findings report on strengths, weaknesses and gaps in the laws and in their implementation, and the practices relating to biosafety and biosecurity at laboratory level. Recommendations are made to address the weaknesses and gaps identified.

Research and development in the life sciences are important elements of South African growth and development and are essential to address the needs of the country. It was thus imperative that ASSAf contributes towards ensuring that life science research in South Africa is conducted safely, securely and ethically. This is in the interests of all South Africans and in the interests of the life science community.

With this broad objective, ASSAf constituted a Biosafety and Biosecurity panel of experts to assess and comment on the relationship between science and security in South Africa. While it is deemed important to extend an assessment of biosafety and biosecurity to the greater southern African region, this was not possible in the timeframe permitted for the study, but remains an important objective in the long term.

The research conducted for this consensus study included:

1. An investigation into the applicability and balance of relevant ethical principles through a review of literature in order to establish a context for biosafety and biosecurity considerations.

2. An assessment of existing, relevant legislation and regulations in relation to biosafety and biosecurity in order to identify strengths, weaknesses and gaps in laws and in their implementation.

3. A critical overview of the implementation of biosafety and biosecurity measures in laboratories in South Africa and an assessment of the extent to which laboratory practices address safety and security concerns.

4. An evaluation of existing measures and capacity to detect, identify, control and prevent the natural, accidental or deliberate spread of infectious agents.

The panel used a variety of methods to conduct the research, including but not limited to:

1. Convening a series of panel discussions on biosafety and biosecurity.

2. Assessing existing legislation and regulations in relation to biosafety and biosecurity to identify strengths, weaknesses and gaps in laws and in their implementation. 
3. Conducting a survey of life scientists' experience and perceptions of biosafety and biosecurity measures in laboratories in South Africa.

4. Evaluating existing measures and capacity to detect, identify, control, and prevent the natural, accidental, or deliberate spread of infectious agents.

5. Consultation with experts from a variety of disciplines (including experts with proven biosecurity expertise).

Ultimately, the goal of the study was to:

1. Make sustainable and evidence-based recommendations to the South African government and the scientific community to address the identified weaknesses in: existing legislation; the implementation of biosafety and biosecurity in laboratories; existing measures and capacity to detect and control spread of infectious diseases; and to raise awareness about existing measures (including practices and legislation) to reduce the risks associated with dual-use research and to engage the life science community in a dialogue about biosafety and biosecurity.

2. Make recommendations to remove weaknesses and gaps in existing legislation and in the implementation of such legislation.

\section{Outline of the report}

Chapter 1 (background) introduces the context of the study and then continues to define its goals, approaches and methodologies.

Chapter 2 (ethical context) offers an introduction to the interface between science and social responsibility, both at the level of the individual scientist and the institutional. Morality and ethics are discussed and the distinction between these concepts is clarified. The dual-use problem, whereby science can be used for both good and bad purposes, is explained and examples pertinent to the biosafety and biosecurity field are provided. The chapter concludes with an overview of how ethics is currently institutionalised and managed in South Africa.

Chapter 3 (regulatory framework) presents the results of the studies undertaken to explore legislation relevant to biosafety and biosecurity in South Africa. A desktop review of legislation currently governing South African biological safety as listed in the governmental submission to the United Nations Security Council Resolution 1540 (UNSCR 1540) Committee is presented. The review also identified and analysed legislation and regulations pertinent to biological safety and security in the country not listed in the UNSCR 1540 submission, through consultations with government departments and ministries involved in the biological safety and security arena. The review revealed that the South African legislative framework is robust and comprehensive, but suffers from several limitations and challenges, including 
coherence in the categorisation of pathogens, the lack of harmonisation of guidelines, and infrastructure and capacity challenges for implementation.

In addition, the results of a systematic review conducted to identify, collate and review current South African governmental regulations, policies and guidelines for detecting, identifying, controlling and preventing the natural, accidental or deliberate spread of infectious agents. The review identified a complex set of South African regulations governing the detection, identification, control, and prevention of human, animal and plant diseases caused by infectious agents. The panel noted that the development of a single, locally relevant list of infectious agents which is regularly updated could potentially enhance the utility and cross-referencing of future regulations.

Chapter 4 (implementation) outlines the survey used to map and compile a database of all functional life science facilities in the country. This included public and private sector facilities engaged in life science research, development or both. The final database comprises 979 facilities, of which 22\% conduct research, $72 \%$ perform diagnostic services and $6 \%$ provide both.

At the start of this survey there was no comprehensive database of public and commercial life sciences facilities in South Africa. Therefore, the panel recommends that the database compiled during this survey be considered a national asset and that its ongoing development and maintenance (including the development of a geographic information system map of all facilities) becomes the responsibility of the Department of Science and Technology (DST). In the view of the panel, the DST is correctly placed to take on this responsibility because laboratories work in the fields of human, animal and plant health and thus fall neither neatly into the scope of the Department of Health (DoH) nor the Department of Agriculture, Forestry and Fisheries (DAFF). In the interim, the database is available from ASSAf on request, but not for commercial use.

In addition, a comprehensive overview is presented of the findings from a survey of 350 life scientists in South Africa regarding the safety and security rules and regulations pertaining to their work. The survey found significant gaps in the training of scientists pertaining to ethics, biosafety, biosecurity and dual-use issues, as well as in relation to how and where to report possible breaches. There also appear to be gaps in relation to the implementation of existing rules and regulations, including in relation to standard operating procedures (SOPs), tests of competence (in biosafety and biosecurity) and even in some instances in the maintenance of laboratory equipment. The panel agreed that this survey highlighted an urgent need to ensure that life scientists are informed about national and international laws and policies relevant to their work. 
Chapter 5 (responsiveness) details the methods and results of a study of qualitative, key participant interviews, conducted with purposively-sampled experts in the field of infectious disease outbreaks in South Africa. The study highlighted the complexity of the systems required to manage infectious disease outbreaks in South Africa. The study participants identified significant strengths of the system, which provide a strong foundation for future improvements. Since many sectors and levels of workers are involved, it was often difficult to navigate these complex systems. The panel recognises that the voices of the participants provide clear advocacy for meaningful engagement between sectors with the shared aim of reducing the incidence of potential infectious disease outbreaks in the future.

Chapter $\mathbf{6}$ summarises the key findings and recommendations arising from the different chapters. Specific recommendations were made under four distinct themes:

1) Improving the capacity to detect and respond to infectious disease outbreaks.

2) Education and awareness raising.

3) Ethics review.

4) Scientific openness and transparency. 


\subsection{Introduction}

Research and development (R\&D) and service delivery within the life science sector in South Africa are important elements in ensuring the well-being of its citizens and the continued growth and development of the sector. Discovery and innovation within the life sciences hold great potential benefits to humankind, but also potential risks, which should be proactively considered and managed to ensure the safe, sustainable and ethical advancement of these sciences and their applications. The considered, safe and ethical conduct of life scientists is not only imperative to ensure safety within the R\&D environment, but also that of the societies and world within which they work and live.

The concepts and practices of biosafety and biosecurity relate directly to the activities and conduct of life scientists and intend to safeguard against exposure to, or the deliberate or inadvertent development or release of, living organisms and/or biological material that may harm humans and/or the environment. Biosafety and biosecurity have a common, general goal, i.e. protecting people and the environment against hazardous living organisms and biological materials, but they mitigate different risks.

Biosafety, or more specifically laboratory biosafety, is a fairly well-established concept that refers to the containment principles, technologies and practices that are implemented to prevent unintentional exposure to (potentially) hazardous biological material, e.g. pathogens and toxins, or their accidental release. ${ }^{1}$ More recently the term has also become synonymous with GMOs - specifically referring to the food/feed and environmental safety of these organisms. The biosafety of GMOs as assessed through food/feed and environmental risk assessments has developed into a separate discipline with related, but distinct, objectives, methodologies and regulatory frameworks. Although there are references to GMO biosafety, this consensus study focuses on laboratory biosafety.

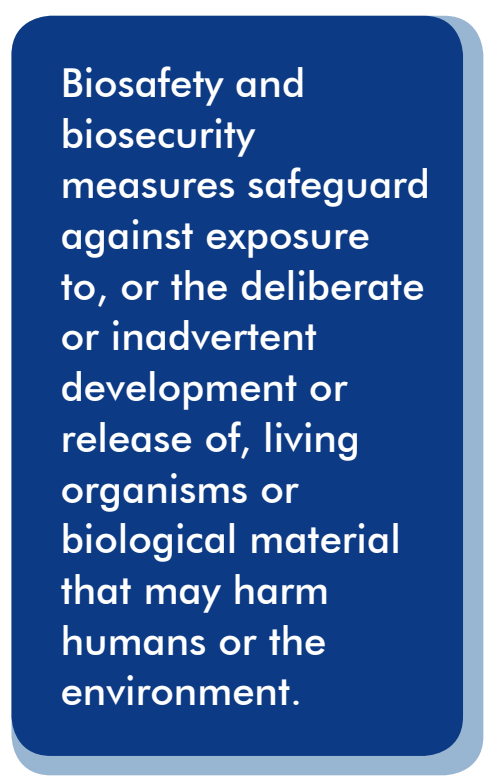

In general, biosecurity refers to management systems designed to protect society and the environment against potentially harmful organisms and biological materials, but it too has divergent meanings depending on the context in which it is used. In an agricultural context, i.e. veterinary and plant health disciplines, the term has come

1 WHO Laboratory Biosafety Manual, 2004. 
to represent the protection of valued biological resources from foreign, harmful or invasive organisms. ${ }^{2}$ In contrast, in a public health context it is used to refer to systems that establish and maintain the security and oversight of potentially hazardous organisms and biological materials - especially those that could be misused to cause deliberate harm. Again, this consensus study will focus only on the latter.

This consensus study report presents the findings of a systematic assessment of the state of laboratory biosafety and biosecurity in a public health context in South Africa. It includes an overview and evaluation of the national legislative framework as well as institutional implementation and practices. The findings report on strengths, weaknesses and gaps in the legal framework and in its implementation at laboratory level. Recommendations are made to address the weaknesses and gaps identified. The study was completed at the time of the Ebola outbreak in West Africa (September 2014), underscoring the importance of recommendations aimed at ensuring the safe, secure and ethical conduct of research in South Africa.

\subsection{Goal of the study}

The overall goal of the study was to:

Make sustainable and evidence-based recommendations to the South African government and the scientific community to address the identified weaknesses in: existing legislation; the implementation of biosafety and biosecurity in laboratories; existing measures and capacity to detect and control the spread of infectious diseases; and to raise awareness about existing measures (including practices and legislation) to reduce the risks associated with dual-use research and to engage the life science community in a dialogue about biosafety and biosecurity.

\subsection{Approach and methodology}

The Academy of Science of South Africa (ASSAf) constituted a Biosafety and Biosecurity panel comprising ten national experts to assess the state of biosafety and biosecurity in South Africa. Brief biographies of the panel members are presented in Appendix 1.

The panel used a variety of methods to conduct the research, including but not limited to:

i) Convening a series of Biosafety and Biosecurity panel meetings.

ii) Conducting a survey of life scientists' experience and perceptions of biosafety and biosecurity measures in laboratories in South Africa.

iii) Assessing existing legislation and regulations in relation to biosafety and biosecurity to identify strengths, weaknesses and gaps in laws and in their implementation.

2 FAO Biosecurity Toolkit, 2007. 
iv) Evaluating existing measures and capacity to detect, identify, control, and prevent the natural, accidental, or deliberate spread of infectious agents.

v) Consultation with experts from a variety of disciplines (including experts with proven security expertise).

The research conducted for this consensus study included:

i) An investigation into the applicability and balance of relevant ethical principles through a review of literature.

ii) A critical overview of the implementation of biosafety and biosecurity measures in laboratories in South Africa and an assessment of the extent to which laboratory practices address safety and security concerns.

iii) An assessment of existing relevant legislation and regulations in relation to biosafety and biosecurity in order to identify strengths, weaknesses and gaps in laws and in their implementation.

iv) An evaluation of existing measures and capacity to detect, identify, control and prevent the natural, accidental or deliberate spread of infectious agents.

A number of studies were commissioned and contributed to the evidence available to the panel when compiling their recommendations. Commissioned studies included: 1. A critical overview of current practice in relation to the implementation of biosafety and biosecurity measures, and the application of ethics in South African laboratories. This study took the form of a survey, based on the application of a self-assessment tool developed by $\mathrm{WHO}^{3}$ adapted for local circumstances.

2. An evaluation of existing measures and capacity (nationally and regionally) to detect, identify, control, and prevent the natural, accidental, or deliberate spread of infectious agents, using a list of selected agents and toxins as a guideline. This evaluation included the engagement of scientists to discuss the strengths and weaknesses in their own facilities.

3. An overview of the existing relevant legislation and regulations in relation to biosafety and biosecurity and the identification of strengths, weaknesses and gaps in laws and implementation.

In addition to the tasks undertaken as part of the scope of work, the panel investigated the applicability and balance of relevant ethical principles through a review of literature, and developed measures to raise awareness about existing measures (including practices and legislation) to reduce the risks associated with dual-use research and engage the life science community in a dialogue about biosafety and biosecurity.

$3 \mathrm{WHO}$, Responsible life sciences research for global health security, 2010. 


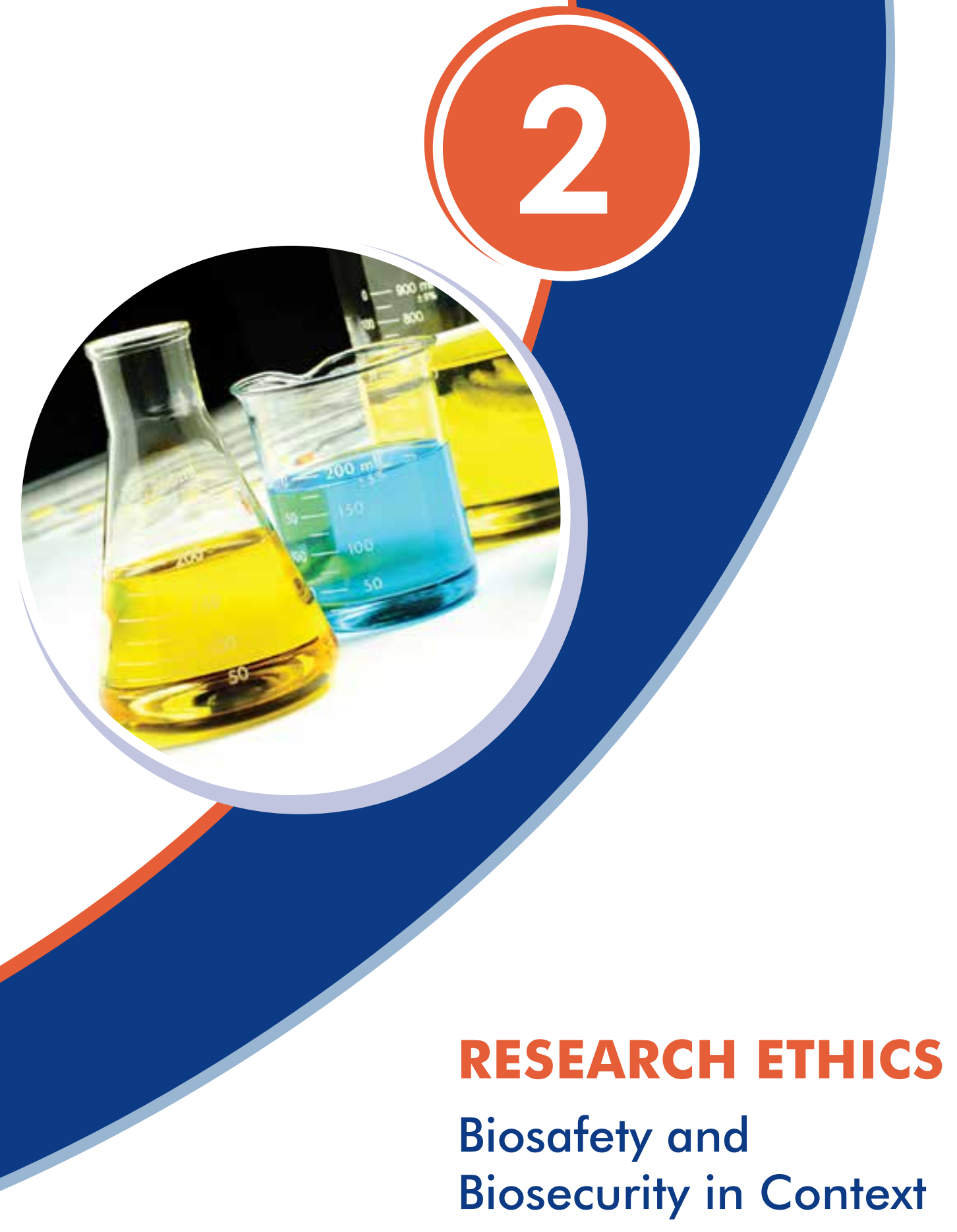




\subsection{Introduction}

Discovery and innovation in the life sciences are booming based on significant, recent technological advance and the benefits it holds for health-care provision, food production, sustainable energy generation, environmental protection, etc. Although $R \& D$ within the life sciences promise a better future for all people, it is easy to also contemplate scenarios where negative impacts could result from such work. In particular, the intentional misuse of biological material and biotechnologies to develop harmful agents should be proactively considered in an effort to establish well-balanced frameworks that will effectively prevent misuse without hampering legitimate R\&D. It is therefore inevitable that any reflections on biosafety and biosecurity will require a strong ethical dimension.

The purpose of this chapter is to reflect on the morality and ethics of R\&D and how this relates to the responsibilities of scientists in the life sciences. Dual-use research and the challenges it pose are discussed in particular and mechanisms of how ethics review should be institutionalised and managed with respect to biosafety and biosecurity are proposed.

\subsection{Defining morality and ethics}

Although the terms 'morality' and 'ethics' are often used interchangeably, it is generally useful and conceptually desirable to distinguish between them. Morality refers to the widely perceptible societal phenomenon that people in all known societies submit their behaviour to normative evaluation. This submission of their behaviour to the judgment of obligation or normativity is the key distinguishing difference between humans and animals. Humans do not simply act in certain ways without the ability to choose to act differently - in contrast to the instinctual actions of animals. People accept that they ought to act in a certain way as informed by societal norms. ${ }^{4}$

Ethics, in contrast, refers to an intellectual activity in which we consciously reflect on the nature of our moral behaviour, as well as the norms that guide that behaviour, the sources of our moral judgements and the theories in terms of which we think and argue when we engage in moral deliberation. The kind of normative ethics that relates to the content of this report is referred to as applied ethics, where ethics theories and approaches to moral reasoning are applied to immediate, serious moral issues that require urgent attention because of their potential impact on society. Ethics comes into play particularly in a context where it is evident that callous, deliberate malicious or careless research behaviour could potentially harm or endanger human life and/or

4 Norms are strong and widely acknowledged action guides, sometimes also strongly linked to a certain society, though often valid in most societies. 
the environment. Concerns regarding life science research and development work, as embodied in biosafety and biosecurity management systems, therefore arise from a widespread realisation that these activities require morally responsible behaviour to guard against their danger and misuse.

The abuse of biological material for harmful actions against humans is indicative of a phenomenon long recognised in philosophical and ethics literature, i.e. that science is not value-free (Feyerabend, 1975; Kuhn, 1962). It is increasingly agreed that value orientations cannot be divorced from the legitimate and responsible practice of science (Rossouw, 1980; Van Niekerk, 1992). Values are in play in particular when the aims of science are to be decided and evaluated. Objectivity and truth are regulative ideals that ought to guide the progresses of science and innovation and at times these ideals do act as important bulwarks against the threat of ideological derailments of science. However, under the direction of malicious intentions and aims, science and its products can also be used as very destructive forces, as illustrated by the infamous use of Zyklon B during the Holocaust to murder millions of people and the development of nuclear weapons during the Second World War.

\subsection{Dual-use research - the main moral dilemma related to biosafety and biosecurity}

Dual-use research (DUR) is defined as life sciences research that can be reasonably anticipated to provide knowledge, information, products or technologies that could be directly misapplied to pose a significant threat, with broad potential consequences to public health and safety, agricultural crops and other plants, animals, the environment, materiel or national security. ${ }^{5}$ The dual-use problematic has evolved in response to ever-growing fears that certain areas of the life sciences are vulnerable to misuse and that research conducted within these areas may be used to develop biological weapons. More specifically, the dual-use literature is driven by concern elicited by the publishing of the results in scientific academic journals of several experiments involving deadly viruses (Cello et al., 2002; Jackson et al., 2001 ; Tumpey et al., 2005), which could be replicated by nefarious individuals or groups, with catastrophic results. Due to this potential for misuse, there is a distinct polarisation within the scientific community regarding whether or not the results should have been published, which has implications for future research of a similar nature.

The debate is comprised, on the one hand, by the position that scientific freedom of enquiry, scientific transparency, the right to publish and the need to replicate and verify research are good or valuable things in themselves and should thus be protected;

$5 \mathrm{NIH}$, Office of Science Policy (www.osp.nih.gov). 
and on the other hand, by security concerns related to the potential for harm that could result from the misuse of such research. Most of life science research which possesses the potential for harmful misuse also results in tangible benefits related to the understanding and treatment of illnesses and diseases and thus for human health in general. The two opposing sets of values, the awareness of an intention to do good in the presence of a possible intention to cause harm, the problems of control and regulation of scientific research to which they give rise to and who must bear responsibility for this, are all aspects of what is generally understood as the dual-use dilemma.

Choice of research focus compels the scientist and associated scientific institution to decide on behalf of society between different, but equally compelling, goods. On the one hand there is the good associated not only with the benefits that could arise from successful research, such as the promotion of human health and flourishing, but also the good associated with the freedom or right of the scientist to pursue and generate knowledge itself and on the other hand, there is the good that arise from avoiding potential casualties associated with the possible misuse of research, materials or technologies. The main issue thus lies in how these competing values or goods should be balanced or adjudicated, who is responsible for this endeavour and how it should be regulated.

The burden of this responsibility must be placed not solely upon the individual scientist, but upon the scientific community as a whole. There is an implicit obligation that exists between the institution of science and the public which enables the former to secure particular privileges such as autonomy, public funding and public trust, in exchange for the fulfilment of certain responsibilities and duties. When there is a threat to public safety, safety concerns must override those related to the right to freedom of scientific enquiry. However, such a conclusion presupposes that it is possible to ascertain clear evidence of a threat.

It may be helpful to discern between the risk that particular dual-use research may represent and the presence of a clear threat that it will in fact be developed for illicit use by nefarious individuals or groups. The presence of such a foreseeable threat would require the enactment of more stringent regulatory measures (Forge, 2010). The real question therefore becomes whether or not it is possible to establish the credibility of a threat regarding the possible misuse of dual-use research. Of course, complexity is added if the manner in which a threat is portrayed serves a particular political agenda.

The way in which a threat is perceived will have direct relevance for how it is addressed - not only at the level of government, but also in terms of the reactions 
of scientists who are the key proponents in the dual-use dilemma. In order to ensure that scientists abide by any regulatory measures that are required, they must concur with the established threat credibility. This implies that scientists must not only be informed of relevant information but must also be involved in the process of threat identification. Perceptions of and the degree of threat posed by dual-use research is highly variable and as such, regulations must be flexible and innovative in order to encompass changes in science, as well as possible changes in threat.

Miller and Selgelid (2007) argue against control resting solely in the hands of either scientific institutions or government. They favour a system where dual control is shared between the two, with the formation of an independent body constituted by both scientific and security experts with ultimate power. Development of a mandatory code of ethical conduct for the life sciences as a profession in order to prevent the misuse of research, akin to the Hippocratic Oath to do no harm which is taken by doctors, has received much attention in the literature (Revill and Dando, 2006).

The intention to commit harm will always be present and in this regard, very little control exists. Where control and regulation are possible, it is vital to ensure that absolute vigilance and due care be taken. Such control and regulation is impossible to achieve without the participation of the scientific community. Rather than requesting that the scientific community blindly adheres to a set of rules or accepts concerns that are viewed as foreign to the ethos of science as an institution, it would be more effective to impart knowledge regarding the dual-use dilemma. Acceptance of scientific responsibility will ensure the necessary participation and cooperation of the scientific community in devising strategies to address the possibility of misuse. There is a far greater likelihood of preventing the misuse of research if those working in vulnerable areas are attuned to the nature of the threat and are committed to taking the necessary precautionary steps required of them.

\subsection{Ensuring ethical research and development}

Experimentation in and the application of biological weapons have been described long before the start of the First World War in 1914. Although international limitations and prohibitions on the abuse of microbes and pathogens for harmful and lethal intent, including the 1925 Geneva Convention and the Biological and Toxins Weapons Convention, were set in place during the $20^{\text {th }}$ century, serious concerns remain. These include concerns regarding the availability and accessibility of microorganisms as well as the technologies based on their use and applications.

The increasing recognition of the role and application of moral values in science practice encouraged the development of various broad ethics guidelines for scientists, which can also be used to assess the ethical standing of R\&D projects - especially in 
the life sciences. For example, the Singapore Statement on Research Integrity 6 states that "the value and benefits of research are vitally dependent on the integrity of the research" and then lists honesty, accountability, professional courtesy and fairness and good stewardship as the fundamental principles on which research integrity is based. It continues to list 14 different responsibilities of researchers to ensure the integrity of their research, of which adherence to regulations, reporting and responding to irresponsible research practices and societal considerations have particular bearing on biosafety and biosecurity matters as discussed in this study.

Similarly, a "universal ethical code for scientists" developed by the United Kingdom's (UK's) Department for Innovation, Universities and Skills endeavours to "renew the trust relationship between scientists and society". In this case the code of conduct is based on the societal values of rigour, respect and responsibility (See text box).

\section{A UNIVERSAL ETHICAL CODE FOR SCIENTISTS}

\section{Rigour}

\section{Rigour, honesty and integrity}

Act with skill and care in all scientific work. Maintain up-to-date skills and assist their development in others. Take steps to prevent corrupt practices and professional misconduct. Declare conflicts of interest. Be alert to the ways in which research derives from and affects the work of other people, and respect the rights and reputations of others.

\section{Respect}

Respect for life, the law and the public good

Ensure that your work is lawful and justified. Minimise and justify any adverse effect your work may have on people, animals and the natural environment.

\section{Responsibility}

\section{Responsible communication: listening and informing}

Seek to discuss the issues that science raises for society. Listen to the aspirations and concerns of others. Do not knowingly mislead, or allow others to be misled, about scientific matters. Present and review scientific evidence, theory or interpretation honestly and accurately.

From "A universal ethical code for scientists", UK Department for Innovation, Universities and Skills.

6 www.singaporestatement.org.

7 www.dius.gov.uk. 


\subsection{The institutionalisation and management of research ethics in South Africa}

Ethics awareness and the ethical review of scientific research in South Africa have increased exponentially over the past 30 years following trends abroad - particularly in the United States of America (USA). In terms of the South African National Health Act (Act 61 of 2003), all scientific research with human participants and animal subjects has to undergo ethical review by a legitimate research ethics committee (REC). All RECs have to be accredited by the National Health Research Ethics Council of South Africa (NHREC). ${ }^{8}$ The NHREC is appointed by the Minister of Health for a period of three years and is the highest policymaking body for research ethics in the country. The NHREC formulates and publishes extensive guidelines for ethical research with human participants and animal subjects, drawing on established international guidelines including the Nuremberg Code, the Belmont Report and the (often revised) Declaration of Helsinki.

Ethical review of research protocols involving research with human participants and animal subjects is standard practice globally. Assessing the impact of research and potential harms on human and animal health, as well as on the environment, is a necessary part of the research process. In the light of earlier comments that science is not always value-neutral and acknowledging its potential adverse effects, it is imperative to set procedures and practices in place that aim to protect the legitimate interests of humans, animals and the environment. This needs to be done in such a way that the progress of science is not hampered or unnecessarily delayed.

It is notable that in South Africa the formulation of guidelines for research on other organisms, and in particular microorganisms, that may negatively impact human health, well-being and/or the environment, has been lagging behind relative to the formulation of guidelines for research with human participants and animal subjects. This is increasingly recognised, and efforts are underway within some government departments, e.g. DAFF and some national research agencies to rectify the situation. For the purposes of this report, the panel acknowledges that much work must still be done to improve the applicability of the current system of ethics review to research on microorganisms.

The panel noted that specific RECs to assess the nature of microorganism research must be appointed at, or be made available to, all research facilities. Guidelines to determine which kinds of research require ethical assessment and what the ideal composition of an REC would be for such purposes need to be developed. The term office for REC

8 http://www.ethicsapp.co.za. 
members and accompanying terms of reference (TOR) and standard operating procedures (SOPs) require formulation.

The panel is of the opinion that members of such an REC should include, first and foremost, experts in the field, as well as people with expertise in ethics, representatives of the community and people with experience in ethical review. It is essential that members of an REC be properly trained for their work. There are a number of relevant certificates, diplomas and Masters programmes available at several South African tertiary institutions. It is important that there not be any direct conflicts of interest in the appointment and practice of members of such an REC.

\section{South Africa should} establish clear, encompassing and balanced ethical guidelines for all life science research and development work to ensure our safety and the integrity of the environment we live in. 


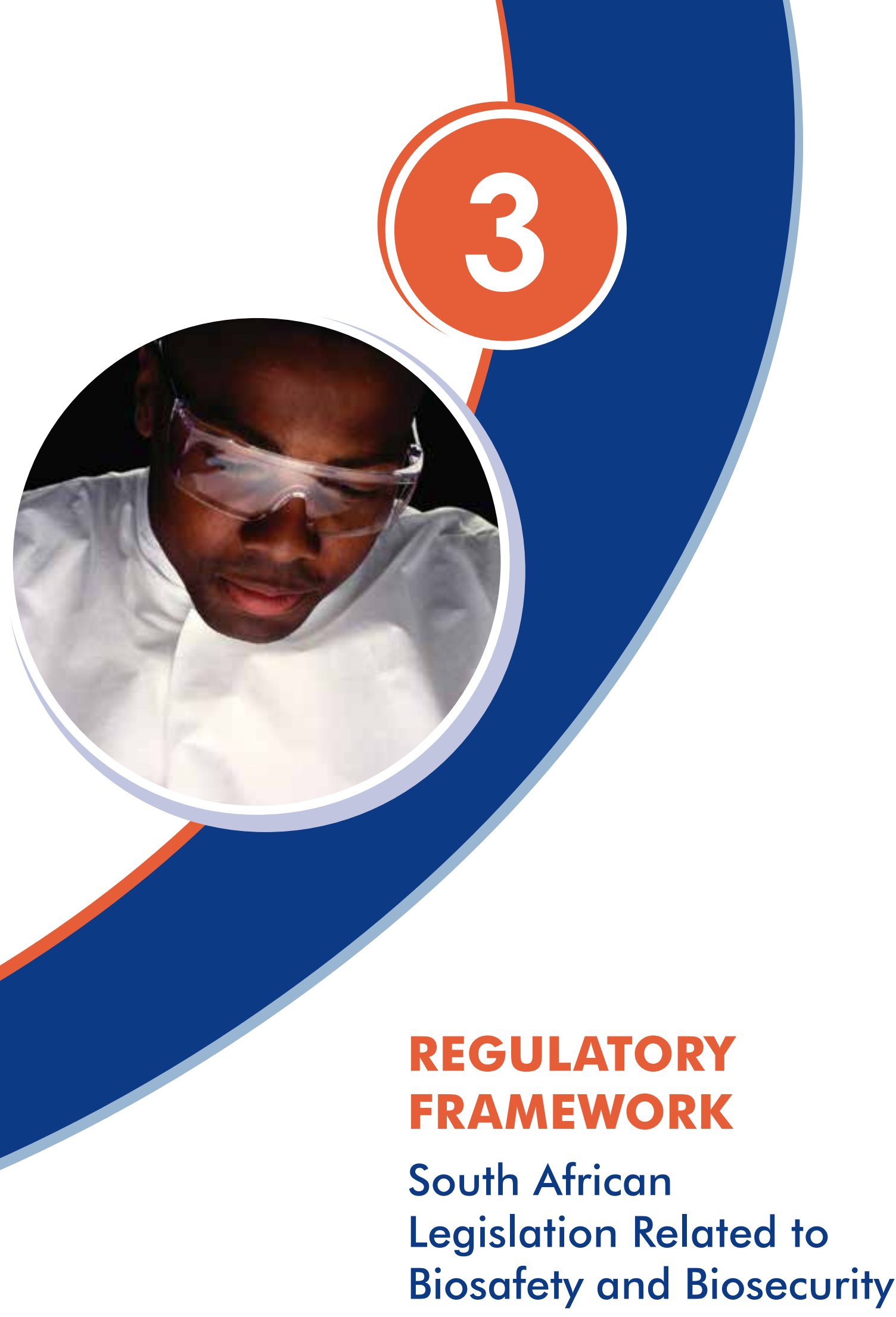




\subsection{Introduction}

The South African government is committed to protecting the health and safety of the South African people. Improved socio-economic conditions, effective vaccination programmes, education and hygiene measures are key to reducing the incidence of communicable diseases in the general population. However, the risk of infectious disease outbreaks and full-scale epidemics is recognised as a major public health threat both nationally and internationally. Emerging pathogens, such as the severe acute respiratory syndrome (SARS) virus, and increasing resistance to antibiotics in existing pathogens contribute to this risk. Global travel and the rise of bioterrorism are additional factors threatening public health and safety (Frieden et al., 2014).

Frieden et al. (2014) outline three components of government responsibility essential to ensuring public health security: 1) prevention; 2) early detection, and 3) timely and adequate response. Prevention includes having systems, policies and procedures in place to mitigate avoidable outbreaks. Detection requires a national surveillance and laboratory system capable of reliable testing for five or more of ten core tests relevant to the country's epidemiological profile, as well as electronic reporting systems and a multidisciplinary public health workforce. Adequate response is reflected by an established national public health emergency operations centre able to activate an emergency response to suspected outbreaks within 120 minutes.

The International Health Regulations (IHR) were revised by the WHO in 2005 and address directly new and emerging epidemic threats (WHO, 2008). South Africa is one of 194 signatory countries that have committed to improving capacity to better meet the requirements of the IHR (Frieden et al., 2014).

The South African government has also adopted the measures laid out in UNSCR 1540 that requires all member states of the United Nations (UN) to address issues relating to nuclear, biological and chemical materials and their associated research, developmental and stockpiling through domestic legislation. Relevant domestic legislation, once developed and ratified, has to be submitted in the form of matrices to a UNSC Committee responsible for the enforcement of Resolution 1540. It is then scrutinised for how it addresses the production, storage, use, accounting and securing of nuclear, biological and chemical materials, as well as the import and export and border controls of such materials.

Despite South Africa's participation in the above conventions, its current ability to prevent, detect and respond to an emerging pathogen outbreak or a bioterrorism attack is not fully known. This study was therefore undertaken to first scope all the South African legislation broadly relevant to biosafety and biosecurity (Section 3.2) and then to address those directly related to the prevention, detection, identification 
and control of infectious agents (Section 3.3). In both sections, the strengths and weaknesses of the existing legislation and regulations are critically discussed and improvements proposed.

\subsection{An assessment of existing legislation and regulations relevant to biosafety and biosecurity in South Africa}

\subsubsection{Aim}

The aim of this study is to assess existing relevant legislation and regulations in relation to biosafety and biosecurity considerations and to identify associated strengths, weaknesses and gaps in the laws and their implementation. The basis for the legislative overview was South Africa's submission to the UN Committee responsible for the implementation of UNSCR 1540.

\subsubsection{Specific objectives}

The specific objectives of the first part of this study were as follows:

i) A desktop review of South Africa's submissions to the UNSCR 1540 Committee and associated matrices.

ii) Identification of all relevant legislation and regulations pertinent to biosafety and biosecurity within South Africa either directly or indirectly mentioned or listed in the above-mentioned legislation.

iii) Consultations with relevant South African government departments in order to discuss their successes and challenges with regard to the drafting, legislating and implementation of the laws.

iv) Analysis of the findings from the desktop review and consultations in order to make recommendations consolidated into this report.

\subsubsection{Methods}

The study was conducted primarily by means of an analytical desktop review of available listed and recorded legislation and the documentation of such legislation in tabular format. This format was then presented to relevant South African government departments who were asked to provide input and their comments were subsequently incorporated into the table and the final report.

\subsubsection{Desktop review of current legislation}

The study commenced with an assessment and analysis of the South African submission to the UNSCR 1540 Committee. The submissions, in the form of matrices, were submitted by the South African government to the UNSCR 1540 Committee in 2005, 2006 and 2007 and each was assessed and analysed. All three years' submissions were taken into account in order to ensure that no legislation was neglected or missed in each subsequent submission. All identified legislation was obtained from either the South African government department websites or from other independent sources. 
The legislation was then assessed, analysed and tabulated, listing the relevant chapter/s or articles using the following characteristics:

1. Biological safety and security as listed in the UNSCR 1540 matrix.

2. Relevance and applicability to biosafety and biosecurity.

3. Relevant department or ministry responsible for the implementation of the legislation or relevant department or ministry listed in the legislation.

\subsubsection{Identification of additional legislation not included in UNSCR 1540}

Once the above table had been completed, legislation and regulations not mentioned in the South African submission to the UNSCR 1540 matrix were identified. The majority of these laws were identified through scrutinising legislation listed in the UNSCR 1540 matrix to identify additional legislation. Once this legislation was identified, the same process as for the UNSCR 1540 legislation was conducted, whereby each piece of legislation or regulation was individually assessed, analysed and tabulated according to the same criteria.

\subsubsection{Consultation with relevant government departments}

After identification, assessment and analysis of the legislation and regulations had been completed, a workshop was held in March 2014 where representatives from relevant government departments were invited to discuss various aspects relating to the legislation and regulations. Even though personnel from all relevant government departments/organisations were invited to this workshop, not all were able to participate. ${ }^{9}$ The participants were provided with the tables of legislation and asked to comment on aspects such as challenges regarding implementation, perceived strengths and weaknesses in the legislation and regulations, and how these could be better improved or addressed. Their inputs were analysed and incorporated into Table 3.1.

\subsubsection{Results}

\subsubsection{Legislation related to the UNSCR 1540 Matrix}

Twenty-two pieces of legislation were identified and acquired. On further inspection, two pieces of legislation had in fact been withdrawn and replaced domestically, and one piece of legislation was unobtainable from the various sources under which it was listed. Full details of the legislation are provided in Table 3.1.

9 The following departments and agencies were represented at the workshop: Department of Health, Department of Environmental Affairs, Department of Science and Technology, Department of International Relations and Co-operation, Department of Agriculture, Forestry and Fisheries; Protechnik Laboratories. 


\subsubsection{Additional legislation not included in UNSCR 1540}

A further nine pieces of relevant legislation were identified which do not form part of the UNSCR 1540 matrix. These are detailed in Table 3.2.

\subsubsection{Workshop discussion and feedback}

The workshop provided useful insights into the reality of the implementation of biosafety and security legislation in the country, indicating various limitations. Workshop participants noted that several of the laws and regulations that should support the control of bio-hazardous agents have deficiencies. These deficiencies are outlined below.

\section{Categorisation of hazardous pathogens is unclear and inconsistent}

This can complicate the inclusion of some pathogens in the lists produced by different departments and create uncertainty regarding which department or ministry is responsible for these.

\section{Responsibilities are divided between departments}

There are cases where multiple departments have responsibilities for different aspects of control. For example, the control of GMOs is required by the GMO Act (Act 15 of 1997), while research with GMOs may also be subject to the Clinical Trials Regulations Act (Act 101 of 1965) and the Non-Proliferation of Weapons of Mass Destruction Act (Act 87 of 1993). In the case of an experimental HIV vaccine using genetically modified Venezuelan Equine Encephalitis Virus as a vector which was submitted for use in a clinical trial, permits were required from each of the responsible bodies. Such a situation, which makes the system difficult to navigate for researchers or institutions, may result in duplication and prolongs the process of acquiring permits. This may impact on the use, production and storage of GMOs for commercial purposes.

Table 3.1: Legislation listed according to the South African government's submission to the United Nations Security Council Resolution 1540 matrix

\begin{tabular}{|l|l|l|l|}
\hline Legislation & $\begin{array}{l}\text { Chapter/Article } \\
\text { as listed in } \\
\text { UNSCR 1540 } \\
\text { Matrix }\end{array}$ & Relevance/Applicability & $\begin{array}{l}\text { Ministry/ } \\
\text { Department } \\
\text { Responsible }\end{array}$ \\
\hline $\begin{array}{l}\text { Agricultural } \\
\text { Pests Act (Act 36 } \\
\text { of 1983) }\end{array}$ & $\begin{array}{l}\text { Account for } \\
\text { Production, Use } \\
\text { \& Storage }\end{array}$ & $\begin{array}{l}\text { Mentions import and export } \\
\text { regulations and control measures } \\
\text { for certain pathogens. } \\
\text { Lists the right to inspection and } \\
\text { how it should be executed. } \\
\text { Lists offences and penalties. }\end{array}$ & $\begin{array}{l}\text { Department } \\
\text { of Agriculture, } \\
\text { Forestry and } \\
\text { Fisheries }\end{array}$ \\
\hline
\end{tabular}




\begin{tabular}{|c|c|c|c|}
\hline Legislation & $\begin{array}{l}\text { Chapter/Article } \\
\text { as listed in } \\
\text { UNSCR } 1540 \\
\text { Matrix }\end{array}$ & Relevance/Applicability & $\begin{array}{l}\text { Ministry/ } \\
\text { Department } \\
\text { Responsible }\end{array}$ \\
\hline $\begin{array}{l}\text { Animal Health } \\
\text { Act (Act } 7 \text { of } \\
\text { 2002) }\end{array}$ & $\begin{array}{l}\text { Account for } \\
\text { Production, Use } \\
\text { \& Storage }\end{array}$ & $\begin{array}{l}\text { Mentions biological experiments. } \\
\text { Lists export and transit limitations. } \\
\text { Lists inspection and search criteria } \\
\text { as well as offences and penalties } \\
\text { associated with deviating/ } \\
\text { breaching the Act. }\end{array}$ & $\begin{array}{l}\text { Department } \\
\text { of Agriculture, } \\
\text { Forestry and } \\
\text { Fisheries }\end{array}$ \\
\hline $\begin{array}{l}\text { Customs and } \\
\text { Excise Act (Act } \\
91 \text { of 1964) as } \\
\text { amended of } \\
2009\end{array}$ & $\begin{array}{l}\text { Section } 4 \\
\text { Section } 6 \\
\text { Section } 113\end{array}$ & Unclear. & $\begin{array}{l}\text { South African } \\
\text { Revenue Service }\end{array}$ \\
\hline $\begin{array}{l}\text { Export Control } \\
\text { Regulations } \\
\text { Notice } 672 \text { of } \\
2008\end{array}$ & $\begin{array}{l}\text { Schedule 1: } \\
\text { Munitions of War }\end{array}$ & $\begin{array}{l}\text { Notice was withdrawn in } \\
2012 \text { and replaced by the } \\
\text { Import Control Notice R92 of } \\
10 \text { February } 2012 \text {. }\end{array}$ & $\mathrm{N} / \mathrm{A}$ \\
\hline $\begin{array}{l}\text { Export Control } \\
\text { Regulations } \\
\text { Notice R92 of } \\
2012\end{array}$ & $\begin{array}{l}\text { Whole notice } \\
\text { but focus on } \\
\text { export controls } \\
\text { for Weapons of } \\
\text { Mass Destruction } \\
\text { and specifically } \\
\text { Biological } \\
\text { Weapons }\end{array}$ & $\begin{array}{l}\text { Lists exports that require licensure. } \\
\text { Specific mention of human blood } \\
\text { products. } \\
\text { Lists classification of export } \\
\text { according to schedules (I-III). }\end{array}$ & $\begin{array}{l}\text { International } \\
\text { Trade } \\
\text { Administration } \\
\text { Commission }\end{array}$ \\
\hline $\begin{array}{l}\text { Geneva } \\
\text { Protocol of } \\
1925\end{array}$ & Whole Protocol & $\begin{array}{l}\text { Deals with accession notification. } \\
\text { Prohibits the use of biological } \\
\text { agents during war or peace. }\end{array}$ & Various \\
\hline $\begin{array}{l}\text { Genetically } \\
\text { Modified } \\
\text { Organism Act } \\
\text { (Act } 15 \text { of 1997) }\end{array}$ & $\begin{array}{l}\text { Enforcement } \\
\text { Section } 21\end{array}$ & $\begin{array}{l}\text { Addresses facilities (all } \\
\text { encompassing). } \\
\text { Mentions the need for accidental } \\
\text { notification. } \\
\text { Lists the need to import and } \\
\text { export permits. } \\
\text { Lists the need for routine } \\
\text { inspections of facilities to ensure } \\
\text { compliance with the Act. } \\
\text { Lists offences and penalties for } \\
\text { deviation/breaching from the Act. }\end{array}$ & $\begin{array}{l}\text { Department } \\
\text { of Agriculture, } \\
\text { Forestry and } \\
\text { Fisheries }\end{array}$ \\
\hline
\end{tabular}




\begin{tabular}{|c|c|c|c|}
\hline Legislation & $\begin{array}{l}\text { Chapter/Article } \\
\text { as listed in } \\
\text { UNSCR } 1540 \\
\text { Matrix }\end{array}$ & Relevance/Applicability & $\begin{array}{l}\text { Ministry/ } \\
\text { Department } \\
\text { Responsible }\end{array}$ \\
\hline $\begin{array}{l}\text { Hazardous } \\
\text { Substances Act } \\
\text { (Act } 15 \text { of 1973) }\end{array}$ & Transport & $\begin{array}{l}\text { Classifies substances according to } \\
\text { their Groups (I-IV). } \\
\text { Prohibits the use, sale, and } \\
\text { production of certain substances/ } \\
\text { pathogens according to their } \\
\text { classification. } \\
\text { Mentions licensure and } \\
\text { transportation criteria and the } \\
\text { powers of inspection. } \\
\text { Lists offences and penalties for } \\
\text { deviation/breaching the Act. }\end{array}$ & $\begin{array}{l}\text { Department of } \\
\text { Health }\end{array}$ \\
\hline $\begin{array}{l}\text { Health Act } \\
\text { (Act } 61 \text { of 2003) }\end{array}$ & $\begin{array}{l}\text { Account for } \\
\text { Production, Use } \\
\text { \& Storage }\end{array}$ & $\begin{array}{l}\text { Mentions production, use and } \\
\text { storage of blood, blood products, } \\
\text { tissues and gametes. } \\
\text { Specifies the legal procedure for } \\
\text { removing tissues from alive/dead } \\
\text { patients. } \\
\text { Details legal procedure for } \\
\text { experimentation/research on } \\
\text { humans. } \\
\text { Lists standards and norms } \\
\text { required at institutions dealing } \\
\text { with biological materials. } \\
\text { Mentions powers of inspection } \\
\text { and environmental health } \\
\text { investigations should biological } \\
\text { materials be thought/seen to be } \\
\text { affecting a population's health. }\end{array}$ & $\begin{array}{l}\text { Department of } \\
\text { Health }\end{array}$ \\
\hline $\begin{array}{l}\text { Import } \\
\text { Regulations } \\
\text { Notice R206 of } \\
2009\end{array}$ & $\begin{array}{l}\text { Schedule 1: } \\
\text { Munitions of War }\end{array}$ & $\begin{array}{l}\text { Notice was withdrawn in } \\
2012 \text { and replaced by the } \\
\text { Import Control Notice R91 of } \\
10 \text { February } 2012 \text {. }\end{array}$ & $\begin{array}{l}\text { International } \\
\text { Trade } \\
\text { Administration } \\
\text { Commission }\end{array}$ \\
\hline $\begin{array}{l}\text { Import Control } \\
\text { Regulations } \\
\text { Notice R91 of } \\
2012\end{array}$ & $\begin{array}{l}\text { Whole notice } \\
\text { but focus on } \\
\text { import controls } \\
\text { for Weapons of } \\
\text { Mass Destruction } \\
\text { and specifically } \\
\text { Biological } \\
\text { Weapons }\end{array}$ & $\begin{array}{l}\text { Lists imports that require licensure. } \\
\text { Mentions weapons systems in } \\
\text { general (may be dual-use). } \\
\text { Mentions the Montreal Protocol } \\
\text { and the } 1988 \text { UN Convention. }\end{array}$ & $\begin{array}{l}\text { International } \\
\text { Trade } \\
\text { Administration } \\
\text { Commission }\end{array}$ \\
\hline
\end{tabular}




\begin{tabular}{|c|c|c|c|}
\hline Legislation & $\begin{array}{l}\text { Chapter/Article } \\
\text { as listed in } \\
\text { UNSCR } 1540 \\
\text { Matrix }\end{array}$ & Relevance/Applicability & $\begin{array}{l}\text { Ministry/ } \\
\text { Department } \\
\text { Responsible }\end{array}$ \\
\hline $\begin{array}{l}\text { International } \\
\text { Trade } \\
\text { Administration } \\
\text { Act (Act } 71 \text { of } \\
2003 \text { ) }\end{array}$ & $\begin{array}{l}\text { Section } 6 \\
\text { Part E }\end{array}$ & $\begin{array}{l}\text { Lists regulations relating to the } \\
\text { import and export and powers } \\
\text { to investigate, search and seize } \\
\text { materials of a general nature } \\
\text { and this can include biological } \\
\text { materials as well. }\end{array}$ & $\begin{array}{l}\text { Department } \\
\text { of Trade and } \\
\text { Industry }\end{array}$ \\
\hline $\begin{array}{l}\text { Non- } \\
\text { Proliferation } \\
\text { of Weapons } \\
\text { of Mass } \\
\text { Destruction } \\
\text { (WMD) Act (Act } \\
87 \text { of 1993) }\end{array}$ & $\begin{array}{l}\text { Section } 13 \\
\text { Section } 26 \\
\text { Section } 27\end{array}$ & $\begin{array}{l}\text { Focus on controlling goods, } \\
\text { issuing permits and registering } \\
\text { materials that could possibly } \\
\text { (dual-use) be used for the } \\
\text { development of a weapon of } \\
\text { mass destruction. } \\
\text { Mentions threat of use and } \\
\text { punishment associated with it. } \\
\text { Details governments' responsibility } \\
\text { to enter into and ratify treaties, } \\
\text { conventions and agreements. } \\
\text { Lists offences and penalties for } \\
\text { deviation/breaching the Act. } \\
\text { Attached to the Act is the } \\
\text { Convention on the Prohibition of } \\
\text { the Development, Production and } \\
\text { Stockpiling of Biological and Toxic } \\
\text { Weapons. }\end{array}$ & $\begin{array}{l}\text { Department } \\
\text { of Trade and } \\
\text { Industry }\end{array}$ \\
\hline $\begin{array}{l}\text { Amendments } \\
\text { to the Non- } \\
\text { Proliferation Act } \\
\text { (Act } 87 \text { of 1993) }\end{array}$ & $\begin{array}{l}\text { Whole } \\
\text { Amendment }\end{array}$ & Attached to the above Act. & $\begin{array}{l}\text { Department } \\
\text { of Trade and } \\
\text { Industry }\end{array}$ \\
\hline $\begin{array}{l}\text { Notice } 16 \text { of } \\
3 \text { February } \\
2010\end{array}$ & Whole Notice & $\begin{array}{l}\text { Registration form for individuals/ } \\
\text { companies seeking to make use } \\
\text { of controlled goods. } \\
\text { Relates to all materials (dual-use) } \\
\text { that could be used to develop } \\
\text { weapons of mass destruction. }\end{array}$ & $\begin{array}{l}\text { Department } \\
\text { of Trade and } \\
\text { Industry }\end{array}$ \\
\hline $\begin{array}{l}\text { Notice } 19 \text { of } \\
3 \text { February } \\
2010\end{array}$ & Whole Notice & $\begin{array}{l}\text { Deals with import and export } \\
\text { of all materials of a biological } \\
\text { nature. } \\
\text { Specific mention made of } \\
\text { licensure and facility requirements. } \\
\text { Lists all materials according to the } \\
\text { group classification. }\end{array}$ & $\begin{array}{l}\text { Department } \\
\text { of Trade and } \\
\text { Industry }\end{array}$ \\
\hline
\end{tabular}




\begin{tabular}{|c|c|c|c|}
\hline Legislation & $\begin{array}{l}\text { Chapter/Article } \\
\text { as listed in } \\
\text { UNSCR } 1540 \\
\text { Matrix }\end{array}$ & Relevance/Applicability & $\begin{array}{l}\text { Ministry/ } \\
\text { Department } \\
\text { Responsible }\end{array}$ \\
\hline $\begin{array}{l}\text { Notice } 22 \text { of } \\
3 \text { February } \\
2010\end{array}$ & Whole Notice & $\begin{array}{l}\text { Deals with missile technology and } \\
\text { components (could be applicable } \\
\text { when looking at dual-use). }\end{array}$ & $\begin{array}{l}\text { Department } \\
\text { of Trade and } \\
\text { Industry }\end{array}$ \\
\hline $\begin{array}{l}\text { Notice } 429 \text { of } \\
10 \text { April } 2002\end{array}$ & Delivery & $\begin{array}{l}\text { Deals with missile technology and } \\
\text { components (could be applicable } \\
\text { when looking at dual-use). }\end{array}$ & $\begin{array}{l}\text { Department } \\
\text { of Trade and } \\
\text { Industry }\end{array}$ \\
\hline $\begin{array}{l}\text { National } \\
\text { Security } \\
\text { Information } \\
\text { (NSI) Act (Act } \\
30 \text { of 2004) }\end{array}$ & $\begin{array}{l}\text { Personnel Security } \\
\text { Checks }\end{array}$ & $\begin{array}{l}\text { Deals with background checks, } \\
\text { etc. }\end{array}$ & $\begin{array}{l}\text { South African } \\
\text { Police Service, } \\
\text { Ministry of Safety } \\
\text { and Security }\end{array}$ \\
\hline $\begin{array}{l}\text { Protection of } \\
\text { Constitutional } \\
\text { Democracy } \\
\text { Against } \\
\text { Terrorists } \\
\text { and Related } \\
\text { Activities Act } \\
\text { (Act } 33 \text { of 2004) } \\
\end{array}$ & $\begin{array}{l}\text { Chapter } 2 \\
\text { Chapter } 3\end{array}$ & $\begin{array}{l}\text { Act deals with terrorist acts against } \\
\text { the state but does mention that } \\
\text { material provision (pathogens, } \\
\text { etc.) can be punishable. } \\
\text { Lists offences/penalties for } \\
\text { deviating/breaching the Act. }\end{array}$ & $\begin{array}{l}\text { South African } \\
\text { Police Service, } \\
\text { Ministry of Safety } \\
\text { and Security }\end{array}$ \\
\hline $\begin{array}{l}\text { Road } \\
\text { Transportation } \\
\text { Act (Act } 74 \text { of } \\
1997 \text { ) }\end{array}$ & Transport & Act unobtainable. & Unclear \\
\hline $\begin{array}{l}\text { South African } \\
\text { Police Service } \\
\text { Amendment Act } \\
\text { (Act } 57 \text { of 2008) }\end{array}$ & Where Applicable & $\begin{array}{l}\text { Mainly deals with the } \\
\text { establishment of the Directorate of } \\
\text { Priority Crimes Investigation. } \\
\text { New sections (amendment) } \\
\text { dealing with violations of the } \\
\text { Non-Proliferation of WMD Act } 87 \\
\text { of } 1993 .\end{array}$ & $\begin{array}{l}\text { South African } \\
\text { Police Service, } \\
\text { Ministry of Safety } \\
\text { and Security }\end{array}$ \\
\hline $\begin{array}{l}\text { Space Affairs } \\
\text { Act (Act } 84 \text { of } \\
1993 \text { ) }\end{array}$ & $\begin{array}{l}\text { Section } 22 \\
\text { Section } 23\end{array}$ & $\begin{array}{l}\text { Mentions dual-use technologies } \\
\text { and their applicability to weapons } \\
\text { of mass destruction. }\end{array}$ & $\begin{array}{l}\text { Department } \\
\text { of Trade and } \\
\text { Industry }\end{array}$ \\
\hline
\end{tabular}


Table 3.2: Legislation additional to that listed in UNSCR 1540

\begin{tabular}{|c|c|c|c|}
\hline Legislation & $\begin{array}{l}\text { Relevant } \\
\text { Chapter/ } \\
\text { Article }\end{array}$ & Relevance/Applicability & $\begin{array}{l}\text { Ministry/ } \\
\text { Department } \\
\text { Responsible }\end{array}$ \\
\hline $\begin{array}{l}\text { Animal Diseases Act } \\
\text { (Act } 35 \text { of 1984) }\end{array}$ & Selected & $\begin{array}{l}\text { Import and export permits. } \\
\text { Experiments, research and } \\
\text { quarantine guidelines. }\end{array}$ & $\begin{array}{l}\text { Department } \\
\text { of Agriculture, } \\
\text { Forestry and } \\
\text { Fisheries }\end{array}$ \\
\hline $\begin{array}{l}\text { Health Act (Act } 61 \text { of } \\
2003 \text { ): Regulations relating } \\
\text { to Artificial Fertilisation of } \\
\text { Persons, R175 of } 2012\end{array}$ & Selected & $\begin{array}{l}\text { Deals with the artificial } \\
\text { fertilisation (insemination } \\
\text { and removal of gametes) of } \\
\text { human beings. }\end{array}$ & $\begin{array}{l}\text { Department } \\
\text { of Health }\end{array}$ \\
\hline $\begin{array}{l}\text { Health Act (Act } 61 \text { of } \\
\text { 2003): Regulations } \\
\text { regarding the Rendering of } \\
\text { Clinical Forensic Medicine } \\
\text { Services, R176 of } 2012\end{array}$ & Selected & $\begin{array}{l}\text { Deals with sexual } \\
\text { assault and the forensic } \\
\text { examinations that follow } \\
\text { from reporting cases of } \\
\text { sexual assault. }\end{array}$ & $\begin{array}{l}\text { Department } \\
\text { of Health }\end{array}$ \\
\hline $\begin{array}{l}\text { Health Act (Act } 61 \text { of } \\
2003 \text { ): Regulations relating } \\
\text { to the use of Human } \\
\text { Biological Material, R177 } \\
\text { of } 2012\end{array}$ & Selected & $\begin{array}{l}\text { Deals with biological } \\
\text { materials for testing and } \\
\text { research. }\end{array}$ & $\begin{array}{l}\text { Department } \\
\text { of Health }\end{array}$ \\
\hline $\begin{array}{l}\text { Health Act (Act } 61 \text { of } \\
2003 \text { ): Regulations } \\
\text { relating to the Registration } \\
\text { of Microbiological } \\
\text { Laboratories and the } \\
\text { Acquisition, Importation, } \\
\text { Handling, Maintenance } \\
\text { and Supply of Human } \\
\text { Pathogens, R178 of } 2012\end{array}$ & Selected & $\begin{array}{l}\text { Deals with legislation } \\
\text { regarding possession, } \\
\text { handling, etc. of biological } \\
\text { pathogens. } \\
\text { Outlines facility } \\
\text { requirements such as safety } \\
\text { standards, transport criteria, } \\
\text { etc. }\end{array}$ & $\begin{array}{l}\text { Department } \\
\text { of Health }\end{array}$ \\
\hline $\begin{array}{l}\text { Health Act (Act } 61 \text { of } \\
2003 \text { ): Regulations relating } \\
\text { to Blood and Blood } \\
\text { Products, R179 of } 2012 .\end{array}$ & Selected & $\begin{array}{l}\text { Mainly the transfer of blood } \\
\text { and blood products. }\end{array}$ & $\begin{array}{l}\text { Department } \\
\text { of Health }\end{array}$ \\
\hline $\begin{array}{l}\text { Health Act (Act } 61 \text { of } \\
\text { 2003): Regulations } \\
\text { regarding the General } \\
\text { Control of Human Bodies, } \\
\text { Tissue, Blood, Blood } \\
\text { Products and Gametes, } \\
\text { R180 of } 2012\end{array}$ & Selected & $\begin{array}{l}\text { Deals with the removal of } \\
\text { blood, gametes and tissue } \\
\text { from living persons, the } \\
\text { establishment of death, } \\
\text { the disposal of unclaimed } \\
\text { bodies and the handling, } \\
\text { conveyance and burial of } \\
\text { bodies. } \\
\text { Lists the institutions } \\
\text { authorised to do removal of } \\
\text { the above. }\end{array}$ & $\begin{array}{l}\text { Department } \\
\text { of Health }\end{array}$ \\
\hline
\end{tabular}




\begin{tabular}{|l|l|l|l|}
\hline Legislation & $\begin{array}{l}\text { Relevant } \\
\text { Chapter/ } \\
\text { Article }\end{array}$ & Relevance/Applicability & $\begin{array}{l}\text { Ministry/ } \\
\text { Department } \\
\text { Responsible }\end{array}$ \\
\hline $\begin{array}{l}\text { Health Act (Act 61 of } \\
\text { 2003): Regulations relating } \\
\text { to the Import and Export } \\
\text { of Human Tissue, Blood, } \\
\text { Blood Products, Cultured } \\
\text { Cells, Stem Cells, Embryos, } \\
\begin{array}{l}\text { Foetal Tissue, Zygotes and } \\
\text { Gametes, R181 of 2012 }\end{array}\end{array}$ & Selected & $\begin{array}{l}\text { Deals with import and } \\
\text { export permits and } \\
\text { registration of companies, } \\
\text { etc. that deal with } \\
\text { biological materials. }\end{array}$ & $\begin{array}{l}\text { Department } \\
\text { of Health }\end{array}$ \\
\hline $\begin{array}{l}\text { Health Act (Act 61 of } \\
2003): \text { Regulations relating } \\
\text { to Tissue Banks, R182 of } \\
2012\end{array}$ & Selected & $\begin{array}{l}\text { Outlines facility } \\
\text { requirements and storage } \\
\text { conditions for biological } \\
\text { materials. }\end{array}$ & $\begin{array}{l}\text { Department } \\
\text { of Health }\end{array}$ \\
\hline
\end{tabular}

Another example refers to shipments containing materials that fall under the control or regulation of DAFF and DoH. In such cases it is unclear whether one department should be responsible for inspecting the entire shipment mentioned or whether each department should send an individual inspector and inspect the shipment together. It was noted that there have been liaison challenges in the past with regard to inspections requiring multiple departments and that this has led to delays in delivery of final shipments. It is unclear how such challenges could be overcome given that the guidelines of each department deal with biological materials specifically under their purview, especially given the significant amount of time it takes to amend and implement legislative changes.

Workshop participants suggested that a "hierarchy of legislation" be developed. This would allow for the identification of 'primary' legislation in such a situation. Participants did not determine how such a hierarchy could be developed and acknowledged that departments may be reluctant to defer their responsibilities to another department. Participants agreed that changes to existing legislation to make it more 'user-friendly' would be welcome, but described the difficulties and delays in the passing of new legislation as a significant barrier.

3. Varied interpretations surrounding domestic and international differences with regard to biological safety levels (BSL)

Domestic guidelines in respect of BSLs are not as stringent and/or detailed as those of international bodies such as the WHO. This could result in domestic BSLs being of a different standard when compared internationally. Workshop participants recommended that domestic legislation be regularly reassessed and harmonised so as to align with international norms and regulations. 
4. Uncertainty regarding implementation of the available domestic legislation Inadequate infrastructure and capacity, in particular the capacity to inspect facilities and identify plants at border control points, are two major issues affecting the implementation of biological safety and security legislation.

\section{Insufficient funding, personnel and facilities with respect to quarantine and inspection}

Workshop participants identified limited resources with respect to 1) maintenance of adequate quarantine and inspection of facilities; 2) appointment, training and retention of well-qualified inspectors, and 3) identification of the responsible department for the enforcement of inspections.

It was noted that due to limited infrastructure and capacity at ports in South Africa, a significant number of incoming inspections are not conducted at port facilities but rather at end facilities, where there is greater infrastructure and capacity.

This is a potential problem as materials are first transported to the end facility and then inspected. Should a hazardous material be discovered in a shipment or should an incident occur during the transport of such materials to an end facility it would make containment extremely difficult to put into operation.

\section{Limited human resources to inspect shipments entering and exiting the country}

Workshop participants mentioned shortages of funding to appoint, train and maintain personnel with the technical knowledge necessary to inspect, detect and deal with hazardous materials and that this is significantly affecting the ability of the country to maintain effective safety and security measures.

The responsibilities for conducting inspections and resource allocations for inspections are poorly defined. Given the wide range and number of departments and ministries involved with biological materials, exact responsibility for various materials can become blurred and difficult to assign. An initiative to strengthen and formalise inter-departmental cooperation in the field of biosecurity would be of benefit to South Africa.

\subsubsection{Additional data-gathering}

Following the presentation of the results of this study and the feedback from the March 2014 workshop, members of the panel collated further relevant legislation specific to agriculture and biodiversity. This supplementary information is in Appendix 2. 


\subsubsection{Conclusions}

This study sought to review legislation currently governing South African biological safety as listed in the governmental submission to the UNSCR 1540 Committee. The study furthermore sought to identify legislation and regulations pertinent to biological safety and security in the country not listed in the UNSCR 1540 submission through consultations with governmental departments and ministries involved in the biological safety and security arena.

The study revealed that although the South African legislative framework is in fact robust and comprehensive, it suffers from some significant limitations and challenges. Through a desktop analysis of this legislation and the conducting of a workshop that brought together experts in the field, it was revealed that the majority of these challenges centred on the categorisation of pathogens, the lack of harmonisation, and infrastructure and capacity challenges in the field.

Although the South African regulatory framework for biosafety and biosecurityrelated issues is robust and comprehensive, it suffers from significant limitations and challenges that should be addressed to ensure effective regulation without impeding research and development.

\subsection{Review of infectious agents and related regulations}

\subsubsection{Aim}

The aim was to identify, collate and review current South African governmental regulations, policies and guidelines for detecting, identifying, controlling and preventing the natural, accidental or deliberate spread of infectious agents.

\subsubsection{Specific objectives}

The specific objectives of the second part of this study were as follows:

i) Compile a list of all infectious agents relevant to South Africa.

ii) Compile a list all of relevant government departments and institutions responsible for or involved in infectious agent detection, identification, control and prevention.

iii) Identify relevant national regulations, policies and guidelines for detecting, identifying, controlling and preventing each listed infectious agent.

iv) Review each regulation to determine where gaps exist for detection, identification, control and prevention of infectious agents.

\subsubsection{Methods}

The study used a methodological approach employed by systematic reviews to ensure that the results were comprehensive and wherever possible, reduced bias. 
A protocol detailing the search strategy, inclusion criteria and analytical methods was developed.

\subsubsection{List of infectious agents}

It was not possible to identify a single, comprehensive list of infectious agents relevant to South Africa. The panel proposed the development of a consensus list of infectious agents relevant and important to South Africa. The list would include infectious agents targeting humans, animals, and/or plants and comprising bacteria, viruses, parasites, fungi, prions and toxins. The final compiled list of all infectious agents was based on two international and four local sources (Table 3.3).

Table 3.3: International and local lists used to develop a single, comprehensive list of South African relevant infectious agents

\begin{tabular}{|c|c|c|c|}
\hline List Name & Source & Issuing Authority & URL ${ }^{1}$ \\
\hline $\begin{array}{l}\text { List of Tests for } \\
\text { International } \\
\text { Trade }^{2}\end{array}$ & $\begin{array}{l}\text { Manual of Diagnostic } \\
\text { Tests and Vaccines for } \\
\text { Terrestrial Animals. } \\
\text { Terrestrial Manual } 7^{\text {th }} \\
\text { Edition, } 2012 \text { Volumes } \\
1 \text { and } 2\end{array}$ & $\begin{array}{l}\text { World Organisation } \\
\text { for Animal Health }\end{array}$ & $\begin{array}{l}\text { http://www.oie.int/ } \\
\text { fileadmin/Home/eng/ } \\
\text { Health_standards/ } \\
\text { tahm/0.02_- } \\
\text { PRESCRIBED_. } \\
\text { TESTS_2012.pdf }\end{array}$ \\
\hline $\begin{array}{l}\text { Select Agents and } \\
\text { Toxins List }\end{array}$ & $\begin{array}{l}\text { United States Select } \\
\text { Agent Regulations ( } 42 \\
\text { CFR Part 73, 9 CFR } \\
\text { Part 121, and } 7 \text { CFR } \\
\text { Part 331) }\end{array}$ & $\begin{array}{l}\text { United States } \\
\text { Departments } \\
\text { of Health and } \\
\text { Human Service and } \\
\text { Agriculture }\end{array}$ & $\begin{array}{l}\text { http://www. } \\
\text { selectagents.gov/ } \\
\text { resources/List_of_ } \\
\text { Select_Agents_and } \\
\text { Toxins_2013-09-10.pdf }\end{array}$ \\
\hline $\begin{array}{l}\text { List of controlled } \\
\text { and notifiable } \\
\text { animal diseases }\end{array}$ & $\begin{array}{l}\text { South African Animal } \\
\text { Diseases Act } 35 \text { of } \\
\text { 1984, } 18 \text { June } 2010\end{array}$ & $\begin{array}{l}\text { Department of } \\
\text { Agriculture, Forestry } \\
\text { and Fisheries }\end{array}$ & $\begin{array}{l}\text { http://www.daff.gov.za/ } \\
\text { vetweb/Disease Control } \\
\text { List of controlled } \\
\text { notifiable Animal } \\
\text { Diseases 2007.pdf }\end{array}$ \\
\hline $\begin{array}{l}\text { List of notifiable } \\
\text { human diseases }\end{array}$ & $\begin{array}{l}\text { South African Health } \\
\text { Act } 63,1977\end{array}$ & $\begin{array}{l}\text { Department of } \\
\text { Health }\end{array}$ & $\begin{array}{l}\text { Link on www.doh.gov. } \\
\text { za not operational. List } \\
\text { obtained from Western } \\
\text { Cape Department of } \\
\text { Health Communicable } \\
\text { Disease Control }\end{array}$ \\
\hline $\begin{array}{l}\text { Annexure A, } \\
\text { Non-Proliferation } \\
\text { of Weapons of } \\
\text { Mass Destruction } \\
\text { Act }\end{array}$ & $\begin{array}{l}\text { South African Non- } \\
\text { Proliferation of } \\
\text { Weapons of Mass } \\
\text { Destruction Act } 87 \text { of } \\
\text { 1993, amended } 2010\end{array}$ & $\begin{array}{l}\text { Department of } \\
\text { Trade and Industry }\end{array}$ & $\begin{array}{l}\text { http://www.thedti.gov. } \\
\text { za/nonproliferation/ } \\
\text { pdf/GN19_English.pdf }\end{array}$ \\
\hline
\end{tabular}




\begin{tabular}{|l|l|l|l|}
\hline List Name & Source & Issuing Authority & URL $^{\text {I }}$ \\
\hline $\begin{array}{l}\text { Annexure B, } \\
\text { Hazardous } \\
\text { Biological Agents } \\
\text { Guidelines }\end{array}$ & $\begin{array}{l}\text { South African } \\
\text { Occupational Health } \\
\text { and Safety Act, } \\
\text { 1993, Regulations for } \\
\text { Hazardous Biological } \\
\text { Agents. 27 December } \\
2001\end{array}$ & $\begin{array}{l}\text { Department of } \\
\text { Labour }\end{array}$ & $\begin{array}{l}\text { http://www.labour.gov. } \\
\text { za/DOL/downloads/ } \\
\text { legislation/regulations/ } \\
\text { occupational- } \\
\text { health-and-safety/ } \\
\text { Regulation2013-2020 } \\
\text { Hazardous Biological } \\
\text { agents.pdf }\end{array}$ \\
\hline
\end{tabular}

1 All of the above lists and URLs were accessed during January and February 2014.

2 The List of Tests for International Trade is produced by the World Organisation for Animal Health and includes prescribed and alternative which are considered optimal for determining the health status of animals and are required for the international movement of animals and animal products.

3 The Select Agents and Toxins List produced by the United States Departments of Health and Human Service and Agriculture includes all organisms which potentially pose a severe threat to both human and animal health, to plant health, or to animal and plant products.

Each infectious agent was classified as follows:

1. Type of infectious agent:
1.1 Bacteria
1.2 Virus
1.5 Mite
1.6 Prion
1.3 Parasite
1.4 Fungi
1.7 Toxin

2. Target of infectious agent (can be a single target or multiple targets, e.g. human and animal):
2.1 Human
2.2 Animal
2.3 Plant

If the type or target of an infectious agent was unclear, information for each organism was sourced from internet sites using the hierarchical process outlined in Figure 3.1 to ensure the quality of the information retrieved.

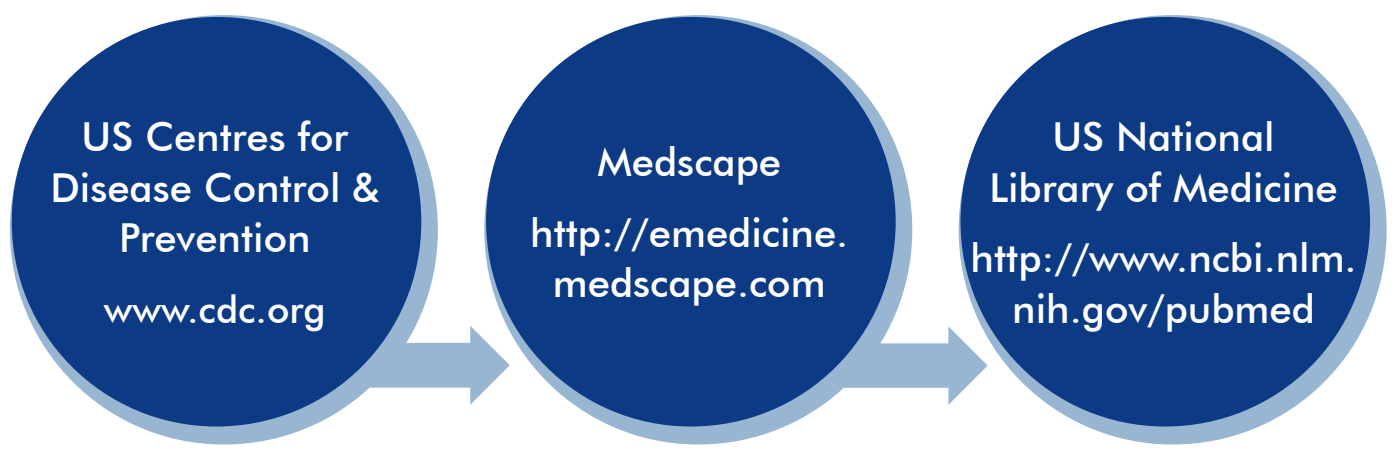

Figure 3.1: Hierarchical process to determine type and target of infectious agent. 
If the above hierarchical process did not yield relevant information for a named infectious organism, the search was broadened to searching www.google.com. This often yielded academic papers (journal articles) which were then read for further information. Where there was an indication from the scientific literature that an infectious agent previously considered only pathogenic to animals, may also affect humans, the target would be recorded as 'animal and human'.

\subsubsection{List of South African government departments and other institutions} Two researchers worked together to identify all relevant national government departments and other institutions responsible or involved in infectious agent detection, identification control and prevention. This was done initially using expert knowledge sourced from the panel to identify relevant departments. The researchers then searched departmental websites and used a snow-balling technique where government departments and institutions cross-referenced other relevant departments or sources. A saturation point was reached when no further departments or institutions were identified in this way. Website and contact details, together with information on whether the institution was state-owned or private, were recorded on an MS Excel spreadsheet.

\subsubsection{Identification of relevant national regulations, policies and guidelines} Two researchers searched each government website for all regulations relevant to the detection, identification, control and prevention of infectious agents in South Africa. If policies and guidelines were also available these were recorded. Where regulations were not available electronically, the relevant departments were telephoned for further information and electronic copies of the relevant regulations were requested. The panel provided copies of relevant documents to supplement the search and identified policies under development and/or regulations which were not yet promulgated or were undergoing a consultative process. The list of regulations compiled in the previous section was cross-checked to ensure consistency.

\subsubsection{Review of relevant national regulations}

Each identified regulation was reviewed for the following:

\section{Source of regulation}

- Department name

- Availability on website/electronic copy via telephone/hard copy

2. Type of infectious agent covered if stipulated:
- Bacteria
- Virus
- Parasite
- Mite
- Prion
- Toxin
- Fungi 
3. Target of infectious agent (can be multiple) if stipulated:
- Human
- Animal
- Plant

4. Focus of regulation (can be multiple):
- Detection
- Identification
- Control
- Prevention

The data were extracted and entered into an MS Excel spreadsheet and summarised in tabular format.

\subsubsection{Analytical framework}

All regulations that specifically included tables or appendices of infectious agents were selected. The single list of infectious agents compiled, was mapped against these regulations and a record made of each regulation, which included the infectious agent by name.

Wherever possible, new taxonomic classifications were used regardless of the taxonomy used in the original regulations. For example, the bacteria previously known as Pseudomonas pseudomallei was recorded under its new name of Burkholderia pseudomallei and all the regulations were scrutinised for either name.

Where regulations used disease terminology rather than the name of the causative agent, the name of the causative agent was sought and preferentially recorded, with the disease name in brackets. For example, the bacteria, Ehrlichia ruminantium is recorded as Ehrichlia species in the Occupational Health and Safety Act (OHSA) (Act 85 of 1993), Regulations for Hazardous Biological Agents (RHB) R1390 of 27 December 2001, whereas in the Office International des Epizooties (OIE) Terrestrial Manual for Animal Health List of Tests for International Trade the condition it causes is recorded as 'Heartwater'. The infectious agent was captured as Ehrlichia ruminantium (Heartwater) and all regulation lists scrutinised for both names.

The list of infectious agents mapped against regulations was sorted by target and type of infectious agent and colour-coded accordingly to produce a visual representation of the coverage of infectious agents in the South African regulations. Each target list (human, animal, animal and human, plant) was sorted according to a reference list.

\subsubsection{Results}

A list of 451 distinct infectious organisms was compiled. Of these, 211 targeted humans, 118 targeted animals, 97 both animals and humans, and 22 targeted plants. For a further three, it was not possible to clearly identify the target. Infectious agents 
comprised bacteria (162), viruses (162), parasites (74), fungi (14), insects (1), flies (2), mites (6), prions (4), toxins (20) and six others that were not clearly classified. The full lists are included in Appendices 3 to 6.

\subsubsection{Regulations, policy and guidelines}

\section{Human health}

In the public sector, three national government departments are responsible for developing and promulgating regulations and/or policy related to detecting, identifying, controlling and/or preventing infectious disease outbreaks in humans. In addition, three parastatal institutions were identified that either assist with developing guidelines and policy or conduct research in the field. One private association was identified as developing guidelines specifically for managing human infectious diseases (Table 3.4).

The DoH drafted revised Regulations regarding Notifiable Medical Conditions in 2012 and requested comments from provincial departments. These have not yet been promulgated. We were unable to obtain further information regarding the due date for promulgation.

Table 3.4: Human health: current regulations, policy and guidelines by issuing department

\begin{tabular}{|l|l|l|}
\hline $\begin{array}{l}\text { Department/ } \\
\text { Institution }\end{array}$ & Regulations & $\begin{array}{l}\text { Policy and } \\
\text { Guidelines }\end{array}$ \\
\hline
\end{tabular}

\section{Government Departments}

Department of $\quad$ National Health Act (Act 61 of 2003). Health
Regulations relating to the registration of microbiological laboratories and the acquisition, importation, handling, maintenance and supply of Human Pathogens (R178) (March 2012).

National Health Act (Act 61 of 2003).

Regulations relating to Blood and Blood Products (R179) (March 2012).

National Health Act (Act 61 of 2003). Regulations relating to the use of Human Biological Material (R177) (March 2012).

National Health Act (Act 61, 2003). Regulations relating to Tissue Banks (R182)(March 2012). Health Act (Act 63 of 1977). List of Notifiable Medical Conditions.'
The National Infection Prevention and Control Policy and Strategy, 2007

Guidelines for Management of SARS, 2004 


\begin{tabular}{|c|c|c|}
\hline $\begin{array}{l}\text { Department/ } \\
\text { Institution }\end{array}$ & Regulations & $\begin{array}{l}\text { Policy and } \\
\text { Guidelines }\end{array}$ \\
\hline $\begin{array}{l}\text { Department of } \\
\text { Labour }\end{array}$ & $\begin{array}{l}\text { Occupational Health and Safety Act (Act } 85 \\
\text { of 1993) Regulations for Hazardous Biological } \\
\text { Agents (R1390) (December 2001). }\end{array}$ & $\mathrm{N} / \mathrm{A}$ \\
\hline $\begin{array}{l}\text { Department of } \\
\text { Trade \& Industry }\end{array}$ & $\begin{array}{l}\text { Non-Proliferation of Weapons of Mass } \\
\text { Destruction Act (Act 87of 1993). }\end{array}$ & $\mathrm{N} / \mathrm{A}$ \\
\hline \multicolumn{3}{|l|}{ Parastatal Institutions } \\
\hline $\begin{array}{l}\text { Medical Research } \\
\text { Council }\end{array}$ & $\begin{array}{l}\text { Researchers use notifiable records to determine } \\
\text { mortality data for national mortality survey. }\end{array}$ & \\
\hline $\begin{array}{l}\text { National Institute } \\
\text { for Communicable } \\
\text { Diseases }\end{array}$ & $\begin{array}{l}\text { Staff provide comments and feedback on } \mathrm{DoH} \\
\text { Regulations and Policy. }\end{array}$ & \\
\hline $\begin{array}{l}\text { National Health } \\
\text { Laboratory } \\
\text { Services }\end{array}$ & $\begin{array}{l}\text { The Quality Assurance Division is entrusted with } \\
\text { the responsibility of setting and implementing } \\
\text { policy with regard to research, quality } \\
\text { assurance and accreditation of laboratories. } \\
\text { Proficiency testing (also known as external } \\
\text { quality assessment) is the evaluation of } \\
\text { laboratory testing performance by means of } \\
\text { inter-laboratory comparisons where the same } \\
\text { items are tested by different laboratories. }\end{array}$ & \\
\hline \multicolumn{3}{|l|}{ Private Institutions } \\
\hline $\begin{array}{l}\text { Federation of } \\
\text { Infectious Disease } \\
\text { Societies of } \\
\text { Southern Africa }\end{array}$ & $\begin{array}{l}\text { Guidelines for the optimal use of blood cultures, } \\
\text { 2010. Isolation precautions in hospitals, } 2001 \\
\text { (Incorporated into Regulations for Hazardous } \\
\text { Biological Agents (R1390) December 2001). }\end{array}$ & \\
\hline
\end{tabular}

1 The National Health Act of 2003 does not include a list of notifiable diseases so the Act of 1977 applies.

\section{Animal health}

The DAFF is responsible for developing and promulgating regulations with respect to the detection, identification, control and prevention of infectious disease in animals (Table 3.5). As for human health, animal health is also protected under the Department of Trade and Industry's (the dti) Non-Proliferation of Weapons of Mass Destruction (NPW) Act (Act 87 of 1993). Only one parastatal, the Agricultural Research Council $(A R C)$, conducts research in the field. 
Table 3.5: Animal health: current regulations, policy and guidelines by issuing department

\begin{tabular}{|l|l|l|}
\hline $\begin{array}{l}\text { Department/ } \\
\text { Institution }\end{array}$ & $\begin{array}{l}\text { Policy and } \\
\text { Guidelines }\end{array}$ \\
\hline Government Departments & N/A \\
\hline $\begin{array}{l}\text { Department } \\
\text { of Agriculture, } \\
\begin{array}{l}\text { Forestry and } \\
\text { Fisheries }\end{array}\end{array}$ & $\begin{array}{l}\text { Animal Diseases Act (Act 35 of 1984). } \\
\text { List of Controlled and Notifiable Animal } \\
\text { Diseases (Act 35 of 7984) (Jun 2010). } \\
\text { Animal Health Act (Act 7 of 2002). } .^{1} \\
\text { Meat Safety Act (Act 40 of 2000). }\end{array}$ & N/A \\
\hline $\begin{array}{l}\text { Department of } \\
\text { Trade \& Industry }\end{array}$ & $\begin{array}{l}\text { Non-Proliferation of Weapons of Mass } \\
\text { Destruction Act (Act 87 of 1993). }\end{array}$ & \\
\hline Parastatal Institution & $\begin{array}{l}\text { Oversees the animal and plant research } \\
\text { institutions within the Council. }\end{array}$ & \\
\hline $\begin{array}{l}\text { Agricultural } \\
\text { Research Council }\end{array}$ &
\end{tabular}

1 The Animal Health Act of 2002 repeals both the Animal Health Act of 1984 and the Animal Diseases Amendment Act of 1991 but it has yet to be promulgated.

\section{Plant health}

One government department is responsible for regulations on detection, identification, control and prevention of infectious disease in plants. One parastatal institution is active in research in the field (Table 3.6).

Table 3.6: Plant health: current regulations, policy and guidelines by issuing department

\begin{tabular}{|c|c|c|}
\hline $\begin{array}{l}\text { Department/ } \\
\text { Institution }\end{array}$ & Regulations & $\begin{array}{l}\text { Policy and } \\
\text { Guidelines }\end{array}$ \\
\hline \multicolumn{3}{|c|}{ Government Departments } \\
\hline $\begin{array}{l}\text { Department } \\
\text { of Agriculture, } \\
\text { Forestry and } \\
\text { Fisheries }\end{array}$ & $\begin{array}{l}\text { Agricultural Pests Act (Act } 36 \text { of 1983). } \\
\text { National Forest Act (Act } 84 \text { of 1998). }\end{array}$ & N/A \\
\hline \multicolumn{3}{|c|}{ Parastatal Institutions } \\
\hline $\begin{array}{l}\text { Agricultural } \\
\text { Research Council }\end{array}$ & $\begin{array}{l}\text { Oversees the horticulture and field crop } \\
\text { research institutions within the Council. }\end{array}$ & \\
\hline
\end{tabular}

A draft Plant Health (Phytosanitary) Bill was published in the Government Gazette on 26 October 2012 and public comment was invited. The aim of the Bill is to provide 
for phytosanitary measures to prevent the introduction, establishment and spread of regulated pests; for the control of regulated pests; for regulation of the movement of plants, plant products and other regulated articles into, within and outside of South Africa; and to provide for matters connected therewith. We were not able to establish the status of the Draft Bill. This is despite requests for further information from the relevant unit within the DAFF.

There are no clear policy and guidelines issued by the DAFF on matters pertaining to the Agricultural Pests Act (Act 36 of 1983). However, the department issues permits on the basis of what pesticides may be used and conditions of how such may be produced. The department regulates the facilities for the production of such pesticides as well.

\section{Other relevant national and international regulations}

Transport of toxic and infectious substances is governed by additional regulations issued by the national Department of Transport and the International Association of Transport Aviation. In South Africa, the South African Bureau of Standards (SABS) publishes South African National Standards. Standard 10228 includes toxic and infectious substances and is referred to in the National Road Traffic Act (Act 93 of 1996) regarding road transport of Dangerous Goods and Substances.

Table 3.7: Additional regulations governing infectious agents

\begin{tabular}{|l|l|}
\hline $\begin{array}{l}\text { Department/ } \\
\text { Institution }\end{array}$ & Regulations \\
\hline Government Departments \\
\hline $\begin{array}{l}\text { Department of } \\
\text { Transport }\end{array}$ & $\begin{array}{l}\text { The National Road Traffic Act (Act 93 of 1996). Chapter VIII of the } \\
\text { Regulations: Transportation of Dangerous Goods and Substances by } \\
\text { Road (with South African National Standard 10228 "The Identification } \\
\text { and Classification of Dangerous Goods for Transport: Class Definitions"). }\end{array}$ \\
\hline $\begin{array}{l}\text { International } \\
\text { Air Transport } \\
\text { Association (IATA) }\end{array}$ & Dangerous Goods Regulations. \\
\hline
\end{tabular}

\subsubsection{Mapping the list of infectious agents to the South African regulations}

Four South African regulations include lists of specific infectious agents:

1. The List of Notifiable Medical Conditions is an annexure to the Health Act (Act 63 of 1977) and includes 33 broad medical conditions. The first health-care professional or facility with whom a patient presenting with one of the medical conditions comes into contact, is legally obliged to notify the case or death to the authorities in the relevant provincial structures. 
2. The OHSA (Act 85 of 1993), Regulations for Hazardous Biological Agents (R1390) (Dec 2001) applies to all employers or self-employed persons at a workplace where hazardous biological agents are produced, processed, used, handled, stored or transported, or incidents which may result in persons being exposed to hazardous biological agents in the performance of his or her work. The Act contains an Annexure that lists specific organisms and the classification of each organism according to its level of risk of infection.

3. The South African NPW (Act 87 of 1993), amended 2010, includes an Annexure of specific microbial or other biological agents and toxins maliciously used in the manufacture of biological and toxin weapons. The infectious agents listed in the Annexure are classified as controlled goods.

4. The South African Animal Diseases Act (Act 35 of 1984), List of Controlled \& Notifiable Animal Diseases (June 2010) includes a list of 1) controlled diseases (any animal disease in respect of which any general or particular control measure has been prescribed and any animal disease which is not indigenous to South Africa), and 2) notifiable diseases.

Appendices 3 to 6 indicate the coverage of each infectious agent included in the comprehensive list in the current list of the four South African regulations outlined above. The tables include the target of the agent and whether the agent is included in the US Select Agent List and for those agents targeting animals, whether the agent is included in the OIE Terrestrial Manual Test List.

\section{Human infectious agents}

Using 31 human agents included in the US List of Select Agents as a reference list (See Appendix 3), seven organisms are listed in the US Centres for Disease Control and Prevention (CDC) List of Select Agents and in each of the three South African lists: two bacteria (Clostridium perfringens and Yersinia pestis) and five viruses (Ebola, Lassa, Marburg, Variola Major and Minor). Three organisms from the US CDC List are included in both the list of the NPW Act and in the OHSA RHB, but not in the South African Notifiable Disease List. A further 17 organisms listed in the CDC List are included in only the NPW List. The remaining four organisms listed in the US CDC List are not included in any of the South African lists. These four organisms are the Chapare Virus, the Reconstructed 1918 Influenza Virus, the SARS-associated Coronavirus and the South American Haemorrhagic Fever Virus.

Of the remaining 181 organisms which are included in lists derived from South African acts and are not listed in the US CDC Select Agent List, six organisms are included in each of the three South African lists: five bacteria (Clostridium perfringens, 
Clostridium tetani, Legionella pneumophilla, Salmonella typhi, Vibrio cholera), and one virus (Yellow Fever). Eighteen organisms are listed in both the OHSA RHB and are also a cause of a listed Notifiable Disease, but are not included in the regulations to the NPW Act. A further eight organisms are listed in the OHSA and in the regulations to the NPW Act, but not in the Notifiable Disease List. Three toxins are included in the regulations to the NPW Act and by default would also be included as causative disease agents in the Notifiable Disease List (Cholera, Clostridium perfringens, and Tetanus toxin). The remaining 131 organisms are listed in the OHSA RHB and are not detailed in any of the other lists.

\section{Animal infectious agents}

Using the 14 animal agents included in the US CDC List of Select Agents as a reference list (See Appendix 4), three viral diseases (African Horse Sickness, Rinderpest and Blue Tongue) are listed in the OIE Terrestrial Manual and in each of the three relevant South African lists, viz. the Animal Diseases Act (Act 35 of 1984), the regulations to the NPW Act and in the OHSA RHB.

Seven viral diseases are listed in the US CDC List, the OIE Terrestrial Manual List, the regulations to the NPW Act and the South African Controlled and Notifiable Animal Diseases List, but are not considered in the OHSA RHB. Four agents (two bacterial: Mycoplasma capricolum and Mycoplasma mycoides; and two viral: Goat Pox Virus and Peste des petits ruminants) are listed in the OIE Terrestrial Manual, the US CDC List and the regulations of the NPW Act, but are not controlled or notifiable in South Africa and do not appear on the OHSA RHB List. A single virus, Porcine Herpesvirus (Aujeszky's Disease), is listed in the OIE Terrestrial Manual and is included in the South African Controlled and Notifiable List and the regulations to the NPW Act, but is not included in the US CDC List of Select Agents or the OHSA RHB.

Three bacteria (Mycobacterium paratuberculosis [Johne's Disease], Salmonella gallinarum [Fowl Typhoid] and Salmonella pullorum) are listed in the OIE Terrestrial Manual, are controlled or notifiable in South Africa and are included in the OHSA RHB, but are not considered select agents in the US CDC List or in the regulations to the NPW Act. Ten agents are included in the US CDC List and the OIE Terrestrial Manual, but are not considered in any of the South African regulations. Two viral agents (Porcine Enterovirus type 1 [Teschen Disease] and Vesicular Stomatitis Virus [VSV-IN2, VSV-IN3]) appear in the US CDC List, but are not included in the OIE Terrestrial Manual or in the NPW or the Controlled and Notifiable Animal Diseases List. Six agents appear in the OIE Terrestrial Manual List and are considered in the OHSA RHB but are not included in the US CDC List, the NPW List or the Controlled and Notifiable Animal Diseases List. 


\section{Human and animal agents}

Using the 15 animal and human agents included in the US CDC List of Select Agents as a reference list (See Appendix 5), four bacterial agents (Bacillus anthracis, Brucella abortus, Brucella melitensis, and Brucella suis) are included in all the relevant lists including the OIE Terrestrial Manual, the regulations to the NPW Act, the OHSA RHB and are Notifiable Medical Conditions and included in the South African Controlled and Notifiable Animal Diseases List. The Pasteur strain of B. anthracis is included in the US CDC List and the OIE Terrestrial Manual but is not considered in the South African regulations. Rift Valley Fever and Newcastle Disease appear in all the lists, except they are not Notifiable Medical Conditions (they are included in the Controlled and Notifiable Animal Diseases). Coxiella burnetti ( $Q$ fever) is included in all lists except in the Controlled and Notifiable Animal Diseases List (it is a Notifiable Medical Condition).

The Hendra Virus (originally Equine Morbillivirus) and Francisella tularensis are included in the OIE Terrestrial Manual, the US CDC List, the NPW regulations and the OHSA RHB, but are not Controlled or Notifiable Animal or Human Diseases in South Africa. Three viruses (Eastern Equine Encephalitis Virus, Nipah Virus and Venezuelan Equine Encephalomyelitis Virus) are included in the OIE Terrestrial Manual, the US CDC List and the NPW regulations, but are not in the OHSA RHB or Controlled or Notifiable Animal or Human Disease in South Africa.

Crimean-Congo Haemorrhagic Fever is included in the US CDC List, the NPW regulations, the OHSA RHB and is a Notifiable Medical Condition. It is not included in the OIE Terrestrial Manual and is not a Controlled or a Notifiable Animal Disease. Burkholderia mallei and pseudomallei (formerly Pseudomonas mallei and pseudomallei) are included in the US CDC List, the NPW regulations and the OHSA RHB, but are not Notifiable or Controlled and are not included in the OIE Terrestrial Manual. Rabies Virus is included in the OIE Terrestrial Manual, is both a Notifiable Medical Condition and a Controlled Animal Disease and appears in the OHSA RHB and the NPW regulations. It is not included on the US CDC Select Agent List.

Salmonella enteritidis is included in the OIE Terrestrial Manual and the OHSA RHB and is both a Notifiable Medical Condition (falls under food poisoning) and is included in the South African Controlled and Notifiable Animal Diseases List. It is not on the US CDC select agent list or in the NPW regulations.

Japanese Encephalitis and Western Equine Encephalitis Virus are included in the OIE Terrestrial Manual and in the NPW regulations, but not considered in other South African lists or the US CDC Select Agent List. 
Eighteen infectious agents are included in the OIE Terrestrial Manual and in the OHSA RHB only. Two parasitic agents (Cystercosis and Cryptosporidiosis) are only included in the OIE Terrestrial Manual. Salmonella paratyphi is included as a Notifiable Medical Condition (under food poisoning) and is also captured in the OIE Terrestrial Manual under Salmonellosis. Chlamydia psittaci (avian strains) are included in the OIE Terrestrial Manual (as Avian Chlamydiosis), the NPW regulations and the OHSA RHB, but are not Notifiable or Controlled Diseases in South Africa. Lyssaviruses as a group are included in the NPW regulations, but not included in other lists (Rabies is a Lyssavirus and is recorded as a specific organism within the lists).

The remaining 54 agents which can cause animal and human disease are only recorded in the OHSA RHB.

\section{Plant infectious agents}

Two plant bacteria, Ralstonia solanacearum (race 3, biovar 2) and Xanthomonas oryzae, are included in both the US CDC select agent list and in the NPW regulations. Five infectious agents included in the US CDC select agent list are not included in the relevant South African regulations. The remaining 15 organisms are included in the NPW regulations (See Appendix 6).

\subsubsection{Discussion}

\subsubsection{Main findings}

This review identified that multiple South African regulations govern the prevention, detection, identification and control of disease due to infectious agents. Five different government departments are responsible for the regulations which ensure public safety with respect to infectious diseases. The lists of specific infectious agents included in the relevant regulations differ depending on the focus of each regulation.

We did not identify cross-references between relevant regulations and were not able to locate all relevant regulations at one source. The dates of the promulgation of regulations span 35 years from 1977 to 2012. We noted that some lists of agents do not include current taxonomic classification indicating that regulations are likely to be out-of-date. There are fewer plant diseases listed in the regulations than human and animal diseases.

\section{Relevance of current lists of infectious agents}

We were not able to identify a single, comprehensive list of all infectious agents that pose a threat to public health relevant to South Africa, be it from accidental or deliberate spread. It is arguably appropriate for each regulation to include a list of agents relevant to the aim and scope of the said regulation, e.g. an agent which may 
pose a threat to the safety of laboratory workers may not be sufficiently infective to necessarily apply to the general population, to be classified as a Notifiable Medical Condition. However, apart from the Notifiable Medical Condition List (Humans) and the Controlled and Notifiable List of Animal Diseases, it is unclear how relevant the lists of agents included in the regulations of the NPW Act (Act 87 of 1993) and the OHSA RHB (Act 85 of 1993) are to the South African context. Interviews with the accountable individuals based in the relevant government departments suggest that the lists included in these regulations were imported from other international lists.

These observations suggest that a single, regularly updated and publicly accessible list of agents based on the South African epidemiological risk profile of each agent would be a helpful tool for policymakers to cross-reference during the development of regulations.

\section{Delays in drafting and promulgating regulations}

Several of the regulations are no longer current and are due to be replaced. The DoH has drafted Regulations regarding Notifiable Medical Conditions to be included in the National Health Act (Act 61 of 2003) to replace the 1977 Notifiable Medical Condition List. The draft was sent for provincial comment in 2012 and no further information regarding its progress was available to us. The Animal Health Act was drafted in 2002 to replace the Animal Disease Act of 1993 but has not been promulgated. It is difficult to identify a specific reason for the delay in the process and given the length of time which has passed since the 2002 draft; it is likely that a major revision is again required.

Drafting, revising and promulgating laws requires several stages (See Figure 3.2) and public participation and stakeholder workshops are necessary during the law-making process. As a result, a reasonable length of time is required to ensure the integrity of each stage. However, our review has identified several instances where the delay is of several years rather than months in duration which may reflect inefficiencies in the system. In addition, there is a lack of public information regarding the process as evidenced by our inability to confirm when departments were planning to promulgate the draft regulations. It is important that South African regulations can address the potentially rapid changes in the profile of infectious diseases, and provision for this needs to be made within the current regulatory processes. 
Green

Paper

White

Paper

Bill

Act

\section{Discussion document drafted in the Ministry or}

Department:

1) provides general thinking around a policy

2) published for comment, suggestions or ideas

\section{Broad statement of government policy drafted by}

Department or Task Team

1) provides more refined discussion document

2) relevant Parliamentary committees may propose amendments

\section{Draft version of the law drawn up by Department under} Ministerial direction

1) published in Government Gazette for public comment

2) debated by committees in both Parliamentary houses

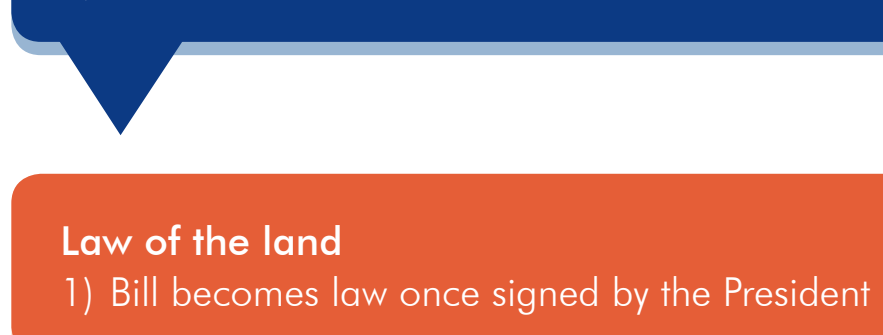

Figure 3.2: Flow diagram of the legislative process in South Africa. ${ }^{10}$

\section{Terminology}

In general, acts include definitions of terms used in the regulations. Despite this, we identified several instances where there is potential confusion regarding terminology. The meaning of a 'controlled disease' is clearly defined in the Animal Health Act

10 The diagram was informed by the legislative process outlined on the government website: Parliament of the Republic of South Africa, How a law is made (http://www.parliament.gov.za/ live/content.php? Item_ID=1843). 
(Act 7 of 2002) as any animal disease in respect of which any general or particular control measure has been prescribed, as well as any animal disease which is not indigenous to South Africa. However, it does not provide a definition for the term 'notifiable disease' and how this differs from a controlled disease in terms of the actions required either by government or by the farmer.

In the case of human health, the 1977 Notifiable Medical Condition List and the associated Health Act is not clear whether a Notifiable Medical Condition is also a Controlled Disease, if indeed this is possible for human diseases. While human diseases cannot necessarily be controlled through quarantine measures or extermination as for animal diseases, notifiable diseases require immediate action on the part of the health professional. The Acts are intended to govern the behaviour primarily of health professionals, but consideration needs to be given to the fact that most are not well-versed in legal terminology and may struggle to fully understand their legal requirements without additional simplification and a comprehensive implementation process. The current (2014) DoH website does not have a functional operational link to the Disease Notification System.

\section{Taxonomic classifications}

As detailed in the Results section, the names of many organisms have changed as taxonomic classifications evolve and this is likely to be an increasing challenge in the future. To ensure consistency and avoid confusion, it is imperative that mechanisms exist to ensure that lists can be updated regularly. This will allow for changes in the taxonomic classifications to be easily adopted and, in the case of Notifiable Medical Conditions and Controlled and Notifiable Animal Diseases, for emerging pathogens to be rapidly included when necessary. For example, SARS is not included as a Notifiable Medical Condition in the 1977 List. We note that the draft Notifiable Medical Condition Act, once promulgated, will facilitate this via the establishment of a Notifiable Medical Conditions Advisory Committee of experts who will meet at least twice a year. Responsibilities of the Committee will include review of the list of Notifiable Medical Conditions for emerging and re-emerging conditions of public health significance.

\section{Prioritisation and identification of gaps}

From the comparative analysis of the lists it is immediately evident which infectious agents are included most frequently in each of the lists. Such a process can assist in prioritising the importance of each agent. The aim of the US CDC Select Agent List and the lists associated with the NPW are prevention and control of those agents which can be used maliciously for acts of bioterrorism. Many of the agents included in both these lists cause diseases which are not controlled or notifiable in South Africa and are not included in the OHSA RHB. It is likely that the diseases caused by many 
of these agents have not occurred in South Africa before and as a result were not included on the Notifiable Medical Condition List and arguably, depending on the epidemiological risk profile, will not need to be. However, the possibility of exposure in a laboratory setting would suggest that agents included in the NPW Lists should also be included in the OHSA RHB List. This would need to be explored further by those with expertise in disease epidemiology, risk profile and laboratory exposure.

\subsubsection{Strengths and limitations}

The review has several strengths. We used systematic review methodology which included the development of an a priori protocol to guide the search process and the data collection and analysis. The search was comprehensive and iterative and undertaken by two researchers to reduce selection bias. Each researcher compiled the comprehensive infectious agent list and assessed all targets and agent classifications. This duplication aimed to reduce measurement bias.

As reported earlier, the issue of changing taxonomy created specific challenges for ensuring the lists were comparable. Each agent had to be checked to ensure that infectious agents were not captured in duplicate if more than one name had been in use in the past, such as Pseudomonas which is now known as Burkholderia. Several lists included only the genus and not the species names. For example, Rabies Virus is not included as a single virus term in the NPW Lists, but is captured under the broad genus name Lyssaviruses. In addition, many animal disease terms do not reflect the agent. For example the OIE Terrestrial Manual refers to Aujesky's Disease, but does not include the infectious agent, viz. Porcine Herpesvirus.

The researcher had to ensure that despite the use of different nomenclature, each agent was correctly mapped to each list. Several checks were used including interrogating the lists after sorting them by a reference list to see where anomalies existed. However, further checking of the lists by a qualified taxonomist would enhance the reliability of the analysis.

The development of the comprehensive list of agents was iterative but it was limited by the agents contained in the current lists and the choice of the lists that were included. The choice was pragmatic and based on what was available at the time. We used the 2012 List of Test for International Trade outlined in the OIE Terrestrial Manual and it must be noted that this is a list of prescribed diagnostic tests required by the OIE Terrestrial Animal Health Code for the international movement of animals and animal products and may not contain prescribed tests for every disease. An example of this is Congo Crimean Haemorrhagic Fever, which does not have a prescribed test listed in the 2012 Manual but is an OlE-listed disease for 2014 (See http://www.oie. int/en/animal-health-in-the-world/oie-listed-diseases-2014/). 
The review was required to be completed in a limited time-frame, and although efforts were made to ensure that all relevant departments and regulations were identified, it is possible that there are some missing data. It was not always possible to obtain confirmation of queries directly from the government departments as the review timeline overlapped with the financial yearend period for government departments, which precluded staff from responding to requests.
The development of a single, locally relevant and current list of infectious agents could enhance the utility of and crossreferencing between all relevant regulations thereby increasing the efficiency with which these are controlled.

\subsubsection{Conclusions}

The study has identified a complex set of South African regulations which govern the detection, identification, control, and prevention of human, animal and plant diseases caused by infectious agents. Challenges exist in accessing the relevant regulatory information from government departments, and understanding and interpreting the requirements of the regulations. The development of a single, locally relevant list of infectious agents which is regularly updated could potentially enhance the utility and cross-referencing of future regulations. 



\subsection{Introduction}

In order to reduce the exposure of laboratory personnel, the public, agriculture, and the environment to potentially infectious agents and other biological hazards, specific biosafety practices and procedures, specific construction features of laboratory facilities, safety equipment, and appropriate occupational health programmes should be implemented in life science research facilities (Bakandize et al., 2010). These facilities should also have systems in place to ensure research integrity and ethics and biosecurity measures to mitigate the potential for science to be misused.

The aim of this part of the study was to determine the extent to which the research and diagnostic facilities in South Africa have systems in place to facilitate research excellence, their adherence to ethical guidelines and laboratory biosafety and biosecurity. A questionnaire that was developed and published by the WHO in 2010 as part of the guidance document Responsible Life Science Research for Global Health Security (WHO, 2010), formed the basis of this investigation. The questionnaire was designed to assist health policymakers, health professionals, laboratory managers and scientists to assess the extent to which the above-mentioned systems are in place in the national public health system and in private laboratories.

The principle that informed the development of the $\mathrm{WHO}$ questionnaire is that the best protection against misuse of science is the development and maintenance of a culture of scientific integrity and excellence characterised by openness, honesty, accountability, responsibility and relevance. This is also the best guarantee of progress and development. Good science and sound scientific research are inextricably linked with the health, development and good policies of a country. Moreover, the confidence of the people and their trust in government and policies depends to a large extent on trustworthy science $(\mathrm{WHO}, 2010)$. An early version of the questionnaire was piloted in 2009 in South Africa at the NICD. It was further successfully used in a WHOsupported study in Kenya in 2011 to assess research and diagnostic laboratories in Nairobi (Kenya et al., 2012).

At the commencement of the study there was no comprehensive database of public and commercial life science facilities in South Africa. Public life science facilities are facilities located within academic institutions, as well as state-run institutions that are funded by a combination of government and non-South African government donors and that undertake teaching and publish their results in peer-reviewed journals. Commercial facilities are those that perform for-profit services. As the first of a suite of empirical studies, a mapping survey was therefore undertaken to gather information about life science facilities according to their geographic location, focus of activities and main sources of funding. 


\subsection{Mapping of the life sciences facilities in South Africa}

\subsubsection{Aim}

The aim of this survey was to understand the landscape of South African life sciences facilities and to map and capture the details of the facilities, institutions and companies that make up the life science community in South Africa, including animal, plant and human health facilities.

\subsubsection{Specific objectives}

The specific objectives of this study were:

1. To enable a point-in-time assessment of research and diagnostic capacity in South Africa.

2. To enable the determination of a representative sample for a perception survey about practice in relation to the implementation of biosafety and biosecurity measures and the application of ethics in South Africa (Section 4.3).

3. To allow the identification of key participants who would be interviewed about measures to prevent, detect and respond to infectious disease outbreaks (Chapter 5).

\subsubsection{Methods}

Mapping was initially achieved by internet searches to identify facilities, which were in turn contacted telephonically in order to obtain the necessary information. The majority of the sites contacted were unwilling to release the information telephonically and thus project information sheets were mailed to the relevant people identified by such initial contact (See Appendix 7). A questionnaire was also made available online ${ }^{11}$ and a request for responses and a link to the questionnaire was circulated widely. ${ }^{12}$

This process was limited by the reluctance of the National Health and Laboratory Services (NHLS) laboratories to participate in the data-gathering without formal ethical approval from the NHLS REC. The NICD did however participate in the study. Furthermore, the private diagnostic facilities were similarly reluctant to release information without express endorsement of the survey by their head office. Delays in obtaining these permissions meant that neither the NHLS nor private diagnostic laboratories were approached directly for participation. The information on these laboratories that was freely available on the company websites was included in the mapping exercise. This is a significant limitation of the study that could be overcome if

11 See www.surveymonkey.com/s/CB6JP65.

12 Circulation means were inter alia the ASSAf website, journal articles published in South African Journal of Science and the South African Medical Journal, appeals to scientific societies and through the circulation of a call for responses amongst contacts identified through internet searches. 
the database were to be updated and maintained by a central authority in accordance with the recommendation of this study.

In addition, although it was anticipated that scientific research and diagnostic facilities in South Africa would be familiar with ASSAf, and would therefore accept the credentials of the researcher and the credibility of the research, this proved not to be true and several institutions were reluctant to make information available. This meant that most of the information in the database was gathered through internet searches. The information available on institutional websites often did not include the detail we sought such as: sources of funding, number of staff members, range of research or diagnostic tests undertaken. ${ }^{13}$ Thus the final dataset described should be augmented with additional data as they become available, and should be regarded as a work in progress.

\subsubsection{Results}

A database of facilities, institutions and companies that make up the life science community in South Africa was generated and is located at ASSAf, Pretoria, South Africa. In accordance with the commitments made on the project information sheet, these data will not be available for commercial reuse and will only be available to projects sanctioned by the Academy and the DST. The main findings from the survey with respect to geographic location, focus of activities and funding sources are summarised below.

The national database comprises 979 different facilities, of which 214 (22\%) conducted research and 700 (72\%) performed diagnostic services. Sixty-five facilities performed both research and diagnostic services. Each of these categories were further divided into business sector, i.e. public (as defined above) or commercial (for-profit) facilities (Figure 4.1).

Most of the laboratories fall into the Human life science sector (64\%), followed by those in the Animal (22\%) and Plant (13\%) sectors (Figure 4.2). A further breakdown by province (Figure 4.3) shows that over two-thirds of the laboratories in Gauteng focus on research and diagnostics in the human sector. A similar dominance of human sector laboratories is also notable for all the other provinces; although less pronounced in some cases.

13 When analysing the responses it was noticed that many laboratories ticked more than one category for range of research (public/private research/diagnostics). It must be recognised that these multiple categories would often not be identifiable from facility websites, where one main category is normally highlighted (such as academic research). It is therefore possible that as the database is augmented additional categories may be added to a number of the facilities that were identified through web searches. 


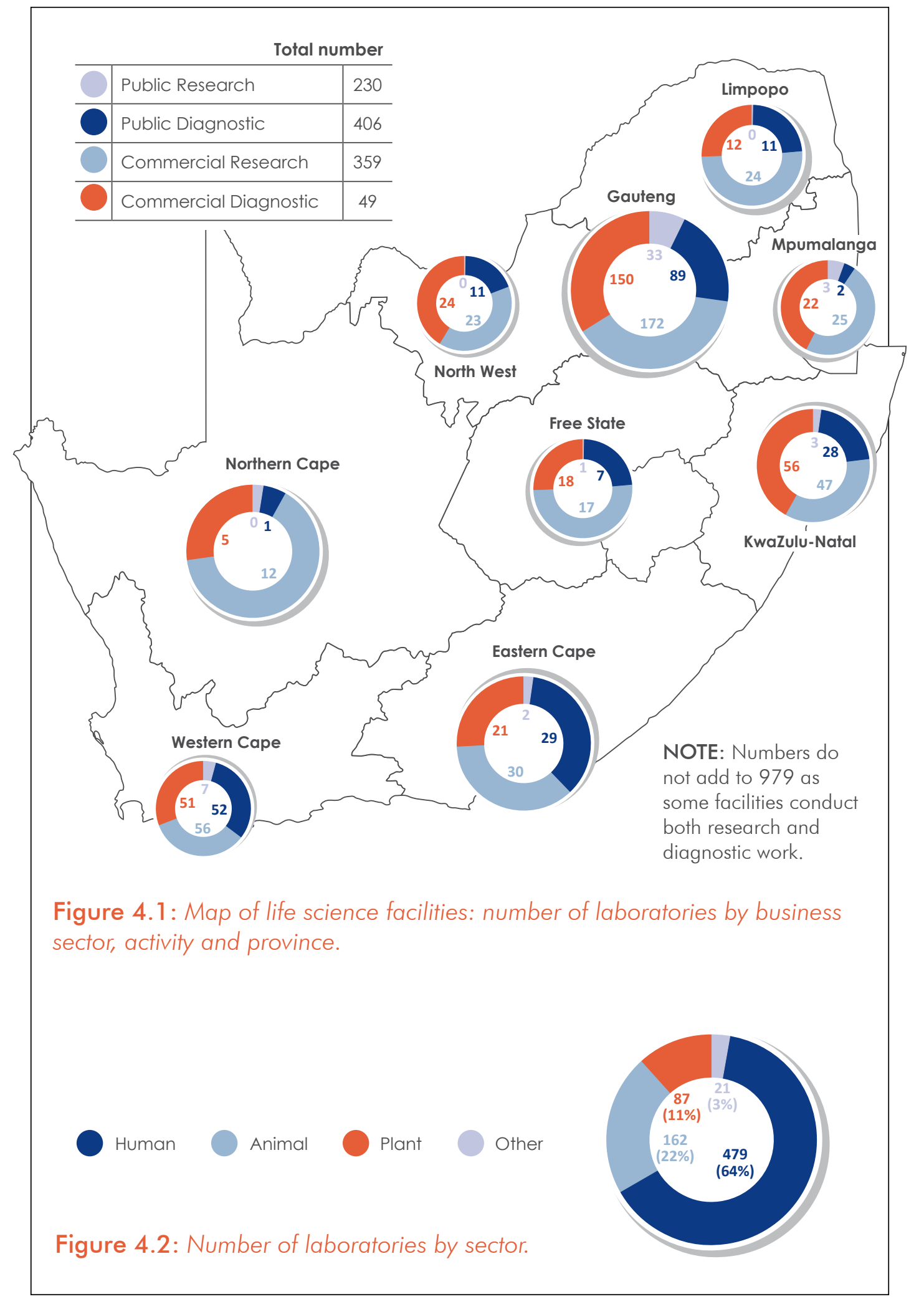




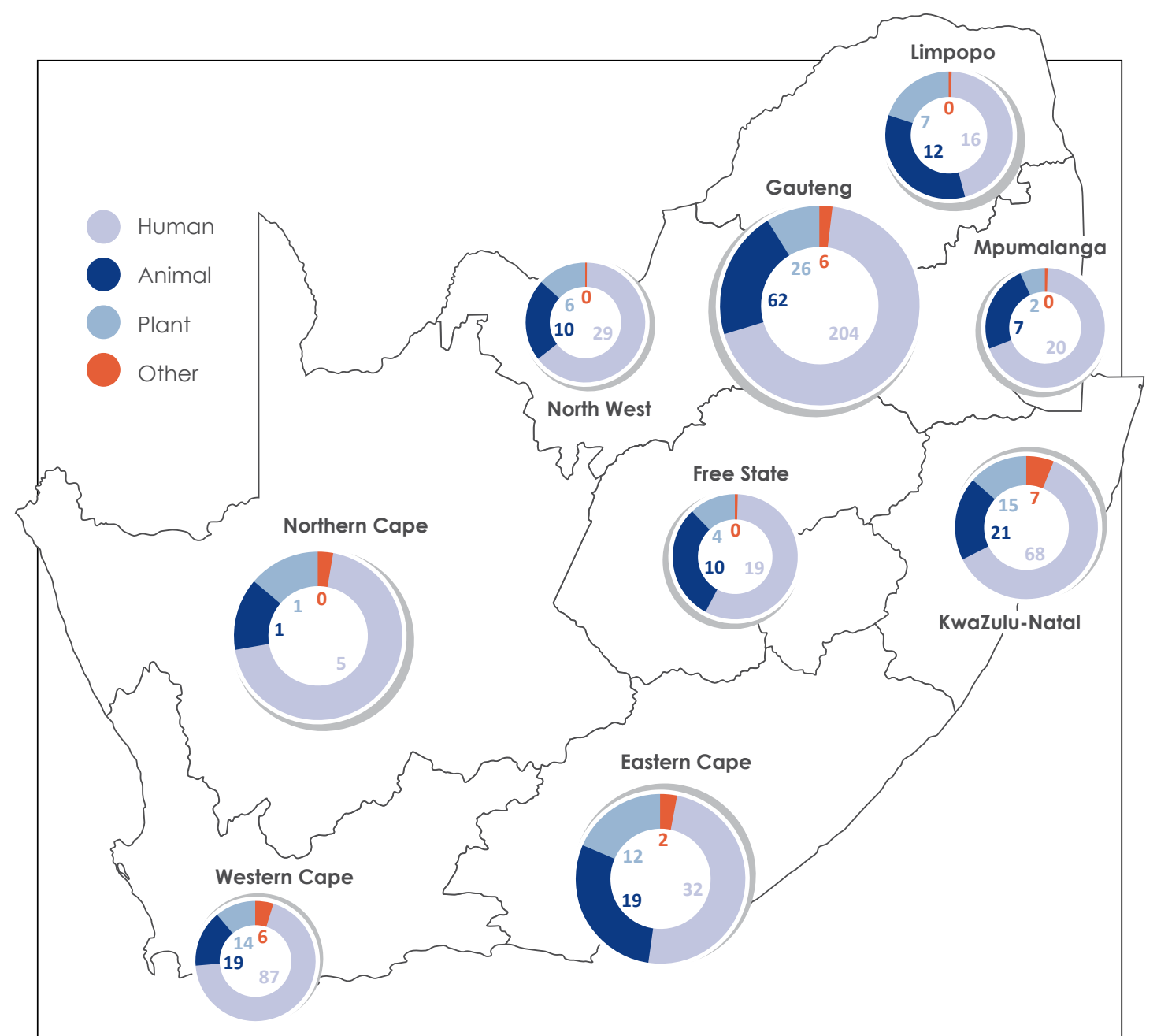

Figure 4.3: Map of life science facilities: number of laboratories by life science sector and province.

The breakdown of funding sources is presented in Figure 4.4. Sixty percent of funding is from local private sources, while government provides $18 \%$ direct funding plus an additional 12\% through the research councils.

Government

Local private funding
Research council

Foreign funding

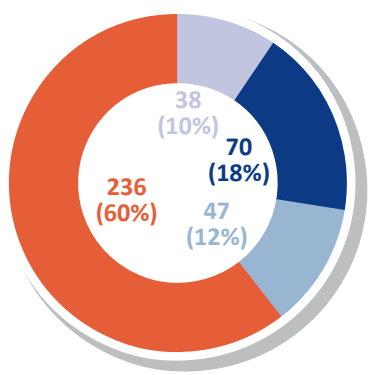

Figure 4.4: Funding sources of life sciences laboratories. 


\subsubsection{Discussion}

This database represents the first comprehensive database of research and diagnostic laboratories in South Africa. Despite its limitations, it represents an important source of information in the event of a disease outbreak. It is important for relevant government departments and agencies to be aware of the research and diagnostic capacity that exists, and to be able to assess gaps in the provision of services in particular areas. It is recommended that the DST becomes the custodian of this database and that it be updated and audited on a regular basis - perhaps as part of the broader bio-portal initiative currently under development. The DST is correctly placed to take on this responsibility because laboratories work in the fields of human, animal and plant health and thus fall neither neatly into the scope of the DoH nor the DAFF.

Given the limitations of this survey it was not possible to develop a geographic information system (GIS) map of research and diagnostic facilities due to the inconsistent availability of the precise addresses of the laboratories on their websites. However, it is recommended that the creation of a GIS map be a future objective for a variety of reasons. For example, a GIS map with additional information overlays would be able to visually represent the ratio of diagnostic laboratories to human population and even to burden of disease. Such information may be valuable when determining the location for new laboratory services. In addition, information about the location and capacity of laboratories is necessary if any monitoring or inspection is to take place to ensure compliance with legislation.

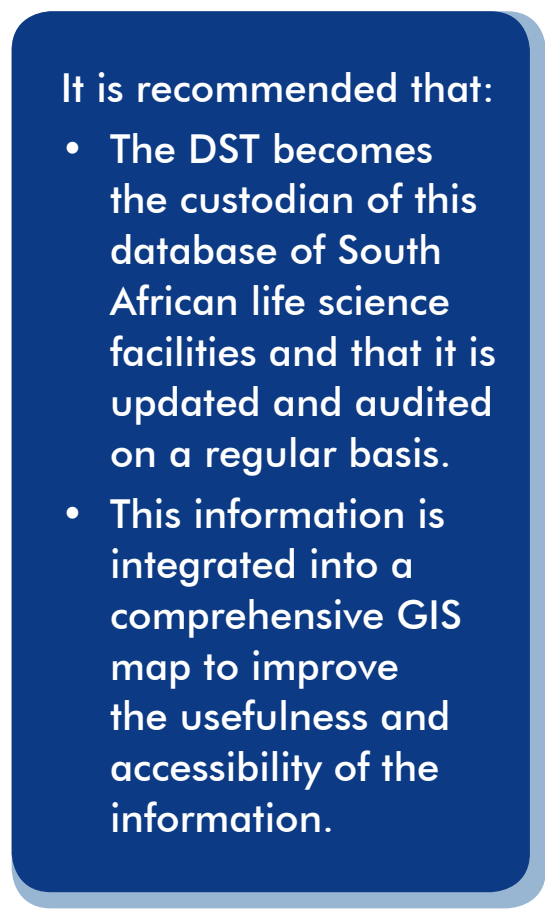

\subsection{Assessment of measures to ensure ethical, biosafety and biosecurity practices in life science facilities in South Africa}

\subsubsection{Aim}

The aim of this study was to assess the extent to which South African life science laboratories have implemented relevant ethical, biosafety and biosecurity measures to answer questions such as:

1. Are South African life scientists adequately prepared to conduct quality life science research, while simultaneously being able to recognise and address research misuse? 
2. What systems are in place in the national public health system and in private laboratories to strengthen ethics, biosecurity and biosafety?

3. What are the knowledge, attitudes and practices of South African life scientists working in public and commercial laboratory facilities?

\subsubsection{Specific objectives}

The two specific objectives of this study were:

1. To assess the extent to which research and diagnostic laboratories have measures or systems in place to ensure and facilitate research excellence, adherence to ethical practices and laboratory biosafety and biosecurity requirements.

2. To raise awareness amongst laboratory scientists, laboratory managers and public health officials about the requirements for ensuring high-quality research, adherence to ethics and laboratory biosafety and biosecurity.

\subsubsection{Methods}

\subsubsection{Ethics approval}

Ethical approval for the study was obtained from the University of Cape Town (UCT) Human Research Ethics Committee (HREC), and the Nelson Mandela Metropolitan University (NMMU) REC (Human). ${ }^{14}$ Approval to conduct the study was also granted by the National Manager: Academic Affairs and Research of the NHLS.

\subsubsection{Questionnaires}

The questionnaire used for data collection was a revised form of the aforementioned WHO 'self-assessment' questionnaire (WHO, 2010). A pilot study consisting of five sites in the Western Cape province was conducted in July 2013 to test the local applicability of the WHO questionnaire for relevant sectors: commercial, academic and state-funded facilities in the animal, plant and human health sectors, and encompassing facilities undertaking both diagnostic and research. The pilot included facilities working in animal, human and plant health in the public and private sector.

Based on feedback from responses obtained in the pilot study, the aforementioned WHO 'self-assessment' questionnaire (WHO, 2010) was revised to be more in keeping with a South African audience particularly with respect to the appropriateness of the language used in the questionnaire, and to make it equally relevant to research and diagnostic laboratories.

14 Although the vast majority of facilities were satisfied by UCT ethics approval, a small number of institutions required in-house ethics oversight. All efforts were made to accommodate institutional preferences, including applying for formal ethics approval from Nelson Mandela Metropolitan University. The questionnaire and information sheets were also checked by the University of the Witwatersrand Research Ethics Committee (Human) prior to distribution. 
The final questionnaire consisted of three sections: 1) research excellence; 2) ethics, and 3 ) biosafety and/or biosecurity. The questionnaire consisted of a set of statements with responses graded on a Likert scale (including options for the responses 'not applicable' or 'don't know'). The details within each section are outlined in Appendix 11.

\subsubsection{Sampling}

\section{Database sampling}

A purposive sample of 50 facilities $^{15}$ was drawn from the database developed as part of the first aim of this study of facilities to ensure geographic and sector ${ }^{16}$ representation. This did not include NHLS laboratories as approval to undertake the survey at NHLS facilities was not granted until very late in the research process. ${ }^{17}$

Of the 50 facilities that formed part of the sample, 12 were substituted due to an inability to establish communication with those facilities. The substitutions of the unreachable facilities were made purposively such that the facilities included matched those that were unreachable in terms of geographic location and sector. Saturation was reached when it was no longer possible to substitute laboratories as the number of applicable laboratories in a province had been exhausted. Five additional sites were then selected due to concerns about low response rates in some provinces ${ }^{18}$ and to ensure that at least one laboratory from each province participated. These sites were selected at random from the provincial lists in the database of national laboratories (described earlier in Chapter 4).

\section{Public sampling}

In addition to the purposive sample, a public call for participation by diagnostic and research scientists was issued through the ASSAf mailing list, through journal articles, scientific society mailing lists, directed emails, and by placing advertisements in journals, and on society and commercial supplier websites. The advertisement invited practising life scientists to complete the online survey.

15 The statistical analysis was conducted by the Consultant Statistical Services at UCT.

16 Public, commercial, research and diagnostic.

17 Permission was delayed by an inability to identify who was responsible for granting permission for the study, and by difficulties in obtaining responses from the responsible individuals by telephone or email. While private diagnostic laboratories were included in the sample, problems associated with getting permission meant that many of them subsequently refused to participate. They were left in the sample but noted as "declined to participate". These problems are indicative of a larger problem related to social science research engaging natural scientists in that ethics committees are not designed to deal with sociological and anthropological studies of science cultures.

18 Sites that did not respond initially received at least two phone calls and five emails. 


\subsubsection{Survey administration}

Each laboratory identified in the database sample was initially contacted telephonically to inform them of the survey and request their participation. An email was subsequently sent containing a copy of the survey and information sheet (See Appendices 7 and 11 and the UCT ethics approval certificate). The email also contained details of the feedback report that would be produced for each laboratory on the basis of the results gathered from their students and staff. The contact person (usually the head of the facility) was invited to discuss their preferences with regard to participation and feedback.

The original intention was for the survey to be administered at each site by the study's contracted researcher, and to provide each facility with a report of the findings from their facility shortly after completion of the survey process at that facility. Many of the heads of departments expressed willingness to participate in the survey, but had reservations about a site visit from the researcher, citing either concerns about the disruption to work routines or low staff numbers (a number of laboratories had between one and five staff members).

These sites were provided with an opportunity to participate in the survey by completing the questionnaire electronically or through using a weblink to the survey. ${ }^{19}$ Sites choosing the online survey were issued with a project information sheet containing a site-specific number to circulate to their staff. ${ }^{20}$ This ensured that their responses could be collated into a site-specific report. Each site was provided with the findings from their facility.

The site-specific numbers ensured that completed questionnaires received in response to the open call could be kept distinct from responses from the purposive sample. The data collected from the open call were compared to data collected during the site-specific visits. As there was little difference in the distribution of the data, these two sample sets were combined.

\subsubsection{Data analysis}

The dataset of responses was analysed by the UCT Statistical Consulting Services, and descriptive statistics were provided to the researchers.

19 Available at www.surveymonkey.com/s/ASSAf_survey.

20 The combination of modalities offered for participation - site visits, completion of an emailed survey or online - assisted in recruiting sites, as sites were able to tailor their participation to the specific situation in their laboratory. 


\subsubsection{Results}

\subsubsection{Response rate}

In total, 161 individuals responded directly to the survey request. The public call yielded a further 222 responses. Together, the 383 individual responses were combined to form one final dataset for analysis. Of the 383 responses, 33 questionnaires had to be excluded as the questionnaires were not completed (only demographic data obtained).

Of the 55 sites selected from the database, 31 sites participated in the survey and five refused, as shown in Table 4.1. Eight provinces were represented, with no facility from the Northern Cape participating.

Table 4.1: Detail of survey sample and distribution

\begin{tabular}{|l|c|c|c|c|}
\hline Province & $\begin{array}{c}\text { Number of } \\
\text { sites (total) }\end{array}$ & $\begin{array}{c}\text { Positive } \\
\text { responses }\end{array}$ & $\begin{array}{c}\text { Negative } \\
\text { responses }\end{array}$ & $\begin{array}{c}\text { No } \\
\text { response }\end{array}$ \\
\hline Eastern Cape & 7 & 3 & 0 & 4 \\
\hline Free State & 7 & 5 & 1 & 1 \\
\hline Gauteng & 9 & 8 & 1 & 0 \\
\hline KwaZulu-Natal & 8 & 7 & 0 & 1 \\
\hline Limpopo & 4 & 1 & 1 & 2 \\
\hline Mpumalanga & 5 & 1 & 0 & 2 \\
\hline Northern Cape & 3 & 2 & 1 & 3 \\
\hline North West & 5 & 4 & 0 & 3 \\
\hline Western Cape & 55 & 31 & 6 & 18 \\
\hline Total & & 0 & 2 & 2 \\
\hline
\end{tabular}

\subsubsection{Mode of response}

It was apparent that in order to ensure the participation of sites, it was important that they were allowed to dictate a manner in which the surveys could be distributed that would cause minimal interruption of work while fitting closely with the way in which the institution was run. There was thus a variation in the manner in which sites participated in the survey, organised their staff and dealt with feedback. For example, some sites organised a laboratory meeting at which the questionnaires were distributed, while others gave the researcher a tour of the laboratories while distributing questionnaires en route. 
A number of the laboratories preferred to participate remotely and either sent back completed questionnaires or made use of the survey weblink. Of the sites that participated in the survey, nine sent back completed questionnaires directly, ten participated online, and 11 were visited in person.

\subsubsection{Demographic details of respondents}

Most respondents worked in the public research sector. Additional details for sector by recruitment source are shown in Figure 4.5.

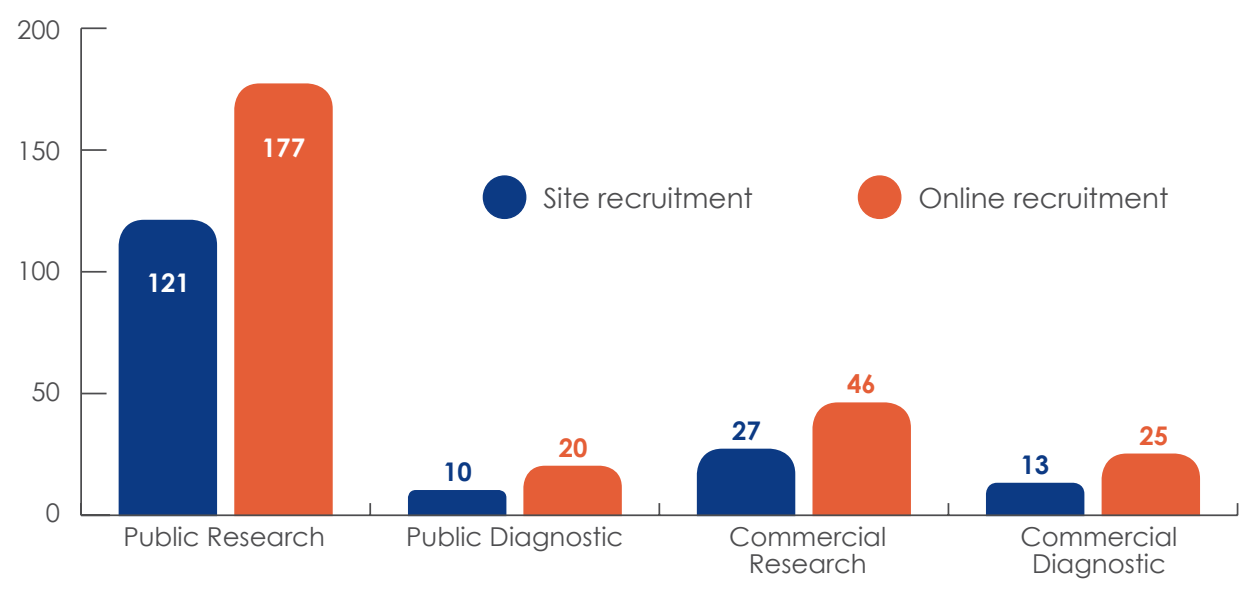

Figure 4.5: Sample demographics according to recruitment source and sector.

NOTE: Fiffy-two respondents selected more than one sector for their work, e.g. ticked the boxes for commercial and public research; or public research and public diagnostic. Thus the numbers represented in the graph are higher than the total number of responses. Public diagnostic facilities refer mainly to those engaged in plant and animal life science activities.

The geographic spread and business sectors of the samples are outlined in Figure 4.6. Responses from Gauteng, KwaZulu-Natal and the Western Cape considerably outnumbered those from other provinces. 


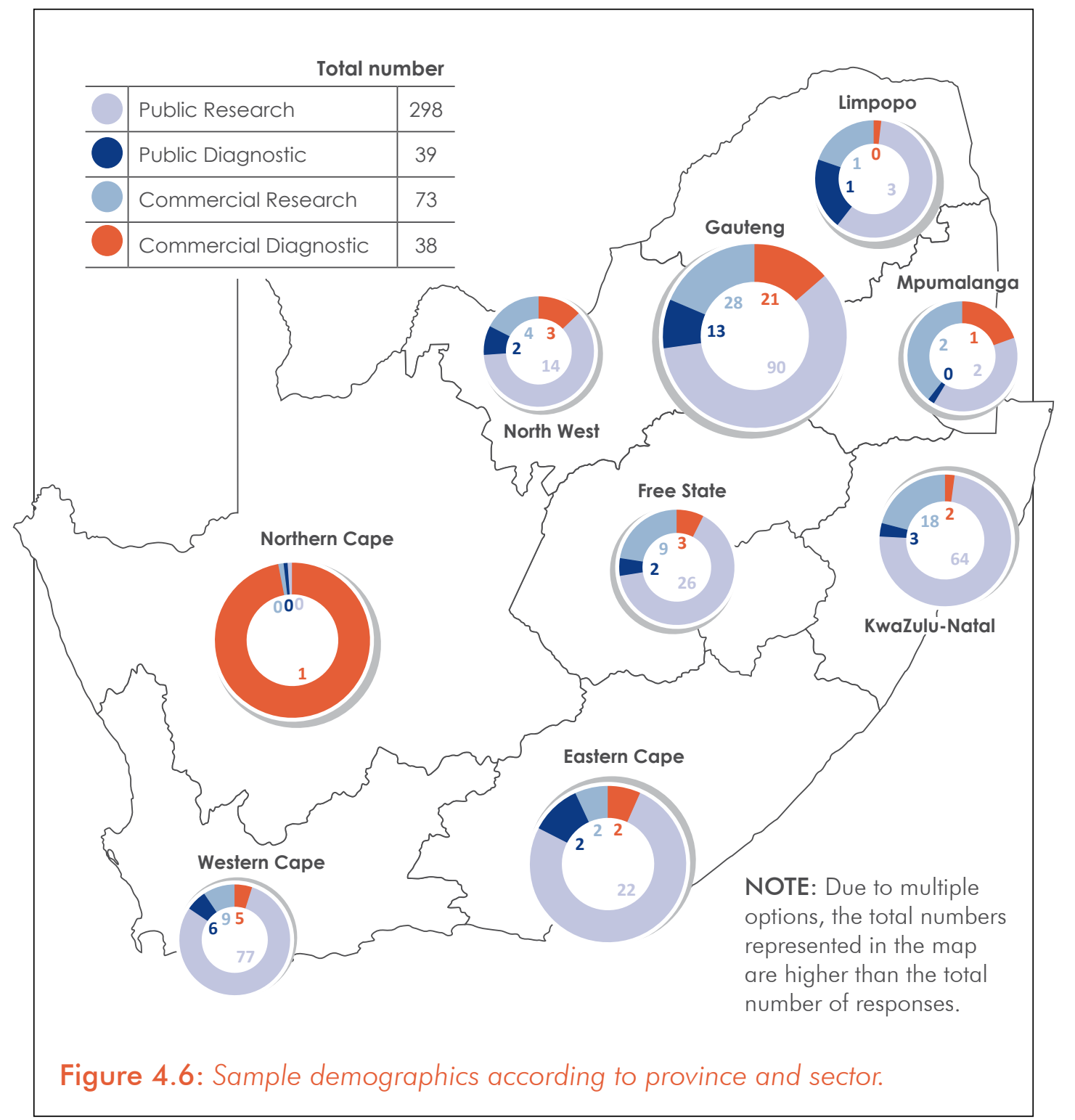

\subsubsection{Selected findings}

The findings are reported below for all responses and, where relevant, reflect responses specifically from the following groups:

- Senior staff: Including senior researchers and technologists and technicians, as well as NHLS laboratory managers and NHLS technologists.

- Junior staff: Junior researchers, junior technicians, NHLS technicians, postgraduate students, support staff.

- Technical staff: Senior technicians, junior technicians, NHLS laboratory managers, NHLS technologists, NHLS technicians, support staff.

- Research staff: Senior researchers, junior researchers, graduate students. 
The full response tables including denominators and percentages are included in Appendix 12. Percentages have been rounded off in the following report. The low response rate from NHLS diagnostic laboratories and commercial diagnostic laboratories means that the findings of the survey can only be generalised to commercial and public research facilities.

\section{Research collaboration}

Three statements were posed relating to respondents' perceptions of the extent to which scientific collaboration is encouraged, within their department, within their institution and between institutions.

- Three-quarters $(261 / 350 ; 75 \%)$ of respondents agreed that intra-departmental collaboration is always or often encouraged.

- Over $70 \%$ (254/348; 73\%) of respondents said that scientific collaboration within their institution was encouraged always or often.

- Scientific collaboration between institutions was less likely to be encouraged with just over half $(189 / 348 ; 54 \%)$ of the respondents saying that inter-institutional collaboration is encouraged and facilitated always or often.

\section{Financial and research accountability and transparency}

Openness about funding sources at institutions was perceived to be less common than financial accountability.

- Fifty-eight percent (202/350) of respondents said that their institutions always or often made an effort to reveal their funding sources.

- Eighty-nine percent (310/348) of participants said that their institution demands financial and research accountability through regular reporting.

- Three-quarters $(262 / 348 ; 75.2 \%)$ of respondents said that their institution always or often stated its research priorities.

- Eighty-three percent (288/349) of respondents agreed that research findings are routinely published, while 10\% (35/349) said this was not the case at their institution.

\section{Training and capacity building}

A number of statements in the questionnaire sought responses to questions about the extent to which training is offered on key issues such as ethics and dual-use.

- The majority of respondents agreed that on-going skills training does take place at their institution, with $77 \%$ (268/347) agreeing that this is always, often or sometimes the case.

- Three-quarters $(259 / 345)$ of all respondents agreed or strongly agreed with the 
statement: Staff conducting life science activities have been properly trained, but there was less agreement about the extent to which training about dual-use issues was offered $-54 \%$ of all respondents (184/344) said that dual-use training was either not offered, or that they did not know whether it was offered at their institution.

- Fewer than half of respondents $(141 / 323 ; 44 \%)$ agreed with the statement: Education and/or training is offered on research ethics including issues such as scientific misconduct (falsification, fabrication and plagiarism). Junior staff were more likely than senior staff to indicate that ethics training happens rarely or never.

- With respect to training in biosafety and biosecurity measures, two-thirds (198/300; $66 \%)$ of respondents agreed or strongly agreed with the statement: Biosafety training is provided to all those working in laboratories when appropriate.

- Only approximately a quarter $(81 / 302 ; 27 \%)$ of respondents agreed that biosafety training always or often includes a test of competence.

\section{Staff satisfaction}

The statement: Junior researchers and/or staff are nurtured and supported sought to determine how respondents felt about the support offered to junior staff members.

- Senior staff were somewhat more likely to believe that junior staff were nurtured and supported with 56\% (119/211) saying this was always or often the case and $26 \%(54 / 211)$ saying this happened sometimes, while $45 \%(60 / 133)$ of junior staff felt that they were always or often nurtured and supported, and 35\% (47/133) said this was sometimes the case.

- Just under a third (110/347; 32\%) of all respondents agreed with the statement: Skilled staff are valued and retained with 38\% (132/347) stating that they were sometimes valued and retained.

5. Policy and legislation

- Slightly more than half $(182 / 347 ; 52 \%)$ of all respondents disagreed or strongly disagreed with the statement: Good communication exists between policymakers at a national level and the life science community.

- Respondents were divided on the statement: National legislation and policy fosters scientific development and freedom with $41 \%$ (139/336) agreeing and 40\% (133/336) disagreeing or strongly disagreeing with the statement.

- Fewer than half $(166 / 350 ; 47 \%)$ of respondents agreed or strongly agreed with the statement: Researchers are aware of and informed about national and international conventions, laws and regulations related to their research. With regard to accessibility of information about the national and international conventions and regulations related to life science, 39\% (135/350) of respondents agreed information was accessible, 33\% (1 14/350) disagreed, and 21\% (72/350) said they don't know. 
- Over two-thirds $(196 / 304 ; 64 \%)$ of respondents agreed with the statement: National legislation/regulation exists that sets safety and security practices and procedures for laboratories, but only 35\% (122/350) agreed that: National legislation and policy relevant to the life sciences provides protection against the misuse of science.

\section{Application of ethics}

A series of statements sought to determine the extent to which respondents were aware of the existence of ethical guidelines and the application of these in decisionmaking about life science research. Other statements sought to determine the scope of ethical review.

- Sixty-four percent (206/323) of all respondents agreed with the statement: Appropriate ethical research guidelines and practices have been published. Junior staff were more likely to say that such guidelines have been published. ${ }^{21}$

- Two-thirds $(215 / 322 ; 67 \%)$ of all respondents reported that appropriate ethical research guidelines and practices are implemented always or often.

- Forty-five percent (156/350) of respondents agreed that ethical approval process exists for studies not involving human or animal subjects.

- Only half of all respondents (170/350; 49\%) agreed with the statement: Adequate mechanisms exist for investigating and responding to non-adherence to ethical standards.

\section{Implications of research and work}

- Seventy percent $(246 / 350)$ of respondents agreed that scientists are competent to assess the societal implications of their work. There was no distinction between responses from junior and senior staff or technical and research staff. ${ }^{22}$

- Less than half (142/320; 44\%) of respondents agreed with the statement: Research is subject to a risk assessment that includes considerations of the broader implications of their life science activities for the environment.

- More than half (192/350; 55\%) of all respondents agreed with the statement: Researchers know how to assess whether the risk outweighs the benefit of continuing with their research activities, with 19\% (67/350) of respondents disagreeing.

21 It must be noted that this response may in some way reflect a contrast in what junior and senior staff members consider 'appropriate' guidelines - something that may be influenced by experience and visits to other research institutions.

22 It is interesting that there is little differentiation across the career trajectory in the responses to this question. What scientists perceive as 'competent' should be investigated in further detail, as should their perceptions on what such an assessment would comprise. 


\section{Biosafety and biosecurity}

- Over 60\% (219/350; 63\%) of respondents agreed with the statement: Measures are in place to prevent non-laboratory individuals from obtaining access to samples or biological materials.

- Half of all respondents $(175 / 350 ; 50 \%)$ agreed with the statement: Potential for misuse of the research is considered at all stages of research/diagnostic processes and appropriate action taken if necessary.

- Almost three-quarters of all respondents $(222 / 305 ; 73 \%)$ agreed with the statement: Facilities and equipment are appropriate to the level of work being done and are adequately maintained.

- Close to $80 \%(237 / 304 ; 78 \%)$ of respondents agreed with the statement: Training of staff is appropriate to the facilities and equipment and the work being conducted.

- Forty-four percent (133/305) of respondents stated that assessment of the biosafety and biosecurity risk associated with research activities is conducted always or often.

- Almost 60\% (177/298; 59\%) of respondents agreed with the statement: Risk assessments are able to identify requirements for risk reduction measures including the level of containment required.

- Three-quarters $(225 / 300 ; 75 \%)$ of respondents agreed that SOPs exist, with two-thirds $(200 / 301 ; 67 \%)$ agreeing that staff were trained to implement these procedures. Thirty percent $(91 / 304)$ of respondents agreed that staff are regularly tested to ensure competence in SOPs, with 48\% (147/304) saying this is not the case. ${ }^{23}$

- Almost two-thirds (186/303; 61\%) of respondents agreed or strongly agreed with the statement: Occupational health surveillance mechanisms exist and are followed (at institutional level).

- Less than half $(132 / 299 ; 44 \%)$ of respondents agreed that occupational health reporting mechanisms are always or often effective at institutional level.

- The great majority $(269 / 302 ; 89 \%)$ of respondents agreed that staff are required to report laboratories incidents and accidents.

- Just over half $(207 / 302 ; 52 \%)$ of respondents agreed with the statement: A record of hazardous biological materials exists and is maintained at institutional level and more than two-thirds $(208 / 305 ; 68 \%)$ said that hazardous biological material is always or often safely and securely stored.

- With regard to whistle-blower protection, 64\% (194/302) of respondents agreed or strongly agreed that there are measures to report irregular or unlawful conduct, but only approximately half of these $(111 / 298 ; 37 \%)$ agreeing that measures exist to protect whistle-blowers.

23 While the issue of SOPs is important, it is possible that the disjunction between the existence of and the training for SOPs may reflect traditions of academic research. While many laboratories have standardised protocols from which many laboratory activities are conducted, they are developed and taught in-house informally by staff. Thus, the training and testing questions might not reflect the true nature of this situation. 


\subsubsection{Discussion}

Scientific integrity is most often considered to refer to accuracy and honesty in relation to the collection, management and reporting of research data, and to accurate and full citation of texts in publications (Barr, 2007). But it also encompasses the management and communication of science and protection against misconduct. In short, scientific integrity is required to establish and maintain trust amongst scientists, between scientists and the policymakers, and between scientists and citizens. In recognition of the importance of scientific integrity, the US Department of Interior developed a policy on scientific integrity, the Scientific and Scholarly Integrity Policy (US Department of Interior, 2011 ). The policy has as its stated goals:

- Decisions based on science and scholarship are respected as credible.

- Science is conducted with integrity and excellence.

- Science has a culture of scientific and scholarly integrity that is enduring.

- Scientists and scholars are widely recognised for excellence.

- Employees are proud to uphold the high standards and lead by example.

The US Departmental Manual developed to give effect to this policy identifies management, communication, collaboration and information-sharing as relevant to scientific integrity. Integrity is further ensured by guidelines for reporting of misconduct, protection of those who report such misconduct, and safeguards to ensure that recruitment is based on a candidate's integrity, knowledge, credentials, and experience relevant to the responsibility of the position (Office of the Deputy Secretary Department of the Interior, 2011).

The questionnaire used for the purposes of this consensus study offers insights into each of these issues, as well as the scope of ethical review and the extent to which communication is perceived to take place between the policy community and the scientific community in South Africa. The survey offers an opportunity for us to establish a baseline assessment of scientific integrity in South Africa.

\subsubsection{Openness and transparency}

Resnik stated that: "Openness is one of the most important principles of scientific research. It is necessary for achieving the goals of science and for enabling society to benefit from the results of research. It plays a key role in confirmation and collaboration, and it promotes innovation and discovery. Additionally, openness is important for holding scientists publicly accountable and for developing well-informed public policy" (Resnik, 2006).

While openness and transparency are regarded as important for scientific progress, there are a number of legitimate reasons why researchers may not be able to be 
entirely open about their research or findings. Reasons may range from the need to protect intellectual property (IP) to the need to protect the identity of research participants. ${ }^{24}$ While these constraints on openness may be legitimate and even necessary, the norm should be towards openness and sharing of information, as openness and knowledge-sharing serve the interests of scientific progress. Given South Africa's past experience where medical professionals, microbiologists and veterinarians were recruited into a secret military programme aimed at developing biological assassination weapons (Truth and Reconciliation Commission, 1998), South Africa has a special responsibility to prevent the recurrence of such activities.

Globally there is a move towards open science with many scientists and scholars choosing to publish their findings in open-access journals ${ }^{25}$, or the editorial boards of journals themselves choosing to remain freely available rather than have their content available only to subscribers. ASSAf promotes quality open-access publications through its precise, full-text, open access journal database, SciELO SA. Other forms of openness include open funding (where funding is sought using public platforms, such as through so-called crowd-sourcing) or where applications for funding are opened for review beyond the staff or collaborators of funding institutions. Other initiatives to promote openness in the sciences are outlined in Box 4.1 (EisfeldReschike et al., 2014).

We will consider the findings of the survey in relation to the following forms of openness: 1) scientific collaboration; 2) transparency about funding; 3) publication of research results; 4) openness about the research priorities of institutions.

\section{Scientific collaboration}

According to the US National Institute of Allergy and Infectious Disease (NIAID), collaborations occur when scientists in different laboratories work together to move their research forward by investigating common research questions and sharing resources and information (United States National Institute for Health, 2014). The South African National Research Foundation (NRF) and the DST also identify scientific collaboration as a necessary requirement for the advancement of South African science and have established systems to encourage such collaboration. ${ }^{26}$

${ }^{24}$ For example, see the special edition of The British Journal for the History of Science, Vol 45, 2012 titled "The states of secrecy", available at http://journals.cambridge.org/action/ displaylssue?jid=BJH\&volumeld=45\&seriesld=0\&issueld=02 (Last accessed 25 May 2014).

25 See the 2012 Budapest Open Access Initiative recommendations http://www.budapestopen accessinitiative.org/boai-10-recommendations.

26 See http://www.nrf.ac.za/risa.php?fdid=13 (Last accessed 24 May 2014). 


\section{Box 4.1: Initiatives to promote openness in science}

1. Open Review, which includes both review of funding proposals and articles that are submitted for publication, the latter traditionally conducted as a peer review. Open Review does not so much aim for Openness according to the Open Definition or the Open Source Principles, rather it is meant to make the review processes more transparent, impeding cliquishness between colleagues as submitting scientists and reviewers.

2. Open Metrics as a tool for establishing metrics for the scientific relevance of publications and data that are independent from proprietary databases like the Web of Science or the SCOPUS database which do not only charge fees, but also disallow unrestricted access to their raw data.

3. Open Access to scientific data according to the Panton Principles (available at http://pantonprinciples.org/).

4. Open Access to scientific publications.

5. Open Bibliography, meaning Open Access to bibliographic data.

6. Open Data.

7. Open Notebook Science (practice of making the entire primary record of a research project publicly available online as it is recorded).

From: http://book.openingscience.org/vision/research_funding.html

The results of the survey indicate that research scientists in South Africa are supported and encouraged to collaborate less often with researchers from other institutions than they are with colleagues from their own institutions. The reasons for this can only be speculated, but are likely to include the effect of competition, particularly between academic institutions. Since most survey respondents were from research institutions receiving public funds, the finding that only slightly more than half of the respondents felt that collaboration with colleagues outside of their institution was routinely facilitated or encouraged suggests that such collaboration is not considered a priority and support for such collaboration could be increased.

\section{Transparency about funding}

While financial accountability appears to be the norm in research facilities, and would be demanded by funders and academic institutions, openness about the sources of funding is not routine, or recognised by scientists. There are several ways in which such openness could be encouraged at institutional level, including requiring staff who received grants to list these on their staff profiles, through the maintenance of 
an online open access list of projects and their donors, or by encouraging funders themselves to require grant recipients to declare the source of their funds when publishing or presenting research results. Similarly, creating awareness about funding information within the science community may offset such perceptions.

\section{Publication of research results}

It can be expected that there would be routine publication of research results by scientists at research facilities, and indeed this is the case. In the interests of assessing the extent to which South African scientists are supported to embrace the move towards open access, it would be useful to conduct an assessment of the extent to which scientists do, or are encouraged to, publish in open-access journals. Moreover, the extent to which universities in South Africa provide curated and searchable repositories in which staff can upload research as 'find-able' and open content is unclear. This is an important element of open research and something that is becoming increasingly topical in data discussions as a means to satisfy data-sharing requirements of funders and priorities of institutions.

\section{Openness about the research priorities of institutions}

Openness about the research priorities of an institution is also important, not only to ensure alignment between work undertaken and identified priorities, but also to ensure alignment between national developmental priorities and needs and work undertaken at institutional level. One in five respondents to the survey said that their institution did not make their institutional research priorities clear, or they were not aware of such priorities at institutional level.

\subsubsection{Staff retention and confidence in staff capacity}

As noted earlier, one of the goals of the US Department of Interior policy on scientific integrity was to establish scientific excellence, and pride amongst scientists to be associated with the Department (US Department of Interior, 2011 ). There was some doubt expressed by respondents about the capacity of some staff to conduct research, with 17\% disagreeing with the statement: Staff conducting life science activities have been properly trained. Since confidence in the excellence of science is both in the national interest and in the interest of individual research institutions, this aspect needs to be addressed.

Equally important, given the need to develop a strong national capacity to undertake life science research is to ensure that junior research staff are supported and encouraged and that senior staff with experience are retained. The survey finding that fewer than half of all junior research staff feel consistently supported and nurtured suggests that at institutional and national levels, attention needs to be paid to develop the capacity of senior staff to mentor junior staff. Perhaps even more concerning is 
the perception that senior staff are not valued, nor are efforts made to retain their skills. More than half of the respondents in this survey felt that senior staff are not consistently valued by their institutions, indicating an imperative to incentivise and encourage staff to remain in the life sciences.

\subsubsection{Ethics}

The integrity of the life sciences in South Africa relies on scientists understanding, being conscious of, and adhering to the basic principles of scientific practice of inter alia not falsifying data and ensuring proper citation of others' work. Yet, one of the most concerning findings from the survey was that South African research scientists do not perceive training and education about basic research ethics - including scientific misconduct - as routine. While ethics review of research and experimentation involving human participants or animal subjects are routine, this does not extend to all research, including research on micro-organisms.

There is a clear need for the scope of ethics training and review to be examined both at national and institutional level. In addition, findings from the survey show that gaps exist in knowledge about dual-use issues, biosafety and biosecurity.

\section{Ethics training}

Much reflection has gone into the question as to how to adequately train scientists in moral matters, and how successful or efficacious such training can be (Van Niekerk, 2003). There seems to be a growing consensus that ethics training ought not to be a small 'add-on', attached to the 'real' scientific training that a scientist undergoes. Scientists, particularly in the life sciences, ought to be made aware at the outset of the possible harm that could arise from their work, and ought to be encouraged to be sensitive not only to the possible misuse of results, but also to discuss these issues amongst colleagues throughout the development of each research project. Science that is not responsible science is bad science (Van Niekerk and Nortié, 2013). It might yield new insights and it might have numerous applications, but if it is prone to be utilised for harmful purposes, it loses its value and desirability.

Many theorists argue that it is futile to teach ethics (Van Niekerk, 201 1; Van Niekerk, 2003); they argue, ethics is "caught, not taught". It is undoubtedly true that mere instruction in ethics does not guarantee more morality. Moral knowledge and the moral dispositions fostered by that knowledge are shaped by many influences, ranging from parents, teachers, friends, television, cultural practices, and books among others. This knowledge and dispositions are carried into the world of work.

As a considerable amount of teaching within laboratories occurs with a highly technical focus at the hands of supervisors and senior colleagues, it is of paramount 
importance that there be widespread recognition within the scientific community of the responsibility to foster ethical working environments and to reinforce and perpetuate the ethics of scientific research - including the implementation of codes of conduct.

Ethics education is likely to equip scientists to cope better with a world that is increasingly morally complex. To have the ability to analyse morally-problematic situations, to be able to identify the precepts that are applicable to them and the argumentative strategies that one might follow in order to make more sense of them and, in the end, to come to responsible judgements about them, is to become significantly better empowered for the world of work and for life in general.

\section{Ethics review}

The system of ethical review by means of RECs is operational in South Africa as in most other countries. It is essential that all research in the life sciences be submitted to such committees, and that these committees are all registered, as required by $\operatorname{law}^{27}$, with the NHREC. If the size and scope of the work of a research laboratory warrants it, such a committee could be created for that institution. If not, permission can be obtained from committees at other, larger institutions to consider and approve research protocols originating from smaller institutions.

The NHREC identifies the following nine guiding principles for health research ${ }^{28}$ :

1. Respect for persons.

2. Relevance and value of research.

3. Scientific integrity.

4. Risk of harm and likelihood of benefit.

5. Informed consent.

6. Distributive justice.

7. Investigator competence.

8. Privacy and confidentiality.

9. Publication of results.

The practice of submitting research protocols in the life sciences to ethical review raises the issue of which ethical guidelines ought to be utilised. In South Africa, no guidelines specifically formulated for life sciences that do not entail research on human participants have been formulated or published. When research does include human participants, such as in this survey, the guidelines can be very complicated in that they are designed to deal specifically with certain types of research (particularly

27 Health Act 61, 2003, Chapter 9, Section 73.

28 See http://www.mrc.ac.za/ethics/DOHEthics.pdf. 
medical research) and not social science research. The guidelines in Chapter 2 of the NHREC Research Guidelines, which are currently (2014) being revised (personal communication, Van Niekerk), are of general relevance to life sciences research on non-human subjects, but they need to be supplemented with more specific guidelines for the latter branch of science. The formulation of such guidelines should be a high priority for non-human life science researchers. Leadership for such an effort would likely require formally professionalising the life sciences.

\section{Ethical conduct}

It is advisable that a code of conduct (COC) be developed for every research institution dealing with research on non-human live entities. The possibility of devising a code of ethical conduct for the life sciences as a profession in order to prevent the misuse of research has received some attention in the literature. The myriad ethical breaches of the twentieth century, coupled with the aftermath of the creation and unleashing of the atomic bomb and the use of chemical agents in the Vietnam war, as well as unease regarding new areas of research, such as cloning and genetic intervention which developed in the second half of the twentieth century, solidified the notion that certain areas of research ought to be either prohibited or at least subject to restrictions (Badash, 2004). The unease created by these events prompted the formation of organisations such as the Committee on Scientific Freedom and Responsibility created by the American Association for the Advancement of Science which aimed to establish the degree to which scientists are accountable for their activities. The possibility of a code of ethical conduct for scientists akin to the Hippocratic Oath taken by doctors to do no harm has also been considered as a means of addressing the dual-use problem (Keuleyan, 2010).

In terms of developing a code of ethical conduct for the life sciences, Interacademy Partnership (IAP) has suggested five principles which may serve as guidelines for institutions wishing to devise their own codes of conduct (Atlas, 2009). These principles include: 1) awareness of possible harm and misuse; 2) safety and security in terms of conduct; 3) education and information referring to the knowledge that scientists should possess regarding the relevant legislation and other important areas; 4) accountability in terms of the fact that scientists must report breaches of the above areas; 5) oversight which refers to the duty of those in supervisory positions who should ensure the above principles are observed.

Kant and Mourya (2010) discuss the possibility of a code of ethical conduct for scientists which would comprise three levels moving from general to specific principles and developed a toolkit to develop institution-specific codes of conduct. The toolkit provides examples of several complete codes that can serve as a useful point of departure for the process. The efficacy of an effective code largely depends on strong 
leadership during development as well as buy-in from, and ownership by, all members of the organisation.

The development of a code of conduct, while no guarantee against unethical behaviour, may serve the purpose of both creating awareness about the ethical responsibilities of scientists, and the basis for holding scientists to account, at least at institutional level. However, it is not a substitute for more substantial ethics training and education that should include information about relevant national and international laws and agreements (such as the Biological Weapons Convention and the NonProliferation of Weapons of Mass Destruction Act).

\subsubsection{Science and policy}

The survey has brought to light that gaps exist in scientists' awareness of national and international conventions, laws and policies, with less than half of the respondents acknowledging awareness. Few respondents (35\%) agreed that these conventions and regulations are easily accessible to scientists. This is supported by the observation that more than half of respondents (53\%) indicated that there was poor communication between policymakers and scientists, pointing to an overall lack of knowledge and training in national and international laws relevant to the life sciences.

While a large proportion of respondents (65\%) agreed that national and international policies relating to safety and security protocols exist, it is of major concern that one-third had no knowledge of such mandatory practices. A single practice that does appear to be well understood is legislation pertaining to disposal of hazardous waste, although a worryingly $4 \%$ of respondents indicated that rules pertaining to its disposal are not followed.

It is worth noting that there is a considerable discrepancy among life scientists with respect to their perception of the extent to which national and international policies facilitate scientific development and freedom. Forty-one percent of respondents agreed that policies foster these principles but a similar proportion (40\%) disagreed that this was the case. This, together with findings outlined above, indicates a general lack of awareness and understanding in the life sciences communities about rules and regulations pertaining to scientific research and the opportunities such policies might afford to the advancement of science.

\subsubsection{Biosafety and biosecurity}

The survey revealed a slight disconnect between the perceived knowledge and appreciation of existing regulatory frameworks for biosafety and biosecurity matters and the practical implementation thereof. In general, life scientists seem to be confident in their theoretical knowledge and skills, but less so for some of the practical 
implementation requirements - especially in terms of risk assessments and the handling of accidents and/or security breaches. Hands-on professional development courses, as part of an effort to professionalise the life sciences as discussed elsewhere, could eliminate such disparity.

\subsubsection{Conclusion}

The findings from the survey show that life scientists in South Africa lack adequate knowledge about the safety and security rules and regulations pertaining to their work. There are also significant gaps in the training of scientists pertaining to ethics, biosafety, biosecurity and dual-use issues, as well as in relation to how and where to report concern about possible breaches. There also appear to be gaps in relation to the implementation of existing rules and regulations, including in relation to SOPs, tests of competence (in biosafety and biosecurity) and even in some instances in the maintenance of laboratory equipment.

In Chapter 3, reference was made to the comprehensive legal framework to control biological agents and to act against the malicious use of pathogens. Such a legal and policy framework is important, but its effect is limited if those who should know about it, do not. The findings of this survey suggest that there is an urgent need to ensure that life scientists are informed about national and international laws and policies relevant to their work.

The panel recommends:

1. Comprehensive ethical review of research and development in the life sciences is an appropriate tool which will also help ensure biosafety and biosecurity compliance.

2. Ethical review guidelines for the life sciences in South Africa should be formulated.

3. Education of scientists needs to include comprehensive ethics training which must make reference to the relevant national and international laws, regulations and conventions. 


\subsection{Introduction}

The need to urgently recognise an infectious disease outbreak and coordinate surveillance and action responses is vital for the health of a country's population. These responses are only possible if there is a thorough understanding of the transmission dynamics and resurgence of the disease. Developing, scaling-up and strengthening all aspects of the outbreak surveillance response system include contact-tracking, public information, community mobilisation, case management, infection prevention and control, and effective co-ordination (Thambo et al., 2014).

An assessment of existing measures and capacity to detect, identify, control and prevent the natural, accidental or deliberate spread of infectious agents in South Africa was performed by interviewing key role players in the field. The database of facilities that was prepared as an earlier part of this study provided a base from which to identify key informants who could be interviewed to provide insights into the management of infectious disease outbreaks in South Africa. These in-depth interviews, although limited in number, provided valuable insights that helped shape the recommendations of this study.

\subsection{Aim and objectives}

The aim was to enhance the prior survey data by collecting and describing the detailed perceptions of key informants regarding the detection, identification, management, recording and prevention of infectious disease outbreaks in South Africa.

Specific objectives were:

1) To determine the current perceived ability of South African systems to detect, identify, manage, record and prevent infectious disease outbreaks in South Africa.

2) To identify challenges and opportunities specific to the South African system to detect, identify, manage, record and prevent infectious disease outbreaks in South Africa.

3) To provide recommendations to improve South African systems to detect, identify, manage, record and prevent infectious disease outbreaks in South Africa where necessary.

\subsection{Methods}

The study was qualitative in design and comprised semi-structured interviews with key informants widely representative of national key stakeholders either active in the field or with in-depth knowledge of the current South African systems to detect, identify, manage, record and prevent infectious disease outbreaks in South Africa. Individual interviews allow for more detailed exploration of the issues identified in the prior surveys, and provide rich, comprehensive data (Mays and Pope, 1995), which was not achievable by the use of the prior survey-driven approach. 


\subsubsection{Recruitment of interviewees}

The first survey conducted by the panel mapped the life science community in South Africa (See Chapter 4). This survey yielded a comprehensive database of life science laboratories in the country including data on the type, location and funding of laboratories. This database also identified key government departments involved in related life science research, diagnostic facilities and management of disease outbreaks.

Key laboratories involved in biorisk management were categorised according to province, city and level of biorisk responsibility. We planned to include directors or senior managers of at least one key laboratory in each province. In addition, key officials in the relevant government departments responsible for outbreak control who were identified in the survey, were included as possible key informants. The panel checked the list and added additional potential participants based on their personal knowledge and expertise.

\subsubsection{Sample size}

Purposeful selection of the interview participants ensured that the sample included those individuals who were most knowledgeable and/or who were in positions with the greatest responsibility for addressing infectious disease outbreaks. The sample size was determined by balancing country, facility and department-wide representation against time and resource constraints. ${ }^{29}$ Each informant was also asked to recommend other potential informants using a snow-balling technique. We planned to continue to interview informants until a saturation point was reached with no new information forthcoming. The panel anticipated that the researcher would interview between ten and 20 individuals between February and May 2014 to reach this point.

\subsubsection{Instrument: semi-structured interviews}

Participants were invited to take part in a semi-structured interview that would last approximately 15-20 minutes. A participant information sheet was provided to all invited participants (Appendix 8).

All interviews were conducted telephonically. Every effort was made to accommodate the preferences of the interviewee in terms of location and timing of the meeting. The interview was structured around specific questions (See Appendix 9), but interviewees were given the opportunity to comment on other related topics if they so wished. The researcher made use of probing techniques to obtain more detailed data when necessary. The researcher took notes during the interview and the telephonic interviews

29 It was often difficult to identify the correct person to interview in a particular department, and in some cases when the correct person was identified they were unavailable for interview. 
were digitally recorded but not transcribed. The recordings were used as an aide memoire to the notes.

\subsubsection{Ethics and informed consent}

The study received ethical approval as a Protocol Amendment from the UCT Faculty of Health Sciences' HREC on 7 February 2014 (HREC REF Number: 294/2013).

Interviewees provided written informed consent prior to study participation. The consent form is available in Appendix 10. Participants were given time to ask questions about the project and to discuss any concerns prior to the interview. The researcher highlighted that the interview was voluntary and could be terminated at any point by the participant.

All data were thoroughly anonymised. Data were stored on a password-protected computer until loaded onto the ASSAf server in an access-restricted file and only made available to the panel chairperson, contracted researcher and ASSAf management. The data will not be deleted after the production of the final consensus report and will be securely stored for seven years at ASSAf.

\subsubsection{Analysis: thematic content analysis}

The recordings and notes from the interviews were reviewed for emerging themes and coded inductively. A code list was generated to identify the emergent codes and sub-codes associated with them in order to organise the data for analysis in terms of the major themes. Analysis identified key themes present in the responses, as well as highlighting important differences where these arose.

A theme was noted to be 'strong' if the issue was raised repeatedly by different participants. In those cases where a participant was a single representative of an area of expertise, consideration was given to highlighting the responses if this was specific to that area of expertise only; for example, if there was only one participant with particular knowledge and experience in plant health. In this way, the qualitative nature of the responses informed the analysis, rather than the quantitative record alone.

All data were entered into an MS Excel spreadsheet. 


\subsection{Results}

The results are presented in themes and verbatim quotations are provided where these are illustrative of or provide additional insights into the identified themes.

\subsubsection{Sample}

In total, 26 individuals who were eligible to be interviewed, were identified. This list included individuals who were initially identified from the mapping of laboratories, those suggested by the panel, those who were suggested as additional participants during interviews and those who were suggested by individuals who declined to be interviewed. Of the 26, 11 agreed to be interviewed, two expressed interest but were not able to commit to a time for the interview, and one agreed but failed to respond when called at the appointed time.

Ten declined the invitation. Reasons for declining included requiring permission from or referral to a more senior manager (2), referral to a participant who had already been interviewed (1), not currently active in the field (3), not engaged specifically with infectious disease control (2), and the interview study period coinciding with a busy period for government departments (2). We were not able to make contact with a further three.

\subsubsection{Dates and duration of interviews}

Interviews took place between 24 February and 25 May 2014. Duration of interviews ranged from 29 to 82 minutes, with a median of 33 minutes and a mean of 39 minutes.

\subsubsection{Demographic and employment profile of key informants}

The demographic and employment profile of the 11 participants is outlined in Table 5.1.

\subsubsection{Participants' contribution to regulations, policies and procedures}

Six participants contributed to the development of either national or international regulations, policies and procedures for the detection, identification, response and/or recording of infectious disease outbreaks. Contributions included drafting legislation (4), updating legislation (4), commenting on drafts of regulation (3) and advising on health systems data collection nationally and/or internationally (3). 
Table 5.1: Demographic and employment profile of participants. $(n=17)$

\begin{tabular}{|c|c|}
\hline Profile & Number \\
\hline \multicolumn{2}{|l|}{ Gender } \\
\hline Male & 7 \\
\hline Female & 4 \\
\hline \multicolumn{2}{|l|}{ Institution } \\
\hline Government Department & 5 \\
\hline Parastatal Institution & 4 \\
\hline University & 1 \\
\hline Private & 1 \\
\hline \multicolumn{2}{|c|}{ Qualification/Background (as reported by participant) } \\
\hline Medical & 2 \\
\hline Veterinary & 3 \\
\hline Science & 3 \\
\hline Public Health & 1 \\
\hline Virology & 2 \\
\hline \multicolumn{2}{|l|}{ Primary work focus } \\
\hline Government Policy & 3 \\
\hline Research & 3 \\
\hline Laboratory & 5 \\
\hline \multicolumn{2}{|l|}{ National or provincial } \\
\hline National & 9 \\
\hline \multicolumn{2}{|l|}{ Provincial } \\
\hline Eastern Cape & 1 \\
\hline Mpumalanga & 1 \\
\hline \multicolumn{2}{|l|}{ Primary agent target } \\
\hline Human & 3 \\
\hline Animal & 3 \\
\hline Human and Animal & 3 \\
\hline Plant & 1 \\
\hline Human, Animal and Plant & 1 \\
\hline
\end{tabular}


Participants were not asked to list all relevant regulations but some chose to note their specific contributions to or involvement with the regulations and procedural bodies listed as follows:

- Notifiable Medical Conditions Act - draft regulations.

- South African Occupational Health and Safety Act (Act 85 of 1993) Regulations for Hazardous Biological Agents.

- The Controlled and Notifiable Animal Diseases Act (Act 35 of 1984).

- Guidelines for inspecting and grading meat (with reference to the Meat Safety Act 40 of 2000).

- Fertilisers, Farm Feeds, Agricultural Remedies and Stock Remedies Act (Act 36 of 1947) as amended.

- Plant Improvement Act (Act 53 of 1976).

- Genetic Modified Organisms Act (Act 15 of 1997).

- Health Data Advisory Committee for monitoring the performance of the Minister of Health.

\subsubsection{Summary of responses to interview questions and related discussions}

\subsubsection{Assessment of the implementation strategies to detect, identify, record, manage and prevent disease outbreaks at a national level}

\section{Strengths}

Participants were asked to speak from their experience about what is currently done well with respect to implementation of strategies to detect, identify, record, manage and prevent disease outbreaks at a national level. Four major strengths were identified:

1) South Africa is very experienced in responding to disease outbreaks (especially those caused by dangerous pathogens). Within human health, several participants mentioned the Outbreak Control Team situated within the Directorate for Communicable Diseases at DoH as a body that functions well. When there have been 'false alarms' of outbreaks, South Africa also responded well and such occasions offered an opportunity for the systems to be tested.

2) There are regulations in place. With respect to animal health, one participant reported that in addition to acts of Parliament, the Abattoir Association has its own self-governing body. In the case of abattoirs, licensing is linked to compliance outlined in the Meat Safety Act, with government inspections taking place regularly. It is thus in the commercial interests of industry to comply with the regulations. A system for approval and/or accreditation of diagnostic laboratories is in place. 
3) There is relatively good communication between sectors. One participant reported that the system of nation-wide notification for animal diseases is in place and is being done well. The system of notification internationally is also in place and as a result, it is acclaimed that South Africa is one of the countries in Africa that notifies the world and updates information as and when necessary. In terms of national/provincial collaboration a system is in place to make implementation of strategies efficient.

4) There is a good system for data collection and availability in some sectors. Informants noted that the NICD monitors laboratory data and provides online tracking of human outbreak response. Two participants noted that data collection is increasingly recognised as important to informing the response to human disease outbreaks, with the data for targeting outbreaks of malaria noted as being of high quality. The NICD maintains a 24/7 emergency hotline (082 883 9920) for disease outbreaks and related enquiries.

\section{Weaknesses}

Participants were asked to outline if they had experience of, or had observed, problems with the implementation of strategies to detect, identify, record, manage and prevent disease outbreaks at a national level.

The following weaknesses emerged:

1) A lack of adequately trained and available human resources. The lack of human resources was noted across all health target areas, with not only a lack of sufficient staff noted, but also of the necessary skills. The absence of sufficient highly-trained clinical staff for managing very large outbreaks in humans was of particular concern to one participant. Another raised the problem of ongoing high staff turnover within the relevant structures to address outbreaks, leading to continual changes to contact persons for notification of diseases.

2) The absence of good surveillance data, especially for the human and plant sectors were recognised across all health target areas. Despite the acknowledgement by some participants that data collection was increasingly recognised as important by officials, most participants reported that the current state of surveillance is inadequate. One participant highlighted that there is a general perception that routine inspections within plant health are sufficient to adequately identify risks.

3) The lack of funding for outbreak control and prevention, with a lack of investment in supportive infrastructure noted.

4) The indiscriminate transport of animals with no proper control of animal movement across the country and between South Africa and other countries. In the past this was more effectively managed by the Department of Transport when there was better communication between sectors responsible for animal health. Contradictory to this was the experience that legitimate requests for permits to transport animal 
research specimens or conduct research itself were viewed with increasing suspicion by those responsible for issuing permits, with permits often being refused.

5) The lack of regular monitoring and inspection of facilities to ensure that laboratories adhere to the minimum requirements for biosafety. A participant noted that despite the regulatory environment governing laboratories, regular monitoring and inspection do not take place.

6) There is confusion surrounding the lists of infectious agents included in the regulations governing laboratories due to changing taxonomies and the lists not being applicable to the local, South African epidemiological risk profile of the included organisms. One participant noted a complicated set of historical and political processes hindering progress in this area.

7) The role of the media was highlighted as a significant obstacle to managing outbreaks by a participant. So-called 'fear-mongering' among the general public by the media had led to clinical staff also becoming fearful and unwilling to engage with the field of outbreak control.

\subsubsection{Recommendations to improve the implementation of national strategies to manage disease outbreaks}

Participants were asked what they thought could be done to improve the implementation of national strategies to manage disease outbreaks.

The following recommendations were made:

1) Human resource capacity needs to be strengthened nationally, provincially and at a district level across all sectors and across all health targets. Gaps were noted at a national level where key co-ordinating roles are currently not filled or where posts have been decentralised to a provincial level. At a provincial level, many state veterinary posts are vacant and in the Eastern Cape, more personnel are required, especially with respect to policing, in order to ensure that there is no illegal transportation of animals. Nurses require more training to manage outbreaks, as well as to increase awareness of how to find relevant information on contacts and infection control when necessary. One participant suggested that practical steps at a clinic level had been forgotten and that posters of the notification process and lists of relevant staff to contact together with their details should be prominently displayed in health-care facilities.

2) Shortcomings in the current legislation need to be addressed. Participants suggested that shortcomings in regulations could be addressed by ensuring that lists of infectious agents were current, classified with the correct taxonomy, relevant to local conditions, based on South African epidemiological risk profiles, and updated regularly. Regulations governing laboratory registration should include monitoring of the registered laboratories. A participant reported that current laboratory regulations focus on the safety of the laboratory worker rather than the 
necessary bio-containment precautions. The legislation could be improved to also focus on bio-containment and would need to include clearer definitions for the biosafety levels of laboratories. With respect to legislation covering the transport of infectious agents in animal health research, a recommendation was made to audit facilities regularly to determine whether SOPs were in place and regular inspections were conducted.

3) Linkages between laboratories and the current notification systems need to be strengthened. Participants advocated that the linkages between the laboratories and the current disease notification systems be formalised and that active disease surveillance be implemented actively rather than only as a passive system. This was noted for both human and plant health. There was a perception among those working in human health and plant health that the system of disease surveillance, control and notification was simpler and more effective within animal health.

4) Communication structures between government and research institutions should be formalised. According to a participant, formalising current virtual networks, which are personality-driven, would lead to more sustainable communication.

5) Awareness campaigns should be launched to increase public knowledge of disease outbreaks.

\subsubsection{Cross-sectoral co-operation with respect to implementation of policies and strategies}

Participants were asked to comment, from their experience, on cross-sectoral cooperation with respect to the implementation of policies and strategies. Two strong contradictory themes emerged:

1) Good co-operation. Several participants reported good communication between sectors, especially with respect to laboratories.

2) Poor co-operation. Some participants reported that cross-sectoral co-operation was historically poor and required departments to engage with each other on a one-on-one basis. Cross-sectoral co-operation with respect to transport of animals was reported consistently to be problematic. 


\subsubsection{National and provincial co-ordination in detecting, identifying, responding, recording and preventing infectious disease outbreaks}

Participants were asked to comment, from their experience, on national and provincial co-ordination in detecting, identifying, responding, recording and preventing infectious disease outbreaks. Experience of national co-ordination was varied, with strong favourable and critical themes emerging.

1) Relationships between sectors are good and clear structures and guidelines exist for managing disease outbreaks. This was particularly the case for managing acute outbreaks.

2) National co-ordination in terms of planning and prevention is poor. Participants suggested that although acute management of disease outbreaks indicated good national co-ordination across health target areas, this was not the case for planning and prevention. Participants reported uncertainty that the necessary mitigations were in place at a provincial level to manage outbreaks and that coordination was particularly poor for animal health, with devolution to control at a provincial level post-1994, raised as the reason for this.

3) Notification of human diseases is poorly co-ordinated between national departments and provinces. An example of the Soccer World Cup 2010 surveillance system which depended on multiple cross-sector co-operation and national co-ordination was provided. The system required local authorities to report directly to a national web-based platform. The system was reportedly not felt to be useful to local authorities, despite being considered groundbreaking nationally.

\subsubsection{Information-sharing regarding the implementation of policies and strategies}

Participants were asked whether there are opportunities for information-sharing between sectors and if not, what the obstacles to such information-sharing are. All informants believed that opportunities for information-sharing between sectors exist. Three strong themes emerged to allow for more information-sharing:

1) More representation from each sector was required in decision-making structures. With respect to increasing representation of all sectors in decision-making platforms, participants noted that there needs to be a common goal between sectors for this to be achieved. The establishment of a new forum would require clear goals and structures to ensure that there was no duplication, given the scarcity of resources. One participant warned that more layers of bureaucracy would not necessarily be optimal.

2) Platforms were required to share 'real-time' data. Participants noted that some sharing of data already occurs and cited the NICD monthly communiques (http:// www.nicd.ac.za/? page $=$ communique\&id $=56$ ), the Medical Research Council 
(MRC) GIS platform for mapping malaria, and the DAFF research and knowledgesharing platform. Participants noted that online resources were not accessible everywhere. The issue of lack of dissemination of research conducted in university settings and the delay to publication of research findings was noted as a significant reason to establish a platform in human health for 'real-time' data-sharing. A further obstacle that was noted is the need for data, not only to be collected but also to be interpreted meaningfully before it can be shared. A lack of skilled human capacity hampered this from taking place.

3) For some diseases, co-ordination should be done nationally. Several participants reported that information-sharing would be optimised between sectors if it was co-ordinated at a national level. Specific diseases required a national response. Participants mentioned that this was true for malaria and some plant diseases, given the inability to contain these within specific demarcated geographic areas or provinces. One participant stated that cross-sectoral government fora are in place for human health, but that there was room for improvement, with competing work priorities sometimes leading to the cancellation of these meetings. There is also an overall lack of co-ordination between sectors, with no specific government department specifically tasked with co-ordination. Another strong theme was the recognition that detecting, identifying, managing and preventing infectious disease outbreaks required the participation of multiple groups spread widely across the country. The reach and scale of the task is large.

\subsubsection{Recommendations to improve the management of disease outbreaks}

Participants were asked what they would recommend for improving the management of disease outbreaks nationally. Three strong themes emerged across all health targets:

1) Secure funding for the improvement and maintenance of infrastructure, human resources and technology. Specific areas requiring secure funding were: 1) the maintenance of established laboratory capacity, with South Africa hosting the only BSL 4 laboratory in Africa; 2) improving the output and quality of research in this area; 3) filling vacant positions within the State Veterinary Services, with possible consideration given to compulsory community service for graduate veterinarians. A participant suggested that international security systems and mechanisms could be utilised to obtain funding for research and infrastructural development, but acknowledged that military funding was often not palatable in the health-care sphere. Additional suggestions included training more workers to be knowledgeable about outbreak control as is currently underway by the $\mathrm{DoH}$ within the provinces.

2) Establish a better regional response to outbreak control and prevention. The issue of outbreak control in the region generated strong responses. Several 
participants noted throughout the interview that historically, South Africa had played a significant role in managing regional outbreaks. Within Africa, local capacity had increased in recent years possibly reducing the need for South Africa to steward the region. The example of the US CDC establishing a purpose-built laboratory in Uganda for human health was mentioned. Across health target areas, participants stressed that infectious disease outbreaks in neighbouring countries impacted the biosafety of South Africans and that organisms were not easily contained within geographic borders.

With respect to human health, a participant asked whether a list of criteria for allowing sick individuals to travel into South Africa specifically for receipt of intensive care existed. A further question included whether South Africa is ethically obliged to provide care to persons travelling from outside its borders and suspected of suffering from a dangerous infectious disease. The case of imported Ebola virus which was transmitted to South African nursing staff in 1996 was noted, with the reflection that South Africans have paid the price of poor disease control in neighbouring countries. In terms of providing support to neighbouring countries, one participant noted that it was unclear what this would mean specifically in terms of notification, surveillance and resources.

With respect to animal health, the example of a 2011 outbreak of foot-andmouth disease was mentioned; South Africa was viewed as being able to help neighbouring countries which would in turn avoid the disease spreading to South Africa. Trans-frontier national parks which span across borders were flagged as a potential risk to biosafety. Although the official borders are controlled between South Africa and neighbouring countries, the transition areas within the park(s) could facilitate the illegal transportation of domestic and wild animals. This is of particular concern if neighbouring countries have limited capacity for disease prevention mechanisms. 
3) Improve systems for collecting data and managing data integrity. Participants commented that in order to protect the health of humans, animals and plants, reporting, surveillance and notification systems needed major improvement. Better linkages were required between laboratories, health practitioners and government departments. The statistical systems for analysing and presenting the data needed to be operational. The lack of compliance with notification of human disease was seen as a huge obstacle to the efficient operation of the current notification system and suggestions for utilising accessible technology such as cell phones and simplification of the notification process were recommended to improve the system. The data collection form employed by the Malaria Control Programme was simple and observational research suggested it was preferentially completed by health-care staff instead of the Notification GW 17/5 form. A participant suggested harmonising the different surveillance systems with the notification system so it could be all part of one integrated system.

\subsubsection{Other issues arising}

Participants were asked to raise any other issues which they believed to be pertinent to the subject and the responses were diverse.

1) A concern was expressed that several terms are used broadly within this field (examples were 'biosafety' and 'biosecurity'), but that different individuals and departments understood the terms differently. Laboratory workers understand 'biosafety' to refer to protecting their health and preventing exposure in the laboratory setting, whereas the Cartagena Protocol on Biosafety (under the United Nations Environment Programme) defines biosafety as the protection of biological diversity from the potential risks posed by living modified organisms (LMOs) resulting from modern biotechnology (the focus is on GMOs ). It is important to gain clarity within government and agreement on terms.

2) Two participants stated that there needs to be an increased focus on prevention and not only responsive management of outbreak control.

3) There was a request that the death notification system be evaluated. Currently at an operational level there was confusion about whether a pathologist or magistrate should complete the cause of death form. This has implications for reporting of Notifiable Medical Conditions and recording of such data within the national mortality statistics.

4) Several participants noted that all players in the field wanted the same outcome viz. to prevent infectious disease outbreaks. There was a request that future processes be developed and adopted in a respectful, conciliatory manner with broad consultation and recognition that health-care professionals, laboratory workers, farmers, industry, researchers, and government officials were all working towards the same goal. Mention was made that there is an undercurrent of suspicion in this area and that it needs to be addressed before meaningful progress can be made. 


\subsection{Discussion}

\subsubsection{Main findings}

Each of the participants willingly and openly shared their knowledge, expertise and opinions based on their own experiences of working in the area of infectious disease outbreaks. Participants were highly qualified and worked in diverse settings, with each target health area (human, animal and plant) represented. Most participants worked in the human and animal area with only two having specific experience of the plant health field. Almost all participants had contributed to developing or revising relevant regulations and were active in the policy arena.

\subsubsection{Strengths and weaknesses of implementation strategies}

Despite the diversity of participant knowledge and experience, participants voiced similar concerns regarding the strengths and weaknesses of implementing national strategies to manage disease outbreaks.

Most participants recognised that South Africa continues to demonstrate an effective response to the control of disease outbreaks attributing this to institutional experience and expertise, the regulatory environment and good inter-sectoral communication during acute episodes. However, all participants noted that prevention, active and passive surveillance, effective data collection, statistical analysis and notification (specifically for human health) and regular planning within and between sectors are lacking. A shortage of skilled staff, vacant positions and limited funding for infrastructural support were key to the inability of South Africa to move from a reactive position to one of greater pro-activity.

\subsubsection{Human resources}

Frieden et al. (2014) note that a well-trained workforce greatly augments effective epidemic responses and recommend a multidisciplinary public health workforce, with one or more epidemiologists per 200000 population. There are no current figures on the numbers of epidemiologists in South Africa, but given the overall shortage of health-care workers it is highly unlikely to be as high as the recommendation. In the 2006 Lancet Series on Health in South Africa, the authors challenged the DoH to work actively with regulatory authorities and training institutions to increase the numbers of health-care workers and to increase their professional abilities for implementation of an expanded range of services (Chopra et al., 2009). This would also need to include trained staff available to deliver not only an outbreak response, but also to engage with planning and prevention. 


\subsubsection{Notifiable Medical Conditions}

Within human health, poor compliance with the statutory obligation to notify Notifiable Medical Conditions was widely recognised. Reasons postulated included health professionals' lack of awareness regarding notification, the complexity of the GW $17 / 5$ notification form and the rapid turnover of staff involved in managing outbreaks at a provincial level. These opinions are supported by Smith et al. (2007) who report that while outbreaks of food-borne disease (notifiable when a food poisoning incident affects $\geq 2$ people) are common in South Africa, food-borne disease is markedly underreported (Smith et al., 2007). In 2011 , Dunbar reported using capture-recapture methodology to evaluate notification of TB in two communities in the Western Cape province, demonstrating the limited accuracy and completeness of routinely collected TB-recording and reporting data (Dunbar et al., 201 1). Nkgudi et al. (2006) published a detailed analysis of incidence and reporting of rheumatic fever (also a notifiable disease) and found that there appeared to be underreporting of cases by health-care professionals, and poor administration of the notification system. They recommended that health-care professionals need to be educated about the statutory requirements to notify and advocate for better co-ordination efforts to establish a seamless system for the accurate reporting of notifiable conditions.

\subsubsection{Control of animal diseases}

It was noteworthy that several participants, who did not work in animal health, viewed the ability of the DAFF to control animal diseases and to provide data on such controlled diseases as superior to the human and plant health field. This was not directly contradicted by those working within animal health, but they pointed to a lack of state veterinarians at provincial level hampering implementation of national policy. In addition, transport of animals was poorly managed because it relied on inter-sectoral co-operation among DAFF, the Department of Transport and the South African Police Services (SAPS), which was noted by participants to be very poor. Better co-ordination between sectors was raised by most participants as key to fulfilling regulatory obligations and policy imperatives. This would also meet international imperatives for global health security. In their list of key global health security areas, Frieden et al. (2014) include policies and practices to reduce the risk of zoonotic disease transmission as necessary to mitigate avoidable outbreaks.

\subsubsection{Regulations}

Participants observed significant shortcomings in current regulations with little crossreferencing between regulations and some contradictory elements between different regulations. Definitions were noted to be unclear especially with respect to levels of bio-containment in the Regulations relating to the registration of microbiological laboratories and the acquisition, importation, handling, maintenance and supply of Human Pathogens (R178)(March 2012). Participants pointed out that lists of infectious 
agents included in specific regulations were imported from other international lists, most notably the lists of the Australian Group, and may not have local relevance. Those working in the laboratory field recommended that lists of agents be based on the South African epidemiological-risk profile of each agent. Concerns were expressed that most regulations were out-of-date, with agent names not adhering to current taxonomic classifications. Provision for regular revisions needs to be made within the current regulatory processes to avoid confusion and aid detection and identification.

\subsubsection{Surveillance and data systems}

In their list of key global health security areas for prevention and detection of infectious disease outbreaks, Frieden et al. (2014) include a requirement for regional and national interoperable electronic reporting systems with timely reporting to $\mathrm{WHO}$, the World Organisation for Animal Health, and the Food and Agricultural Organisation (FAO) of the UN. Given the comments made by the informants, South Africa is currently not meeting this key requirement, with non-existent linkages between reporting systems and laboratories and questionable data quality. There was uncertainty about whether South Africa is currently providing regular, high-quality reports to the international agencies. Several participants suggested an integrated system of active surveillance (looking for disease in the community) and passive surveillance (reporting on disease presenting to health-care facilities). These systems should be linked to laboratory data, should be updated regularly and be accessible publicly.

\subsubsection{Regional responsibility}

There was consensus among the participants that South Africa must engage with neighbouring countries to prevent, detect, identify, control and record infectious disease outbreaks. The nature of this engagement was unclear. Participants recognised that ensuring that systems in neighbouring countries were optimal was self-serving in that it ultimately protects the public health of South Africans. There were few suggestions as to what specifically could be done to achieve this and whether or not South Africa should expend scarce resources on strengthening systems elsewhere. Nonetheless, there was a desire to see regional co-operation as a priority area for managing outbreaks.

\subsubsection{Strengths and limitations of the study}

The study is subject to limitations inherent in qualitative research (Britten, 1995). The participants were purposively sampled and so cannot be considered representative of all stakeholders. Nonetheless, given their cumulative knowledge and expertise (the reason for their inclusion) their voices and opinions provide comprehensive insights into the responses elicited by the prior survey and contribute to our understanding of the area under study. Perhaps most limiting were the voices missing from this study, notably those from several government departments who were not able to commit to 
an interview due to time pressures. We were also not able to include representatives from at least one laboratory in each province. The limited time available in which to conduct the study significantly hampered our ability to include all those participants who could have provided additional meaning to the responses outlined here. Despite the short duration of the study, every effort was made to accommodate the preferences of participants and the researcher made herself available after hours when necessary. The cited time pressure of many government officials supports the commentaries that there is little time for strategic planning and preparation within government, again confirming a need for greater human resource deployment or evaluation of priority setting.

The study has highlighted the complexity of the systems required to manage infectious disease outbreaks in South Africa. Many sectors and levels of workers are required to navigate these complex systems to secure the health of the South African public, its animals and its plants. This study has identified significant strengths of the system which provide a strong foundation for future improvements. The voices of the participants provide clear advocacy for meaningful engagement between sectors with the shared aim of reducing the incidence of infectious disease outbreaks in the future.

\subsection{Summary and conclusions}

This chapter reported on a qualitative key-informant interview study to garner expert opinion related to managing disease outbreaks. Valuable insights were gained into current perceptions within the scientific community regarding biosafety and biosecurity practices.

It was revealed that many of these challenges are extremely complicated in nature and may require changes to existing legislation. However, improved inter-departmental communication and cooperation, together with adequate funding for legally-mandated responsibilities would improve biosafety and biosecurity in South Africa and enable the country to meet its agreed international obligations.
Improved
inter-departmental
communication
and cooperation
together with
adequate funding
for legally-mandated
responsibilities would
improve biosafety
and biosecurity
management in
South Africa. 
Based on the findings from this study, the panel offers the following recommendations. Where possible, care has been taken to identify specific institutions or agencies that should take responsibility for implementing the recommendations; however, this is not always possible or applicable. It is our overall recommendation that these conclusions and recommendations be considered and discussed at a Southern African Development Community (SADC) regional symposium on biosafety and biosecurity where they can be refined and additions can be made.

\subsection{Improving the capacity to detect and respond to infectious disease outbreaks}

1. At the outset of this study, no comprehensive database of public and commercial research and diagnostic facilities existed in South Africa. One of the outputs of this study is a database that is a resource of laboratories for DoH, DAFF and DST. It can be a determination of national research and diagnostic capacity, and an assessment of gaps in the particular areas, particularly in relation to diagnostic capacity.

The panel recommends that the database compiled during this survey be considered a national asset and that its ongoing development and maintenance (including the development of a GIS map of all facilities) becomes the responsibility of the DST.

In the view of the panel, the DST is correctly placed to take on this responsibility since it straddles the fields of human, animal and plant health. In the interim, the database is available from ASSAf on request, but not for commercial use. The development of a GIS map of facilities, together with additional information overlays, so as to be able to, for example visually represent the ratio of diagnostic laboratories per area or region, and even to the burden of disease, is recommended. Such information may be valuable when determining the location for new laboratory services. In addition, information about the location and capacity of laboratories is necessary if any monitoring or inspection is to take place to ensure adherence with legislation.

2. This study identified that multiple South African laws and regulations govern the prevention, detection, identification and control of disease due to infectious agents. Five different government departments are responsible for the regulations which ensure public safety with respect to infectious diseases. No single, regularly updated and publicly accessible list of agents based on the South African epidemiological risk profile of each agent currently exists. 
The panel recommends that DoH, DAFF and DST, along with other relevant agencies, collectively determine whether such a comprehensive list would be a helpful tool for policymakers to cross-reference during the development of regulations; and if so, to undertake the development and maintenance of such a list.

3. Within human health, the study found poor compliance with the statutory obligation to notify Notifiable Medical Conditions. Reasons postulated included health professionals' lack of awareness regarding notification, the complexity of the GW 17/5 notification form and the rapid turnover of staff involved in managing outbreaks at a provincial level.

It is recommended that DoH ensure that health-care professionals are made aware of the statutory requirement to notify and improve the current system to ensure a seamless system for the accurate reporting of notifiable conditions. This could be done by providing training/ workshops to discuss how to report notifiable conditions or by providing access to training materials or information.

\subsection{Education and awareness raising}

1. The survey of practising life scientists (reported on in Chapter 5) found that education and/or training on research ethics, including issues such as scientific misconduct (falsification, fabrication and plagiarism) is not routine for life scientists. Such training is essential to ensure the integrity of science in South Africa.

It is recommended that the NRF and the Department of Higher Education and Training consider means to ensure the inclusion of research ethics training in the training of all life scientists in South Africa.

2. With respect to biosafety and biosecurity training measures, it was found that biosafety training is not routine for staff working in laboratories, nor was a test of competence routinely required. 
The panel recommends that the DoH consider drafting regulations to require that relevant laboratory staff undergo biosafety training that includes an assessment of competence.

Laboratory safety manuals, signed-for by all scientific and technical personnel, should be an obligatory requirement of all life science laboratories.

3. It was found that there is a low level of awareness among life scientists about national and international conventions, laws and regulations related to their research; and that information about these instruments is not readily available.

It is recommended that the Council for the Non-Proliferation of Weapons of Mass Destruction develop and disseminate (digitally and in print) details of the relevant national and international laws to all research and diagnostic facilities and all educational facilities in South Africa. This can also include an online guideline to relevant regulations on biosafety and biosecurity.

4. It was found that the terms biosafety, biosecurity and dual-use are neither commonly understood, nor is there consensus on the meaning or use of the term 'biosecurity'.

It is recommended that the NRF require researchers to demonstrate familiarity with these terms when submitting applications for research that could be considered 'dual-use'.

5. The study found that assessments of the biosafety and biosecurity risk associated with research activities are not routinely conducted, including assistance in identifying the level of containment required for the organisms being studied.

It is recommended that institutional research ethics committees require evidence of such an assessment having taken place before ethical approval is granted for research, including research not involving human and animal subjects. 
6. Given the need to develop a strong national capacity to undertake life science research, it is important to ensure that junior research staff are supported and encouraged and that senior staff with experience are retained. The survey finding that fewer than half of all junior research staff feel consistently supported and nurtured suggests that at institutional and national levels, attention needs to be paid to develop the capacity of senior staff to mentor junior staff.

Perhaps even more concerning is the perception that senior staff are not valued, nor are efforts made to retain their skills. More than half of the respondents in this survey felt that senior staff are not consistently valued by their institutions, indicating an imperative to incentivise and encourage staff to remain in the life sciences.

The panel recommends that universities and research institutions take note of this finding and seek to put in place measures to mentor junior staff.

\subsection{Ethics review}

1. In South Africa, no ethical guidelines specifically formulated for life sciences that do not entail research on humans or animals have been formulated or published. The Research Guidelines of the NHREC are currently (2014) being revised. The guidelines in Chapter 2 of the revised Research Guidelines are of general relevance to life sciences research on non-human subjects, but they need to be supplemented with more specific guidelines for the latter branch of science.

The panel recommends that the NHREC take the findings of this study into consideration in the process of revising the research guidelines. It is also recommended that the funding agencies (such as NRF, MRC) take ownership of addressing the more general research guidelines for all life science research.

2. While a code of conduct itself may not prevent undesirable behaviour or actions, the process of developing such a code may have the effect of raising awareness and encouraging reflection. However, this should not be seen as a substitute for more substantial training that should include reference to the relevant national and international laws, regulations and conventions. 
We propose that every research institution undertaking life science research consider developing and applying a code of conduct (COC) for researchers. We recommend that the training of life scientists should include a comprehensive ethics component and reference to all relevant national and international laws, regulations and conventions.

\subsection{Scientific openness and transparency}

While openness and transparency are regarded as important for scientific progress, there are a number of legitimate reasons why researchers may not be able to be entirely open about their research or findings. Reasons may range from the need to protect IP to the need to protect the identity of research participants.

While these constraints on openness may be legitimate and even necessary, the norm should be towards openness and sharing of information, as openness and knowledgesharing serve the interests of scientific progress.

1. The results of the survey indicate that research scientists in South Africa are supported and encouraged to collaborate less often with researchers from other institutions than they are with colleagues from their own institutions. Since most respondents were from research institutions receiving public funds, the finding that only slightly more than half of the respondents felt that collaboration with colleagues outside of their institution was routinely facilitated or encouraged suggests that such collaboration is not considered a priority and support for such collaboration could be increased.

The panel recommends that the NRF actively encourages interinstitutional collaboration through establishing incentives. 
2. While financial accountability appears to be the norm in research facilities, and would be demanded by funders and academic institutions, openness about the sources of funding is not routine, or recognised by scientists, this being confirmed by the survey data accumulated here. There are several ways in which such openness could be encouraged at institutional level. This includes requiring staff who received grants to list these on their staff profiles, through the maintenance of an online open access list of projects and their donors. Alternatively, by encouraging funders themselves to require grant recipients to declare the source of their funds when publishing or presenting research results.

It is recommended that the NRF and the DST encourage universities and research institutions in South Africa to publish details of their research projects and the funders thereof in the interests of accountability and transparency. 


\section{References}

Atlas, R. M., 2009: Responsible conduct by life scientists in an age of terrorism. Science and Engineering Ethics, 15, 293-301.

Badash, L., 2004: Science and social responsibility. Minerva, 42, 290-291.

Bakandize, L., Imnadze, P. and Perkins, D., 2010: Biosafety and biosecurity as essential pillars of international health security and cross-cutting elements of biological nonproliferation. BMC Public Health 2010 3;10 Suppl 1:S12.

Barr, D., 2007: Integrity in science. Journal of Exposure Science and Environmental Epidemiology, 17, 123. doi: doi:10.1038/sj.jes.7500573.

Britten, N., 1995: Qualitative research: Qualitative interviews in medical research. British Medical Journal, $311,251-253$.

Chopra, M., Lawn, J. E., Sanders, D., Barron, P., Abdool Karim, S. S., Bradshaw, D., Jewkes, R., Abdool Karim, Q., Flisher, A. J., Mayosi, B. M., Tollman, S. M., Churchyard, G. J., Coovadia, H. and Lancet South Africa, t., 2009: Achieving the health Millennium Development Goals for South Africa: Challenges and priorities. Lancet, 374(9694), 1023-1031. doi: 10.1016/s0140-6736(09)61122-3.

Cello, J., Paul, A. V. and Wimmer, E., 2002: Chemical synthesis of poliovirus cDNA: Generation of infectious virus in the absence of natural template. Science, 297, 1016-1018.

Dunbar, R., van Hest, R., Lawrence, K., Verver, S., Enarson, D. A., Lombard, C., Beyers, N. and Barnes, J. M., 2011 : Capture-recapture to estimate completeness of tuberculosis surveillance in two communities in South Africa. International Journal of Tuberculosis and Lung Disease, 15(8), 1038-1043. doi: 10.5588/ijtld.10.0695.

Ehni, H. J., 2008: Dual-use and the ethical responsibility of scientists. Archivum Immunologiae et Therapia Experimentalis, 56, 147-152.

European Commission for Standardisation., 2008: CEN Workshop Agreement. Laboratory National Institute of Communicable Diseases management standard. Retrieved on 31 March 2015 from: ftp://ftp.cenorm.be/PUBLIC/CWAs/wokrshop31/ CWA15793.pdf.

Eisfeld-Reschike, J., Herb, U. and Wenzlaff, K. Research funding in Open Science. Retrieved from http://book.openingscience.org/vision/research_funding.html. (Last accessed 14 April 2015.) 
Feyerabend, P. K., 1975: Against Method. London: Verso Books.

Forge, J., 2010: A note on the definition of 'Dual-Use'. Science and Engineering Ethics, 16, 111-118.

Frieden, T. R., Tappero, J. W., Dowell, S. F., Hien, N. T., Guillaume, F. D. and Aceng, J. R., 2014: Safer countries through global health security. Lancet, 383(9919), 764-766. doi: 10.1016/s0140-6736(14)60189-6.

Friedman, D., Rager-Zisman, B., Bibi, E. and Keynan, A., 2010: The bioterrorism threat and dual-use biotechnological research: An Israeli perspective. Science and Engineering Ethics, 16, 85-97.

Jackson, R. J., Ramsay, A. J., Christensen, C. D., Beaton, S., Hall, D. F. and Ramshaw, I. A., 2001: Expression of mouse interleukin-4by a recombinant ectromelia virus suppresses cytolytic lymphocyte responses overcomes genetic resistance to mouse pox. Journal of Virololgy, 75, 1205-1210.

Kant, L. and Mourya, D. T., 2010: Managing dual-use technology: It takes two to tango. Science and Engineering Ethics, 16, 77-83.

Kenya, E., Muturi, M. and Gould, C., 2012: An assessment of the capacity of research and diagnostic laboratories in Nairobi: World Health Organisation.

Keuleyan, E., 2010: Liberty to decide on dual-use biomedical research: An acknowledged necessity. Science and Engineering Ethics, 16, 43-58.

Koepsell, D., 2010: On genies and bottles: Scientists' moral responsibility and dangerous technology R\&D. Science and Engineering Ethics, 16, 119-133.

Kuhlau, F., Eriksson, S., Evers, K. and Hoglund, A. T., 2008: Taking due care: Moral obligations in dual use research. Bioethics, 22, 477-487.

Kuhn, T. S., 1962: The Structure of Scientific Revolutions. Chicago: University of Chicago Press.

Mays, N. and Pope, C., 1995: Qualitative research: rigour and qualitative research. British Medical Journal, $311,109-112$.

Miller, S. and Selgelid, M. J., 2007: Ethical and philosophical consideration of the dual-use dilemma in the biological sciences. Science and Engineering Ethics, 13, 523-580. 
National Institute for Health. Opportunities and guidelines to facilitate scientific collaborations. Retrieved from http://www.niaid.nih.gov/researchfunding/grant/ pages/extraintracollab.aspx. (Last accessed 3 September 2014.)

Nkgudi, B., Robertson, K. A., Volmink, J. and Mayosi, B. M., 2006: Notification of rheumatic fever in South Africa - evidence for underreporting by health-care professionals and administrators. South African Medical Journal, 96(3), 206-208.

Office of the Deputy Secretary Department of the Interior. Departmental Manual, Chapter 3: Integrity of scientific and scholarly activities, 2011 : Retrieved from http:// elips.doi.gov/elips/Browse.aspx? startid=971. (Last accessed 3 September 2014.)

Resnik, D. B., 2006: Openness versus secrecy in Scientific Abstract. Episteme, 2(3), 135-147.

Revill, J. and Dando, M. R., 2006: A hippocratic oath for life scientists. EMBO Reports, 7, S55-S60.

Rossouw, H. W., 1980: Verskuiwinge in die filosofiese wetenskapsbeeld. In H. W. Rossouw (Ed.), Wetenskap, Interpretasie, Wysheid. Port Elizabeth: Universiteit van Port Elizabeth Seminare, Simposia en Lesings B7, 1-16.

Selgelid, M. J., 2006: Commentary: the ethics of dangerous discovery. Cambridge Quarterly of Healthcare Ethics, 15, 444-447.

Selgelid, M. J., 2009: Dual-use research codes of conduct: Lessons from the life Sciences. Nanoethics, 3, 175-183.

Smith, A. M., Gouws, A. M., Hoyland, G., Sooka, A. and Keddy, K. H., 2007: Outbreaks of food-borne disease - a common occurrence but rarely reported. S Afr Med J, 97(12), 1272.

Truth and Reconciliation Commission., 1998: Truth and Reconciliation Commission of South Africa Report (Vol. Two). Cape Town: TRC.

Tumpey, T. M., Basler, C. F., Aguilar, P. V., Zeng, H., Solorzano, A., Swayne, D. E., Cox, N. J., Katz, J. M., Taubenberger, J. K., Palese, P. and Garcia-Sastre, A., 2005: Characterisation of the reconstructed 1918 Spanish influenza pandemic virus. Science, 310(5745), 77-80. doi: 10.1126/science.1119392.

United States Department of Interior. Integrity of scientific and scholarly activities. Retrieved from http://www.doi.gov/scientificintegrity/index.cfm. (Last accessed 3 September 2014.) 
United States National Science Advisory Board for Biosecurity. Retrieved from http:// osp.od.nih.gov/sites/default/files/resources/A_code_of_conduct_tool_kit_PPJan2012. pdf. (Last accessed 14 April 2015.)

Van Niekerk, A. A., 1992: Rasionaliteit en relativisme: Op soek na 'n rasionaliteitsmodel vir die Menswetenskappe. Pretoria: Raad vir Geesteswetenskaplike Navorsing.

Van Niekerk, A. A., 2003: Can more business ethics teaching halt corruption in companies? South Africa Journal of Philosophy, 22, 128-138.

Van Niekerk, A. A., 2011 : Does teaching ethics make a difference? IRENSA Impact Report, 124-125. Bioethics Centre, University of Cape Town.

Van Niekerk, A. A. and Nortié, N., 2013: Phronesis and an ethics of responsibility. South African Journal of Bioethics and Law, 6, 28-31.

Winslow C. E., 1920: The untilled fields of public health. Science, 1920, 51:23-33.

World Health Organisation, 2004: Laboratory biosafety manual. Third edition.

World Health Organisation, 2005: Life science research: opportunities and risks for public health. Mapping the issues. Retrieved on 1 April 2015 from: http://www.who. $\mathrm{int} / \mathrm{csr} /$ resources/publications/deliberate/WHO_CDS_CSR_LYO_2005_20/en/.

World Health Organisation 2006: Biorisk management: Laboratory biosecurity guidance. September 2006.

World Health Organisation, 2007a: Scientific working group on life science research and global health security. Report of the first meeting. Retrieved on 1 April 2015 from: http://whqlibdoc.who.int/hq/2007/WHO_CDS_EPR_2007.4_eng.pdf.

World Health Organisation, 2007b: The world health report 2007. A safer future: global public health security in the $21^{\text {st }}$ century.

World Health Organisation, 2008: International Health Regulations 2005. Retrieved 23 March, 2014, from http://whqlibdoc.who.int/publications/2008/9789241580410_ eng.pdf? $\cup a=1$.

World Health Organisation, 2010: Responsible life science research for global health security. Retrieved from http://whqlibdoc.who.int/hq/2010/WHO_HSE_GAR_ BDP_2010.2_eng.pdf. 


\section{Appendices}

\section{Appendix 1: Biographies of panel members}

(in alphabetical order)

\section{Professor Daniel du Toit, PhD}

Prof Du Toit joined Technikon Pretoria (now Tshwane University of Technology) in 1997 after a career at the University of Pretoria. He holds a PhD in Medical Sciences (Human Physiology). His research expertise and focus is on bio-ethics and human reproduction. His academic outputs have included supervision of doctorate studies and supervision of Masters degree studies. He has authored and co-authored over 42 publications, 150 papers and posters, focusing mainly on reproductive physiology, presented at national and international level. He is the Chairperson of the Medical Research Council Ethics Committee.

\section{Professor Jill Farrant, PhD, MASSAf; FRSSAf; FTWAS - Panel Chairperson}

Prof Farrant holds a Research Chair (Molecular Physiology of Plant Desiccation Tolerance) at the Department of Molecular and Cell Biology, University of Cape Town. She obtained an MSc and PhD from the University of Natal (now University of KwaZulu-Natal). Her MSc was with distinction and was awarded the South African Association for the Advancement of Science Bronze Medal and also the Junior Captain Scott Memorial Bronze Medal in 1986. She obtained the PhD in 1992 and the South African Association of Botanists (SAAB) Junior Medal for Excellence in Botany was awarded for that work. She has also received the SAAB Silver medal of excellence in Botany and has been President of the Society. She obtained the NRF President's award in 1993, the Oppenheimer Memorial Trust Fellowship in 2009; the DST Distinguished Women in Science award in 2010 and the L'Oreal-UNESCO award in 2012 that recognises women "whose exceptional careers in science have opened up new and sometimes revolutionary ways of improving human well-being". Her research is on the mechanisms of desiccation tolerance in rare and endemic South African flora and she holds an NRF A-rating. She has over 106 peer-reviewed publications in international journals and an excess of 200 conference abstracts. She has graduated a number of MSc and PhD students and is an Associate Editor for Plant Growth Regulation, South African Journal of Botany and Frontiers in Plant Biotechnology. 


\section{Dr Chandré Gould, DPhil}

Dr Gould is a senior researcher in the Crime and Justice Programme of the Institute for Security Studies (ISS). Between 1996 and 1999 she was in investigator and evidence analyst for the Truth and Reconciliation Commission, where she was involved in the investigation of Project Coast - the chemical and biological weapons programme of the apartheid government. After 1999 she continued researching Project Coast and co-authored a monograph published by the United Nations' Institute for Disarmament Research, and numerous papers and articles. She also co-authored a commercially published book about the trial of Dr Wouter Basson in 2002. In 2004 and 2005, she was the global network coordinator for the BioWeapons Prevention Project. Her areas of expertise are: biological weapons control and prevention; social crime prevention; human trafficking and sex work. She is an Editor of South African Crime Quarterly, a quarterly journal that is accredited by the Department of Higher Education in South Africa and published by ISS. She's an author and editor of several books and numerous papers on crime and criminal justice in South Africa; biological weapons control; South Africa's apartheid chemical and biological weapons programme; small arms control and human trafficking.

\section{Dr Petrus Jansen van Vuren, PhD}

Dr Jansen van Vuren is a Medical Scientist at the Centre for Emerging and Zoonotic Diseases at the National Institute for Communicable Diseases (NICD). His research at NICD includes development and validation of new diagnostic tests for viral hemorrhagic fever and arbovirus infections. He is also responsible for supervision of work in the Biosafety Level 4 laboratory, production and quality control testing of diagnostic reagents, laboratory animal work for research purposes at Level 3 and 4 , and assisting in field research and outbreak response during outbreaks of arthropod-borne and hemorrhagic fever viruses and VHF ecology studies. His research towards his PhD included evaluation of a recombinant antigen of Rift Valley Fever virus as a possible vaccine candidate and pathogenesis on a gene expression level. He has an interest in the role that bats play in the maintenance and transmission of dangerous pathogens, in particular those causing VHF. He has been involved in field and laboratory studies involving bats, including the first experimental infection of the Egyptian fruit bat with Marburg Virus. He have published in international peer-reviewed journals, as well as presented results at various local and international meetings, $\mathrm{He}$ currently co-supervise one MSc student and one PhD student. He has a South Africa NRF Y2 researcher rating.

\section{Dr Shadrack Moephuli, PhD}

Dr Moephuli is the President and Chief Executive Officer of the Agricultural Research Council (ARC). He is also a member of the Genetic Resource Policy Committee of the Consultative Group of International Agricultural Research. He has chaired the 
National Agricultural Research Forum, a multi-stakeholder consultative initiative. Prior to joining the ARC, he served as acting Deputy Director-General responsible for production and natural resource management in the Department of Agriculture, South Africa. He has also served as the Chief Director for agricultural production in the same department as well as the country's representative on various agricultural matters at the Convention for Biological Diversity, Cartagena Protocol for Biosafety, Food and Agriculture Organisation (FAO), International Treaty for Plant Genetic Resources for Food and Agriculture, Organisation for Economic Cooperation and Development. Prior to joining government, he was a biochemistry lecturer at the University of the Witwatersrand. To his credit are a number of research publications, including invited speaking events. He obtained his PhD from the University of Connecticut, USA.

\section{Dr Nhlanhla Msomi, PhD}

Dr Msomi is a consultant and the former Chief Executive Officer for Technology Innovation Agency (TIA) and Executive Chairman for City Works (Pty) Ltd, an Indo-South Africa joint venture company. He competed his postgraduate training in biotechnology, science policy and innovation from Sussex. He also has qualifications in finance (CIBM), international executive development (Wits) and corporate governance. His professional career has spanned scientific research, lecturing, innovation management, corporate finance and entrepreneurship. He was previously a partner and Executive Director for Principal Investments at Africa Vukani Capital. He has founded and invested in a number of businesses in the medical biotechnology and ICT sectors. His recent career has included serving on the Investment Committee of the Southern African Intellectual Property Fund and the Boards of the National Advisory Committee on Innovation, Council for Scientific and Industrial Research, KZN Government Central Procurement Committee, LIFELab (CEO and Deputy Chair), National Bioinformatics Network (Chair), and SA Bioproducts. He is a former Advisor to the Senior VicePresidents of the International AIDS Vaccine Initiative. He still serves on the Boards of Trade and Investment KwaZulu-Natal, International Centre for Genetic Engineering and Biotechnology, SA Society of Biochemistry and Molecular Biology, United World College- SA Trust, as well as the TIA.

\section{Professor lqbal Parker, PhD, MASSAf}

Prof Parker is the Director of the International Centre for Genetic Engineering and Biotechnology Cape Town Component. Previously he was the Head of the Division of Medical Biochemistry and Director of Research in the Health Science Faculty at the University of Cape Town. He obtained his PhD in Biochemistry in 1979, completed a postdoctoral fellowship with Gary Stein in the USA and returned to join the Department of Medical Biochemistry in 1981. He was President of the South African Society of Biochemistry and Molecular Biology (1998-2001), founder Secretary-General of the 
Federation of African Societies of Biochemistry and Molecular Biology from 1996 to 2003. He is a founder member of the Academy of Science of South Africa and served as General Secretary from 2000-2004 and Vice-President since 2010. He served on the international jury panel for the Loreal/UNESCO Awards for Women in Science for the period 1997-2002. In 2006, he was elected to the Executive Committee of the International Union of Biochemistry and Molecular Biology as the Chair of the Committee on Symposia since 2006. In 2004, he was awarded the South African Society for Biochemistry and Molecular Biology Gold Medal for his contributions to biochemistry and the National Science and Technology Forum award for Outstanding Contributions in Science, Engineering and Technology in 2003.

\section{Dr James Southern}

Dr Southern is currently a consultant to the biotechnology industry, advisor to the National Medicines Regulatory Agency (Biological Medicines, Clinical Trials \& Pharmacovigilance) and temporary evaluator for WHO Prequalification of Vaccines. $\mathrm{He}$ is also the Chair of the Developing Countries Vaccine Regulators' Network. He has worked in all aspects of vaccine development, production and control between 1968 and 2000 and he has been a member of the Biological Weapons Working Group reporting to the Non-Proliferation Council since 1993, and was a member of the Non-Proliferation Council from 1994 to 2009. He advises the Biosafety Directorate of the Department of Agriculture on the safety of medicines incorporating genetically modified organisms.

\section{Professor Anton van Niekerk, DPhil, MASSAf}

Prof Van Niekerk is a Distinguished Professor of Philosophy and Director of the Centre for Applied Ethics at Stellenbosch University. He specialises in the fields of bioethics, philosophy of religion and philosophy of the human sciences. He is the author, coauthor and editor of 18 books and more than 140 peer-reviewed journal articles and book chapters. He holds a B-rating as researcher by the NRF. He was awarded the Chancellor's Medal of Stellenbosch University in 1980 and the Stals Prize for Philosophy in 1995. He is Chairperson of the Board of the Ethics Institute of South Africa, former member of the Ethics Committee of the Medical Research Council and a former Director of the International Association of Bioethics. He has recently been appointed as a member of the National Health Research Ethics Council of South Africa. He is a former President of the Philosophical Society of Southern Africa, a former editor of the South African Journal of Philosophy and a former member of the council of the Stellenbosch University. He has delivered 66 papers at international conferences and has supervised over 72 completed Masters and 21 completed doctoral dissertations. 


\section{Ms Delille Wessels}

Ms Wessels is the Quality Assurance Manager at the Agricultural Research Council Onderstepoort Veterinary Institute responsible for the Quality Management Systems policy and accreditation of the Institute, standardisation of policies and procedures and the harmonisation and co-ordination of quality standards and procedures in all the laboratories. She is also the Acting Safety Officer. She is the President and Founder Member of the South African Biorisk Association. She is a member of several other committees/boards which include board member - Southern Africa Centre for Infectious Diseases (SACIDS), SACIDS Work Package Coordinator for Biosafety and Quality Management, member of various committees of the South African Bureau of Standards, member of various committees of the International Dairy Federation, SADC Subcommittee for Veterinary Diagnostic Laboratories, South African Veterinary Laboratory Scientific Forum, African Biological Safety Association and Consultant for the International Atomic Energy Agency on Quality Management Systems since 2003. 


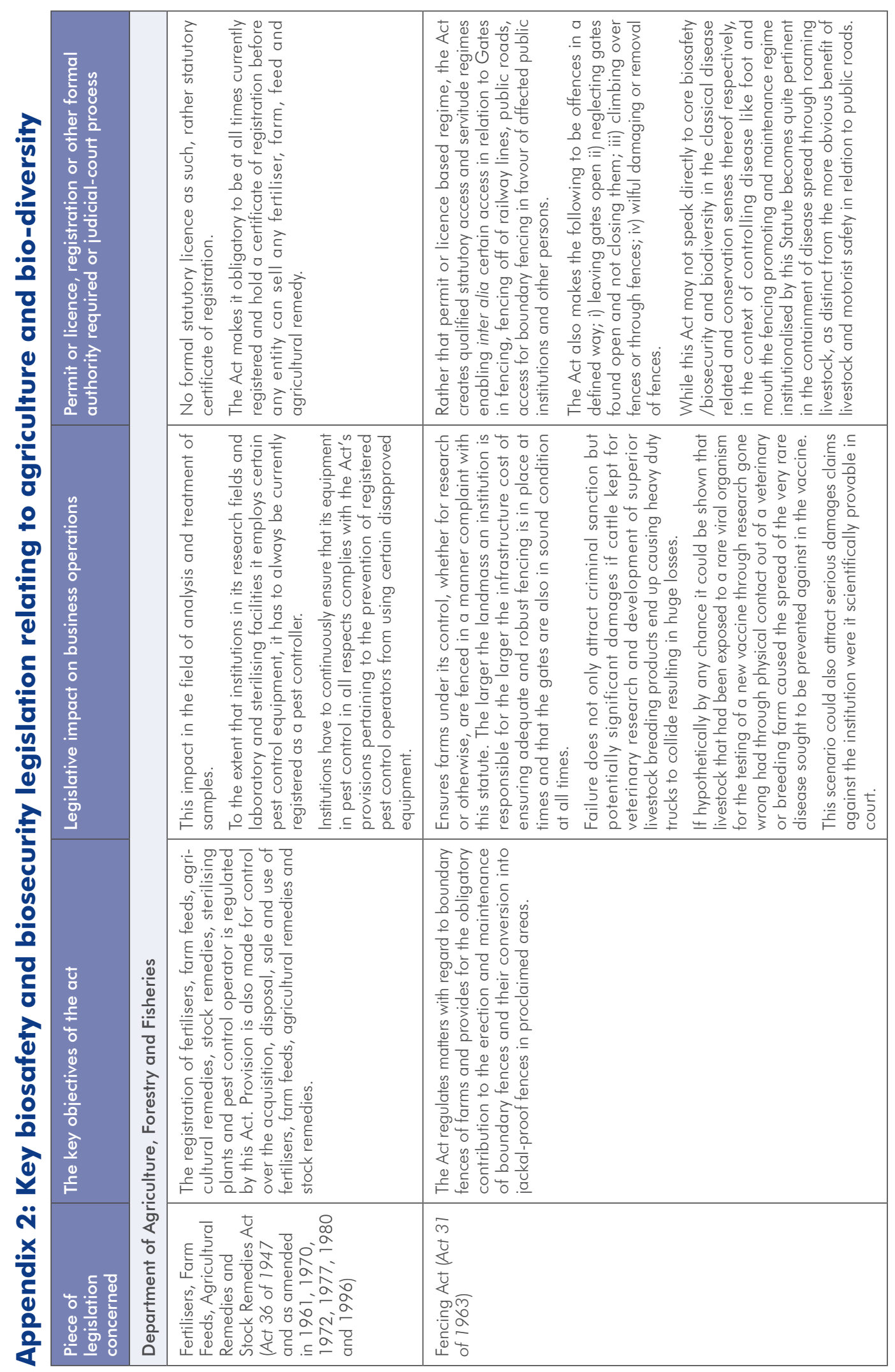




\begin{tabular}{|c|c|c|c|}
\hline 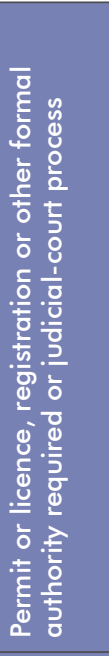 & & 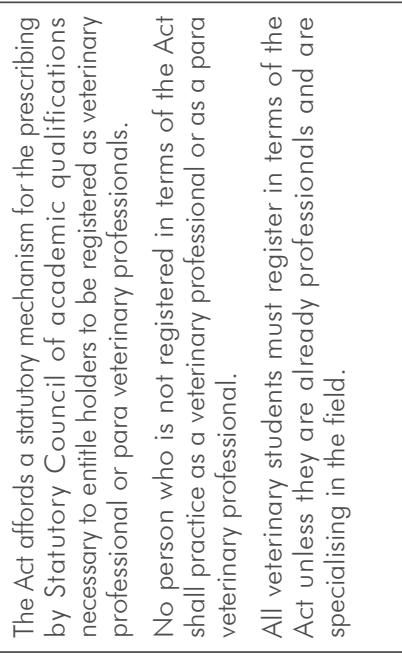 & 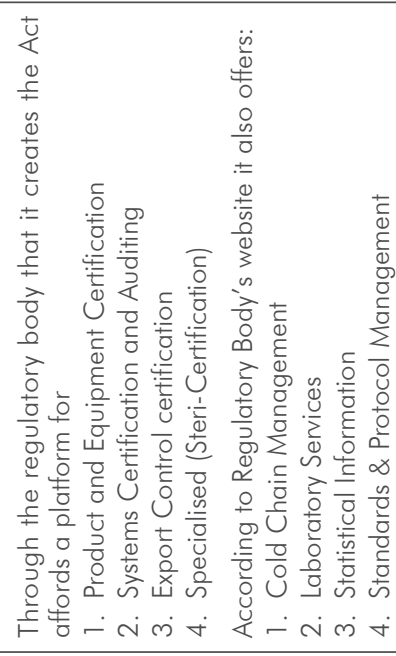 \\
\hline 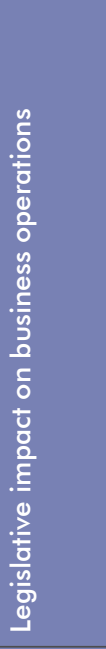 & 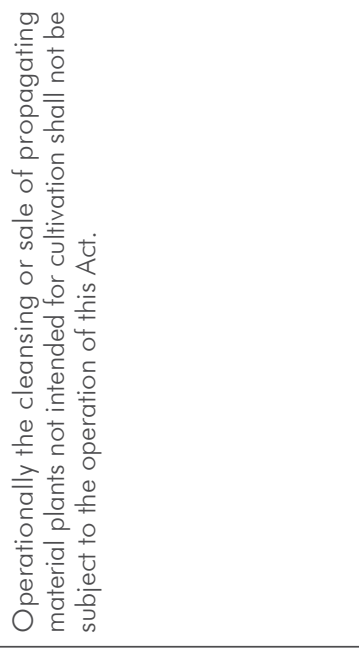 & 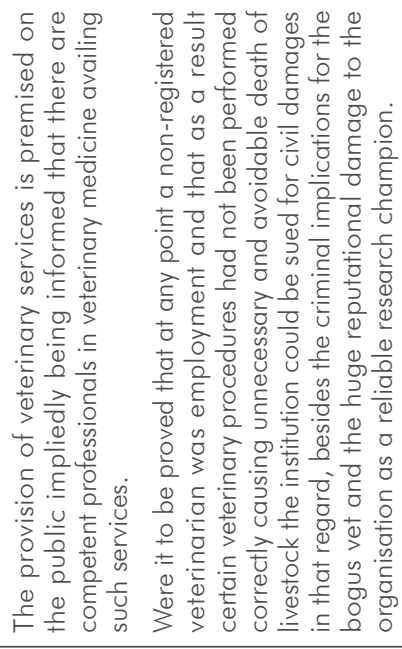 & \\
\hline 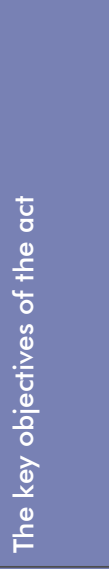 & 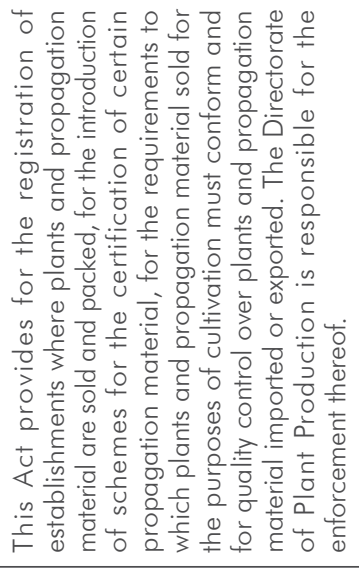 & 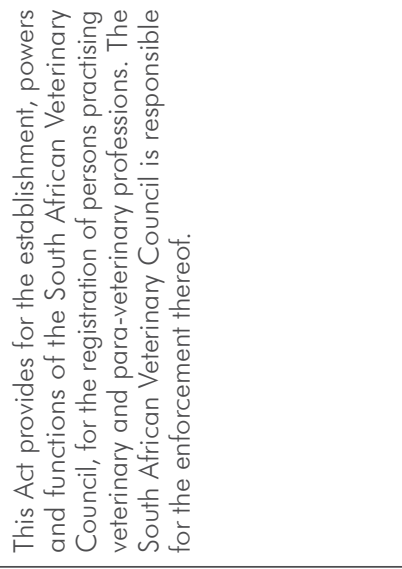 & 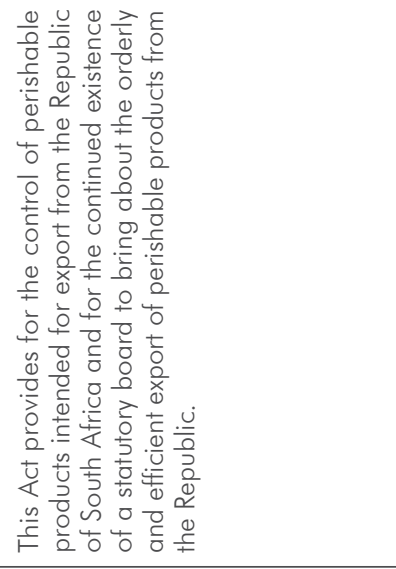 \\
\hline 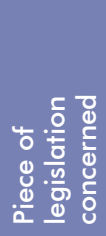 & 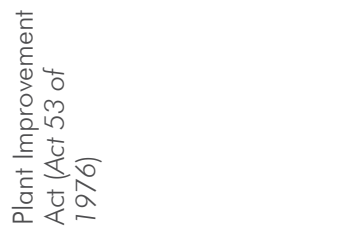 & 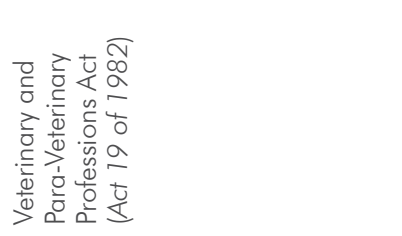 & 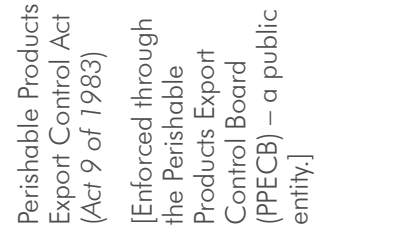 \\
\hline
\end{tabular}




\begin{tabular}{|c|c|c|c|}
\hline 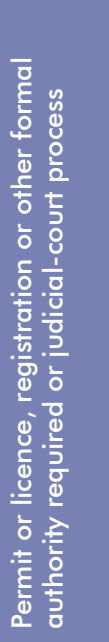 & 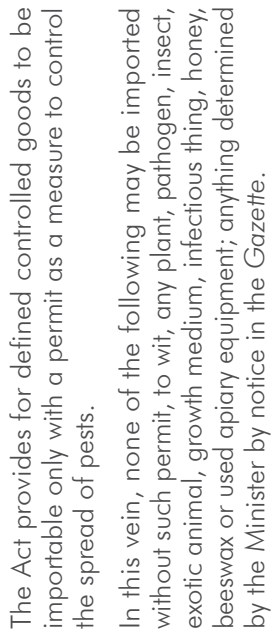 & 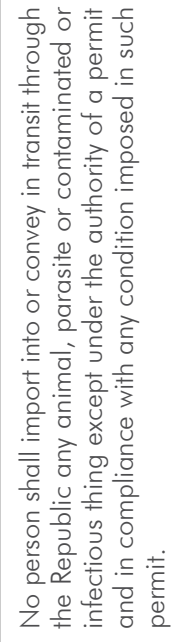 & 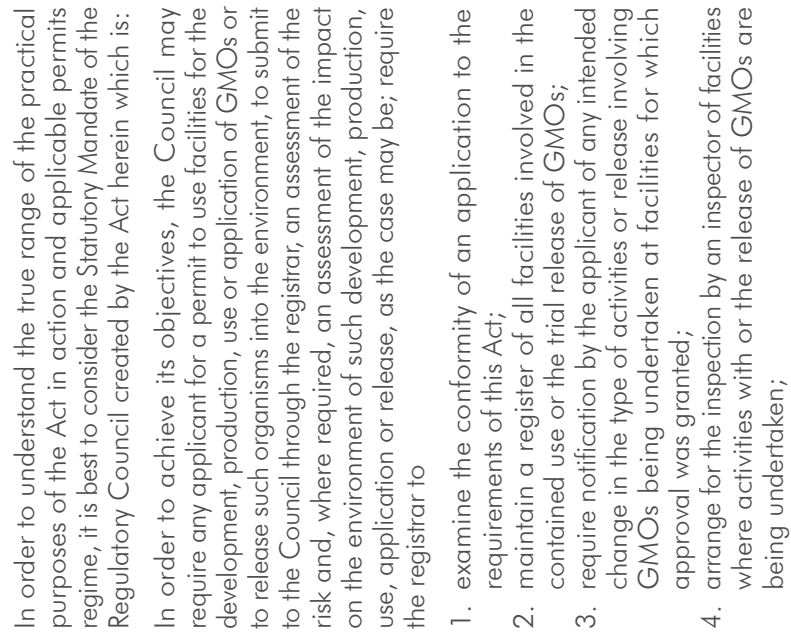 \\
\hline 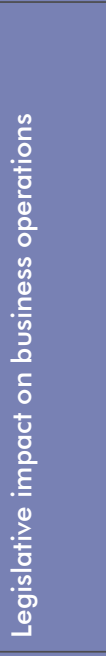 & 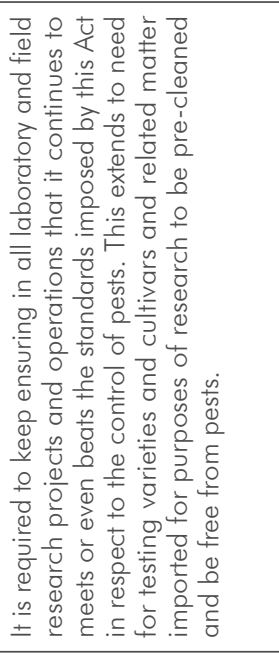 & 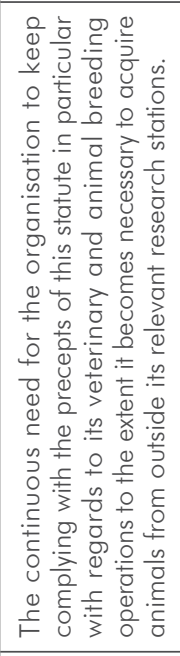 & 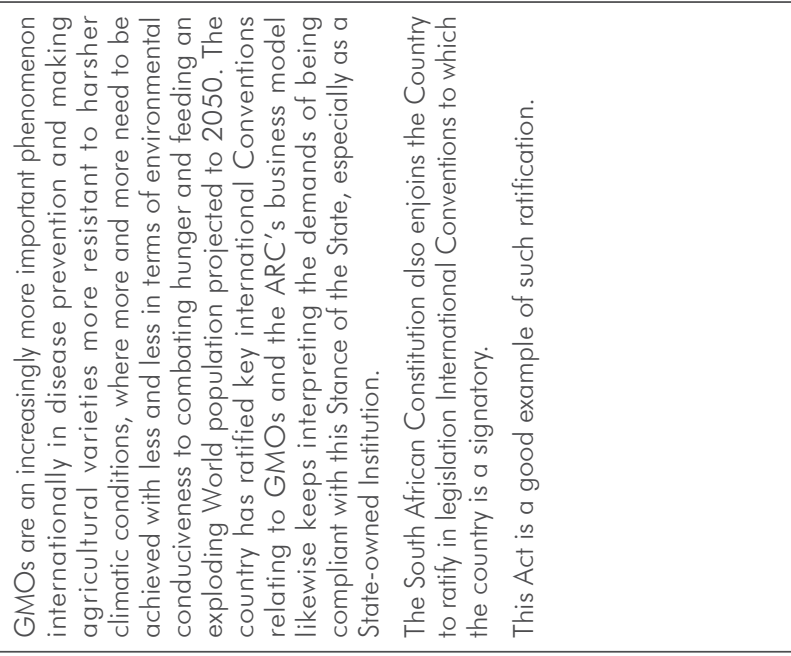 \\
\hline 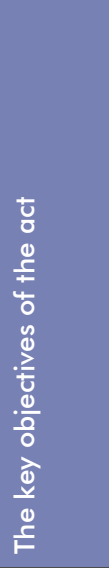 & 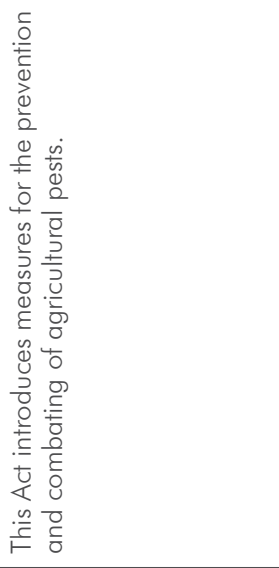 & 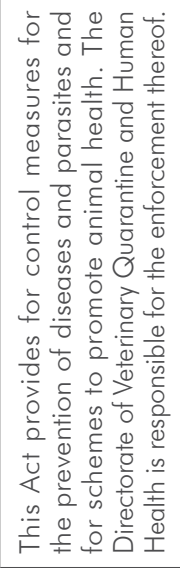 & 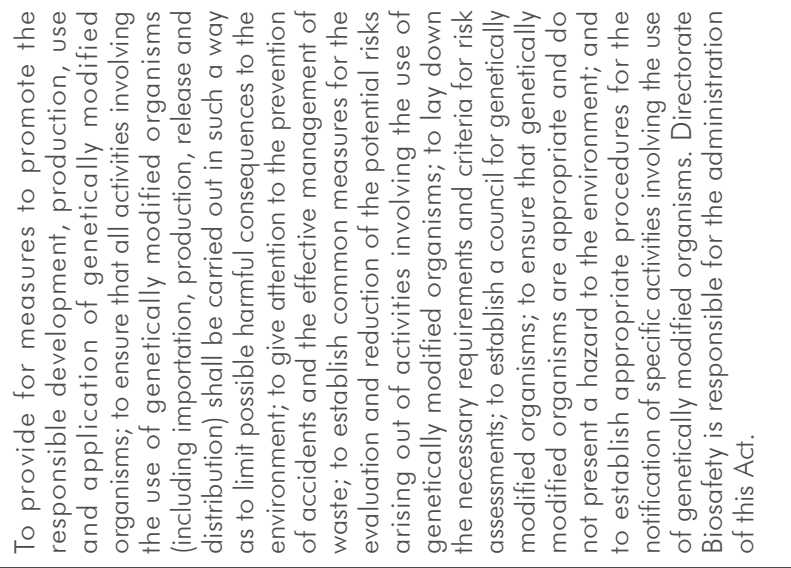 \\
\hline 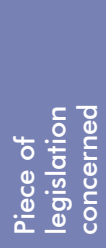 & 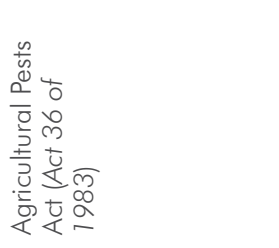 & 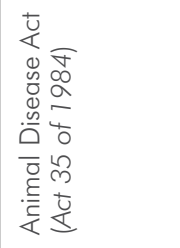 & 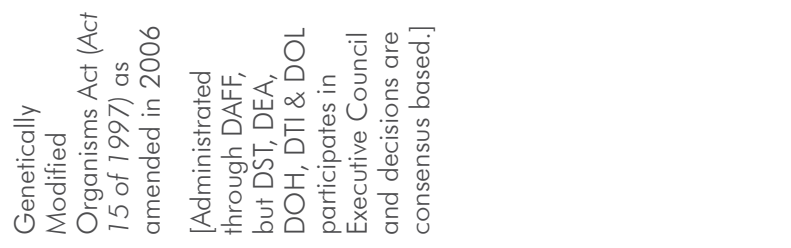 \\
\hline
\end{tabular}




$$
\text { | }
$$




\begin{tabular}{|c|c|c|c|c|}
\hline 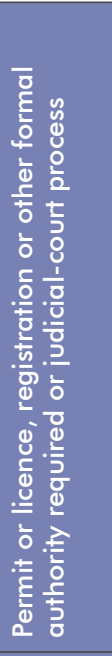 & 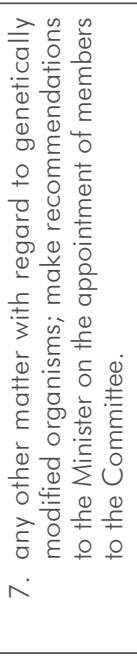 & 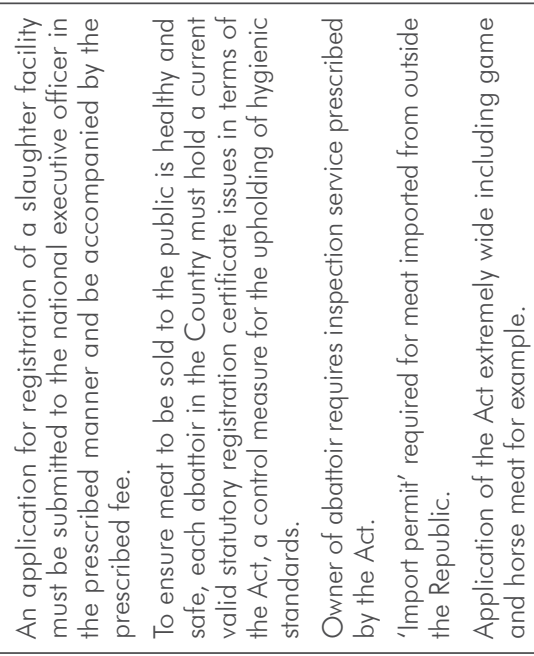 & 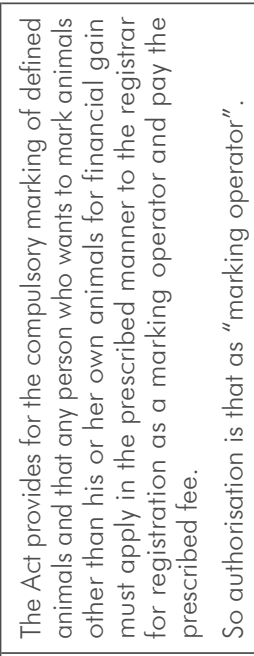 & 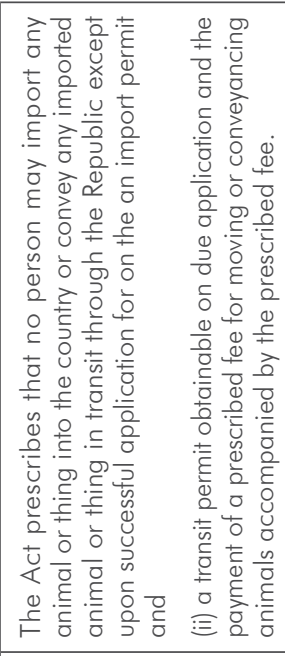 \\
\hline 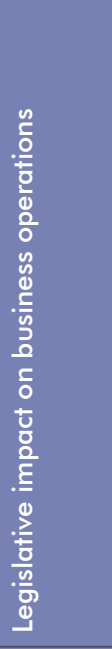 & & & 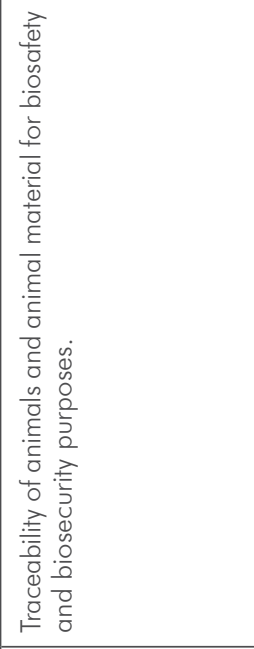 & 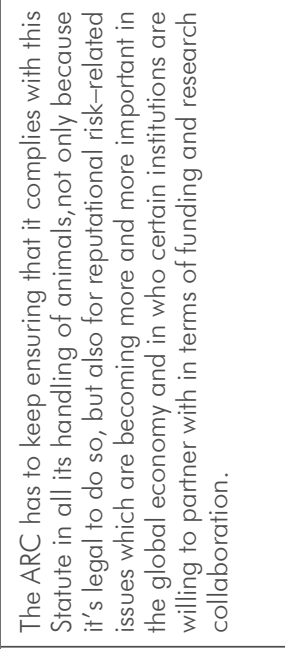 \\
\hline 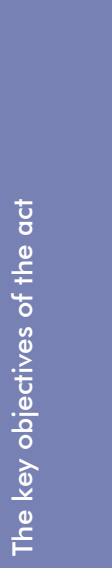 & & 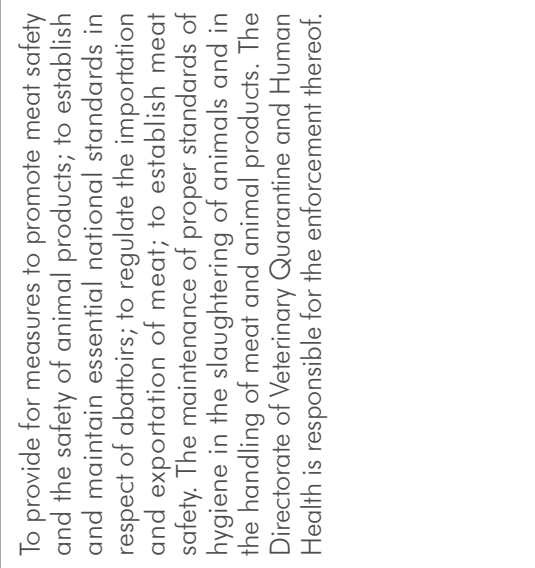 & 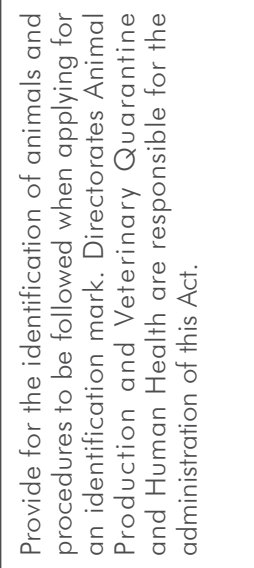 & 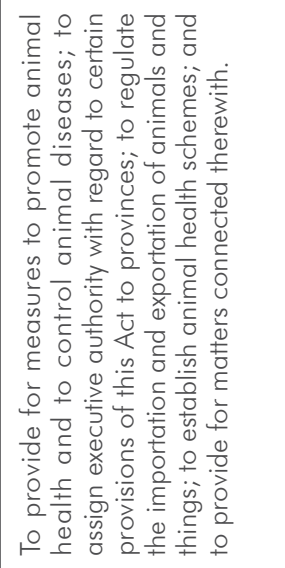 \\
\hline 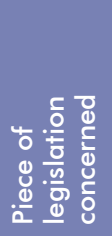 & & 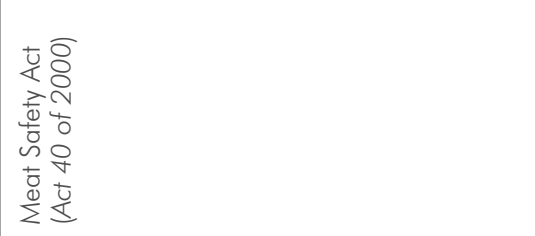 & 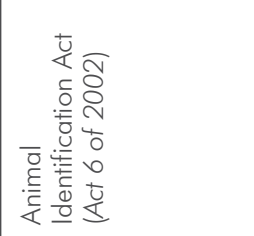 & 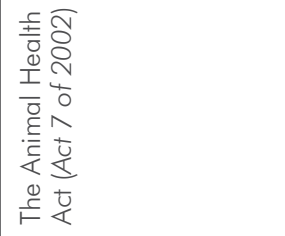 \\
\hline
\end{tabular}




\begin{tabular}{|c|c|c|c|}
\hline 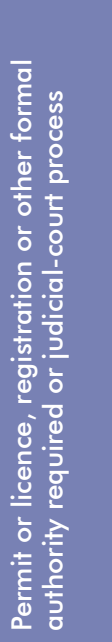 & 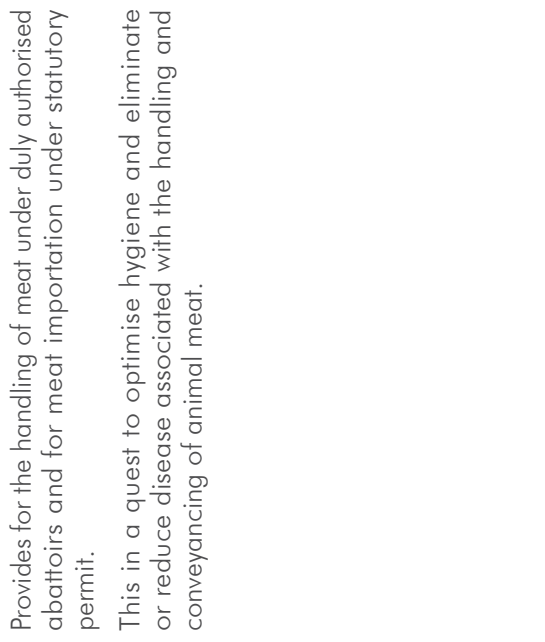 & 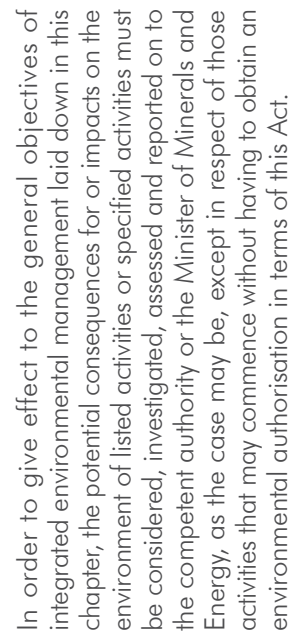 & 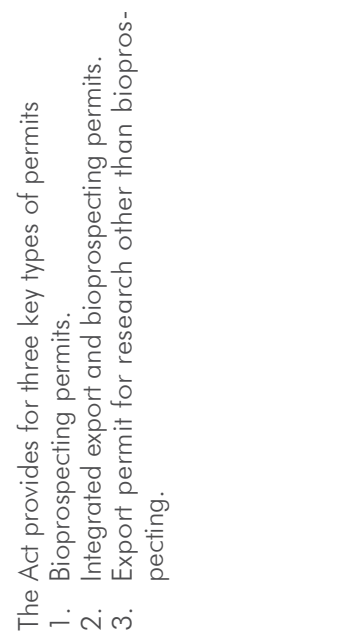 \\
\hline 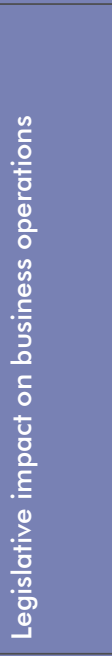 & 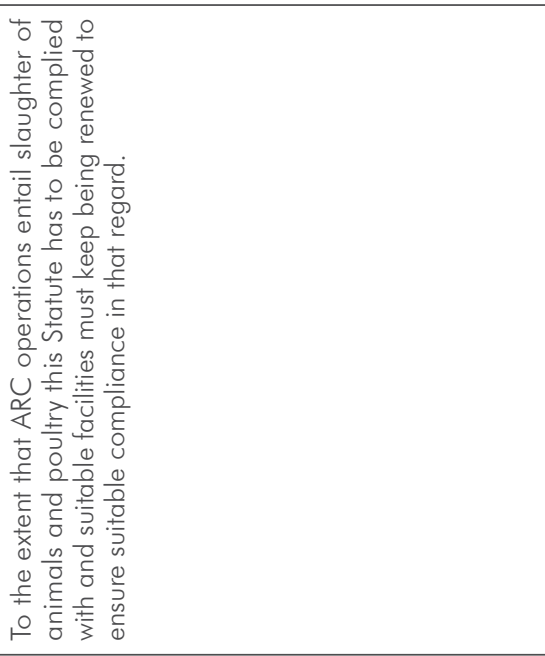 & & \\
\hline 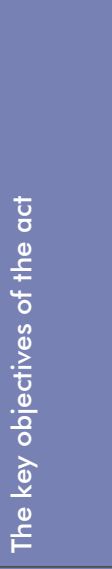 & 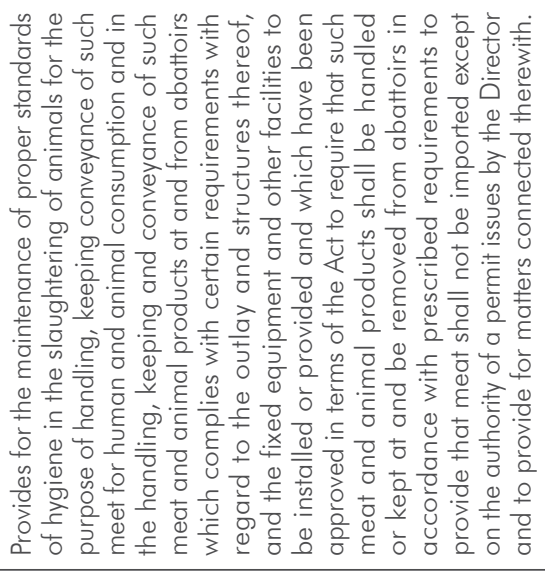 & 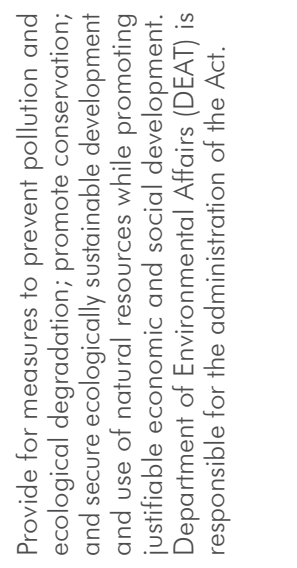 & 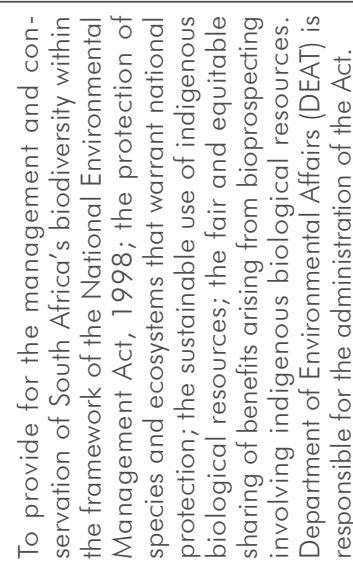 \\
\hline 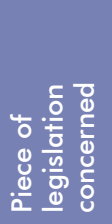 & 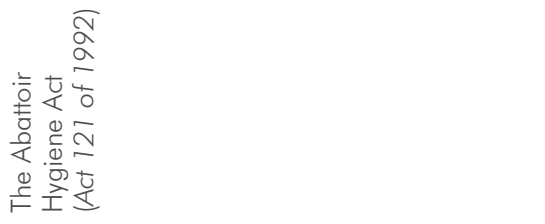 & 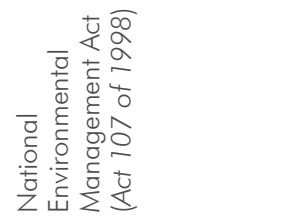 & 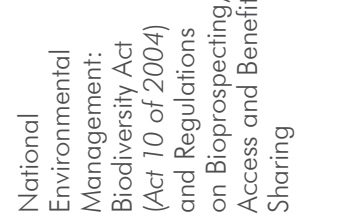 \\
\hline
\end{tabular}




\begin{tabular}{|c|c|c|c|c|}
\hline 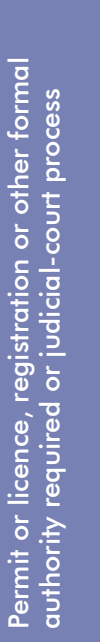 & 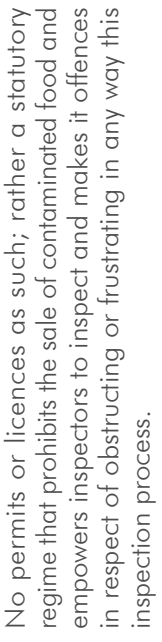 & 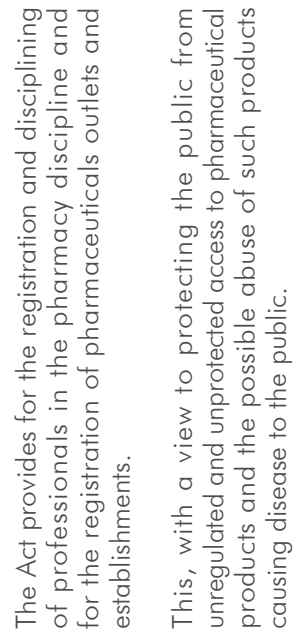 & & 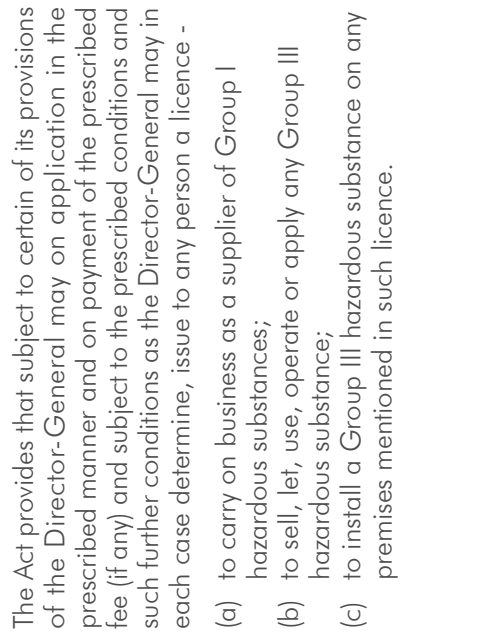 \\
\hline 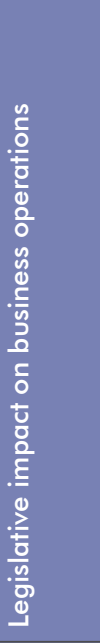 & & 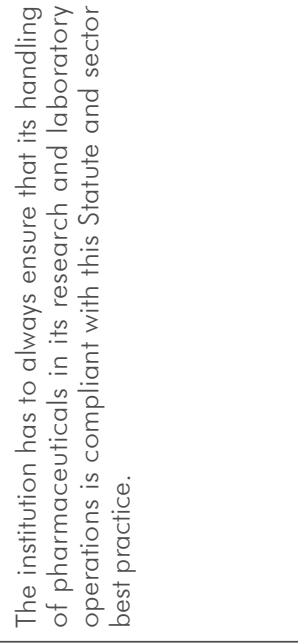 & & \\
\hline 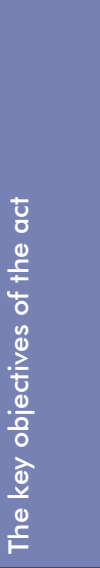 & 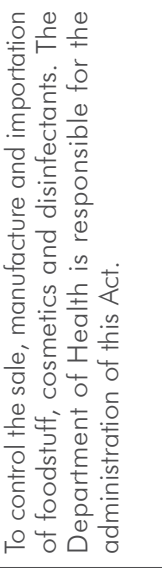 & 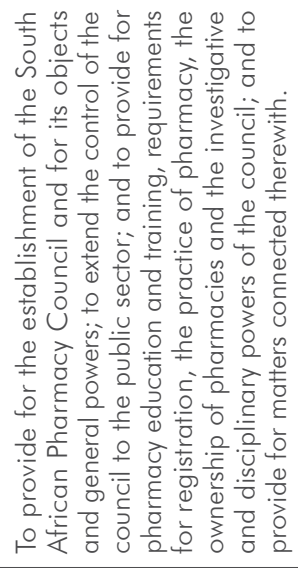 & 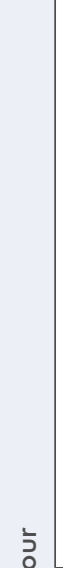 & 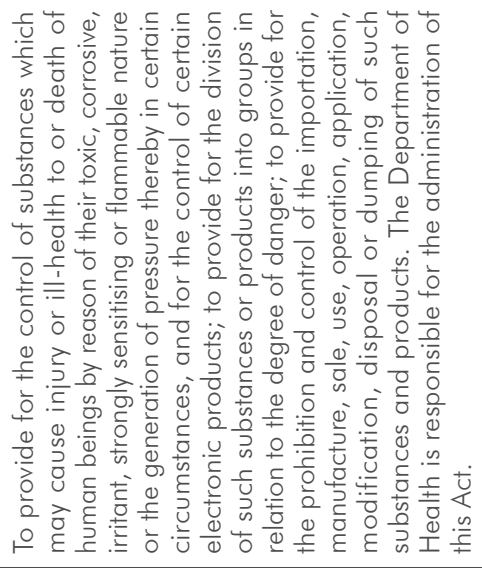 \\
\hline 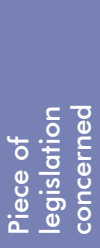 & 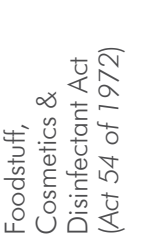 & 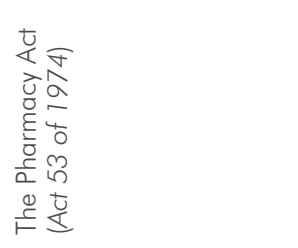 & 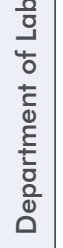 & 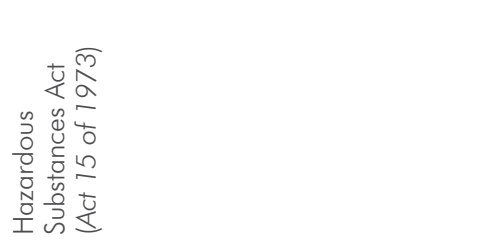 \\
\hline
\end{tabular}




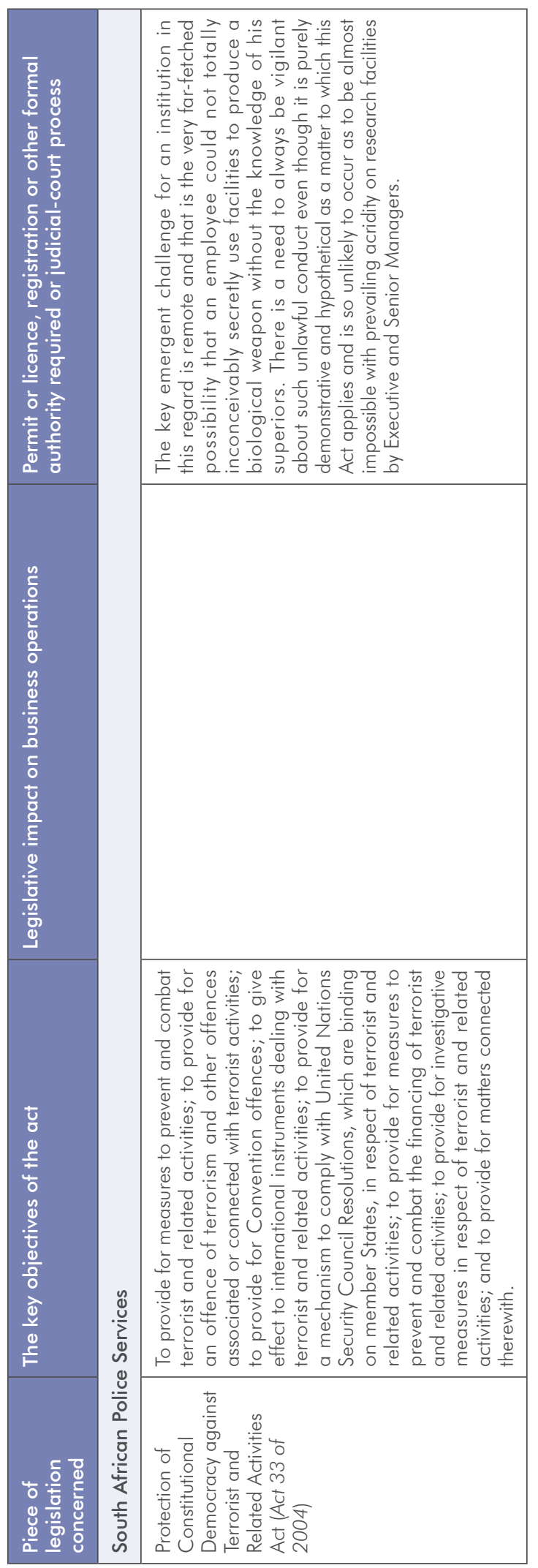




\section{Appendix 3: Human infectious agents and the regulations in which they are specifically named highlighted in colour}

\begin{tabular}{|c|c|c|c|c|c|c|}
\hline Agent name (or disease) & 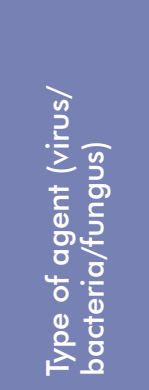 & 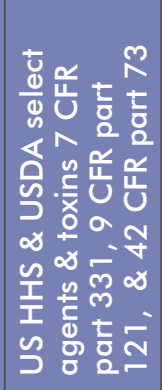 & 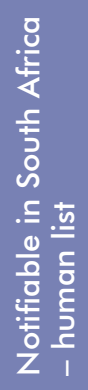 & 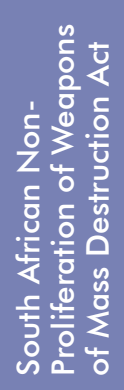 & 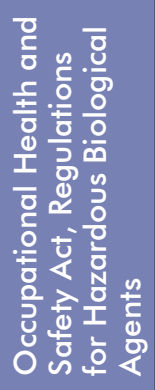 & 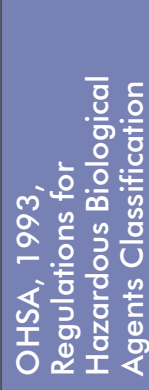 \\
\hline Clostridium botulinum & Bacteria & Yes & Yes & Yes & Yes & 2 \\
\hline Yersinia pestis & Bacteria & Yes & Yes & Yes & Yes & 3 \\
\hline Ebola virus & Virus & Yes & Yes & Yes & Yes & 4 \\
\hline Lassa fever virus & Virus & Yes & Yes & Yes & Yes & 2 \\
\hline Marburg virus & Virus & Yes & Yes & Yes & Yes & 4 \\
\hline Variola major virus (smallpox) & Virus & Yes & Yes & Yes & Yes & 4 \\
\hline Variola minor virus (alastrim) & Virus & Yes & Yes & Yes & Yes & 4 \\
\hline Rickettsia prowazekii & Bacteria & Yes & & Yes & Yes & 3 \\
\hline Junin & Virus & Yes & & Yes & Yes & \\
\hline $\begin{array}{l}\text { Tick-bourne encephalitis } \\
\text { complex (flavi) viruses }\end{array}$ & Virus & Yes & & Yes & Yes & 3 \\
\hline Abrin & Toxin & Yes & & Yes & & \\
\hline Botulinum neurotoxins & Toxin & Yes & & Yes & & \\
\hline Conotoxins & Toxin & Yes & & Yes & & \\
\hline Diacetoxyscirpenol toxin & Toxin & Yes & & Yes & & \\
\hline Ricin (biotoxin) & Toxin & Yes & & Yes & & \\
\hline Saxitoxin & Toxin & Yes & & Yes & & \\
\hline Staphylococcal enterotoxins & Toxin & Yes & & Yes & & \\
\hline T-2 toxin & Toxin & Yes & & Yes & & \\
\hline Tetrodotoxin & Toxin & Yes & & Yes & & \\
\hline $\begin{array}{l}\text { Far Eastern tick-bourne } \\
\text { encephalitis virus (formerly } \\
\text { known as Russian Spring and } \\
\text { Summer encephalitis) }\end{array}$ & Virus & Yes & & Yes & & \\
\hline Guanarito & Virus & Yes & & Yes & & \\
\hline Kyasanur forest disease virus & Virus & Yes & & Yes & & \\
\hline
\end{tabular}




\begin{tabular}{|c|c|c|c|c|c|c|}
\hline Agent name (or disease) & 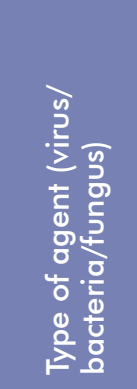 & 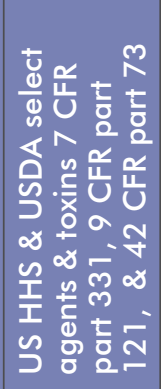 & 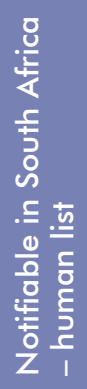 & 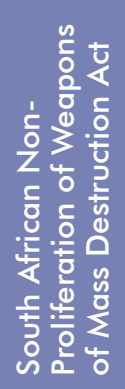 & 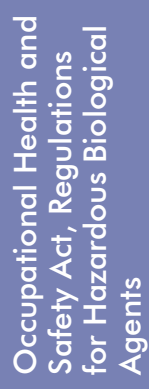 & 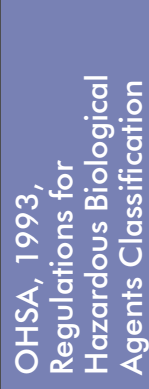 \\
\hline Lujo virus & Virus & Yes & & Yes & & \\
\hline Machupo & Virus & Yes & & Yes & & \\
\hline Monkeypox virus & Virus & Yes & & Yes & & \\
\hline Omsk haemorrhagic fever & Virus & Yes & & Yes & & \\
\hline Sabia & Virus & Yes & & Yes & & \\
\hline Chapare & Virus & Yes & & & & \\
\hline Reconstructed 1918 influenza & Virus & Yes & & & & \\
\hline SARS-associated coranavirus & Virus & Yes & & & & \\
\hline $\begin{array}{l}\text { South American } \\
\text { haemorrhagic fever virus }\end{array}$ & Virus & Yes & & & & \\
\hline $\begin{array}{l}\text { Clostridium perfingens } \\
\text { epsilon toxin-producing types }\end{array}$ & Bacteria & & Yes & Yes & Yes & 2 \\
\hline Clostridium tetani & Bacteria & & Yes & Yes & Yes & 2 \\
\hline $\begin{array}{l}\text { Legionella pneumophila } \\
\text { (OHSA HBA reg } \\
\text { Fluorobacter) }\end{array}$ & Bacteria & & Yes & Yes & Yes & 2 \\
\hline Salmonella typhi & Bacteria & & Yes & Yes & Yes & 3 \\
\hline Vibrio cholerae & Bacteria & & Yes & Yes & Yes & 2 \\
\hline Yellow fever & Virus & & Yes & Yes & Yes & 3 \\
\hline Cholera toxin & Toxin & & Yes & Yes & & \\
\hline Clostridium perfringens toxin & Toxin & & Yes & Yes & & \\
\hline Tetanus toxin & Toxin & & Yes & Yes & & \\
\hline Bacillus cereus & Bacteria & & Yes & & Yes & 2 \\
\hline Bordetella pertussis & Bacteria & & Yes & & Yes & 2 \\
\hline Chlamydia trachomatis & Bacteria & & Yes & & Yes & 2 \\
\hline Corynebacterium diphtheria & Bacteria & & Yes & & Yes & 2 \\
\hline Haemophilus influenza & Bacteria & & Yes & & Yes & 2 \\
\hline Mycobacterium leprae & Bacteria & & Yes & & Yes & 3 \\
\hline
\end{tabular}




\begin{tabular}{|c|c|c|c|c|c|c|}
\hline Agent name (or disease) & 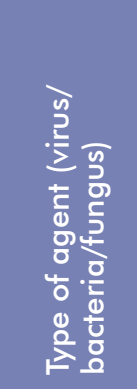 & 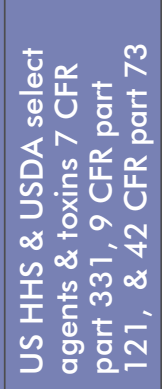 & 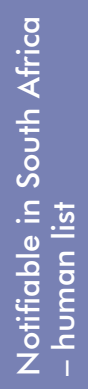 & 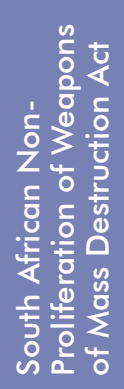 & 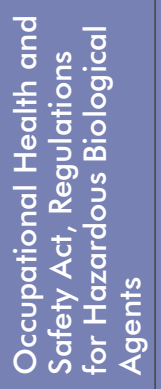 & 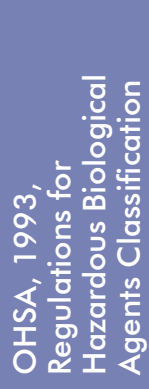 \\
\hline Mycobacterium tuberculosis & Bacteria & & Yes & & Yes & 3 \\
\hline Neisseria meningitidis & Bacteria & & Yes & & Yes & 2 \\
\hline $\begin{array}{l}\text { Streptococcus spp (Rheumatic } \\
\text { fever is notifiable) }\end{array}$ & Bacteria & & Yes & & Yes & 2 \\
\hline Treponema spp & Bacteria & & Yes & & Yes & 2 \\
\hline $\begin{array}{l}\text { Malaria (Plasmodium } \\
\text { falciparum) }\end{array}$ & Parasite & & Yes & & Yes & 3 \\
\hline $\begin{array}{l}\text { Hepatitis A (Human } \\
\text { enterovirus type } 72 \text { ) }\end{array}$ & Virus & & Yes & & Yes & 2 \\
\hline Hepatitis B & Virus & & Yes & & Yes & 3 \\
\hline Hepatitis C & Virus & & Yes & & Yes & 3 \\
\hline Hepatitis D & Virus & & Yes & & Yes & 3 \\
\hline Hepatitis $E$ & Virus & & Yes & & Yes & 3 \\
\hline Measles & Virus & & Yes & & Yes & 2 \\
\hline Polioviruses & Virus & & Yes & & Yes & 2 \\
\hline Bartonella quintana & Bacteria & & & Yes & Yes & 2 \\
\hline $\begin{array}{l}\text { Enterohaemorrhagic } \\
\text { escherichia coli, serotype } \\
0157 \text { and other verotoxin- } \\
\text { producing sub-types }\end{array}$ & Bacteria & & & Yes & Yes & 2 \\
\hline Rickettsia rickettsii & Bacteria & & & Yes & Yes & 3 \\
\hline Shigella dysenteriae & Bacteria & & & Yes & Yes & 3 \\
\hline Yersinia pseudotuberculosis & Bacteria & & & Yes & Yes & 2 \\
\hline Chikungunya & Virus & & & Yes & Yes & 3 \\
\hline Dengue & Virus & & & Yes & Yes & 3 \\
\hline Hanta virus & Virus & & & Yes & Yes & 3 \\
\hline $\begin{array}{l}\text { Coccidioides posadasii/ } \\
\text { Coccidioides immitis }\end{array}$ & Fungi & & & Yes & & \\
\hline Aflatoxin & Toxin & & & Yes & & \\
\hline
\end{tabular}




\begin{tabular}{|c|c|c|c|c|c|c|}
\hline Agent name (or disease) & 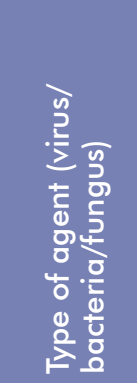 & 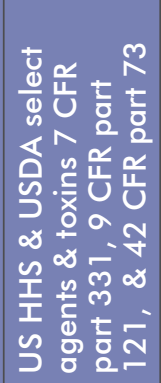 & 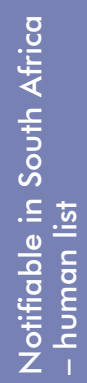 & 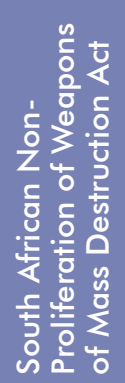 & 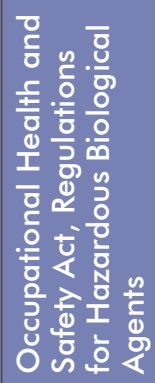 & 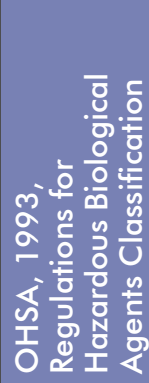 \\
\hline Mictocystin (Cyanginosin) & Toxin & & & Yes & & \\
\hline Modeccin toxin & Toxin & & & Yes & & \\
\hline Mycotoxin & Toxin & & & Yes & & \\
\hline Shiga toxins & Toxin & & & Yes & & \\
\hline Verotoxin & Toxin & & & Yes & & \\
\hline Viscum album lectin 1 & Toxin & & & Yes & & \\
\hline Volkensin & Toxin & & & Yes & & \\
\hline Dandenong & Virus & & & Yes & & \\
\hline Flexal & Virus & & & Yes & & \\
\hline Murray valley encephalitis & Virus & & & Yes & & \\
\hline Oropouche virus & Virus & & & Yes & & \\
\hline Rocio & Virus & & & Yes & & \\
\hline St Louis encephalitis virus & Virus & & & Yes & & \\
\hline Acinetobacter calcoaeceticus & Bacteria & & & & Yes & 2 \\
\hline Acinetobacter iwoffi & Bacteria & & & & Yes & 2 \\
\hline $\begin{array}{l}\text { Actinobacillus } \\
\text { actinomycetemcomitans }\end{array}$ & Bacteria & & & & Yes & 2 \\
\hline Actinomadura madurae & Bacteria & & & & Yes & 2 \\
\hline Actinomadura pelletieri & Bacteria & & & & Yes & 2 \\
\hline Alcaligines spp & Bacteria & & & & Yes & 2 \\
\hline $\begin{array}{l}\text { Arcanobacterium } \\
\text { haemolyticum } \\
\text { (Corynebacterium } \\
\text { haemolyticum) }\end{array}$ & Bacteria & & & & Yes & 2 \\
\hline Bacteroides spp & Bacteria & & & & Yes & 2 \\
\hline Bartonella spp & Bacteria & & & & Yes & 2 \\
\hline Bordetella parapertussis & Bacteria & & & & Yes & 2 \\
\hline Borellia burgdorferi & Bacteria & & & & Yes & 2 \\
\hline
\end{tabular}




\begin{tabular}{|c|c|c|c|c|c|c|}
\hline Agent name (or disease) & 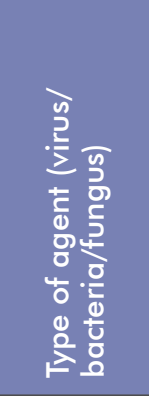 & 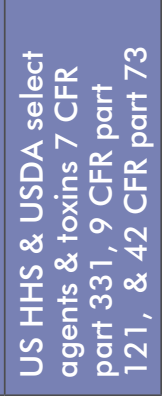 & 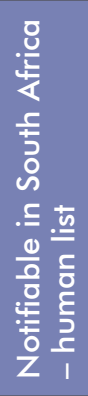 & 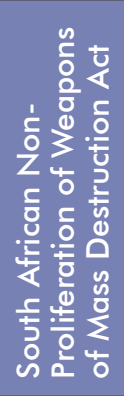 & 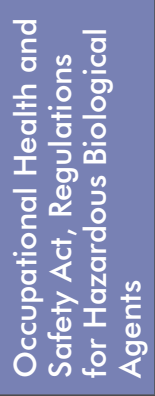 & 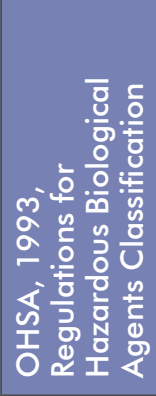 \\
\hline Burkholderia cepacia & Bacteria & & & & Yes & 2 \\
\hline Cardiobacterium hominis & Bacteria & & & & Yes & 2 \\
\hline $\begin{array}{l}\text { Corynebacterium } \\
\text { minutissimum }\end{array}$ & Bacteria & & & & Yes & 2 \\
\hline Ehrlichia spp & Bacteria & & & & Yes & 3 \\
\hline Eikenella corrodens & Bacteria & & & & Yes & 2 \\
\hline Eneterobacter spp & Bacteria & & & & Yes & 2 \\
\hline Enterococcus spp & Bacteria & & & & Yes & 2 \\
\hline $\begin{array}{l}\text { Flavobacterium } \\
\text { meningosepticum }\end{array}$ & Bacteria & & & & Yes & 2 \\
\hline Fusobacterium spp & Bacteria & & & & Yes & 2 \\
\hline Gardnerella vaginalis & Bacteria & & & & Yes & 2 \\
\hline Haemophilus ducreyi & Bacteria & & & & Yes & 2 \\
\hline Haemophilus spp & Bacteria & & & & Yes & 2 \\
\hline Helicobacter pylori & Bacteria & & & & Yes & 2 \\
\hline Klebsiella oxytoca & Bacteria & & & & Yes & 2 \\
\hline Klebsiella pneumoniae & Bacteria & & & & Yes & 2 \\
\hline Klebsiella spp & Bacteria & & & & Yes & 2 \\
\hline Moraxella catarrhalis & Bacteria & & & & Yes & 2 \\
\hline Moraxella lacunata & Bacteria & & & & Yes & 2 \\
\hline Morganella moganii & Bacteria & & & & Yes & 2 \\
\hline Mycobacterium africanum & Bacteria & & & & Yes & 3 \\
\hline $\begin{array}{l}\text { Mycobacterium bovis (BCG } \\
\text { strain) }\end{array}$ & Bacteria & & & & Yes & 2 \\
\hline Mycobacterium chelonae & Bacteria & & & & Yes & 2 \\
\hline Mycobacterium fortuitum & Bacteria & & & & Yes & 2 \\
\hline Mycobacterium kansasii & Bacteria & & & & Yes & 3 \\
\hline Mycobacterium malmoense & Bacteria & & & & Yes & 3 \\
\hline
\end{tabular}




\begin{tabular}{|c|c|c|c|c|c|c|}
\hline Agent name (or disease) & 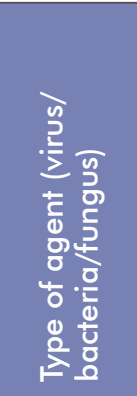 & 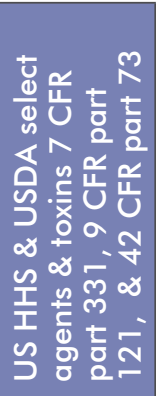 & 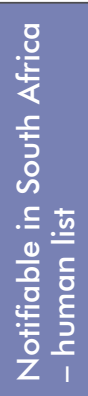 & 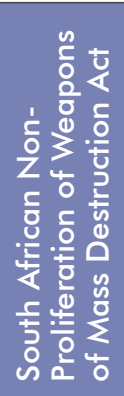 & 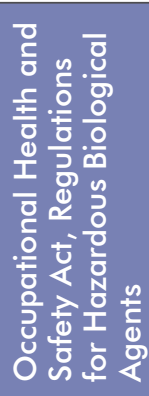 & 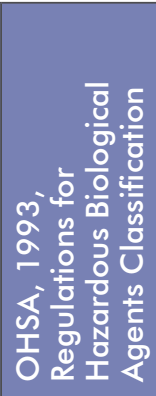 \\
\hline Mycobacterium marinum & Bacteria & & & & Yes & 2 \\
\hline Mycobacterium scrofulaceum & Bacteria & & & & Yes & 3 \\
\hline Mycobacterium szulgai & Bacteria & & & & Yes & 3 \\
\hline $\begin{array}{l}\text { Mycobacterium ulcerans } \\
\text { (Buruli ulcer) }\end{array}$ & Bacteria & & & & Yes & 3 \\
\hline Mycoplasma hominis & Bacteria & & & & Yes & 2 \\
\hline Mycoplasma pneumoniae & Bacteria & & & & Yes & 2 \\
\hline Neisseria gonorrhoeae & Bacteria & & & & Yes & 2 \\
\hline Nocardia spp & Bacteria & & & & Yes & 2 \\
\hline Pasteurella spp & Bacteria & & & & Yes & 2 \\
\hline Peptrostreptococcus spp & Bacteria & & & & Yes & 2 \\
\hline Plesiomonas shigelioides & Bacteria & & & & Yes & 2 \\
\hline Prevotella spp & Bacteria & & & & Yes & 2 \\
\hline Proteus mirabilis & Bacteria & & & & Yes & 2 \\
\hline Proteus penneri & Bacteria & & & & Yes & 2 \\
\hline Proteus vulgaris & Bacteria & & & & Yes & 2 \\
\hline Providencia spp & Bacteria & & & & Yes & 2 \\
\hline Pseudomonas aeruginosa & Bacteria & & & & Yes & 2 \\
\hline Serratia liquefaciens & Bacteria & & & & Yes & 2 \\
\hline Serratia marcescens & Bacteria & & & & Yes & 2 \\
\hline Shigella boydi & Bacteria & & & & Yes & 2 \\
\hline Shigella flexneri & Bacteria & & & & Yes & 2 \\
\hline Shigella sonnei & Bacteria & & & & Yes & 2 \\
\hline Staphylococcus aureus & Bacteria & & & & Yes & 2 \\
\hline $\begin{array}{l}\text { Stenotrophomonas } \\
\text { maltophilia }\end{array}$ & Bacteria & & & & Yes & 2 \\
\hline $\begin{array}{l}\text { Strepobacillus moniliformis } \\
\text { (Rat bite fever) }\end{array}$ & Bacteria & & & & Yes & 2 \\
\hline
\end{tabular}




\begin{tabular}{|c|c|c|c|c|c|c|}
\hline Agent name (or disease) & 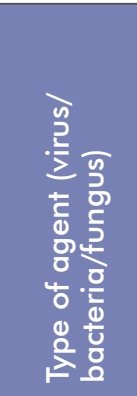 & 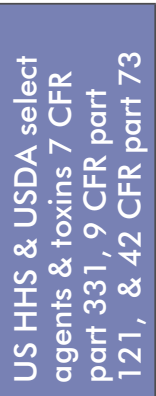 & 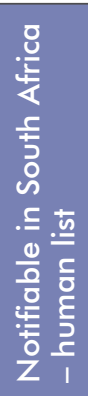 & 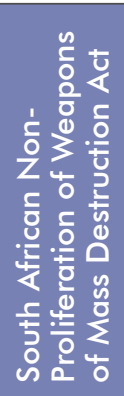 & 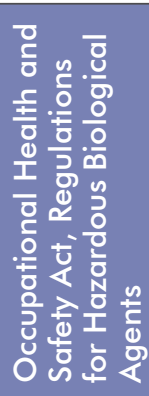 & 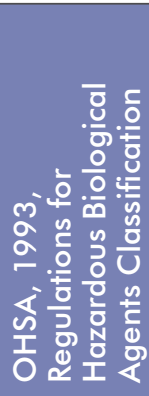 \\
\hline Ureaplasma urealyticum & Bacteria & & & & Yes & 2 \\
\hline Vibrio parahaemolyticus & Bacteria & & & & Yes & 2 \\
\hline Vibrio spp & Bacteria & & & & Yes & 2 \\
\hline Yersinia enterocolitica & Bacteria & & & & Yes & 2 \\
\hline Yersinia spp & Bacteria & & & & Yes & 2 \\
\hline Acanthamoeba spp & Parasite & & & & Yes & 2 \\
\hline Ancylostoma duodenale & Parasite & & & & Yes & 2 \\
\hline Ascaris lumbricoides & Parasite & & & & Yes & 2 \\
\hline Balantidium coli & Parasite & & & & Yes & 2 \\
\hline Blastocystis homines & Parasite & & & & Yes & 2 \\
\hline Brugia spp & Parasite & & & & Yes & 2 \\
\hline Capillaria spp & Parasite & & & & Yes & 2 \\
\hline Cyclospora cayetanensis & Parasite & & & & Yes & 2 \\
\hline Dientamoeba fragilis & Parasite & & & & Yes & 2 \\
\hline Dracunculus medinensis & Parasite & & & & Yes & 2 \\
\hline Entamoeba histolytica & Parasite & & & & Yes & 2 \\
\hline Entamoeba vermicularis & Parasite & & & & Yes & 2 \\
\hline Isopora belli & Parasite & & & & Yes & 2 \\
\hline Loa loa & Parasite & & & & Yes & 2 \\
\hline Mansonella ozzardi & Parasite & & & & Yes & 2 \\
\hline Mansonella perstans & Parasite & & & & Yes & 2 \\
\hline Mansonella streptocoerca & Parasite & & & & Yes & 2 \\
\hline Naegleria fowleri & Parasite & & & & Yes & 3 \\
\hline Necator americanus & Parasite & & & & Yes & 2 \\
\hline Onchocerca volvulus & Parasite & & & & Yes & 2 \\
\hline Schistosoma spp & Parasite & & & & Yes & 2 \\
\hline Strongyloides spp & Parasite & & & & Yes & 2 \\
\hline
\end{tabular}




\begin{tabular}{|c|c|c|c|c|c|c|}
\hline Agent name (or disease) & 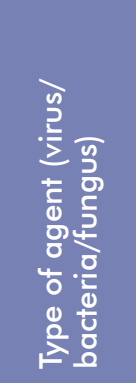 & 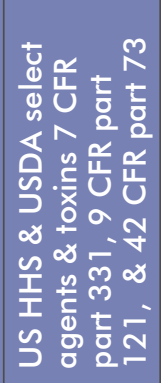 & 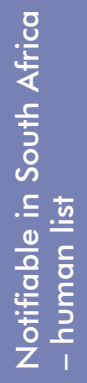 & 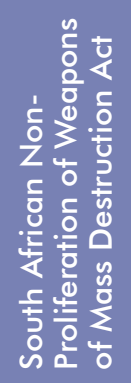 & 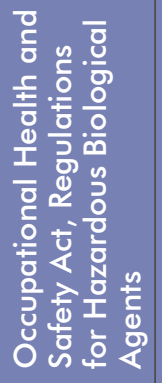 & 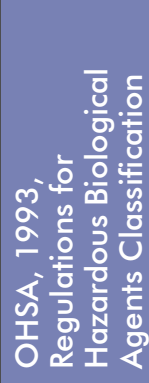 \\
\hline Trichomonas vaginalis & Parasite & & & & Yes & 2 \\
\hline Trichuris trichiura & Parasite & & & & Yes & 2 \\
\hline $\begin{array}{l}\text { Wuchereria bancrofti } \\
\text { (Lymphatic filariasis) }\end{array}$ & Parasite & & & & Yes & 2 \\
\hline $\begin{array}{l}\text { Unconventional agents } \\
\text { associated with Gerstmann- } \\
\text { Strussler-Scheinker }\end{array}$ & PRION & & & & Yes & 3 \\
\hline $\begin{array}{l}\text { Unconventional agents } \\
\text { associated with Kuru }\end{array}$ & PRION & & & & Yes & 3 \\
\hline $\begin{array}{l}\text { Acute haemorrhagic } \\
\text { conjunctivitis virus }\end{array}$ & Virus & & & & Yes & 2 \\
\hline Adenoviridae & Virus & & & & Yes & 2 \\
\hline Alphavirus & Virus & & & & Yes & 2 \\
\hline Astroviridae & Virus & & & & Yes & 2 \\
\hline$B K$ and $J C$ viruses & Virus & & & & Yes & 2 \\
\hline $\begin{array}{l}\text { Blood-borne hepatitis viruses } \\
\text { not yet identified }\end{array}$ & Virus & & & & Yes & 3 \\
\hline Coronaviridae & Virus & & & & Yes & 2 \\
\hline Coxsackie viruses & Virus & & & & Yes & 2 \\
\hline Cyłomegalovirus & Virus & & & & Yes & 2 \\
\hline Echoviruses & Virus & & & & Yes & 2 \\
\hline Epstein-Barr & Virus & & & & Yes & 2 \\
\hline $\begin{array}{l}\text { Flaviviruses known to be } \\
\text { pathogenic }\end{array}$ & Virus & & & & Yes & 2 \\
\hline Herpes simplex type 1 and 2 & Virus & & & & Yes & 2 \\
\hline Herpesvirus varicella-zoster & Virus & & & & Yes & 2 \\
\hline Human herpesvirus type 6 & Virus & & & & Yes & 2 \\
\hline Human herpesvirus type 7 & Virus & & & & Yes & 2 \\
\hline $\begin{array}{l}\text { Human immunodeficiency } \\
\text { viruses }\end{array}$ & Virus & & & & Yes & 3 \\
\hline
\end{tabular}




\begin{tabular}{|c|c|c|c|c|c|c|}
\hline Agent name (or disease) & 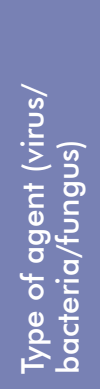 & 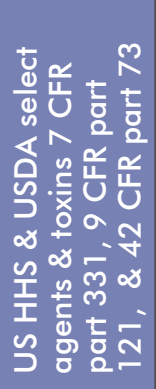 & 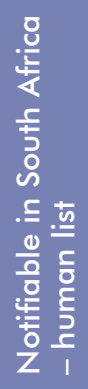 & 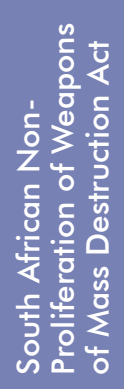 & 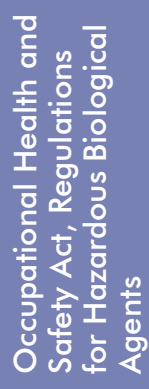 & 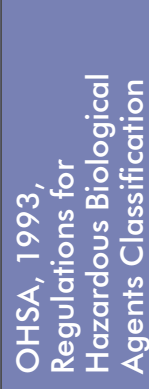 \\
\hline Human papillomaviruses & Virus & & & & Yes & 2 \\
\hline Human parvovirus (B19) & Virus & & & & Yes & 2 \\
\hline Human rotaviruses & Virus & & & & Yes & 2 \\
\hline $\begin{array}{l}\text { Human T-cell lymphotropic } \\
\text { virus }\end{array}$ & Virus & & & & Yes & 3 \\
\hline Influenza types A, B and C2 & Virus & & & & Yes & 2 \\
\hline Lymphocytic chloriomeningitis & Virus & & & & Yes & 3 \\
\hline Mobala & Virus & & & & Yes & 2 \\
\hline Molluscum contagiosum virus & Virus & & & & Yes & 2 \\
\hline Monkeypox & Virus & & & & Yes & 3 \\
\hline Mopeia & Virus & & & & Yes & 3 \\
\hline Mumps & Virus & & & & Yes & 2 \\
\hline Norwalk (Norovirus) & Virus & & & & Yes & 2 \\
\hline O'nyong-nyong & Virus & & & & Yes & 2 \\
\hline Other Calciviridae & Virus & & & & Yes & 2 \\
\hline Parainfluenza (Types 1 to 4) & Virus & & & & Yes & 2 \\
\hline Respiratory syncytial virus & Virus & & & & Yes & 2 \\
\hline Rhinoviruses & Virus & & & & Yes & 2 \\
\hline Rubella & Virus & & & & Yes & 2 \\
\hline Spondweni & Virus & & & & Yes & 3 \\
\hline $\begin{array}{l}\text { Vaccinia (including strains } \\
\text { originally classified as } \\
\text { rabbitpox) }\end{array}$ & Virus & & & & Yes & 2 \\
\hline
\end{tabular}




\section{Appendix 4: Animal infectious agents and the regulations in which they are specifically named highlighted in colour}

\begin{tabular}{|c|c|c|c|c|c|c|c|}
\hline Agent name (or disease) & 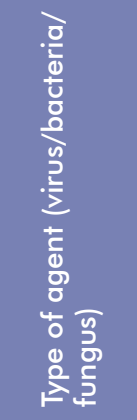 & 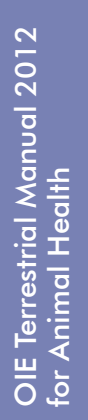 & 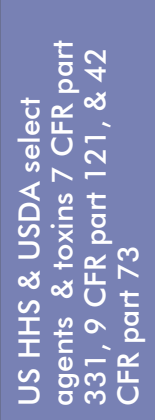 & 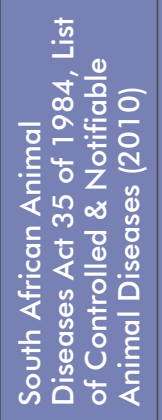 & 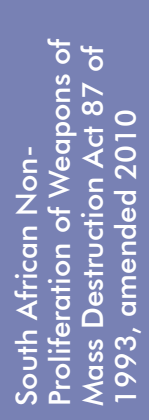 & 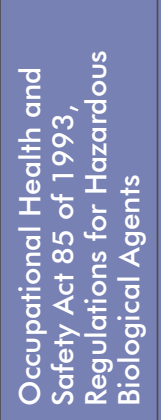 & 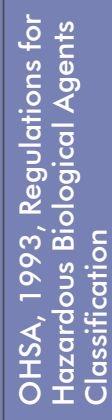 \\
\hline $\begin{array}{l}\text { African horse sickness } \\
\text { (Orbivirus serogroup L) }\end{array}$ & Virus & Yes & Yes & Yes & Yes & Yes & 2 \\
\hline Rinderpest & Virus & Yes & Yes & Yes & Yes & Yes & 4 \\
\hline $\begin{array}{l}\text { Bluetongue (Orbivirus } \\
\text { serogroup } L \text { ) }\end{array}$ & Virus & Yes & Yes & Yes & Yes & Yes & 2 \\
\hline $\begin{array}{l}\text { Classical swine fever } \\
\text { (Hog cholera) }\end{array}$ & Virus & Yes & Yes & Yes & Yes & & \\
\hline Foot and mouth disease & Virus & Yes & Yes & Yes & Yes & & \\
\hline Lumpy skin disease & Virus & Yes & Yes & Yes & Yes & & \\
\hline $\begin{array}{l}\text { Porcine enterovirus } \\
\text { type } 9 \text { (Swine vesicular } \\
\text { disease) }\end{array}$ & Virus & Yes & Yes & Yes & Yes & & \\
\hline Sheep pox virus & Virus & Yes & Yes & Yes & Yes & & \\
\hline African swine fever & Virus & Yes & Yes & Yes & Yes & & \\
\hline Avian influenza & Virus & Yes & Yes & Yes & Yes & & \\
\hline Mycoplasma capricolum & Bacteria & Yes & Yes & & Yes & & \\
\hline Mycoplasma mycoides & Bacteria & Yes & Yes & & Yes & & \\
\hline Goat pox virus & Virus & Yes & Yes & & Yes & & \\
\hline Peste des petits ruminants & Virus & Yes & Yes & & Yes & & \\
\hline $\begin{array}{l}\text { Porcine herpesvirus } \\
\text { (Aujeszky's disease) }\end{array}$ & Virus & Yes & & Yes & Yes & & \\
\hline $\begin{array}{l}\text { Mycobacterium } \\
\text { paratuberculosis } \\
\text { (Johne's disease) }\end{array}$ & Bacteria & Yes & & Yes & & Yes & 2 \\
\hline $\begin{array}{l}\text { Salmonella gallinarum } \\
\text { (Fowl typhoid) }\end{array}$ & Bacteria & Yes & & Yes & & Yes & 2 \\
\hline
\end{tabular}




\begin{tabular}{|c|c|c|c|c|c|c|c|}
\hline Agent name (or disease) & 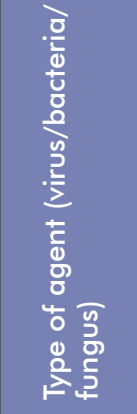 & 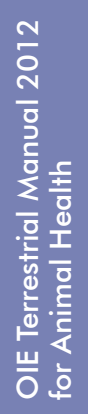 & 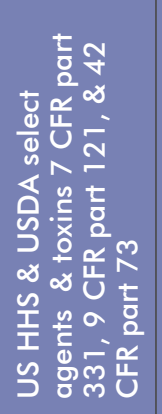 & 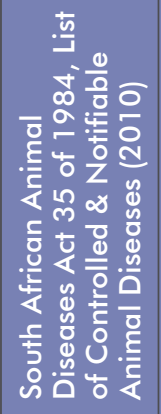 & 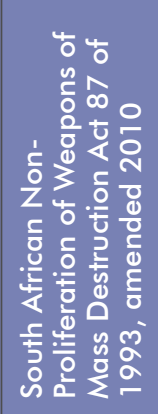 & 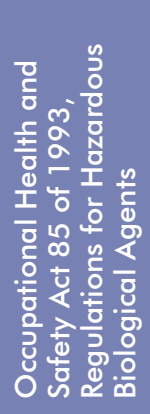 & 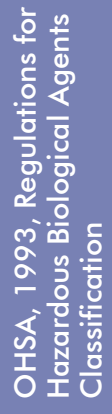 \\
\hline Salmonella pullorum & Bacteria & Yes & & Yes & & Yes & 2 \\
\hline $\begin{array}{l}\text { Trypanosoma brucei } \\
\text { brucei (Nagana) }\end{array}$ & Parasite & Yes & & Yes & & Yes & 2 \\
\hline $\begin{array}{l}\text { Contagious equine } \\
\text { metritis }\end{array}$ & Bacteria & Yes & & Yes & & & \\
\hline Glanders & Bacteria & Yes & & Yes & & & \\
\hline $\begin{array}{l}\text { Haemorrhagic } \\
\text { septicaemia }\end{array}$ & Bacteria & Yes & & Yes & & & \\
\hline Dourine & Parasite & Yes & & Yes & & & \\
\hline $\begin{array}{l}\text { Bovine spongiform } \\
\text { encephalopathy }\end{array}$ & PRION & Yes & & Yes & & & \\
\hline Scrapie & PRION & Yes & & Yes & & & \\
\hline $\begin{array}{l}\text { Equine infectious } \\
\text { anaemia }\end{array}$ & Virus & Yes & & Yes & & & \\
\hline Equine influenza & Virus & Yes & & Yes & & & \\
\hline Equine viral arteritis & Virus & Yes & & Yes & & & \\
\hline $\begin{array}{l}\text { Porcine reproductive } \\
\text { and respiratory } \\
\text { syndrome virus }\end{array}$ & Virus & Yes & & Yes & & & \\
\hline $\begin{array}{l}\text { Porcine enterovirus } \\
\text { type } 1 \text { (Teschen disease) }\end{array}$ & Virus & Yes & & & Yes & & \\
\hline $\begin{array}{l}\text { Vesicular stomatitis virus } \\
\text { (VSV-IN2, VSV-IN3) }\end{array}$ & Virus & Yes & & & Yes & & \\
\hline $\begin{array}{l}\text { Pasteurella multocida } \\
\text { (Fowl cholera) }\end{array}$ & Bacteria & Yes & & & & Yes & 2 \\
\hline $\begin{array}{l}\text { Pasteurella multocidia } \\
\text { (Atrophic rhinitis of } \\
\text { swine) }\end{array}$ & Bacteria & Yes & & & & Yes & 2 \\
\hline Salmonella abortusovis & Bacteria & Yes & & & & Yes & 2 \\
\hline $\begin{array}{l}\text { Bovine babesiosis } \\
\text { (Babesia divergens) }\end{array}$ & Parasite & Yes & & & & Yes & 2 \\
\hline
\end{tabular}




\begin{tabular}{|c|c|c|c|c|c|c|c|}
\hline Agent name (or disease) & 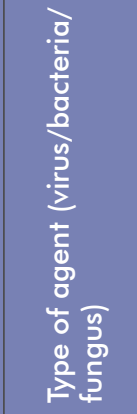 & 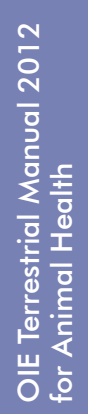 & 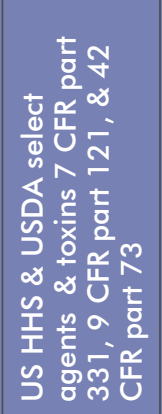 & 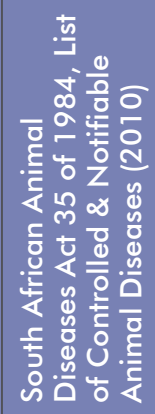 & 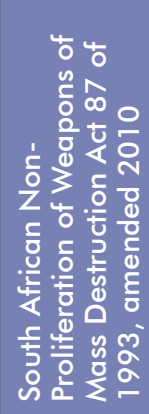 & 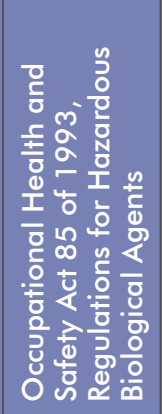 & 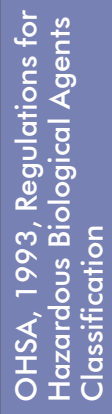 \\
\hline $\begin{array}{l}\text { Ehrlichia ruminantium } \\
\text { (Heartwater) }\end{array}$ & Bacteria & Yes & & & & Yes & 3 \\
\hline West Nile fever & Virus & Yes & & & & Yes & 3 \\
\hline Bovine anaplasmosis & Bacteria & Yes & & & & & \\
\hline $\begin{array}{l}\text { Bovine genital } \\
\text { campylobacteriosis }\end{array}$ & Bacteria & Yes & & & & & \\
\hline $\begin{array}{l}\text { Caprine and ovine } \\
\text { brucellosis (excluding } \\
\text { Brucella ovis) }\end{array}$ & Bacteria & Yes & & & & & \\
\hline Contagious agalactia & Bacteria & Yes & & & & & \\
\hline $\begin{array}{l}\text { Contagious bovine } \\
\text { pleuropneumonia }\end{array}$ & Bacteria & Yes & & & & & \\
\hline $\begin{array}{l}\text { Contagious caprine } \\
\text { pleuropneumonia }\end{array}$ & Bacteria & Yes & & & & & \\
\hline Dermatophilosis & Bacteria & Yes & & & & & \\
\hline $\begin{array}{l}\text { Enzootic abortion } \\
\text { of ewes (Ovine } \\
\text { chlamydiosis) }\end{array}$ & Bacteria & Yes & & & & & \\
\hline $\begin{array}{l}\text { Melissococcus plutonius } \\
\text { (European foulbrood of } \\
\text { honey bees) }\end{array}$ & Bacteria & Yes & & & & & \\
\hline $\begin{array}{l}\text { Mycoplasma } \\
\text { gallisepticum, M. } \\
\text { synoviae (Avian } \\
\text { mycoplasmosis) }\end{array}$ & Bacteria & Yes & & & & & \\
\hline $\begin{array}{l}\text { Ovine epididymitis } \\
\text { (Brucella ovis) }\end{array}$ & Bacteria & Yes & & & & & \\
\hline $\begin{array}{l}\text { Paenibacillus larvae } \\
\text { (American foulbrood of } \\
\text { honey bees) }\end{array}$ & Bacteria & Yes & & & & & \\
\hline Porcine brucellosis & Bacteria & Yes & & & & & \\
\hline Trichomoniasis (animal) & Bacteria & Yes & & & & & \\
\hline
\end{tabular}




\begin{tabular}{|c|c|c|c|c|c|c|c|}
\hline Agent name (or disease) & 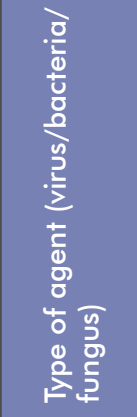 & 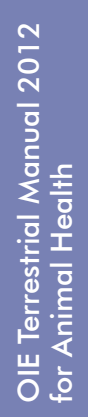 & 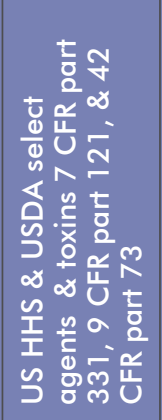 & 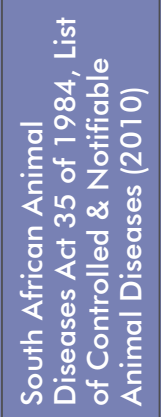 & 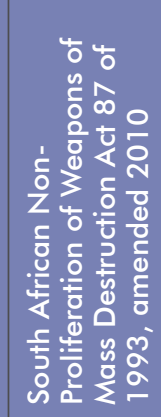 & 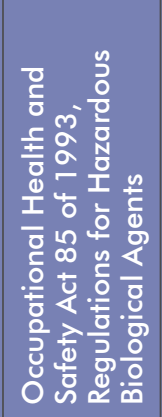 & 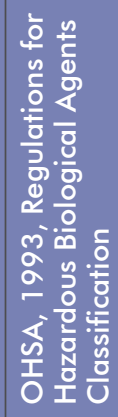 \\
\hline $\begin{array}{l}\text { Chrysomya bezziana } \\
\text { (Old World screwworm) }\end{array}$ & Fly & Yes & & & & & \\
\hline $\begin{array}{l}\text { Cochliomyia } \\
\text { hominivorax (New } \\
\text { World screwworm) }\end{array}$ & Fly & Yes & & & & & \\
\hline Epizootic lymphangitis & Fungi & Yes & & & & & \\
\hline Nosemosis of bees & Fungi & Yes & & & & & \\
\hline $\begin{array}{l}\text { Small hive beetle } \\
\text { infestation }\end{array}$ & Insect & Yes & & & & & \\
\hline $\begin{array}{l}\text { Acarapisosis of honey } \\
\text { bees }\end{array}$ & Mite & Yes & & & & & \\
\hline Horse mange & Mite & Yes & & & & & \\
\hline Mange & Mite & Yes & & & & & \\
\hline $\begin{array}{l}\text { Tropilaelaps infestation } \\
\text { of honey bees }\end{array}$ & Mite & Yes & & & & & \\
\hline Varroosis of honey bees & Mite & Yes & & & & & \\
\hline $\begin{array}{l}\text { Trypanosoma evansi } \\
\text { infections }\end{array}$ & Parasite & Yes & & & & & \\
\hline Equine piroplasmosis & Parasite & Yes & & & & & \\
\hline Theileriosis & Parasite & Yes & & & & & \\
\hline $\begin{array}{l}\text { Birnavirus (Infectious } \\
\text { bursal disease - } \\
\text { Gumboro disease) }\end{array}$ & Virus & Yes & & & & & \\
\hline Border disease & Virus & Yes & & & & & \\
\hline Bovine viral diarrhea & Virus & Yes & & & & & \\
\hline $\begin{array}{l}\text { Bunyaviral disease of } \\
\text { animals (excluding Rift } \\
\text { valley fever) }\end{array}$ & Virus & Yes & & & & & \\
\hline Camelpox & Virus & Yes & & & & & \\
\hline
\end{tabular}




\begin{tabular}{|c|c|c|c|c|c|c|c|}
\hline Agent name (or disease) & 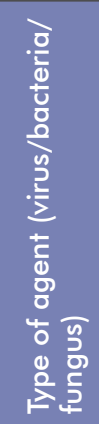 & 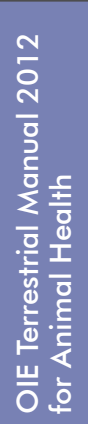 & 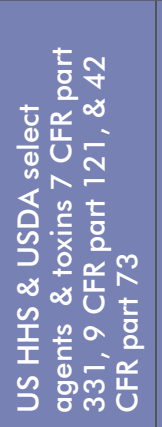 & 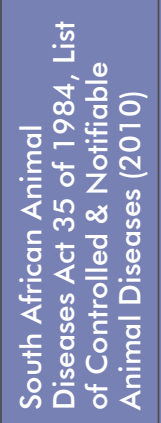 & 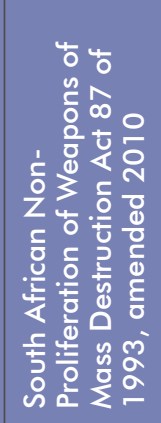 & 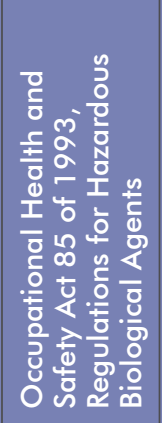 & 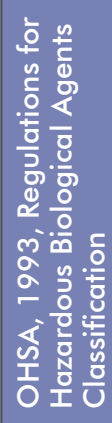 \\
\hline $\begin{array}{l}\text { Caprine arthritis/ } \\
\text { encephalitis and Maedi- } \\
\text { visna }\end{array}$ & Virus & Yes & & & & & \\
\hline Duck virus enteritis & Virus & Yes & & & & & \\
\hline Enzootic bovine leukosis & Virus & Yes & & & & & \\
\hline $\begin{array}{l}\text { Equine } \\
\text { rhinopneumonitis }\end{array}$ & Virus & Yes & & & & & \\
\hline Fowl pox virus & Virus & Yes & & & & & \\
\hline $\begin{array}{l}\text { Infectious bovine } \\
\text { rhinotracheitis/infectious } \\
\text { pustular vulvovaginitis }\end{array}$ & Virus & Yes & & & & & \\
\hline Marek's disease & Virus & Yes & & & & & \\
\hline Menangle virus & Virus & Yes & & & & & \\
\hline Myxomatosis & Virus & Yes & & & & & \\
\hline $\begin{array}{l}\text { Nairobi sheep disease } \\
\text { virus }\end{array}$ & Virus & Yes & & & & & \\
\hline $\begin{array}{l}\text { Ovine pulmonary } \\
\text { adenocarcinoma }\end{array}$ & Virus & Yes & & & & & \\
\hline $\begin{array}{l}\text { Rabbit haemorrhagic } \\
\text { disease }\end{array}$ & Virus & Yes & & & & & \\
\hline Swine influenza & Virus & Yes & & & & & \\
\hline $\begin{array}{l}\text { Transmissible } \\
\text { gastroenteritis }\end{array}$ & Virus & Yes & & & & & \\
\hline $\begin{array}{l}\text { Turkey } \\
\text { rhinotracheitis (avian } \\
\text { metapheumovirus) }\end{array}$ & Virus & Yes & & & & & \\
\hline $\begin{array}{l}\text { Alcelaphine herpesvirus } \\
\text { type } 1 \text { (Malignant } \\
\text { catarrhal fever) }\end{array}$ & Virus & Yes & & & & & \\
\hline $\begin{array}{l}\text { Avian infectious } \\
\text { bronchitis virus }\end{array}$ & Virus & Yes & & & & & \\
\hline
\end{tabular}




\begin{tabular}{|c|c|c|c|c|c|c|c|}
\hline Agent name (or disease) & 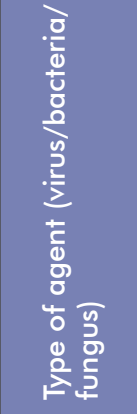 & 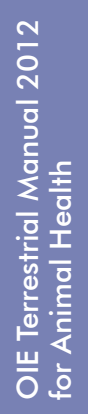 & 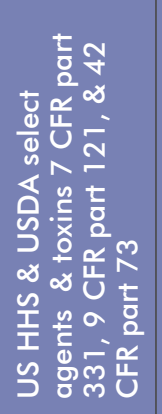 & 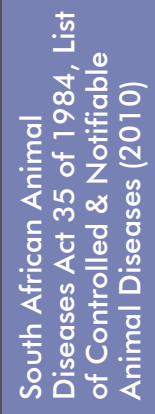 & 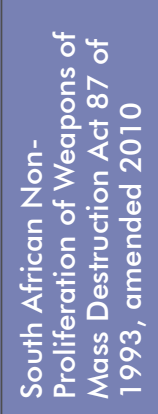 & 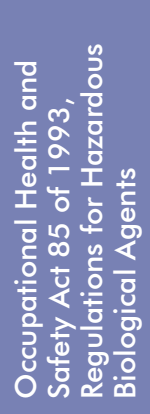 & 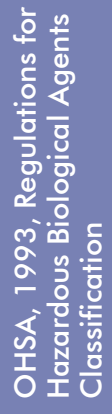 \\
\hline $\begin{array}{l}\text { Avian infectious } \\
\text { laryngotracheitis } \\
\text { herpesvirus }\end{array}$ & Virus & Yes & & & & & \\
\hline $\begin{array}{l}\text { Teschovirus } \\
\text { encephalomyelitis } \\
\text { (previously Enterovirus } \\
\text { encephalomyelitis or } \\
\text { Teschen/Talfan disease) }\end{array}$ & Virus & Yes & & & & & \\
\hline $\begin{array}{l}\text { Zoonoses transmissible } \\
\text { from non-human } \\
\text { primates }\end{array}$ & & Yes & & & & & \\
\hline $\begin{array}{l}\text { Erysipelothrix } \\
\text { rhusiopathiae (Swine } \\
\text { erysipelas) }\end{array}$ & Bacteria & & & Yes & & Yes & 2 \\
\hline $\begin{array}{l}\text { Bacterial kidney disease } \\
\text { (fish) }\end{array}$ & Bacteria & & & Yes & & & \\
\hline $\begin{array}{l}\text { Bovine contagious } \\
\text { pleuropneumonia }\end{array}$ & Bacteria & & & Yes & & & \\
\hline $\begin{array}{l}\text { Contagious } \\
\text { haemopoetic necrosis } \\
\text { (fish) }\end{array}$ & Bacteria & & & Yes & & & \\
\hline $\begin{array}{l}\text { Contagious pancreatic } \\
\text { necrosis (fish) }\end{array}$ & Bacteria & & & Yes & & & \\
\hline $\begin{array}{l}\text { Corridor or buffalo } \\
\text { disease }\end{array}$ & Bacteria & & & Yes & & & \\
\hline Johne's disease & Bacteria & & & Yes & & & \\
\hline Psittacosis & Bacteria & & & Yes & & & \\
\hline $\begin{array}{l}\text { Streptoccocus equi } \\
\text { (Strangels) }\end{array}$ & Bacteria & & & Yes & & & \\
\hline Sheep scab & Mite & & & Yes & & & \\
\hline $\begin{array}{l}\text { Bovine malignant } \\
\text { catarrhal fever }\end{array}$ & Virus & & & Yes & & & \\
\hline
\end{tabular}




\begin{tabular}{|c|c|c|c|c|c|c|c|}
\hline Agent name (or disease) & 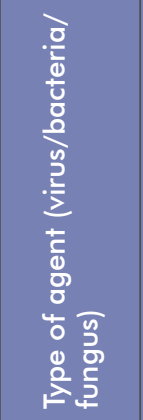 & 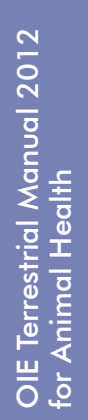 & 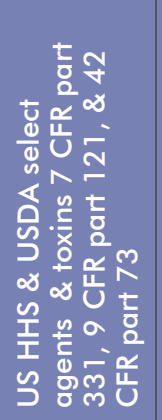 & 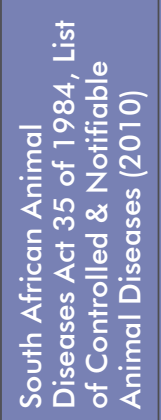 & 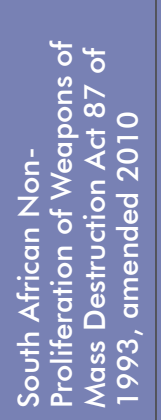 & 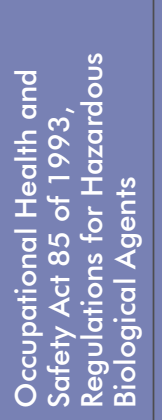 & 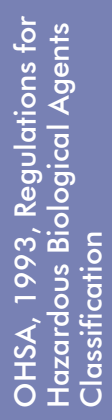 \\
\hline East Coast fever & Virus & & & Yes & & & \\
\hline Skin conditions in sheep & & & & Yes & & & \\
\hline Bordetella broncispetica & Bacteria & & & & & Yes & 2 \\
\hline $\begin{array}{l}\text { Corynebacterium } \\
\text { pseudotuberculosis }\end{array}$ & Bacteria & & & & & Yes & 2 \\
\hline Serpulina spp & Bacteria & & & & & Yes & 2 \\
\hline Ascaris suum & Parasite & & & & & Yes & 2 \\
\hline Trypanosoma rangeli & Parasite & & & & & Yes & 2 \\
\hline Hazara & Virus & & & & & Yes & 2 \\
\hline Middelburg & Virus & & & & & Yes & 2 \\
\hline Ndumu & Virus & & & & & Yes & 2 \\
\hline Yatapox (Tana \& Yaba) & Virus & & & & & Yes & 2 \\
\hline Israel turkey virus & Virus & & & & & Yes & 3 \\
\hline Mokola virus & Virus & & & & & Yes & 3 \\
\hline $\begin{array}{l}\text { Simian } \\
\text { immunodeficiency virus }\end{array}$ & Virus & & & & & Yes & 3 \\
\hline Akabane & Virus & & & & & Yes & 3 \\
\hline Akabane virus & Virus & & & & & Yes & 3 \\
\hline Canine distemper & Virus & & & & & Yes & \\
\hline $\begin{array}{l}\text { Unconventional agents } \\
\text { associated with strains } \\
\text { including whitepox virus }\end{array}$ & Virus & & & & & Yes & \\
\hline
\end{tabular}




\section{Appendix 5: Human and animal infectious agents and the regulations in which they are specifically named highlighted in colour}

\begin{tabular}{|c|c|c|c|c|c|c|c|c|}
\hline $\begin{array}{l}\text { Agent name } \\
\text { (or disease) }\end{array}$ & 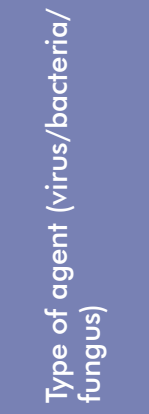 & 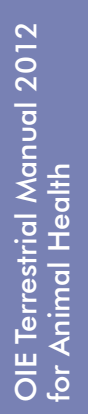 & 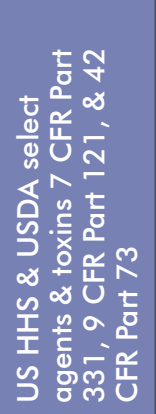 & 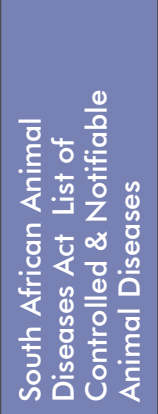 & 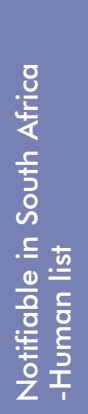 & 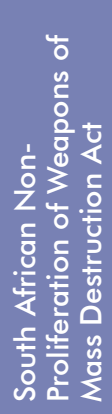 & 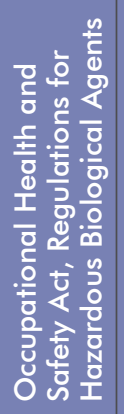 & 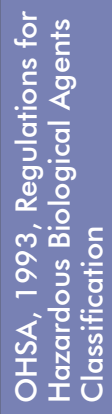 \\
\hline Bacillus anthracis & Bacteria & Yes & Yes & Yes & Yes & Yes & Yes & 3 \\
\hline Brucella abortus & Bacteria & Yes & Yes & Yes & Yes & Yes & Yes & 3 \\
\hline Brucella melitensis & Bacteria & Yes & Yes & Yes & Yes & Yes & Yes & 3 \\
\hline Brucella suis & Bacteria & Yes & Yes & Yes & Yes & Yes & Yes & 3 \\
\hline Rift valley fever & Virus & Yes & Yes & Yes & & Yes & Yes & 3 \\
\hline Newcastle disease & Virus & Yes & Yes & Yes & & Yes & Yes & 2 \\
\hline $\begin{array}{l}\text { Coxiella burnetii } \\
\text { ( } Q \text { fever) }\end{array}$ & Bacteria & Yes & Yes & & Yes & & Yes & 3 \\
\hline $\begin{array}{l}\text { Francisella tularensis } \\
\text { (Tuleremia) }\end{array}$ & Bacteria & Yes & Yes & & & Yes & Yes & 2 \\
\hline $\begin{array}{l}\text { Hendra virus } \\
\text { (Equine } \\
\text { morbillivirus) }\end{array}$ & Virus & Yes & Yes & & & Yes & Yes & 3 \\
\hline $\begin{array}{l}\text { Eastern equine } \\
\text { encephalitis virus }\end{array}$ & Virus & Yes & Yes & & & Yes & & \\
\hline $\begin{array}{l}\text { Nipah virus } \\
\text { encephalitis }\end{array}$ & Virus & Yes & Yes & & & Yes & & \\
\hline $\begin{array}{l}\text { Venezuelan equine } \\
\text { encephalomyelitis }\end{array}$ & Virus & Yes & Yes & & & Yes & & \\
\hline $\begin{array}{l}\text { Bacillus anthracis } \\
\text { (Pasteur strain) }\end{array}$ & Bacteria & Yes & Yes & & & & & \\
\hline $\begin{array}{l}\text { Crimean-Congo } \\
\text { haemorrhagic fever }\end{array}$ & Virus & & Yes & & Yes & Yes & Yes & 4 \\
\hline $\begin{array}{l}\text { Burkholderia mallei } \\
\text { (Pseudomonas } \\
\text { mallei) }\end{array}$ & Bacteria & & Yes & & & Yes & Yes & 3 \\
\hline $\begin{array}{l}\text { Burkholderia } \\
\text { pseudomallei } \\
\text { (Pseudomonas } \\
\text { pseudomallei) }\end{array}$ & Bacteria & & Yes & & & Yes & Yes & 3 \\
\hline
\end{tabular}




\begin{tabular}{|c|c|c|c|c|c|c|c|c|}
\hline $\begin{array}{l}\text { Agent name } \\
\text { (or disease) }\end{array}$ & 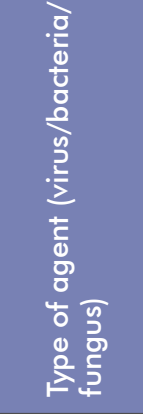 & 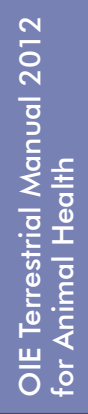 & 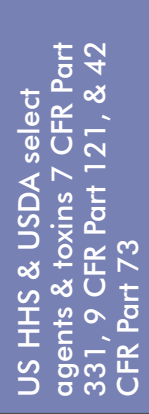 & 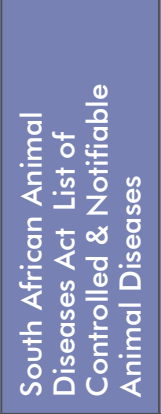 & 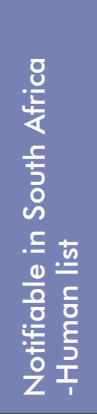 & 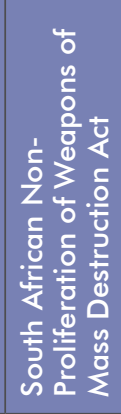 & 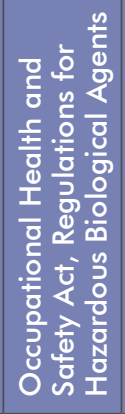 & 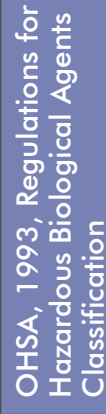 \\
\hline Rabies & Virus & Yes & & Yes & Yes & Yes & Yes & 3 \\
\hline $\begin{array}{l}\text { Salmonella } \\
\text { enteritidis }\end{array}$ & Bacteria & Yes & & Yes & Yes & & Yes & 2 \\
\hline $\begin{array}{l}\text { Japanese } \\
\text { encephalitis }\end{array}$ & Virus & Yes & & & & Yes & & \\
\hline $\begin{array}{l}\text { Western equine } \\
\text { encephalitis virus }\end{array}$ & Virus & Yes & & & & Yes & & \\
\hline Leishmaniosis & Bacteria & Yes & & & & & Yes & 3 \\
\hline $\begin{array}{l}\text { Mycobacterium } \\
\text { avium/intracellulare }\end{array}$ & Bacteria & Yes & & & & & Yes & 3 \\
\hline $\begin{array}{l}\text { Mycobacterium } \\
\text { bovis }\end{array}$ & Bacteria & Yes & & & & & Yes & 3 \\
\hline $\begin{array}{l}\text { Echinococcosis/ } \\
\text { Hydatidosis }\end{array}$ & Parasite & Yes & & & & & Yes & 3 \\
\hline $\begin{array}{l}\text { Leishmania } \\
\text { brasiliensis }\end{array}$ & Parasite & Yes & & & & & Yes & 3 \\
\hline $\begin{array}{l}\text { Leishmania } \\
\text { donovani }\end{array}$ & Parasite & Yes & & & & & Yes & 3 \\
\hline $\begin{array}{l}\text { Taenia solium } \\
\text { (Cystercicosis) }\end{array}$ & Parasite & Yes & & & & & Yes & 3 \\
\hline $\begin{array}{l}\text { Campylobacter } \\
\text { jejuni and C. Coli }\end{array}$ & Bacteria & Yes & & & & & Yes & 2 \\
\hline Leptospirosis & Bacteria & Yes & & & & & Yes & 2 \\
\hline $\begin{array}{l}\text { Listeria } \\
\text { monocytogenes }\end{array}$ & Bacteria & Yes & & & & & Yes & 2 \\
\hline Leishmania major & Parasite & Yes & & & & & Yes & 2 \\
\hline Leishmania tropica & Parasite & Yes & & & & & Yes & 2 \\
\hline $\begin{array}{l}\text { Taenia saginata } \\
\text { (Bovine } \\
\text { cysticercosis) }\end{array}$ & Parasite & Yes & & & & & Yes & 2 \\
\hline $\begin{array}{l}\text { Toxoplasma gondii } \\
\text { (Toxoplasmosis) }\end{array}$ & Parasite & Yes & & & & & Yes & 2 \\
\hline
\end{tabular}




\begin{tabular}{|c|c|c|c|c|c|c|c|c|}
\hline $\begin{array}{l}\text { Agent name } \\
\text { (or disease) }\end{array}$ & 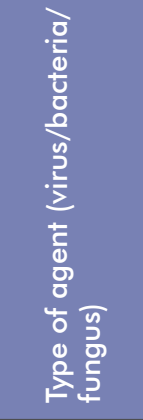 & 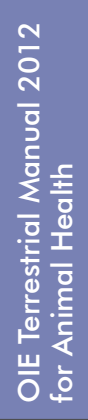 & 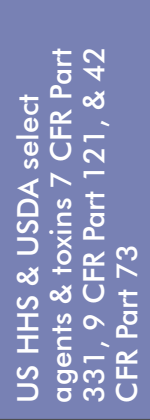 & 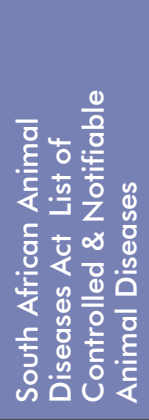 & 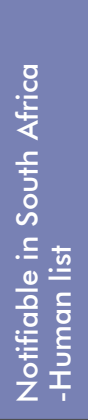 & 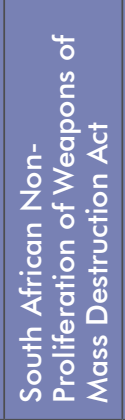 & 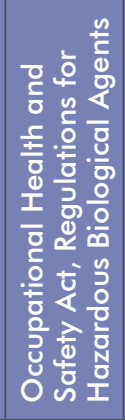 & 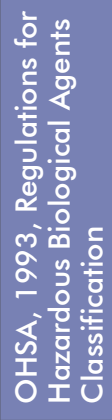 \\
\hline Trichinella nativa & Parasite & Yes & & & & & Yes & 2 \\
\hline Trichinella nelsoni & Parasite & Yes & & & & & Yes & 2 \\
\hline $\begin{array}{l}\text { Trichinella } \\
\text { pseudospiralis }\end{array}$ & Parasite & Yes & & & & & Yes & 2 \\
\hline Trichinella spiralis & Parasite & Yes & & & & & Yes & 2 \\
\hline Cysticercosis & Parasite & Yes & & & & & & \\
\hline Cryptosporidiosis & Parasite & Yes & & & & & & \\
\hline $\begin{array}{l}\text { Salmonella } \\
\text { paratyphi }\end{array}$ & Bacteria & Yes & & & Yes & & & \\
\hline $\begin{array}{l}\text { Chlamydia psittaci } \\
\text { (Avian strains) }\end{array}$ & Bacteria & Yes & & & & Yes & Yes & 3 \\
\hline Lyssaviruses & Virus & & & & & Yes & & \\
\hline Ippy 2 & Virus & & & & & & Yes & 4 \\
\hline $\begin{array}{l}\text { Mycobacterium } \\
\text { microti }\end{array}$ & Bacteria & & & & & & Yes & 3 \\
\hline $\begin{array}{l}\text { Mycobacterium } \\
\text { simiae }\end{array}$ & Bacteria & & & & & & Yes & 3 \\
\hline $\begin{array}{l}\text { Mycobacterium } \\
\text { xenopi }\end{array}$ & Bacteria & & & & & & Yes & 3 \\
\hline Rickettsia spp & Bacteria & & & & & & Yes & 3 \\
\hline $\begin{array}{l}\text { Trypanosoma cruzi } \\
\text { (Chagas disease) }\end{array}$ & Parasite & & & & & & Yes & 3 \\
\hline Bhanja & Virus & & & & & & Yes & 3 \\
\hline Duvenhage & Virus & & & & & & Yes & 3 \\
\hline Germiston & Virus & & & & & & Yes & 3 \\
\hline $\begin{array}{l}\text { Herpesvirus simaie } \\
\text { (B virus) }\end{array}$ & Virus & & & & & & Yes & 3 \\
\hline Lagos bat & Virus & & & & & & Yes & 3 \\
\hline Semliki forest & Virus & & & & & & Yes & 3 \\
\hline
\end{tabular}




\begin{tabular}{|c|c|c|c|c|c|c|c|c|}
\hline $\begin{array}{l}\text { Agent name } \\
\text { (or disease) }\end{array}$ & 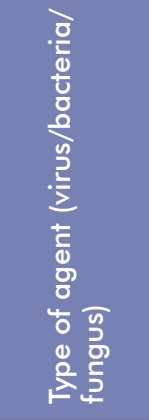 & 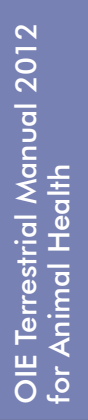 & 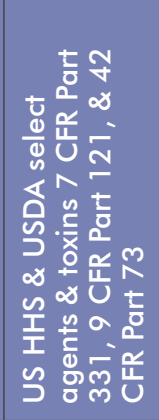 & 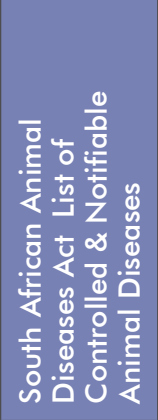 & 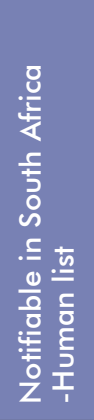 & 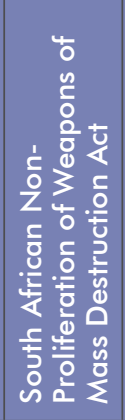 & 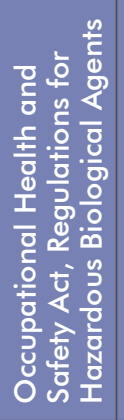 & 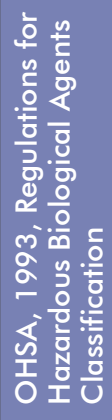 \\
\hline $\begin{array}{l}\text { Unconventional } \\
\text { agents associated } \\
\text { with Creutzfeldt- } \\
\text { Jakob disease }\end{array}$ & Virus & & & & & & Yes & 3 \\
\hline Wesselsbron & Virus & & & & & & Yes & 3 \\
\hline Actinomyces spp & Bacteria & & & & & & Yes & 2 \\
\hline Borellia spp & Bacteria & & & & & & Yes & 2 \\
\hline $\begin{array}{l}\text { Chlamydia psittaci } \\
\text { (Non-avian strains) }\end{array}$ & Bacteria & & & & & & Yes & 2 \\
\hline Porphyromonas spp & Bacteria & & & & & & Yes & 2 \\
\hline Rhodococcus equi & Bacteria & & & & & & Yes & 2 \\
\hline Salmonella arizona & Bacteria & & & & & & Yes & 2 \\
\hline $\begin{array}{l}\text { Angiostrongylus } \\
\text { cantonensis }\end{array}$ & Parasite & & & & & & Yes & 2 \\
\hline $\begin{array}{l}\text { Angiostrongylus } \\
\text { cantonensis }\end{array}$ & Parasite & & & & & & Yes & 2 \\
\hline Babesia microti & Parasite & & & & & & Yes & 2 \\
\hline Cyclospora species & Parasite & & & & & & Yes & 2 \\
\hline $\begin{array}{l}\text { Diphyllobothrium } \\
\text { latum }\end{array}$ & Parasite & & & & & & Yes & 2 \\
\hline $\begin{array}{l}\text { Enterocytozon } \\
\text { bieneusi }\end{array}$ & Parasite & & & & & & Yes & 2 \\
\hline Fasciola gigantica & Parasite & & & & & & Yes & 2 \\
\hline Fasciola hepatica & Parasite & & & & & & Yes & 2 \\
\hline Fasciolopsis buski & Parasite & & & & & & Yes & 2 \\
\hline Giardia lamblia & Parasite & & & & & & Yes & 2 \\
\hline $\begin{array}{l}\text { Hymenolepsis } \\
\text { diminuta }\end{array}$ & Parasite & & & & & & Yes & 2 \\
\hline Hymenolepsis nana & Parasite & & & & & & Yes & 2 \\
\hline Opisthorcis fellineus & Parasite & & & & & & Yes & 2 \\
\hline
\end{tabular}




\begin{tabular}{|c|c|c|c|c|c|c|c|c|}
\hline $\begin{array}{l}\text { Agent name } \\
\text { (or disease) }\end{array}$ & 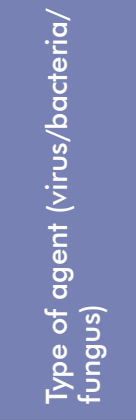 & 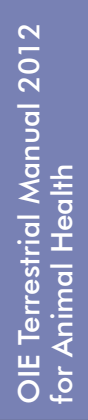 & 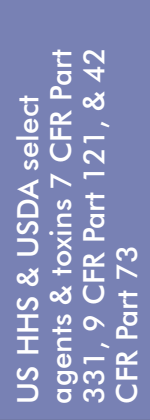 & 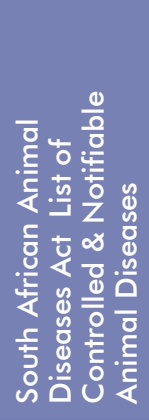 & 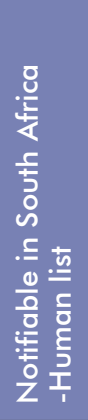 & 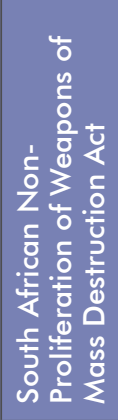 & 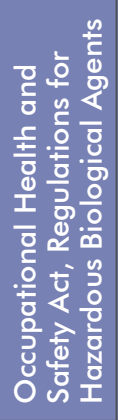 & 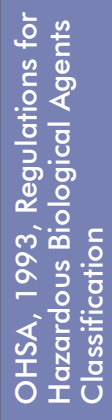 \\
\hline $\begin{array}{l}\text { Opisthorcis sinensis } \\
\text { (Chlonorchis } \\
\text { sinensis) }\end{array}$ & Parasite & & & & & & Yes & 2 \\
\hline $\begin{array}{l}\text { Opisthorcis viverrini } \\
\text { (Chlonorchis } \\
\text { viverrini) }\end{array}$ & Parasite & & & & & & Yes & 2 \\
\hline Opsithorcis spp & Parasite & & & & & & Yes & 2 \\
\hline Paragonimus & Parasite & & & & & & Yes & 2 \\
\hline $\begin{array}{l}\text { Plasmodium spp } \\
\text { (human and simian) }\end{array}$ & Parasite & & & & & & Yes & 2 \\
\hline $\begin{array}{l}\text { Sarcocystis } \\
\text { suihominis }\end{array}$ & Parasite & & & & & & Yes & 2 \\
\hline Toxocara canis & Parasite & & & & & & Yes & 2 \\
\hline Toxocara cati & Parasite & & & & & & Yes & 2 \\
\hline $\begin{array}{l}\text { Trichostrongylus } \\
\text { orientalis }\end{array}$ & Parasite & & & & & & Yes & 2 \\
\hline Trichostrongylus spp & Parasite & & & & & & Yes & 2 \\
\hline $\begin{array}{l}\text { Trypanosoma brucei } \\
\text { gambiense }\end{array}$ & Parasite & & & & & & Yes & 2 \\
\hline $\begin{array}{l}\text { Trypanosoma brucei } \\
\text { rhodesiense }\end{array}$ & Parasite & & & & & & Yes & 2 \\
\hline Buffalopox & Virus & & & & & & Yes & 2 \\
\hline Bunyamwera & Virus & & & & & & Yes & 2 \\
\hline Coltivirus & Virus & & & & & & Yes & 2 \\
\hline Cowpox & Virus & & & & & & Yes & 2 \\
\hline Dhori and Thogoto & Virus & & & & & & Yes & 2 \\
\hline Milker's nodes & Virus & & & & & & Yes & 2 \\
\hline Reoviruses & Virus & & & & & & Yes & 2 \\
\hline Sindbis & Virus & & & & & & Yes & 2 \\
\hline Toroviridae & Virus & & & & & & Yes & 2 \\
\hline
\end{tabular}




\section{Appendix 6: Plant infectious agents and the regulations in which they are specifically named highlighted in colour}

\begin{tabular}{|c|c|c|c|c|c|}
\hline Agent name (or disease) & 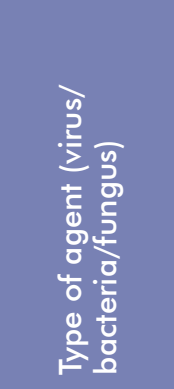 & 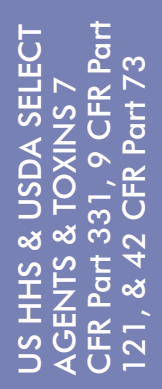 & 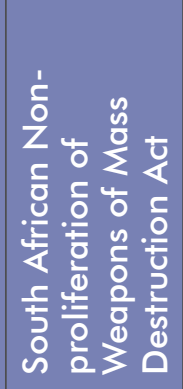 & 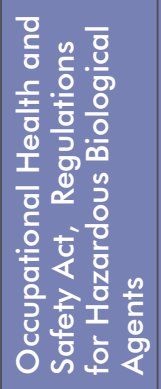 & 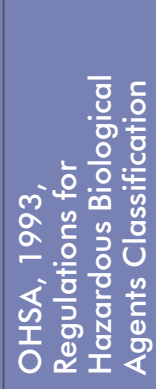 \\
\hline $\begin{array}{l}\text { Ralstonia solanacearum (Race } 3 \text {, } \\
\text { biovar 2) }\end{array}$ & Bacteria & Yes & Yes & & \\
\hline Xanthomonas oryzae & Bacteria & Yes & Yes & & \\
\hline $\begin{array}{l}\text { Peronosclerospora philippinesis } \\
\text { (Peronosclerospora sacchari) }\end{array}$ & Oomycete & Yes & & & \\
\hline Rathayibacter toxicus & Bacteria & Yes & & & \\
\hline $\begin{array}{l}\text { Phoma glycinicola (Pyrenochaeta } \\
\text { glycines) }\end{array}$ & Fungi & Yes & & & \\
\hline Sclerophthora rayssiae var zeae & Fungi & Yes & & & \\
\hline Synchytrium endobioticum & Fungi & Yes & & & \\
\hline Clavibacter michiganensis & Bacteria & & Yes & & \\
\hline Xanthomonas albilineans & Bacteria & & Yes & & \\
\hline Xanthomonas campestris & Bacteria & & Yes & & \\
\hline $\begin{array}{l}\text { Xylella fastidiosa (Citrus } \\
\text { variegated chlorosis strain) }\end{array}$ & Bacteria & & Yes & & \\
\hline Cochliobolus miyabeanus & Fungi & & Yes & & \\
\hline Colletotrichum kahawae & Fungi & & Yes & & \\
\hline Deuterophonas tracheiphila & Fungi & & Yes & & \\
\hline Magnaporthe grisea & Fungi & & Yes & & \\
\hline Microcyclus ulei & Fungi & & Yes & & \\
\hline Monilia rorei & Fungi & & Yes & & \\
\hline Puccinia graminis & Fungi & & Yes & & \\
\hline Puccinia striiformis & Fungi & & Yes & & \\
\hline Banana bunchy top virus & Virus & & Yes & & \\
\hline Potato andean latent tymovirus & Virus & & Yes & & \\
\hline Potato spindle tuber viroid & Virus & & Yes & & \\
\hline
\end{tabular}




\section{Appendix 7: Life sciences mapping information sheet}

The Academy of Science of South Africa (ASSAf) invites you to take part in a mapping study on life science research and diagnostic facilities in South Africa which will assess the distribution, types and research focus of laboratories within the country. This mapping study is voluntary; however you are strongly encouraged to participate as the information you provide will significantly contribute towards understanding the distribution of life science research in South Africa.

In order to build a clear understanding of laboratory-based life science research in South Africa we request that you fill in this survey on behalf of your diagnostic facility or research department. The study consists of 10 questions and will take no more than 5 minutes to complete. The results of the survey will form a database which will be stored at the Academy of Science of South Africa. The results will be securely held, and will not be distributed to any third party for commercial gain.

This database resulting from this survey will be used for a subsequent survey which will assessing the extent to which systems are in place in to ensure high-quality, safe, secure and responsible life science research and assess the penetrance of biosafety, biosecurity and bioethics knowledge amongst the scientific community. Participants for this later survey will be identified from the database, although participation in each survey is independent and voluntary.

\section{Researchers:}

If you have any questions or queries about taking part you can contact the principle researchers: Prof Jill Farrant and Dr Chandre Gould.

\section{Contact addresses:}

Prof Jill Farrant

Department of Molecular and Cell Biology

University of Cape Town

Private Bag X3, Rondebosch, 7701

Email: jill.farrant@uct.ac.za

\author{
Dr Chandre Gould \\ Institute for Security Studies \\ PO Box 192 \\ Hoekwil, 6538 \\ Email:cgould@issafrica.org
}

This research is being undertaken by the ASSAf.

\section{Contact address:}

The Academy of Science of South Africa

$1^{\text {st }}$ Floor Block A, The Woods, 41 de Havilland Crescent, Persequor Park,

Meiring Naude Road, Lynnwood, Pretoria, 0020

DrLouise Bezuidenhout_E-mail: Loviseb@assaf.org.za

Thank you for taking the time to contribute to this research. 


\section{Appendix 8: Participation information sheet for qualitative interviews}

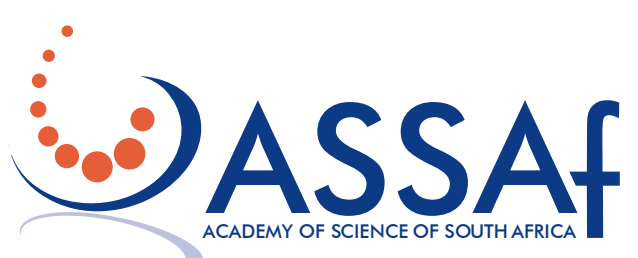

Applying scientific thinking

in the service of society

\section{Participant Information Sheet}

You are invited to take part in a study on responsible life science research. This study examines biosafety, biosecurity and bioethics provisions within South African laboratories and the strengths and weaknesses of current national policies that guide this risk management.

This interview will focus on your experience of current biosafety and biosecurity management policies in South Africa, and your perceptions of the strengths and weaknesses of the current regulatory system. This is a voluntary interview and the information you provide will be treated as confidential.

If you agree to participate the interview will last approximately 15 minutes.

\section{Purpose of the study}

This project seeks to:

- Contribute to knowledge about laboratory research and diagnostic capacity in South Africa;

- Contribute to assessing the extent to which systems are in place to ensure highquality, safe, secure and responsible life science research; and

- Identify the needs and capacities of laboratories and to assist laboratories to develop appropriate system to access the services and expertise that exists at national and international levels.

\section{Voluntary participation}

Participation in this interview is entirely voluntary and you are entitled to terminate the interview at any time. You are free to withdraw from the interview process at any time, and this action will not have any effect on your current or future employment. As a voluntary process, participants will not be remunerated for their involvement. 


\section{Data Management and Confidentiality}

The interview may be digitally recorded and your consent for this process is required on the attached consent sheet. If for any reason you would prefer not to be recorded please let the researcher know prior to the commencement of the interview.

The information you provide to us will be treated as strictly confidential. You will not be identified in any of the transcripts or publications unless you agree to being quoted. Your data will be stored on the password protected Academy of Science of South Africa server and will be destroyed at the end of the project. Access to the data will be limited to the researchers involved in the project.

\section{Researchers}

If you have any questions or queries about taking part you can contact the principal researchers: Prof Jill Farrant and Dr Chandre Gould, or the contracted researcher Dr Nandi Siegfried.

\section{Contact:}

Prof Jill Farrant

jill.farrant@uct.ac.za

Dr Chandre Gould cgould@issafrica.org

Dr Nandi Siegfried Nandi.Siegfried@gmail.com 


\section{Appendix 9: Question guide for semi-structured interviews regarding responsiveness to infectious disease outbreaks in South Africa}

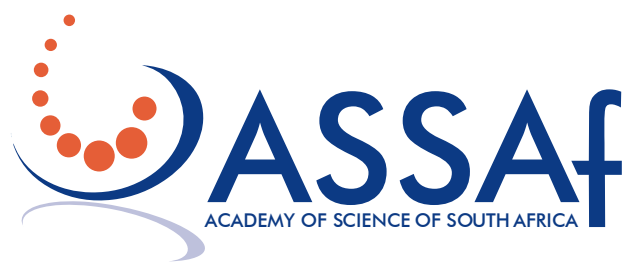

Applying scientific thinking

in the service of society

\section{Interview Schedule}

These questions serve to guide the interview. Should the interviewee raise other concerns these will be addressed if relevant to the topic. The interview will be tailored to the experience and knowledge of the interviewee.

1. Please describe your work to me as it relates to detection, identification, response and/or recording of infectious disease outbreaks.

2. Please explain your involvement nationally or internationally, with regard to developing or contributing to policies and procedures for the detection, identification, response and/or recording of infectious disease outbreaks?

3. Could you talk about the policies and regulations for the detection, identification, response and/or recording of infectious disease outbreaks in SA?

4. Strengths and weaknesses in current implementation strategies

- From your experience, what is currently done well when it comes to implementation of strategies to manage disease outbreaks at a national level?

- Are there any problems with implementing the strategies nationally?

- What do you think could be done to improve the implementation of national strategies to manage disease outbreaks?

5. From your experience, do you have any comments on:

- Cross-sectoral co-operation with respect to implementation of policies and strategies?

- Overall co-ordination nationally and provincially?

- Are there opportunities for information-sharing between sectors?

- If not, what are the obstacles to sharing information?

6. Areas for future development

- What do you think should be done in the future to better manage disease outbreaks nationally?

7. Do you wish to raise any other issues related to this topic? 


\section{Appendix 10: Informed consent form for qualitative interviews}

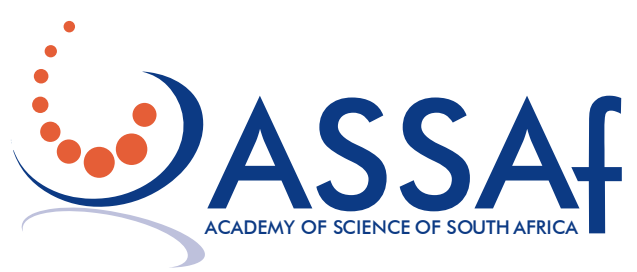

Applying scientific thinking

in the service of society

\section{Life Science Research and Diagnostic Laboratories in South Africa}

\section{Consent form for interviewees}

Please tick the boxes, fill in the lines below and sign the form. Thank you for your help. Please note that this consent form is accompanied by an information sheet detailing the nature of this project.

[ ] I confirm that I have read and understood the information sheet for the above study and have had the opportunity to ask questions about participating in the research.

[ ] My questions concerning participation in this study have been answered by the Academy of Science of South Africa researcher to my satisfaction.

[ ] I understand that my participation is voluntary and that I am free to withdraw at any time, without giving any reason.

[ ] I agree to take part in the research and to the use of my data for the purposes of the study specified in the information sheet.

[ ] I agree to any interviews being recorded and understand that the data will be kept securely and will remain confidential except in the case of legal subpoena.

[ ] Should any quotes be used, I will not be identified in any subsequent transcription or publication unless I indicate otherwise.

Name of Interviewee:

Organisation:

Contact Email:

Date:

Signature: 


\section{Appendix 11: Information sheet and questionnaire for mapping life science facilities}

\section{QUESTIONNAIRE}

\section{Responsible life sciences research for global health security}

You are invited to take part in a study on responsible life science research. Answering this questionnaire will contribute to assessing the capacity of life science research, diagnostic and manufacturing facilities in South Africa. This is a voluntary survey and the information you provide will be treated as confidential. If you agree to answer this questionnaire, it will take you between 10 to 20 minutes to complete.

By completing the questionnaire you will be contributing to research that aims at assessing diagnostic, research and manufacturing capacities in South Africa. You will be contributing to the identification and promotion of best practices for responsible life science research.

When you have completed this survey please return it to louiseb@assaf.org.za.

\section{Purpose}

This project seeks to:

- Contribute to knowledge about life science research, diagnostic and manufacturing capacity in South Africa; and

- Contribute to assessing the extent to which systems are in place in to ensure highquality, safe, secure and responsible life science research.

\section{Voluntary responses}

This is a voluntary survey so you do not have to take in part, but if you do it will be of great help to us. We are interested in your opinion so there are no "wrong" or "right" answers. The questionnaire should take about 10 to 20 minutes to complete. If you do not have the answer to all the questions, you can simply put a cross next to the "don't know" box. Please note that you will not be paid for your participation in this study. No known disadvantages or risk are associated with taking part in this research.

\section{Confidentiality}

The information you provide to us will be treated as strictly confidential. You do not need to put your name on the questionnaire. We do ask that you tell us your position in the facility so that we are able to distinguish between the answers given by managers, junior staff, senior staff and technical staff. This is important in order for us to understand the perspective of each level of employee. This information should not identify you. If you do provide any information which might identify you, it will be kept securely and separately by the researchers. Moreover, the research findings will 
be reported in an aggregate manner and in such a way that the specific results of the survey for each laboratory will not be linked to the laboratory or facility by name.

Your completed questionnaire will be handed to the researchers who will capture the data on a computer. Your answers will be kept confidential by the researchers and will only be reported as part of an overall report to the facility.

\section{Results of the study}

The results of the survey for each laboratory will be made available to all staff in the institution and will be discussed with the managers of the facility. At the end of the research project the overall research results will be published in a report. The results will be presented at meetings to discuss and promote best practices on responsible life sciences research. You will not be identifiable from any report or publication.

\section{Researchers}

If you have any questions or queries about taking part you can contact the principle researchers:

Prof Jill Farrant and Dr Chandre Gould.

\section{Contact address:}

Prof Jill Farrant

Department of Molecular and Cell Biology

University of Cape Town

Email: jill.farrant@uct.ac.za
Dr Chandre Gould

Institute for Security Studies

Email:cgould@issafrica.org

This research is being undertaken by the Academy of Science of South Africa (ASSAf).

\section{Contact address:}

ASSAf

c/o Dr Louise Bezuidenhout

$1^{\text {st }}$ Floor Block A, The Woods, 41 de Havilland Crescent,

Persequor Park, Meiring Naude Road, Lynnwood, Pretoria, 0020

Email: loviseb@assaf.org.za 
Preliminary data - please complete the following:

\begin{tabular}{|c|c|}
\hline i. Province in which you work & $\begin{array}{l}\text { 1. Eastern Cape [ ] } \\
\text { 2. Free State [ ] } \\
\text { 3. Gauteng [ ] } \\
\text { 4. KwaZulu-Natal [ ] } \\
\text { 5. Limpopo [ ] } \\
\text { 6. Mpumalanga [ ] } \\
\text { 7. Northern Cape [ ] } \\
\text { 8. North-West [ ] } \\
\text { 9. Western Cape [ ] }\end{array}$ \\
\hline $\begin{array}{l}\text { ii. Type of life science activities you are } \\
\text { engaged in }\end{array}$ & $\begin{array}{l}\text { 1. Publically-funded research [ ] } \\
\text { 2. Publically-funded diagnostics [ ] } \\
\text { 3. Commercial research [ ] } \\
\text { 4. Commercial diagnostics [ ] } \\
\text { 5. Other (therapeutics, forensics etc.) [ ] } \\
\text { Please specify: }\end{array}$ \\
\hline ii. Your position within the institution & $\begin{array}{l}\text { 1. Senior researcher [ ] } \\
\text { 2. Junior researcher (less than } 5 \text { years' } \\
\text { work experience) [ ] } \\
\text { 3. Senior technicians [ ] } \\
\text { 4. Junior technician (less than } 5 \text { years' } \\
\text { work experience) [ ] } \\
\text { 5. Support staff [ ] } \\
\text { 6. Postgraduate student [ ] } \\
\text { 7. NHLS Laboratory manager [ ] } \\
\text { 8. NHLS technologist [ ] } \\
\text { 9. NHLS technician [ ] }\end{array}$ \\
\hline ii. Gender & $\begin{array}{l}\text { 1. Male [ ] } \\
\text { 2. Female [ ] } \\
\text { 3. Undisclosed [ ] }\end{array}$ \\
\hline iii. Main focus of your work & $\begin{array}{l}\text { 1. Plant [ ] } \\
\text { 2. Animal [ ] } \\
\text { 3. Human [ ] }\end{array}$ \\
\hline
\end{tabular}


Your responses to the following survey questions should reflect your perceptions of your current work environment and your activities as a life scientist. Please put a cross in the box next to the answer that you choose. Where answer boxes are marked with PTO, please turn over the page for more options.

\section{PILLAR 1: RESEARCH EXCELLENCE}

1.1 Scientific collaboration is encouraged within your department
1. Always
2. Often
3. Sometimes
4. Rarely
5. Never
6. Not applicable
7. Don't know

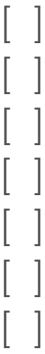

1.2 Scientific collaboration is encouraged within your institution
1. Always
2. Often
3. Sometimes
4. Rarely
5. Never
6. Not applicable
7. Don't know

1.3 Scientific collaboration between your institution and other institutions is facilitated 1. Always

2. Often

3. Sometimes

4. Rarely

5. Never

6. Not applicable

7. Don't know

1.4 Your institution makes efforts to make any funding it receives transparent

1. Strongly agree

2. Agree

3. Disagree

4. Strongly disagree

5. Not applicable

6. Don't know 
1.5 Accountability is required (e.g. through regular reporting of financial expenditure as well as scientific progress)
1. Strongly agree
2. Agree
3. Disagree
4. Strongly disagree
5. Not applicable
6. Don't know

1.6 Your institution clearly states its research priorities

1. Strongly agree

2. Agree

3. Disagree

4. Strongly disagree

5. Not applicable

6. Don't know

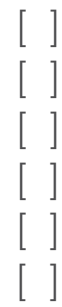

1.7 Research findings are routinely published

1. Strongly agree

2. Agree

3. Disagree

4. Strongly disagree

5. Not applicable

6. Don't know

[ ]
[ ]
[ ]
[ ]
[ ]
[ ]

1.8 Good communication exists between policymakers at your facility and the life science community

1. Strongly agree

2. Agree

3. Disagree

4. Strongly disagree

5. Not applicable

6. Don't know

1.9 Good communication exists between policymakers at a national level and the life science community

1. Strongly agree

2. Agree

3. Disagree

4. Strongly disagree 

5. Not applicable
6. Don't know

1.10 On-going formal and/or informal research training takes place (that is not for postgraduate degree purposes)
1. Always
2. Often
3. Sometimes
4. Rarely
5. Never
6. Not applicable
7. Don't know

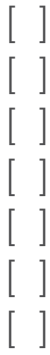

1.11 Junior researchers and/or staff are nurtured and supported

1. Always

2. Often

3. Sometimes

4. Rarely

5. Never

6. Not applicable

7. Don't know

[ ]

[ ]

[ ]

[ ]

[ ]

[ ]

[ ]

1.12 Staff conducting research have been properly trained

1. Strongly agree

2. Agree

3. Disagree

4. Strongly disagree

5. Not applicable

6. Don't know

1.13 Quality control is conducted within the institution for relevant diagnostic tests or experiments to avoid false positives or negative results

1. Always

2. Often

3. Sometimes

4. Rarely

5. Never

6. Not applicable

7. Don't know 
1.14 Quality control is conducted between institutions for relevant diagnostic tests or experiments to avoid false positives or negative results
1. Always
2. Often
3. Sometimes
4. Rarely
5. Never
6. Not applicable
7. Don't know

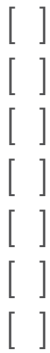

1.15 Samples and reagents are checked to ensure that they match accompanying documentation
1. Always
2. Often
3. Sometimes
4. Rarely
5. Never
6. Not applicable
7. Don't know

1.16 Measures are in place to double check results before they are given to patients/ clinicians (for diagnostic laboratories) or published (for research laboratories) 1. Strongly agree

2. Agree

3. Disagree

4. Strongly disagree

5. Not applicable

6. Don't know

1.17 Education and/or training is offered on dual-use issues. This refers to the potential for data that was generated for beneficial purposes to be misused for malicious purposes by a third party.

1. Strongly agree

2. Agree

3. Disagree

4. Strongly disagree

5. Not applicable

6. Don't know 
1.18 Skilled staff are valued and retained
1. Always
2. Often
3. Sometimes
4. Rarely
5. Never
6. Not applicable
7. Don't know

1.19 National legislation and policy fosters scientific development and freedom

1. Strongly agree

2. Agree

3. Disagree

4. Strongly disagree

5. Not applicable

6. Don't know

[ ]
[ ]
[ ]
[ ]
[ ]
[ ]

\section{PILLAR 2: ETHICS}

2.1 Education and/or training is offered on research ethics including issues such as scientific misconduct (falsification, fabrication and plagiarism)

1. Always

2. Often

3. Sometimes

4. Rarely

5. Never

6. Not applicable

7. Don't know

2.2 Appropriate ethical research guidelines and practices have been published

1. Strongly agree

2. Agree

3. Disagree

4. Strongly disagree

5. Not applicable

6. Don't know

2.3 Appropriate ethical research guidelines and practices are implemented

1. Always

2. Often

3. Sometimes

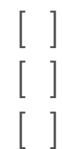



4. Rarely
5. Never
6. Not applicable
7. Don't know

2.4 Adequate mechanisms exist for investigating and responding to non-adherence to ethical standards

1. Strongly agree

2. Agree

3. Disagree

4. Strongly disagree

5. Not applicable

6. Don't know

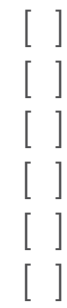

2.5 Measures are in place to prevent non-laboratory individuals from obtaining access to samples or biological materials

1. Strongly agree

2. Agree

3. Disagree

4. Strongly disagree

5. Not applicable

6. Don't know

2.6 Measures are in place to prevent non-laboratory individuals from providing confidential information to people outside the laboratory

1. Strongly agree [ ]

2. Agree

3. Disagree

4. Strongly disagree

5. Not applicable

6. Don't know

2.7 Discussions in the facility focus on the broader implications of your life science activities for society in general
1. Always
2. Often
3. Sometimes
4. Rarely
5. Never
6. Not applicable
7. Don't know 
2.8 Researchers are competent to assess the potential broader implications of their life science activities for society in general

1. Strongly agree

2. Agree

3. Disagree

4. Strongly disagree

5. Not applicable

6. Don't know

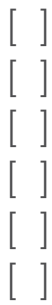

2.9 Research is subject to a risk assessment that includes considerations of the broader implications of their life science activities for the environment
1. Always
2. Often
3. Sometimes
4. Rarely
5. Never
6. Not applicable
7. Don't know

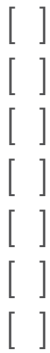

2.10 Researchers are competent to make the assessment of the broader implications of their life science activities for the environment

1. Strongly agree

2. Agree

3. Disagree

4. Strongly disagree

5. Not applicable

6. Don't know

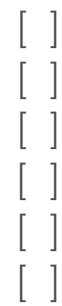

2.11 Potential for misuse of the research is considered at all stages of research/ diagnostic processes and appropriate action taken if necessary

1. Strongly agree

2. Agree

3. Disagree

4. Strongly disagree

5. Not applicable

[ ]

6. Don't know

2.12 Researchers know how to assess whether the risk outweighs the benefit of continuing with their research activities

1. Strongly agree

2. Agree 

3. Disagree
4. Strongly disagree
5. Not applicable
6. Don't know

2.13 A code of conduct/practice for life scientists exists at an institutional level

1. Strongly agree

2. Agree

3. Disagree

4. Strongly disagree

5. Not applicable

6. Don't know 

3. Sometimes
4. Rarely
5. Never
6. Not applicable
7. Don't know

2.18 A review process exists to assess ethical issues raised by research proposals not involving human or animal subjects

1. Strongly agree [ ]

2. Agree

3. Disagree

4. Strongly disagree

5. Not applicable

6. Don't know

2.19 Information about the national and international conventions and regulations related to all fields of science is easily accessible

1. Strongly agree

2. Agree

3. Disagree

4. Strongly disagree

5. Not applicable

6. Don't know [ ]

2.20 National legislation and policy relevant to the life sciences provides protection against the misuse of science

1. Strongly agree

2. Agree

3. Disagree

4. Strongly disagree

$[$ ]

5. Not applicable

6. Don't know 

5. Not applicable
6. Don't know

3.2 Training of staff is appropriate to the facilities and equipment and the work being conducted

1. Strongly agree

2. Agree

3. Disagree

4. Strongly disagree

5. Not applicable

6. Don't know

3.3 Researchers have somewhere to turn to get competent advice if they have safety or security questions relating to their research

1. Strongly agree [ ]

2. Agree

3. Disagree

4. Strongly disagree

5. Not applicable

6. Don't know

3.4 National legislation/regulation exists that sets safety and security practices and procedures for laboratories

1. Strongly agree

2. Agree

3. Disagree

4. Strongly disagree

5. Not applicable

6. Don't know

[ ]
[ ]
[ ]
[ ]
[ ]
[ ]

3.5 An assessment of the biosafety and biosecurity risk associated with research activities is conducted

1. Always

2. Often

3. Sometimes

4. Rarely

5. Never

6. Not applicable

7. Don't know 
3.6 Risk assessments are able to identify requirements for risk reduction measures including the level of containment required
1. Strongly agree
2. Agree
3. Disagree
4. Strongly disagree
5. Not applicable
6. Don't know

3.7 Biosafety training is provided to all those working in laboratories when appropriate
1. Strongly agree
2. Agree
3. Disagree
4. Strongly disagree
5. Not applicable
6. Don't know

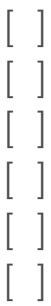

3.8 Biosecurity training is provided to all those working in laboratories when appropriate
1. Strongly agree
2. Agree
3. Disagree
4. Strongly disagree
5. Not applicable
6. Don't know

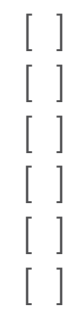

3.9 Biosafety training includes a test of competence
1. Always
2. Often
3. Sometimes
4. Rarely
5. Never
6. Not applicable
7. Don't know

3.10 Biosecurity training includes a test of competence
1. Always
2. Often
3. Sometimes
4. Rarely 

5. Never
6. Not applicable
[ ]
7. Don't know

3.11 Standard Operating Procedures have been developed (in your facility)

1. Strongly agree

2. Agree

3. Disagree

4. Strongly disagree

5. Not applicable

6. Don't know

3.12 Staff are trained to work according to the Standard Operating Procedures

1. Strongly agree

2. Agree

3. Disagree

4. Strongly disagree

5. Not applicable

6. Don't know

3.13 Staff are regularly tested to ensure competence in the Standard Operating Procedures

1. Strongly agree

2. Agree

3. Disagree

4. Strongly disagree

5. Not applicable

6. Don't know

3.14 Legislation/regulations exist to address hazardous waste disposal

1. Strongly agree

2. Agree

3. Disagree

4. Strongly disagree

5. Not applicable

6. Don't know 

4. Rarely
5. Never
6. Not applicable
7. Don't know

3.16 Occupational health surveillance mechanisms exist and are followed (at institutional level)

1. Strongly agree

2. Agree

3. Disagree

4. Strongly disagree

5. Not applicable

6. Don't know

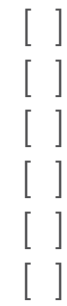

3.17 Occupational health reporting mechanisms effective at institutional level 1. Always

2. Often

3. Sometimes

4. Rarely

5. Never

6. Not applicable

7. Don't know

3.18 Staff are required to report laboratory accidents, and incidents

1. Strongly agree

2. Agree

3. Disagree

4. Strongly disagree

5. Not applicable

6. Don't know

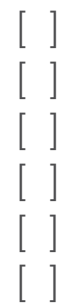

3.19 A record of research projects exists and is maintained at institutional level

1. Strongly agree

2. Agree

3. Disagree

4. Strongly disagree

5. Not applicable

6. Don't know 
3.17 A record of hazardous biological materials exists and is maintained at institutional level
1. Strongly agree
2. Agree
3. Disagree
4. Strongly disagree
5. Not applicable
6. Don't know

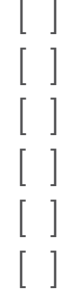

3.18 Hazardous biological material is safely and securely stored
1. Always
2. Often
3. Sometimes
4. Rarely
5. Never
6. Not applicable
7. Don't know

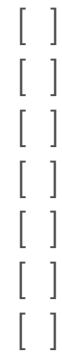

3.19 Mechanisms exist for staff to report unlawful or irregular conduct (i.e. whistleblowing mechanisms exist)

1. Strongly agree

2. Agree

3. Disagree

4. Strongly disagree

5. Not applicable

6. Don't know

3.20 Measures exist to protect staff who report unlawful or irregular conduct from occupational detriment

1. Strongly agree

2. Agree

3. Disagree

4. Strongly disagree

5. Not applicable

6. Don't know 


\section{Appendix 12: Data tables of responses to survey questions}

All figures are percentages of total (n).

\section{Research Excellence}

1. Scientific collaboration is encouraged within your department

\begin{tabular}{|l|c|c|c|c|c|}
\hline & $\begin{array}{c}\text { Always and } \\
\text { offen }\end{array}$ & Sometimes & $\begin{array}{c}\text { Rarely and } \\
\text { never }\end{array}$ & N/A & Don't know \\
\hline All responses $(n=350)$ & 74.57 & 14.86 & 8.57 & 1.14 & 0.86 \\
\hline Senior staff $(n=213)$ & 73.71 & 16.43 & 7.98 & 0.47 & 1.41 \\
\hline Junior staff $(n=135)$ & 75.56 & 12.59 & 9.63 & 1.48 & 0.74 \\
\hline Technical staff $(n=64)$ & 65.63 & 21.88 & 6.25 & 3.13 & 3.13 \\
\hline \multicolumn{7}{|l|}{ Research staff $(n=284)$} & 76.41 & 13.38 & 9.15 & 0.35 & 0.70 \\
\hline \multicolumn{7}{|l|}{ 2. Scientific collaboration is encouraged within your institution } \\
\hline
\end{tabular}

\begin{tabular}{|l|c|c|c|c|c|}
\hline & $\begin{array}{c}\text { Always and } \\
\text { often }\end{array}$ & Sometimes & $\begin{array}{c}\text { Rarely and } \\
\text { never }\end{array}$ & N/A & Don't know \\
\hline All responses $(n=348)$ & 72.99 & 17.53 & 8.05 & 0.29 & 1.15 \\
\hline Senior staff $(n=213)$ & 73.71 & 18.31 & 6.57 & 0.47 & 0.94 \\
\hline Junior staff $(n=133)$ & 71.43 & 16.54 & 10.53 & 0.00 & 1.50 \\
\hline Technical staff $(n=64)$ & 76.56 & 14.06 & 7.81 & 0.00 & 1.56 \\
\hline Research staff $(n=282)$ & 71.99 & 18.44 & 8.16 & 0.35 & 1.06 \\
\hline
\end{tabular}

3. Scientific collaboration between your institution and other institutions is facilitated

\begin{tabular}{|l|c|c|c|c|c|}
\hline & $\begin{array}{c}\text { Always and } \\
\text { often }\end{array}$ & Sometimes & $\begin{array}{c}\text { Rarely and } \\
\text { never }\end{array}$ & N/A & Don't know \\
\hline All responses $(n=348)$ & 54.31 & 27.87 & 12.93 & 0.86 & 4.02 \\
\hline Senior staff $(n=207)$ & 53.62 & 32.37 & 8.21 & 0.48 & 5.31 \\
\hline Junior staff $(n=122)$ & 63.93 & 22.95 & 11.48 & 0.00 & 1.64 \\
\hline Technical staff $(\mathbf{n}=\mathbf{6 4})$ & 56.25 & 25.00 & 9.38 & 1.56 & 7.81 \\
\hline Research staff $(\mathbf{n}=\mathbf{2 8 2})$ & 54.26 & 28.01 & 13.83 & 0.71 & 3.19 \\
\hline
\end{tabular}

4. Your institution makes efforts to make any funding it receives transparent

\begin{tabular}{|l|c|c|c|c|}
\hline & $\begin{array}{c}\text { Strongly } \\
\text { agree and } \\
\text { agree }\end{array}$ & $\begin{array}{c}\text { Disagree } \\
\text { and } \\
\text { strongly } \\
\text { disagree }\end{array}$ & N/A & Don't know \\
\hline All responses $(\mathbf{n}=\mathbf{3 5 0})$ & 57.71 & 24.86 & 4.00 & 13.43 \\
\hline Senior staff $(\mathbf{n}=\mathbf{2 1 3})$ & 58.22 & 24.41 & 5.63 & 11.74 \\
\hline Junior staff $(\mathbf{n}=135)$ & 56.30 & 25.93 & 1.48 & 16.30 \\
\hline Technical staff $(\mathbf{n}=\mathbf{6 4})$ & 51.56 & 20.31 & 9.38 & 18.75 \\
\hline Research staff $(\mathbf{n}=\mathbf{2 8 4})$ & 58.80 & 26.06 & 2.82 & 12.32 \\
\hline
\end{tabular}




\section{Research Excellence}

5. Accountability is required (e.g. through regular reporting of financial expenditure as well as scientific progress)

\begin{tabular}{|c|c|c|c|c|}
\hline & $\begin{array}{l}\text { Strongly } \\
\text { agree and } \\
\text { agree }\end{array}$ & $\begin{array}{c}\text { Disagree } \\
\text { and } \\
\text { strongly } \\
\text { disagree }\end{array}$ & N/A & Don't know \\
\hline All responses $(n=348)$ & 89.08 & 5.17 & 1.44 & 4.31 \\
\hline Senior staff $(n=212)$ & 91.51 & 3.77 & 1.89 & 2.83 \\
\hline Junior staff $(n=134)$ & 85.07 & 7.46 & 0.75 & 6.72 \\
\hline Technical staff $(n=63)$ & 82.54 & 4.76 & 0.00 & 12.70 \\
\hline Research staff $(n=283)$ & 90.46 & 5.30 & 1.77 & 2.47 \\
\hline \multicolumn{5}{|c|}{ 6. Your institution clearly states its research priorities } \\
\hline & $\begin{array}{l}\text { Strongly } \\
\text { agree and } \\
\text { agree }\end{array}$ & $\begin{array}{c}\text { Disagree } \\
\text { and } \\
\text { strongly } \\
\text { disagree }\end{array}$ & N/A & Don't know \\
\hline All responses $(n=348)$ & 75.29 & 18.10 & 3.45 & 3.16 \\
\hline Senior staff $(n=211)$ & 71.56 & 19.91 & 5.21 & 3.32 \\
\hline Junior staff $(n=135)$ & 80.74 & 15.56 & 0.74 & 2.96 \\
\hline Technical staff $(n=64)$ & 73.44 & 9.38 & 9.38 & 7.81 \\
\hline Research staff $(n=282)$ & 75.53 & 20.21 & 2.13 & 2.13 \\
\hline \multicolumn{5}{|c|}{ 7. Research findings are routinely published } \\
\hline & $\begin{array}{l}\text { Strongly } \\
\text { agree and } \\
\text { agree }\end{array}$ & $\begin{array}{c}\text { Disagree } \\
\text { and } \\
\text { strongly } \\
\text { disagree }\end{array}$ & N/A & Don't know \\
\hline All responses $(n=349)$ & 82.52 & 10.03 & 5.16 & 2.29 \\
\hline Senior staff $(n=212)$ & 80.19 & 10.85 & 7.08 & 1.89 \\
\hline Junior staff $(n=135)$ & 86.67 & 8.15 & 2.22 & 2.96 \\
\hline Technical staff $(n=64)$ & 67.19 & 10.94 & 17.19 & 4.69 \\
\hline Research staff $(n=283)$ & 86.22 & 9.54 & 2.47 & 1.77 \\
\hline \multicolumn{5}{|c|}{$\begin{array}{l}\text { 8. Good communication exists between policymakers at your facility and the life } \\
\text { science community }\end{array}$} \\
\hline & $\begin{array}{l}\text { Strongly } \\
\text { agree and } \\
\text { agree }\end{array}$ & $\begin{array}{c}\text { Disagree } \\
\text { and } \\
\text { strongly } \\
\text { disagree }\end{array}$ & N/A & Don't know \\
\hline All responses $(n=344)$ & 38.08 & 45.35 & 2.33 & 14.24 \\
\hline Senior staff $(n=207)$ & 37.20 & 47.83 & 3.86 & 11.11 \\
\hline Junior staff $(n=133)$ & 38.35 & 42.11 & 0.00 & 19.55 \\
\hline Technical staff $(n=64)$ & 42.19 & 34.38 & 3.13 & 20.31 \\
\hline Research staff ( $n=278$ ) & 37.05 & 47.84 & 2.16 & 12.95 \\
\hline
\end{tabular}




\section{Research Excellence}

9. Good communication exists between policymakers at a national level and the life science community

\begin{tabular}{|l|c|c|c|c|} 
& $\begin{array}{c}\text { Strongly } \\
\text { agree and } \\
\text { agree }\end{array}$ & $\begin{array}{c}\text { Disagree } \\
\text { and } \\
\text { strongly } \\
\text { disagree }\end{array}$ & N/A & Don't know \\
\hline All responses $(n=347)$ & 21.61 & 52.45 & 4.03 & 21.90 \\
\hline Senior staff $(n=211)$ & 21.80 & 54.50 & 6.16 & 17.54 \\
\hline Junior staff $(n=134)$ & 21.64 & 49.25 & 0.00 & 29.10 \\
\hline Technical staff $(n=64)$ & 28.13 & 31.25 & 3.13 & 37.50 \\
\hline Research staff $(n=281)$ & 20.28 & 57.30 & 3.91 & 18.51 \\
\hline
\end{tabular}

10. On-going formal and/or informal career training takes place (that is not for postgraduate degree purposes)

\begin{tabular}{|l|c|c|c|c|c|}
\hline & $\begin{array}{c}\text { Always and } \\
\text { often }\end{array}$ & Sometimes & $\begin{array}{c}\text { Rarely and } \\
\text { never }\end{array}$ & N/A & Don't know \\
\hline All responses $(n=347)$ & 44.67 & 32.56 & 16.43 & 2.88 & 3.46 \\
\hline Senior staff $(n=212)$ & 46.70 & 34.91 & 13.68 & 1.89 & 2.83 \\
\hline Junior staff $(n=133)$ & 41.35 & 28.57 & 21.05 & 4.51 & 4.51 \\
\hline Technical staff $(n=64)$ & 45.31 & 25.00 & 17.19 & 3.13 & 9.38 \\
\hline Research staff $(n=281)$ & 44.48 & 34.16 & 16.37 & 2.85 & 2.14 \\
\hline
\end{tabular}

11. Junior researchers and/or staff are nurtured and supported

\begin{tabular}{|l|c|c|c|c|c|}
\hline & $\begin{array}{c}\text { Always and } \\
\text { often }\end{array}$ & Sometimes & $\begin{array}{c}\text { Rarely and } \\
\text { never }\end{array}$ & N/A & Don't know \\
\hline All responses $(n=346)$ & 52.31 & 29.19 & 14.45 & 1.73 & 2.31 \\
\hline Senior staff $(n=211)$ & 56.40 & 25.59 & 16.11 & 1.42 & 0.47 \\
\hline Junior staff $(n=133)$ & 45.11 & 35.34 & 12.03 & 2.26 & 5.26 \\
\hline Technical staff $(n=63)$ & 39.68 & 44.44 & 9.52 & 1.59 & 4.76 \\
\hline Research staff $(n=281)$ & 54.80 & 25.98 & 15.66 & 1.78 & 1.78 \\
\hline
\end{tabular}

12. Staff conducting life science activities have been properly trained

\begin{tabular}{|l|c|c|c|c|}
\hline & $\begin{array}{c}\text { Strongly } \\
\text { agree and } \\
\text { agree }\end{array}$ & $\begin{array}{c}\text { Disagree } \\
\text { and } \\
\text { strongly } \\
\text { disagree }\end{array}$ & N/A & Don't know \\
\hline All responses $(n=345)$ & 75.07 & 16.81 & 2.03 & 6.09 \\
\hline Senior staff $(n=210)$ & 73.33 & 18.10 & 2.86 & 5.71 \\
\hline Junior staff $(n=133)$ & 77.44 & 15.04 & 0.75 & 6.77 \\
\hline Technical staff $(n=63)$ & 69.84 & 17.46 & 3.17 & 9.52 \\
\hline Research staff $(n=280)$ & 76.07 & 16.79 & 1.79 & 5.36 \\
\hline
\end{tabular}




\section{Research Excellence}

13. Quality control is conducted within the institution for relevant diagnostic tests or experiments to avoid false positives or negative results

\begin{tabular}{|l|c|c|c|c|c|} 
& $\begin{array}{c}\text { Always and } \\
\text { often }\end{array}$ & Sometimes & $\begin{array}{c}\text { Rarely and } \\
\text { never }\end{array}$ & N/A & Don't know \\
\hline All responses $(n=344)$ & 53.49 & 12.79 & 9.01 & 12.21 & 12.50 \\
\hline Senior staff $(n=209)$ & 54.07 & 11.96 & 7.66 & 15.79 & 10.53 \\
\hline Junior staff $(n=133)$ & 51.88 & 14.29 & 11.28 & 6.77 & 15.79 \\
\hline Technical staff $(n=63)$ & 74.60 & 4.76 & 4.76 & 6.35 & 9.52 \\
\hline Research staff $(n=279)$ & 48.39 & 14.70 & 10.04 & 13.62 & 13.26 \\
\hline
\end{tabular}

14. Quality control is conducted between institutions for relevant diagnostic tests or experiments to avoid false positives or negative results

\begin{tabular}{|l|c|c|c|c|c|} 
& $\begin{array}{c}\text { Always and } \\
\text { often }\end{array}$ & Sometimes & $\begin{array}{c}\text { Rarely and } \\
\text { never }\end{array}$ & N/A & Don't know \\
\hline All responses $(n=344)$ & 37.21 & 12.21 & 10.47 & 15.99 & 24.13 \\
\hline Senior staff $(n=209)$ & 35.89 & 12.92 & 10.53 & 20.57 & 20.10 \\
\hline Junior staff $(n=133)$ & 38.35 & 11.28 & 10.53 & 9.02 & 30.83 \\
\hline Technical staff $(n=62)$ & 50.00 & 11.29 & 4.84 & 8.06 & 25.81 \\
\hline Research staff $(n=280)$ & 33.93 & 12.50 & 11.79 & 17.86 & 23.93 \\
\hline
\end{tabular}

15. Samples and reagents are checked to ensure that they match accompanying documentation

\begin{tabular}{|l|c|c|c|c|c|} 
& $\begin{array}{c}\text { Always and } \\
\text { often }\end{array}$ & Sometimes & $\begin{array}{c}\text { Rarely and } \\
\text { never }\end{array}$ & N/A & Don't know \\
\hline All responses $(n=346)$ & 60.40 & 10.69 & 5.78 & 12.14 & 10.98 \\
\hline Senior staff $(n=210)$ & 57.62 & 10.48 & 4.76 & 14.76 & 12.38 \\
\hline Junior staff $(n=134)$ & 64.18 & 11.19 & 7.46 & 5.22 & 11.94 \\
\hline Technical staff $(n=63)$ & 74.60 & 7.94 & 4.76 & 1.59 & 11.11 \\
\hline Research staff $(n=281)$ & 56.94 & 11.39 & 6.05 & 13.17 & 12.46 \\
\hline
\end{tabular}

16. Measures are in place to double check results before they are given to patients/ clinicians (for diagnostic laboratories) or published (for research laboratories)

\begin{tabular}{|l|c|c|c|c|}
\hline & $\begin{array}{c}\text { Strongly } \\
\text { agree and } \\
\text { agree }\end{array}$ & $\begin{array}{c}\text { Disagree } \\
\text { and } \\
\text { strongly } \\
\text { disagree }\end{array}$ & N/A & Don't know \\
\hline All responses $(n=344)$ & 58.14 & 8.14 & 21.51 & 12.21 \\
\hline Senior staff $(n=209)$ & 55.98 & 6.70 & 27.27 & 10.05 \\
\hline Junior staff $(n=133)$ & 60.90 & 10.53 & 12.78 & 15.79 \\
\hline Technical staff $(n=63)$ & 69.84 & 1.59 & 20.63 & 7.94 \\
\hline Research staff $(n=279)$ & 55.20 & 9.68 & 21.86 & 13.26 \\
\hline
\end{tabular}


I. Research Excellence

17. Education and/or training is offered on dual-use issues. This refers to the potential for data that was generated for beneficial purposes to be misused for malicious purposes by a third party.

\begin{tabular}{|c|c|c|c|c|c|}
\hline & & $\begin{array}{l}\text { Strongly } \\
\text { agree and } \\
\text { agree }\end{array}$ & $\begin{array}{l}\text { Disagree } \\
\text { and } \\
\text { strongly } \\
\text { disagree }\end{array}$ & N/A & Don't know \\
\hline \multicolumn{2}{|l|}{ All responses $(n=344)$} & 28.20 & 18.31 & 18.31 & 35.17 \\
\hline \multicolumn{2}{|l|}{ Senior staff $(n=211)$} & 26.54 & 21.33 & 22.27 & 29.86 \\
\hline \multicolumn{2}{|l|}{ Junior staff $(n=132)$} & 30.30 & 13.64 & 12.12 & 43.94 \\
\hline \multicolumn{2}{|l|}{ Technical staff $(n=64)$} & 32.81 & 14.06 & 17.19 & 35.94 \\
\hline \multicolumn{2}{|l|}{ Research staff $(n=279)$} & 26.88 & 19.35 & 18.64 & 35.13 \\
\hline \multicolumn{6}{|c|}{ 18. Skilled staff are valued and retained } \\
\hline & $\begin{array}{l}\text { Always and } \\
\text { often }\end{array}$ & Sometimes & $\begin{array}{c}\text { Rarely and } \\
\text { never }\end{array}$ & N/A & Don't know \\
\hline All responses $(n=347)$ & 31.70 & 38.04 & 25.36 & 0.58 & 4.32 \\
\hline Senior staff(n=211) & 29.38 & 40.76 & 28.91 & 0.00 & 0.95 \\
\hline Junior staff $(n=146)$ & 20.55 & 21.23 & 47.26 & 8.90 & 2.05 \\
\hline Technical staff $(n=64)$ & 35.94 & 28.13 & 32.81 & 0.00 & 3.13 \\
\hline Research staff $(n=281)$ & 30.60 & 40.21 & 23.84 & 0.71 & 4.63 \\
\hline \multicolumn{6}{|c|}{ 19. National legislation and policy fosters scientific development and freedom } \\
\hline & & $\begin{array}{l}\text { Strongly } \\
\text { agree and } \\
\text { agree }\end{array}$ & $\begin{array}{c}\text { Disagree } \\
\text { and } \\
\text { strongly } \\
\text { disagree }\end{array}$ & N/A & Don't know \\
\hline \multicolumn{2}{|l|}{ All responses $(n=336)$} & 41.37 & 39.58 & 1.19 & 17.86 \\
\hline \multicolumn{2}{|l|}{ Senior staff $(n=206)$} & 39.32 & 42.72 & 0.97 & 16.99 \\
\hline \multicolumn{2}{|l|}{ Junior staff $(n=128)$} & 45.31 & 34.38 & 1.56 & 18.75 \\
\hline \multicolumn{2}{|l|}{ Technical staff $(n=61)$} & 40.98 & 37.70 & 3.28 & 18.03 \\
\hline \multicolumn{2}{|l|}{ Research staff $(n=273)$} & 41.76 & 39.93 & 0.73 & 17.58 \\
\hline
\end{tabular}




\section{Ethics}

1. Education and/or training is offered on research ethics including issues such as scientific misconduct (falsification, fabrication and plagiarism)

\begin{tabular}{|l|c|c|c|c|c|} 
& $\begin{array}{c}\text { Always and } \\
\text { offen }\end{array}$ & Sometimes & $\begin{array}{c}\text { Rarely and } \\
\text { never }\end{array}$ & N/A & Don't know \\
\hline All responses $(n=323)$ & 43.65 & 29.10 & 23.84 & 1.55 & 1.86 \\
\hline Senior staff $(n=197)$ & 39.09 & 31.98 & 24.87 & 2.03 & 2.03 \\
\hline Junior staff $(n=151)$ & 41.72 & 19.21 & 34.44 & 1.32 & 3.31 \\
\hline Technical staff $(n=59)$ & 35.59 & 33.90 & 22.03 & 1.69 & 6.78 \\
\hline Research staff $(n=262)$ & 45.80 & 28.24 & 23.66 & 1.53 & 0.76 \\
\hline 2. Appropriate ethical research guidelines and practices have been published \\
\begin{tabular}{l|c|c|c|c|} 
Disagree \\
and \\
All responses $(n=323)$
\end{tabular} & $\begin{array}{c}\text { Strongly } \\
\text { agree and } \\
\text { agree }\end{array}$ & $\begin{array}{c}\text { strongly } \\
\text { disagree }\end{array}$ & Don't know \\
\hline Senior staff $(n=211)$ & 63.78 & 17.96 & 6.81 & 11.46 \\
\hline Junior staff $(n=124)$ & 56.40 & 21.33 & 13.27 & 9.00 \\
\hline Technical staff $(n=59)$ & 70.16 & 9.68 & 6.45 & 13.71 \\
\hline Research staff $(n=262)$ & 59.32 & 10.17 & 11.86 & 18.64 \\
\hline
\end{tabular}

3. Appropriate ethical research guidelines and practices are implemented

\begin{tabular}{|l|c|c|c|c|c|}
\hline & $\begin{array}{c}\text { Always and } \\
\text { often }\end{array}$ & Sometimes & $\begin{array}{c}\text { Rarely and } \\
\text { never }\end{array}$ & N/A & Don't know \\
\hline All responses $(n=322)$ & 66.77 & 14.91 & 3.11 & 6.21 & 9.01 \\
\hline Senior staff $(n=197)$ & 66.50 & 15.23 & 3.05 & 7.11 & 8.12 \\
\hline Junior staff $(n=123)$ & 67.48 & 14.63 & 3.25 & 4.88 & 9.76 \\
\hline Technical staff $(n=59)$ & 66.10 & 13.56 & 1.69 & 5.08 & 13.56 \\
\hline Research staff $(n=261)$ & 67.05 & 15.33 & 3.45 & 6.51 & 7.66 \\
\hline
\end{tabular}

4. Adequate mechanisms exist for investigating and responding to non-adherence to ethical standards

\begin{tabular}{|l|c|c|c|c|}
\hline & $\begin{array}{c}\text { Strongly } \\
\text { agree and } \\
\text { agree }\end{array}$ & $\begin{array}{c}\text { Disagree } \\
\text { and } \\
\text { strongly } \\
\text { disagree }\end{array}$ & N/A & Don't know \\
\hline All responses $(n=350)$ & 48.57 & 20.57 & 3.14 & 19.43 \\
\hline Senior staff $(n=213)$ & 51.17 & 20.66 & 1.88 & 18.31 \\
\hline Junior staff $(n=135)$ & 30.37 & 24.44 & 22.22 & 5.19 \\
\hline Technical staff $(n=64)$ & 43.75 & 20.31 & 3.13 & 25.00 \\
\hline Research staff $(n=284)$ & 49.65 & 20.42 & 3.17 & 18.31 \\
\hline
\end{tabular}




\section{Ethics}

5. Measures are in place to prevent non-laboratory individuals from obtaining access to samples or biological materials

\begin{tabular}{|c|c|c|c|c|}
\hline & $\begin{array}{l}\text { Strongly } \\
\text { agree and } \\
\text { agree }\end{array}$ & $\begin{array}{c}\text { Disagree } \\
\text { and } \\
\text { strongly } \\
\text { disagree }\end{array}$ & N/A & Don't know \\
\hline All responses $(n=350)$ & 62.57 & 14.29 & 7.14 & 7.43 \\
\hline Senior staff $(n=213)$ & 61.03 & 13.62 & 8.92 & 7.98 \\
\hline Junior staff $(n=135)$ & 64.44 & 15.56 & 5.19 & 5.93 \\
\hline Technical staff $(n=64)$ & 71.88 & 10.94 & 1.56 & 6.25 \\
\hline Research staff $(n=284)$ & 60.21 & 15.14 & 8.80 & 7.39 \\
\hline \multicolumn{5}{|c|}{$\begin{array}{l}\text { 6. Measures are in place to prevent non-laboratory individuals from providing } \\
\text { confidential information to people outside the laboratory }\end{array}$} \\
\hline & $\begin{array}{l}\text { Strongly } \\
\text { agree and } \\
\text { agree }\end{array}$ & $\begin{array}{c}\text { Disagree } \\
\text { and } \\
\text { strongly } \\
\text { disagree }\end{array}$ & $\mathrm{N} / \mathrm{A}$ & Don't know \\
\hline All responses $(n=350)$ & 54.00 & 13.71 & 12.86 & 10.86 \\
\hline Senior staff $(n=213)$ & 61.03 & 13.62 & 8.92 & 7.98 \\
\hline Junior staff $(n=135)$ & 64.44 & 15.56 & 5.19 & 5.93 \\
\hline Technical staff $(n=64)$ & 71.88 & 10.94 & 1.56 & 6.25 \\
\hline Research staff $(n=284)$ & 60.21 & 15.14 & 8.80 & 7.39 \\
\hline
\end{tabular}

7. Discussions in the facility focus on the broader implications of your life science activities for society in general

\begin{tabular}{|l|c|c|c|c|c|} 
& $\begin{array}{c}\text { Always and } \\
\text { often }\end{array}$ & Sometimes & $\begin{array}{c}\text { Rarely and } \\
\text { never }\end{array}$ & N/A & Don't know \\
\hline All responses $(n=322)$ & 38.20 & 30.43 & 22.36 & 3.73 & 5.28 \\
\hline Senior staff $(n=196)$ & 34.69 & 31.12 & 25.51 & 5.10 & 3.57 \\
\hline Junior staff $(n=124)$ & 42.74 & 29.84 & 17.74 & 1.61 & 8.06 \\
\hline Technical staff $(n=58)$ & 36.21 & 27.59 & 17.24 & 6.90 & 12.07 \\
\hline Research staff $(n=262)$ & 38.17 & 31.30 & 23.66 & 3.05 & 3.82 \\
\hline
\end{tabular}

8. Scientists are competent to assess the potential broader implications of their life science activities for society in general

\begin{tabular}{|l|c|c|c|c|}
\hline & $\begin{array}{c}\text { Strongly } \\
\text { agree and } \\
\text { agree }\end{array}$ & $\begin{array}{c}\text { Disagree } \\
\text { and } \\
\text { strongly } \\
\text { disagree }\end{array}$ & N/A & Don't know \\
\hline All responses $(n=350)$ & 70.29 & 14.00 & 6.29 & 1.71 \\
\hline Senior staff $(n=213)$ & 69.01 & 15.02 & 2.35 & 6.10 \\
\hline Junior staff $(n=135)$ & 71.85 & 12.59 & 6.67 & 1.48 \\
\hline Technical staff $(n=64)$ & 65.63 & 14.06 & 3.13 & 9.38 \\
\hline Research staff $(n=284)$ & 71.13 & 14.08 & 1.41 & 5.63 \\
\hline
\end{tabular}




\section{Ethics}

9. Research is subject to a risk assessment that includes considerations of the broader implications of their life science activities for the environment

\begin{tabular}{|l|c|c|c|c|c|} 
& $\begin{array}{c}\text { Always and } \\
\text { often }\end{array}$ & Sometimes & $\begin{array}{c}\text { Rarely and } \\
\text { never }\end{array}$ & N/A & Don't know \\
\hline All responses $(n=320)$ & 44.38 & 22.50 & 15.31 & 4.69 & 13.13 \\
\hline Senior staff $(n=196)$ & 45.92 & 20.92 & 16.33 & 6.63 & 10.20 \\
\hline Junior staff $(n=122)$ & 40.98 & 25.41 & 13.93 & 1.64 & 18.03 \\
\hline Technical staff $(n=59)$ & 44.07 & 20.34 & 10.17 & 5.08 & 20.34 \\
\hline Research staff $(n=259)$ & 44.02 & 23.17 & 16.60 & 4.63 & 11.58 \\
\hline
\end{tabular}

10. Scientists are competent to make the assessment of the broader implications of their life science activities for the environment

\begin{tabular}{|l|c|c|c|c|}
\hline & $\begin{array}{c}\text { Strongly } \\
\text { agree and } \\
\text { agree }\end{array}$ & $\begin{array}{c}\text { Disagree } \\
\text { and } \\
\text { strongly } \\
\text { disagree }\end{array}$ & N/A & Don't know \\
\hline All responses $(n=350)$ & 66.86 & 10.29 & 3.14 & 10.57 \\
\hline Senior staff $(n=213)$ & 65.26 & 12.21 & 3.76 & 10.33 \\
\hline Junior staff $(n=135)$ & 68.89 & 7.41 & 2.22 & 11.11 \\
\hline Technical staff $(n=64)$ & 59.38 & 7.81 & 6.25 & 17.19 \\
\hline Research staff $(n=284)$ & 68.31 & 10.92 & 2.46 & 9.15 \\
\hline
\end{tabular}

11. Potential for misuse of the research is considered at all stages of research/ diagnostic processes and appropriate action taken if necessary

\begin{tabular}{|c|c|c|c|c|}
\hline & $\begin{array}{l}\text { Strongly } \\
\text { agree and } \\
\text { agree }\end{array}$ & $\begin{array}{l}\text { Disagree } \\
\text { and } \\
\text { strongly } \\
\text { disagree }\end{array}$ & N/A & Don't know \\
\hline All responses $(n=350)$ & 50.00 & 17.71 & 8.29 & 16.29 \\
\hline Senior staff $(n=213)$ & 48.83 & 18.31 & 9.86 & 15.49 \\
\hline Junior staff $(n=135)$ & 51.85 & 16.30 & 5.93 & 17.78 \\
\hline Technical staff $(n=64)$ & 42.19 & 18.75 & 10.94 & 20.31 \\
\hline Research staff $(n=284)$ & 51.76 & 17.25 & 7.75 & 15.49 \\
\hline \multicolumn{5}{|c|}{$\begin{array}{l}\text { 12. Researchers know how to assess whether the risk outweighs the benefit of } \\
\text { continuing with their research activities }\end{array}$} \\
\hline & $\begin{array}{l}\text { Strongly } \\
\text { agree and } \\
\text { agree }\end{array}$ & $\begin{array}{c}\text { Disagree } \\
\text { and } \\
\text { strongly } \\
\text { disagree }\end{array}$ & N/A & Don't know \\
\hline All responses $(n=350)$ & 54.86 & 19.14 & 10.86 & 8.29 \\
\hline Senior staff $(n=213)$ & 52.11 & 20.66 & 7.98 & 10.80 \\
\hline Junior staff $(n=135)$ & 58.52 & 17.04 & 4.44 & 11.11 \\
\hline Technical staff $(n=64)$ & 43.75 & 15.63 & 10.94 & 21.88 \\
\hline Research staff $(n=284)$ & 57.04 & 20.07 & 8.45 & 1.76 \\
\hline
\end{tabular}




\section{Ethics}

13. A code of conduct/practice for life scientists exists at an institutional level

\begin{tabular}{|c|c|c|c|c|}
\hline & $\begin{array}{l}\text { Strongly } \\
\text { agree and } \\
\text { agree }\end{array}$ & $\begin{array}{c}\text { Disagree } \\
\text { and } \\
\text { strongly } \\
\text { disagree }\end{array}$ & N/A & Don't know \\
\hline All responses $(n=350)$ & 57.71 & 16.29 & 1.14 & 17.14 \\
\hline Senior staff $(n=213)$ & 54.93 & 19.72 & 1.41 & 16.43 \\
\hline Junior staff $(n=135)$ & 62.22 & 11.11 & 0.74 & 17.78 \\
\hline Technical staff $(n=64)$ & 54.69 & 18.75 & 0.00 & 18.75 \\
\hline Research staff $(n=284)$ & 58.45 & 15.85 & 1.41 & 16.55 \\
\hline \multicolumn{5}{|c|}{ 14. A code of conduct/practice for life scientists exists at a national level } \\
\hline & $\begin{array}{l}\text { Strongly } \\
\text { agree and } \\
\text { agree }\end{array}$ & $\begin{array}{c}\text { Disagree } \\
\text { and } \\
\text { strongly } \\
\text { disagree }\end{array}$ & N/A & Don't know \\
\hline All responses $(n=350)$ & 36.86 & 14.29 & 0.57 & 40.29 \\
\hline Senior staff $(n=213)$ & 36.15 & 16.90 & 0.94 & 38.03 \\
\hline Junior staff $(n=135)$ & 38.52 & 10.37 & 0.00 & 42.96 \\
\hline Technical staff $(n=64)$ & 42.19 & 10.94 & 0.00 & 39.06 \\
\hline Research staff $(n=284)$ & 35.92 & 15.14 & 0.70 & 40.14 \\
\hline
\end{tabular}

15. Researchers are aware of and informed about national and international conventions, laws and regulations related to their research

\begin{tabular}{|c|c|c|c|c|c|}
\hline & & $\begin{array}{l}\text { Strongly } \\
\text { agree and } \\
\text { agree }\end{array}$ & $\begin{array}{l}\text { Disagree } \\
\text { and } \\
\text { strongly } \\
\text { disagree }\end{array}$ & N/A & Don't know \\
\hline \multicolumn{2}{|l|}{ All responses $(n=350)$} & 47.43 & 28.00 & 1.43 & 15.14 \\
\hline \multicolumn{2}{|l|}{ Senior staff $(n=213)$} & 47.42 & 27.70 & 2.35 & 14.55 \\
\hline \multicolumn{2}{|l|}{ Junior staff $(n=135)$} & 48.15 & 28.15 & 0.00 & 15.56 \\
\hline \multicolumn{2}{|l|}{ Technical staff $(n=64)$} & 51.56 & 21.88 & 1.56 & 17.19 \\
\hline \multicolumn{2}{|l|}{ Research staff $(n=284)$} & 46.83 & 29.23 & 1.41 & 14.44 \\
\hline \multicolumn{6}{|c|}{ 16. An ethics committee assesses research proposals involving human subjects } \\
\hline & $\begin{array}{l}\text { Always and } \\
\text { often }\end{array}$ & Sometimes & $\begin{array}{l}\text { Rarely and } \\
\text { never }\end{array}$ & N/A & Don't know \\
\hline All responses $(n=322)$ & 69.88 & 3.11 & 0.31 & 19.88 & 6.83 \\
\hline Senior staff $(n=197)$ & 69.04 & 4.57 & 0.00 & 22.84 & 3.55 \\
\hline Junior staff $(n=123)$ & 72.36 & 0.81 & 0.81 & 13.82 & 12.20 \\
\hline Technical staff $(n=58)$ & 53.45 & 5.17 & 0.00 & 31.03 & 10.34 \\
\hline Research staff $(n=262)$ & 74.05 & 2.67 & 0.38 & 16.79 & 6.11 \\
\hline
\end{tabular}




\section{Ethics}

17. An ethics committee assesses research proposals involving animal subjects

\begin{tabular}{|l|c|c|c|c|c|} 
& $\begin{array}{c}\text { Always and } \\
\text { often }\end{array}$ & Sometimes & $\begin{array}{c}\text { Rarely and } \\
\text { never }\end{array}$ & N/A & Don't know \\
\hline All responses $(n=323)$ & 80.80 & 1.24 & 1.24 & 11.15 & 5.57 \\
\hline Senior staff $(n=197)$ & 81.22 & 1.52 & 1.02 & 11.68 & 4.57 \\
\hline Junior staff $(n=124)$ & 79.84 & 0.81 & 1.61 & 10.48 & 7.26 \\
\hline Technical staff $(n=59)$ & 67.80 & 5.08 & 0.00 & 16.95 & 10.17 \\
\hline Research staff $(n=262)$ & 83.59 & 0.38 & 1.53 & 9.92 & 4.58 \\
\hline
\end{tabular}

18. A review process exists to assess ethical issues raised by research proposals not involving human or animal subjects

\begin{tabular}{|l|c|c|c|c|}
\hline & $\begin{array}{c}\text { Strongly } \\
\text { agree and } \\
\text { agree }\end{array}$ & $\begin{array}{c}\text { Disagree } \\
\text { and } \\
\text { strongly } \\
\text { disagree }\end{array}$ & N/A & Don't know \\
\hline All responses $(n=350)$ & 44.57 & 12.86 & 7.43 & 26.57 \\
\hline Senior staff $(n=213)$ & 44.60 & 15.49 & 7.98 & 23.47 \\
\hline Junior staff $(n=135)$ & 44.44 & 8.15 & 6.67 & 31.85 \\
\hline Technical staff $(n=64)$ & 40.63 & 3.13 & 14.06 & 32.81 \\
\hline Research staff $(n=284)$ & 45.42 & 14.79 & 5.99 & 25.35 \\
\hline
\end{tabular}

19. Information about the national and international conventions and regulations related to all fields of science is easily accessible

\begin{tabular}{|c|c|c|c|c|}
\hline & $\begin{array}{l}\text { Strongly } \\
\text { agree and } \\
\text { agree }\end{array}$ & $\begin{array}{c}\text { Disagree } \\
\text { and } \\
\text { strongly } \\
\text { disagree }\end{array}$ & N/A & Don't know \\
\hline All responses $(n=350)$ & 38.57 & 32.57 & 0.29 & 20.57 \\
\hline Senior staff $(n=213)$ & 37.56 & 32.86 & 0.47 & 21.60 \\
\hline Junior staff $(n=135)$ & 40.74 & 31.11 & 0.00 & 19.26 \\
\hline Technical staff $(n=64)$ & 35.94 & 29.69 & 0.00 & 26.56 \\
\hline Research staff $(n=284)$ & 39.44 & 32.75 & 0.35 & 19.37 \\
\hline \multicolumn{5}{|c|}{$\begin{array}{l}\text { 20. National legislation and policy relevant to the life sciences provides protection } \\
\text { against the misuse of science }\end{array}$} \\
\hline & $\begin{array}{l}\text { Strongly } \\
\text { agree and } \\
\text { agree }\end{array}$ & $\begin{array}{c}\text { Disagree } \\
\text { and } \\
\text { strongly } \\
\text { disagree }\end{array}$ & N/A & Don't know \\
\hline All responses $(n=350)$ & 34.86 & 17.71 & 1.14 & 38.00 \\
\hline Senior staff $(n=213)$ & 35.21 & 19.25 & 1.41 & 36.15 \\
\hline Junior staff $(n=135)$ & 34.07 & 15.56 & 0.74 & 40.74 \\
\hline Technical staff $(n=64)$ & 29.69 & 15.63 & 1.56 & 45.31 \\
\hline Research staff $(n=284)$ & 35.92 & 18.31 & 1.06 & 36.27 \\
\hline
\end{tabular}


III. Laboratory Biosafety and Biosecurity

1. Facilities and equipment are appropriate to the level of work being done and are adequately maintained

\begin{tabular}{|l|c|c|c|c|}
\hline & $\begin{array}{c}\text { Strongly } \\
\text { agree and } \\
\text { agree }\end{array}$ & $\begin{array}{c}\text { Disagree } \\
\text { and } \\
\text { strongly } \\
\text { disagree }\end{array}$ & N/A & $\begin{array}{c}\text { Don't } \\
\text { know }\end{array}$ \\
\hline All responses $(n=305)$ & 72.79 & 23.93 & 1.31 & 1.97 \\
\hline Senior staff $(n=190)$ & 69.47 & 26.32 & 2.11 & 2.11 \\
\hline Junior staff $(n=113)$ & 77.88 & 20.35 & 0.00 & 1.77 \\
\hline Technical staff $(n=57)$ & 87.72 & 8.77 & 0.00 & 3.51 \\
\hline Research staff $(n=246)$ & 69.11 & 27.64 & 1.63 & 1.63 \\
\hline
\end{tabular}

2. Training of staff is appropriate to the facilities and equipment and the work being conducted

\begin{tabular}{|l|c|c|c|c|}
\hline & $\begin{array}{c}\text { Strongly } \\
\text { agree and } \\
\text { agree }\end{array}$ & $\begin{array}{c}\text { Disagree } \\
\text { and } \\
\text { strongly } \\
\text { disagree }\end{array}$ & N/A & $\begin{array}{c}\text { Don't } \\
\text { know }\end{array}$ \\
\hline All responses $(n=304)$ & 77.96 & 18.09 & 1.32 & 2.63 \\
\hline Senior staff $(n=190)$ & 77.89 & 17.89 & 2.11 & 2.11 \\
\hline Junior staff $(n=112)$ & 77.68 & 18.75 & 0.00 & 3.57 \\
\hline Technical staff $(n=56)$ & 76.79 & 14.29 & 1.79 & 7.14 \\
\hline Research staff $(\mathbf{n}=\mathbf{2 4 6})$ & 78.05 & 19.11 & 1.22 & 1.63 \\
\hline
\end{tabular}

3. Researchers have somewhere to turn to get competent advice if they have safety or security questions relating to their research

\begin{tabular}{|l|c|c|c|c|}
\hline & $\begin{array}{c}\text { Strongly } \\
\text { agree and } \\
\text { agree }\end{array}$ & $\begin{array}{c}\text { Disagree } \\
\text { and } \\
\text { strongly } \\
\text { disagree }\end{array}$ & N/A & $\begin{array}{c}\text { Don't } \\
\text { know }\end{array}$ \\
\hline All responses $(\mathbf{n = 3 0 3 )}$ & 69.31 & 21.78 & 1.65 & 7.26 \\
\hline Senior staff $(\mathbf{n}=\mathbf{1 8 8})$ & 67.02 & 22.87 & 2.66 & 7.45 \\
\hline Junior staff $(\mathrm{n}=1 \mathbf{1 3})$ & 72.57 & 20.35 & 0.00 & 7.08 \\
\hline Technical staff $(\mathbf{n}=\mathbf{5 7})$ & 73.68 & 14.04 & 1.75 & 10.53 \\
\hline Research staff $(\mathbf{n}=\mathbf{2 4 4})$ & 68.03 & 23.77 & 1.64 & 6.56 \\
\hline
\end{tabular}

4. National legislation/regulation exists that sets safety and security practices and procedures for laboratories

\begin{tabular}{|l|c|c|c|c|}
\hline & $\begin{array}{c}\text { Strongly } \\
\text { agree and } \\
\text { agree }\end{array}$ & $\begin{array}{c}\text { Disagree } \\
\text { and } \\
\text { strongly } \\
\text { disagree }\end{array}$ & N/A & $\begin{array}{c}\text { Don't } \\
\text { know }\end{array}$ \\
\hline All responses $(n=304)$ & 64.47 & 10.86 & 2.63 & 22.04 \\
\hline Senior staff $(n=189)$ & 64.02 & 11.11 & 4.23 & 20.63 \\
\hline
\end{tabular}


III. Laboratory Biosafety and Biosecurity

\begin{tabular}{|l|c|c|c|c|}
\hline Junior staff $(n=113)$ & 65.49 & 10.62 & 0.00 & 23.89 \\
\hline Technical staff $(n=57)$ & 68.42 & 7.02 & 1.75 & 22.81 \\
\hline Research staff $(n=245)$ & 63.67 & 11.84 & 2.86 & 21.63 \\
\hline
\end{tabular}

5. An assessment of the biosafety and biosecurity risk associated with research activities is conducted

\begin{tabular}{|l|c|c|c|c|c|}
\hline & $\begin{array}{c}\text { Always } \\
\text { and often }\end{array}$ & Sometimes & $\begin{array}{c}\text { Rarely and } \\
\text { never }\end{array}$ & N/A & $\begin{array}{c}\text { Don't } \\
\text { know }\end{array}$ \\
\hline All responses $(n=305)$ & 43.61 & 20.33 & 15.08 & 6.56 & 14.43 \\
\hline Senior staff $(n=190)$ & 43.68 & 20.53 & 14.74 & 8.95 & 12.11 \\
\hline Junior staff $(n=113)$ & 42.48 & 20.35 & 15.93 & 2.65 & 18.58 \\
\hline Technical staff $(n=57)$ & 40.35 & 28.07 & 14.04 & 3.51 & 14.04 \\
\hline Research staff $(n=246)$ & 43.90 & 18.70 & 15.45 & 7.32 & 14.63 \\
\hline
\end{tabular}

6. Risk assessments are able to identify requirements for risk reduction measures including the level of containment required

\begin{tabular}{|c|c|c|c|c|}
\hline & $\begin{array}{l}\text { Strongly } \\
\text { agree and } \\
\text { agree }\end{array}$ & $\begin{array}{c}\text { Disagree } \\
\text { and } \\
\text { strongly } \\
\text { disagree }\end{array}$ & N/A & $\begin{array}{l}\text { Don't } \\
\text { know }\end{array}$ \\
\hline All responses $(n=298)$ & 59.40 & 11.07 & 8.72 & 20.81 \\
\hline Senior staff $(n=184)$ & 57.07 & 12.50 & 11.41 & 19.02 \\
\hline Junior staff $(n=112)$ & 63.39 & 8.93 & 3.57 & 24.11 \\
\hline Technical staff $(n=56)$ & 67.86 & 7.14 & 0.00 & 25.00 \\
\hline Research staff $(n=240)$ & 57.50 & 12.08 & 10.42 & 20.00 \\
\hline \multicolumn{5}{|c|}{$\begin{array}{l}\text { 7. Biosafety training is provided to all those working in laboratories when } \\
\text { appropriate }\end{array}$} \\
\hline & $\begin{array}{l}\text { Strongly } \\
\text { agree and } \\
\text { agree }\end{array}$ & $\begin{array}{c}\text { Disagree } \\
\text { and } \\
\text { strongly } \\
\text { disagree }\end{array}$ & N/A & $\begin{array}{l}\text { Don't } \\
\text { know }\end{array}$ \\
\hline All responses $(n=300)$ & 66.00 & 17.33 & 6.00 & 10.67 \\
\hline Senior staff $(n=188)$ & 62.77 & 19.15 & 8.51 & 9.57 \\
\hline Junior staff $(n=110)$ & 70.91 & 14.55 & 1.82 & 12.73 \\
\hline Technical staff $(n=57)$ & 77.19 & 12.28 & 1.75 & 8.77 \\
\hline Research staff $(n=241)$ & 63.07 & 18.67 & 7.05 & 11.20 \\
\hline
\end{tabular}


III. Laboratory Biosafety and Biosecurity

8. Biosecurity training is provided to all those working in laboratories when appropriate

\begin{tabular}{|l|c|c|c|c|}
\hline & $\begin{array}{c}\text { Strongly } \\
\text { agree and } \\
\text { agree }\end{array}$ & $\begin{array}{c}\text { Disagree } \\
\text { and } \\
\text { strongly } \\
\text { disagree }\end{array}$ & N/A & $\begin{array}{c}\text { Don't } \\
\text { know }\end{array}$ \\
\hline All responses $(n=300)$ & 66.00 & 17.33 & 6.00 & 10.67 \\
\hline Senior staff $(n=189)$ & 44.97 & 29.63 & 11.11 & 14.29 \\
\hline Junior staff $(n=113)$ & 59.29 & 16.81 & 4.42 & 19.47 \\
\hline Technical staff $(n=57)$ & 66.67 & 17.54 & 1.75 & 14.04 \\
\hline Research staff $(n=245)$ & 46.53 & 26.53 & 10.20 & 16.73 \\
\hline
\end{tabular}

9. Biosafety training includes a test of competence

\begin{tabular}{|l|c|c|c|c|c|} 
& $\begin{array}{c}\text { Always and } \\
\text { offen }\end{array}$ & Sometimes & $\begin{array}{c}\text { Rarely and } \\
\text { never }\end{array}$ & N/A & $\begin{array}{c}\text { Don't } \\
\text { know }\end{array}$ \\
\hline All responses $(\mathbf{n}=\mathbf{3 0 2})$ & 26.82 & 12.91 & 23.51 & 10.93 & 25.83 \\
\hline Senior staff $(\mathbf{n}=188)$ & 25.00 & 13.83 & 22.34 & 13.83 & 25.00 \\
\hline Junior staff $(\mathbf{n}=1 \mathbf{1 2})$ & 29.46 & 11.61 & 25.89 & 5.36 & 27.68 \\
\hline Technical staff $(\mathbf{n}=57)$ & 40.35 & 21.05 & 19.30 & 1.75 & 17.54 \\
\hline Research staff $(\mathbf{n}=\mathbf{2 4 3})$ & 23.46 & 11.11 & 24.69 & 12.76 & 27.98 \\
\hline
\end{tabular}

10. Biosecurity training includes a test of competence

\begin{tabular}{|l|c|c|c|c|c|}
\hline & $\begin{array}{c}\text { Always } \\
\text { and often }\end{array}$ & Sometimes & $\begin{array}{c}\text { Rarely and } \\
\text { never }\end{array}$ & N/A & $\begin{array}{c}\text { Don't } \\
\text { know }\end{array}$ \\
\hline All responses $(\mathbf{n = 3 4 6})$ & 19.36 & 9.83 & 21.97 & 24.86 & 23.99 \\
\hline Senior staff $(\mathbf{n = 1 8 8})$ & 25.00 & 13.83 & 22.34 & 13.83 & 25.00 \\
\hline Junior staff $(\mathbf{n = 1 1 2 )}$ & 29.46 & 11.61 & 25.89 & 5.36 & 27.68 \\
\hline Technical staff $(\mathbf{n}=\mathbf{5 7})$ & 40.35 & 21.05 & 19.30 & 1.75 & 17.54 \\
\hline Research staff $(\mathbf{n}=\mathbf{2 4 3})$ & 23.46 & 11.11 & 24.69 & 12.76 & 27.98 \\
\hline
\end{tabular}

11. Standard operating procedures have been developed (in your facility)

\begin{tabular}{|l|c|c|c|c|}
\hline & $\begin{array}{c}\text { Strongly } \\
\text { agree and } \\
\text { agree }\end{array}$ & $\begin{array}{c}\text { Disagree } \\
\text { and } \\
\text { strongly } \\
\text { disagree }\end{array}$ & N/A & $\begin{array}{c}\text { Don't } \\
\text { know }\end{array}$ \\
\hline All responses $(n=300)$ & 75.00 & 15.33 & 4.33 & 5.33 \\
\hline Senior staff $(n=187)$ & 74.87 & 13.37 & 5.88 & 5.88 \\
\hline Junior staff $(n=111)$ & 74.77 & 18.92 & 1.80 & 4.50 \\
\hline Technical staff $(n=57)$ & 87.72 & 7.02 & 0.00 & 5.26 \\
\hline Research staff $(n=241)$ & 71.78 & 17.43 & 5.39 & 5.39 \\
\hline
\end{tabular}


III. Laboratory Biosafety and Biosecurity

12. Staff are trained to work according to the standard operating procedures

\begin{tabular}{|l|c|c|c|c|}
\hline & $\begin{array}{c}\text { Strongly } \\
\text { agree and } \\
\text { agree }\end{array}$ & $\begin{array}{c}\text { Disagree } \\
\text { and } \\
\text { strongly } \\
\text { disagree }\end{array}$ & N/A & $\begin{array}{c}\text { Don't } \\
\text { know }\end{array}$ \\
\hline All responses $(n=301)$ & 66.45 & 18.60 & 6.64 & 8.31 \\
\hline Senior staff $(n=188)$ & 66.49 & 17.02 & 9.57 & 6.91 \\
\hline Junior staff $(n=111)$ & 65.77 & 21.62 & 1.80 & 10.81 \\
\hline Technical staff $(n=56)$ & 78.57 & 12.50 & 0.00 & 8.93 \\
\hline Research staff $(n=243)$ & 63.37 & 20.16 & 8.23 & 8.23 \\
\hline
\end{tabular}

13. Staff are regularly tested to ensure competence in the standard operating procedures

\begin{tabular}{|c|c|c|c|c|c|}
\hline & & $\begin{array}{l}\text { Strongly } \\
\text { agree and } \\
\text { agree }\end{array}$ & $\begin{array}{c}\text { Disagree } \\
\text { and } \\
\text { strongly } \\
\text { disagree }\end{array}$ & N/A & $\begin{array}{l}\text { Don't } \\
\text { know }\end{array}$ \\
\hline \multicolumn{2}{|l|}{ All responses $(n=304)$} & 29.93 & 48.36 & 8.55 & 13.16 \\
\hline \multicolumn{2}{|l|}{ Senior staff $(n=190)$} & 30.00 & 50.00 & 11.58 & 8.42 \\
\hline \multicolumn{2}{|l|}{ Junior staff $(n=112)$} & 29.46 & 45.54 & 3.57 & 21.43 \\
\hline \multicolumn{2}{|l|}{ Technical staff $(n=57)$} & 54.39 & 36.84 & 1.75 & 7.02 \\
\hline \multicolumn{2}{|l|}{ Research staff $(n=284)$} & 20.77 & 44.01 & 8.80 & 12.68 \\
\hline \multicolumn{6}{|c|}{ 14. Legislation/regulations exist to address hazardous waste disposal } \\
\hline & & $\begin{array}{l}\text { Strongly } \\
\text { agree and } \\
\text { agree }\end{array}$ & $\begin{array}{c}\text { Disagree } \\
\text { and } \\
\text { strongly } \\
\text { disagree }\end{array}$ & N/A & $\begin{array}{l}\text { Don't } \\
\text { know }\end{array}$ \\
\hline \multicolumn{2}{|l|}{ All responses $(n=302)$} & 87.75 & 4.64 & 1.66 & 5.96 \\
\hline \multicolumn{2}{|l|}{ Senior staff $(n=185)$} & 88.65 & 4.32 & 2.70 & 4.32 \\
\hline \multicolumn{2}{|l|}{ Junior staff $(n=112)$} & 85.71 & 5.36 & 0.00 & 8.93 \\
\hline \multicolumn{2}{|l|}{ Technical staff $(n=57)$} & 92.98 & 3.51 & 0.00 & 3.51 \\
\hline \multicolumn{2}{|l|}{ Research staff $(n=284)$} & 73.94 & 4.23 & 1.76 & 5.63 \\
\hline \multicolumn{6}{|c|}{ 15. Legislation/regulations regarding hazardous waste disposal are followed } \\
\hline & $\begin{array}{l}\text { Always } \\
\text { and often }\end{array}$ & Sometimes & $\begin{array}{c}\text { Rarely and } \\
\text { never }\end{array}$ & N/A & $\begin{array}{l}\text { Don't } \\
\text { know }\end{array}$ \\
\hline All responses $(n=301)$ & 74.42 & 9.30 & 3.65 & 2.99 & 9.63 \\
\hline Senior staff $(n=188)$ & 76.06 & 6.91 & 3.72 & 4.26 & 9.04 \\
\hline Junior staff $(n=111)$ & 71.17 & 13.51 & 3.60 & 0.90 & 10.81 \\
\hline Technical staff $(n=57)$ & 78.95 & 10.53 & 3.51 & 0.00 & 7.02 \\
\hline Research staff $(n=242)$ & 73.14 & 9.09 & 3.72 & 3.72 & 10.33 \\
\hline
\end{tabular}


III. Laboratory Biosafety and Biosecurity

16. Occupational health surveillance mechanisms exist and are followed (at institutional level)

\begin{tabular}{|l|c|c|c|c|}
\hline & $\begin{array}{c}\text { Strongly } \\
\text { agree and } \\
\text { agree }\end{array}$ & $\begin{array}{c}\text { Disagree } \\
\text { and } \\
\text { strongly } \\
\text { disagree }\end{array}$ & N/A & $\begin{array}{c}\text { Don't } \\
\text { know }\end{array}$ \\
\hline All responses $(n=303)$ & 61.39 & 21.78 & 2.97 & 13.86 \\
\hline Senior staff $(n=189)$ & 66.14 & 21.16 & 2.65 & 10.05 \\
\hline Junior staff $(n=112)$ & 52.68 & 23.21 & 3.57 & 20.54 \\
\hline Technical staff $(n=57)$ & 71.93 & 19.30 & 0.00 & 8.77 \\
\hline Research staff $(n=284)$ & 50.35 & 19.37 & 3.17 & 13.03 \\
\hline
\end{tabular}

17. Occupational health reporting mechanisms effective at institutional level

\begin{tabular}{|l|c|c|c|c|c|}
\hline & $\begin{array}{c}\text { Always } \\
\text { and often }\end{array}$ & Sometimes & $\begin{array}{c}\text { Rarely and } \\
\text { never }\end{array}$ & N/A & $\begin{array}{c}\text { Don't } \\
\text { know }\end{array}$ \\
\hline All responses $(n=299)$ & 44.15 & 20.74 & 12.37 & 1.34 & 21.40 \\
\hline Senior staff $(n=188)$ & 43.62 & 23.40 & 13.30 & 2.13 & 17.55 \\
\hline Junior staff $(n=109)$ & 44.04 & 16.51 & 11.01 & 0.00 & 28.44 \\
\hline Technical staff $(n=55)$ & 54.55 & 25.45 & 9.09 & 0.00 & 10.91 \\
\hline Research staff $(n=242)$ & 41.32 & 19.83 & 13.22 & 1.65 & 23.97 \\
\hline
\end{tabular}

18. Staff are required to report laboratory accidents and incidents

\begin{tabular}{|l|c|c|c|c|}
\hline & $\begin{array}{c}\text { Strongly } \\
\text { agree and } \\
\text { agree }\end{array}$ & $\begin{array}{c}\text { Disagree } \\
\text { and } \\
\text { strongly } \\
\text { disagree }\end{array}$ & N/A & $\begin{array}{c}\text { Don't } \\
\text { know }\end{array}$ \\
\hline All responses $(n=302)$ & 89.07 & 3.97 & 4.97 & 1.99 \\
\hline Senior staff $(n=189)$ & 89.95 & 4.76 & 2.65 & 2.65 \\
\hline Junior staff $(n=111)$ & 87.39 & 2.70 & 0.90 & 9.01 \\
\hline Technical staff $(n=56)$ & 96.43 & 0.00 & 0.00 & 3.57 \\
\hline Research staff $(n=284)$ & 75.00 & 4.23 & 2.11 & 4.58 \\
\hline 19. A record of research projects exists and is maintained at institutional level \\
\hline & $\begin{array}{c}\text { Strongly } \\
\text { agree and } \\
\text { agree }\end{array}$ & $\begin{array}{c}\text { Disagree } \\
\text { and } \\
\text { strongly } \\
\text { disagree }\end{array}$ & N/A & Don't \\
know & \\
\hline All responses $(n=302)$ & 68.54 & 12.58 & 2.32 & 16.56 \\
\hline Senior staff $(n=188)$ & 65.43 & 13.30 & 3.19 & 18.09 \\
\hline Junior staff $(n=112)$ & 73.21 & 11.61 & 0.89 & 14.29 \\
\hline Technical staff $(n=57)$ & 73.68 & 5.26 & 3.51 & 17.54 \\
\hline Research staff $(n=284)$ & 57.39 & 12.32 & 1.76 & 14.08 \\
\hline
\end{tabular}


III. Laboratory Biosafety and Biosecurity

20. A record of hazardous biological materials exists and is maintained at institutional level

\begin{tabular}{|c|c|c|c|c|c|}
\hline & & $\begin{array}{l}\text { Strongly } \\
\text { agree and } \\
\text { agree }\end{array}$ & $\begin{array}{c}\text { Disagree } \\
\text { and } \\
\text { strongly } \\
\text { disagree }\end{array}$ & N/A & Don't know \\
\hline \multicolumn{2}{|l|}{ All responses $(n=302)$} & 51.99 & 16.89 & 5.96 & 25.17 \\
\hline \multicolumn{2}{|l|}{ Senior staff $(n=213)$} & 44.13 & 15.02 & 7.51 & 22.07 \\
\hline \multicolumn{2}{|l|}{ Junior staff $(n=135)$} & 45.93 & 14.07 & 0.74 & 21.48 \\
\hline \multicolumn{2}{|l|}{ Technical staff $(n=64)$} & 60.94 & 9.38 & 1.56 & 17.19 \\
\hline \multicolumn{2}{|l|}{ Research staff $(n=284)$} & 41.20 & 15.85 & 5.63 & 22.89 \\
\hline \multicolumn{6}{|c|}{ 21. Hazardous biological material is safely and securely stored } \\
\hline & $\begin{array}{l}\text { Always and } \\
\text { often }\end{array}$ & Sometimes & $\begin{array}{c}\text { Rarely and } \\
\text { never }\end{array}$ & N/A & Don't know \\
\hline All responses $(n=305)$ & 68.20 & 9.51 & 2.95 & 7.21 & 12.13 \\
\hline Senior staff $(n=190)$ & 69.47 & 7.89 & 2.63 & 9.47 & 10.53 \\
\hline Junior staff $(n=113)$ & 66.37 & 12.39 & 3.54 & 2.65 & 15.04 \\
\hline Technical staff $(n=57)$ & 71.93 & 14.04 & 3.51 & 3.51 & 7.02 \\
\hline Research staff $(n=246)$ & 67.48 & 8.54 & 2.85 & 7.72 & 13.41 \\
\hline
\end{tabular}

22. Mechanisms exist for staff to report unlawful or irregular conduct (i.e. whistleblowing mechanisms exist)

\begin{tabular}{|c|c|c|c|c|}
\hline & $\begin{array}{l}\text { Strongly } \\
\text { agree and } \\
\text { agree }\end{array}$ & $\begin{array}{c}\text { Disagree } \\
\text { and } \\
\text { strongly } \\
\text { disagree }\end{array}$ & N/A & Don't know \\
\hline All responses $(n=302)$ & 64.24 & 15.89 & 0.99 & 18.87 \\
\hline Senior staff $(n=213)$ & 62.91 & 11.27 & 0.94 & 13.62 \\
\hline Junior staff $(n=135)$ & 43.70 & 17.78 & 0.74 & 20.00 \\
\hline Technical staff $(n=64)$ & 65.63 & 14.06 & 0.00 & 7.81 \\
\hline Research staff $(n=284)$ & 53.17 & 13.73 & 1.06 & 17.96 \\
\hline \multicolumn{5}{|c|}{$\begin{array}{l}\text { 23. Measures exist to protect staff who report unlawful or irregular conduct from } \\
\text { occupational detriment }\end{array}$} \\
\hline & $\begin{array}{l}\text { Strongly } \\
\text { agree and } \\
\text { agree }\end{array}$ & $\begin{array}{c}\text { Disagree } \\
\text { and } \\
\text { strongly } \\
\text { disagree }\end{array}$ & N/A & Don't know \\
\hline All responses $(n=298)$ & 37.25 & 21.48 & 0.34 & 40.94 \\
\hline Senior staff $(n=213)$ & 33.80 & 17.37 & 1.41 & 35.21 \\
\hline Junior staff $(n=135)$ & 28.15 & 20.00 & 0.74 & 34.07 \\
\hline Technical staff $(n=64)$ & 40.63 & 18.75 & 0.00 & 29.69 \\
\hline Research staff $(n=284)$ & 29.58 & 18.31 & 1.41 & 35.92 \\
\hline
\end{tabular}




2015

\section{The State of Biosafety and Biosecurity in South Africa}

\section{Academy of Science of South Africa (ASSAf)}

Academy of Science of South Africa

Academy of Science of South Africa (ASSAf), (2015). The State of Biosafety and Biosecurity in South Africa. [Online] Available from: DOI http://dx.doi.org/10.17159/assaf/0020 http://hdl.handle.net/20.500.11911/58

Downloaded from ASSAf Research Repository, Academy of Science of South Africa (ASSAf) 